\title{
NON-PARAMETRIC EDGE DETECTION IN SPECKLED IMAGERY
}

\author{
EDWIN GIOVANNY GIRÓN AMAYA
}

\author{
Primary advisor: Prof. Dr Alejandro C. Frery \\ Secondary advisor: Prof. Dr Francisco Cribari-Neto \\ Concentration area: Computational Statistics
}

Dissertation submitted to the Department of Statistics of the Federal University of Pernambuco, in partial fulfillment of the requirements for the degree of MSc in Statistics.

Recife, February 2008 
Amaya, Edwin Giovanny Girón

Ilon-parametric edge detection in speckled imagery / Edwin Giovanny Girón Amaya. - Recife: 0 Autor, 2008.

v, 121 folhas: il., fig., tab.

Dissertaçäo (mestrado) - Universidade Federal de Pernambuco. CCEll. Depto. de Estatística. 2008.

Inclui bibliografia e apêndices.

1. Estatística näo paramétrica. 2. Detecção de bordas. 3. magens SAR. I. Título.

519.5 CDD (22.ed) MEL2008-020 


\section{Universidade Federal de Pernambuco Pós-Graduação em Estatística}

15 de fevereiro de 2008

(data)

Nós recomendamos que a dissertaçẫo de mestrado de autoria de

\section{Edwin Giovanny Girón Amaya}

intitulada

\section{"Deteç̧ão não Paramétrica de Bordas em Imagens SAR"}

seja aceita como cumprimento parcial dos requerimentos para o grau de Mestre en Estatística.

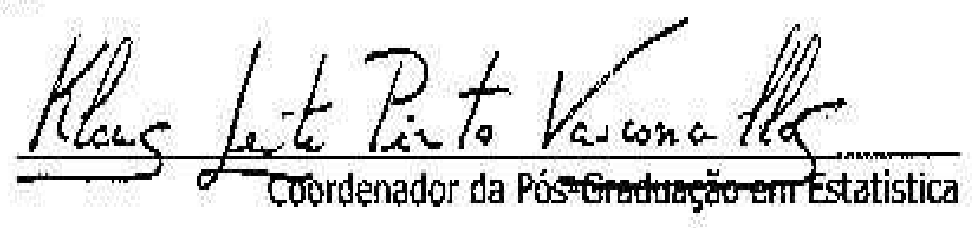

Bạnta Examinadora:

$\frac{\text { Alejandro César Frêty Orgambide }}{\text { Orientador }}$

\section{(4) Jencos.}

Corina da Costa Freitas Yanasse (INPE)

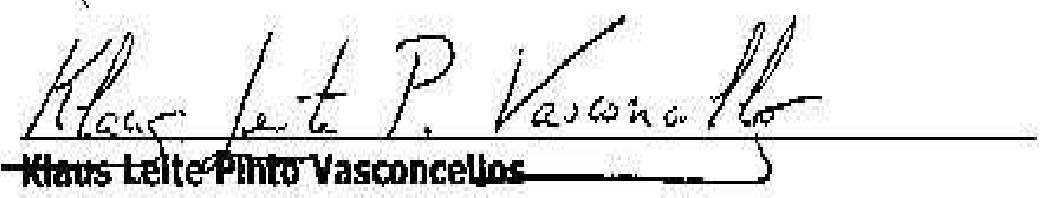

Ește documento será anexado à versão final da dissertação. 
To my parents, Cecilia Amaya and Ernesto Giron, my Grandparents Antonio and Cecilia, my sister Jessica. It is my tribute for so many wait and sacrifice.

I dedicate this work to Alexandra Esteban, friend, girlfriend and adviser, with whom I learned that the life is not fair, and even like that, she gave to me force not to desist. Do not stop Ale... 


\section{Acknowledgements}

First thank God for fortifying me and for taking care of me and allowing me to be careful myself and to permit reach the current stage of my life.

I would like to thank my advisors, Alejandro Frery and Francisco Cribari-Neto. Throughout my career as student, combined with their careful advice, they have been invaluable in providing guidance and support. Alejandro and Francisco have been exemplary models, showing me how to choose important research topics grounded in real-world problems and how to attack them; I clearly would not be where I am without the time and effort they devoted to his mentorship.

I am very grateful to all my friends and colleagues at UFPE, in special, Hemilio Fernandes, Carlos Raphael, Valmir Rogerio, Marcelo Rodrigo, Fabio Jaques, Abraão David Costa with whom I spent many hours talking about a wide variety of academic and non-academic topics.

I would like to thank the staff at the Department of Statistics of Federal University of Pernambuco, in special Valeria Betancourt.

Most of all, I want to express my gratitude to Alexandra Johanna, my confidante and best friend. She gives me strength and helps me in countless ways. Above all, I am thankful for how she fills my life with happiness and joy.

I also thank CAPES for financial suggest of my post-graduation studies, without which this work would not be materialized.

Finally, I thank the thesis committee members for suggestions and corrections. 
The most beautiful thing we can experience is the mysterious. It is the source of all true art and science. He to whom this emotion is a stranger, who can no longer pause to wonder and stand rapt in awe, is as good as dead: his eyes are closed.

Albert Einstein 


\section{Resumo}

Este trabalho propõe uma técnica não-paramétrica para deteç̧ão de bordas em imagens speckle. As imagens SAR ("Synthetic aperture Radar"), sonar, B-ultrasound e laser são corrompidas por um ruído não aditivo chamado speckle. Vários modelos estatísticos foram propostos para descrever este ruído, levando ao desenvolvimento de técnicas especiais para melhoramento e análise de imagens. A distribuição $\mathcal{G}^{0}$ é um modelo estatístico que consegue descrever uma ampla gama de áreas, como, por exemplo, em dados SAR, pastos (lisos), florestas (rugosos) e áreas urbanas (muito rugosos). O objetivo deste trabalho é estudar técnicas alternativas na deteç̧ão de imagens speckled, tomando como ponto de partida Gambini et al. $(2006,2008)$.

Um novo detector de borda baseado no teste de Kruskal Wallis é proposto. Os nossos resultados numéricos mostram que esse detector é uma alternativa atraente ao detector de M. Gambini, que é baseado na função de verossimilhança.

Neste trabalho fornecemos evidências de que a técnica de M. Gambini pode ser substituída com sucesso pelo método Kruskal Wallis. O ganho reside em ter um algoritmo 1000 vezes mais rápido, sem comprometer a qualidade dos resultados.

Palavras-chave: estatística não-paramétrica, deteç̧ão de bordas, imagens SAR, imagens speckled, ruído speckle. 


\section{Abstract}

This thesis proposes a non-parametric technique for boundary detection in speckled imagery. Synthetic Aperture Radar (SAR), sonar, B-ultrasound and laser imagery is corrupted by a signal-dependent non-additive noise called speckle. Several statistical models have been proposed to describe such a noise, thus of specialized techniques for image improvement and analysis. The $\mathcal{G}^{0}$ distribution is a statistical model that succeeds in describing a wide range of areas as, for instance in SAR data, pastures (smooth), forests (rough) and urban (extremely rough) areas. The aim of this thesis is to develop alternative techniques for edge detection in speckled imagery. Its starting point are the works by Gambini et al. $(2006,2008)$. We describe a new edge detector based on the Kruskal Wallis test and show that it is an useful alternative to the method proposed by M. Gambini, which is based on the likelihood function of the data. We provide evidence that the M. Gambini technique can be successfully replaced by the Kruskal Wallis method. The latter is more computationally efficient, the corresponding algorithm being up to 1000 times fasted that the M. Gambini algorithm.

Keywords: non-parametrics statistics, edges detection, SAR imagery, speckled imagery, speckle noise. 


\section{Contents}

1 Introduction $\quad 6$

2 Methodology 15

2.1 The multiplicative model . . . . . . . . . . . . . . . . . . . . 19

$2.2 \mathcal{G}_{\mathrm{I}}^{0}$ distribution: properties and estimation . . . . . . . . . . 23

2.3 Edge detection in SAR imagery . . . . . . . . . . . . 27

2.3.1 Gambini algorithm for edge detection . . . . . . . . . 29

2.3.2 Non-parametric edge detection . . . . . . . . . . . . . . 31

2.3.3 The Mann-Whitney test . . . . . . . . . . . . . . . . 33

2.3.4 The Kruskal-Wallis test . . . . . . . . . . . . . . . . . . 34

2.3.5 The Squared Ranks test for variances . . . . . . . . . 37

2.3.6 The TPE empirical statistic . . . . . . . . . . . . . . 39

2.4 Proposal . . . . . . . . . . . . . . . . . . . . . 40

3 Results $\quad 43$

3.1 Extremely heterogeneous areas, $n=1$ and $\alpha_{\ell}=-3 \ldots \ldots 48$

3.2 Heterogeneous areas, $n=1$ and $\alpha_{\ell}=-8 \ldots \ldots \ldots \ldots \ldots$

3.3 Homogeneous areas, $n=1$ and $\alpha_{\ell}=-12 \ldots \ldots \ldots \ldots$

3.4 Homogeneous areas, $n=1$ and $\alpha_{\ell}=-18 \ldots \ldots \ldots \ldots 57$

3.5 Extremely heterogeneous areas, $n=3$ and $\alpha_{\ell}=-3 \ldots \ldots 60$

3.6 Heterogeneous areas, $n=3$ and $\alpha_{\ell}=-8 \ldots \ldots \ldots \ldots 62$

3.7 Homogeneous areas, $n=3$ and $\alpha_{\ell}=-12 \ldots \ldots \ldots 65$ 
3.8 Homogeneous areas, $n=3$ and $\alpha_{\ell}=-18 \ldots \ldots$. . . . . . . . 68

3.9 Extremely heterogeneous areas, $n=8$ and $\alpha_{\ell}=-3$....... . 71

3.10 Heterogeneous areas, $n=8$ and $\alpha_{\ell}=-8 \ldots \ldots$. . . . . . . . 74

3.11 Homogeneous areas, $n=8$ and $\alpha_{\ell}=-12 \ldots$. . . . . . . . . 77

3.12 Homogeneous areas, $n=8$ and $\alpha_{\ell}=-18 \ldots \ldots$. . . . . . 80

4 Conclusions $\quad 84$

$\begin{array}{lll}\text { A Simulation results for } n=1 & 88\end{array}$

B Simulation results for $n=3 \quad 94$

$\begin{array}{lr}\text { C Simulation results for } n=8 & 100\end{array}$

$\begin{array}{lr}\text { D Ox Codes } & 106\end{array}$ 


\section{List of Figures}

1.1 Interpretation of the roughness parameter . . . . . . . . 13

2.1 Densidade do speackle para $1,2,4$ e 8 looks . . . . . . . . . 20

$2.2 \Gamma^{-1}$ densities for $\alpha=-0.5,-2,-4,-10 \ldots \ldots \ldots \ldots 22$

$2.3 \mathcal{G}_{\mathrm{I}}^{0}$ densities for $\alpha=-2,-4,-6,-8-12 \ldots \ldots \ldots \ldots 24$

2.4 Radial straight lines projected . . . . . . . . . . . . . . 30

2.5 Values of the objective function for a segment of straight . . . . . 31

2.6 Displacement of a rectangular window on a straight segment . . . 40

2.7 Typical values of the non-parametric statistics _ . . . . . . . . 42

3.1 Scheme of a rectangular window on a straight segment . . . . . . . 46

3.2 Synthetic images $\mathcal{G}_{\mathrm{I}}^{0}(-3,1,1) \ldots \ldots \ldots \ldots \ldots$

3.3 Average execution time for $\alpha_{\ell}=-3$ and $n=1 \ldots \ldots$

3.4 Synthetic images from $\mathcal{G}_{\mathrm{I}}^{0}(-8,1,1) \ldots \ldots \ldots \ldots \ldots$

3.5 Error rate in edge detection for $\alpha_{\ell}=-8$ and $n=1 \ldots 53$

3.6 Average execution time for $\alpha_{\ell}=-8$ and $n=1 \ldots \ldots 53$

3.7 Synthetic images from $\mathcal{G}_{\mathrm{I}}^{0}(-12,1,1) \ldots \ldots \ldots \ldots \ldots$

3.8 Error rate in edge detection for $\alpha_{\ell}=-12$ and $n=1 \ldots 56$

3.9 Average execution time for $\alpha_{\ell}=-12$ and $n=1 \ldots \ldots 56$

3.10 Synthetic images $\mathcal{G}_{\mathrm{I}}^{0}(-18,1,1) \ldots \ldots \ldots \ldots \ldots \ldots$

3.11 Error rate for $\alpha_{\ell}=-18$ and $n=1 \ldots \ldots \ldots \ldots$

3.12 Average execution time for $\alpha_{\ell}=-18$ and $n=1 \ldots \ldots 59$

3.13 Synthetic images $\mathcal{G}_{\mathrm{I}}^{\mathrm{O}}(-3,1,3) \ldots \ldots \ldots \ldots \ldots \ldots$ 
3.14 Average execution time for $\alpha_{\ell}=-3$ and $n=3 \ldots \ldots 61$

3.15 Synthetic images $\mathcal{G}_{\mathrm{I}}^{0}(-8,1,3) \ldots \ldots \ldots \ldots \ldots . \ldots \ldots$

3.16 Error rate in edge detection for $\alpha_{\ell}=-8$ and $n=3 \ldots \ldots 64$

3.17 Average execution time for $\alpha_{\ell}=-8$ and $n=3 \ldots \ldots 64$

3.18 Synthetic images $\mathcal{G}_{\mathrm{I}}^{\mathrm{O}}(-12,1,3) \ldots \ldots \ldots \ldots \ldots \ldots \ldots$

3.19 Error rate in edge detection for $\alpha_{\ell}=-12$ and $n=3 \ldots \ldots 67$

3.20 Average execution time for $\alpha_{\ell}=-12$ and $n=3 \ldots \ldots 67$

3.21 Synthetic images $\mathcal{G}_{\mathrm{I}}^{0}(-18,1,3) \ldots \ldots \ldots \ldots \ldots$

3.22 Error rate in edge detection for $\alpha_{\ell}=-18$ and $n=3 \ldots \ldots 70$

3.23 Average execution time for $\alpha_{\ell}=-18$ and $n=3 \ldots \ldots 70$

3.24 Synthetic images $\mathcal{G}_{\mathrm{I}}^{0}(-3,1,8) \ldots \ldots \ldots \ldots \ldots \ldots \ldots$

3.25 Average execution time for $\alpha_{\ell}=-3$ and $n=8 \ldots \ldots 73$

3.26 Synthetic images $\mathcal{G}_{\mathrm{I}}^{0}(-8,1,8) \ldots \ldots \ldots \ldots \ldots \ldots$

3.27 Error rate in edge detection for $\alpha_{\ell}=-8$ and $n=8 \ldots \ldots 76$

3.28 Average execution time for $\alpha_{\ell}=-8$ and $n=8 \ldots \ldots \ldots$

3.29 Synthetic images $\mathcal{G}_{\mathrm{I}}^{\mathrm{O}}(-12,1,8) \ldots \ldots \ldots \ldots \ldots \ldots$

3.30 Error rate in edge detection for $\alpha_{\ell}=-12$ and $n=8 \ldots \ldots 79$

3.31 Average execution time for $\alpha_{\ell}=-12$ and $n=8 \ldots \ldots \ldots 79$

3.32 Synthetic images $\mathcal{G}_{\mathrm{I}}^{0}(-18,1,8) \ldots \ldots \ldots \ldots \ldots \ldots$

3.33 Error rate in edge detection for $\alpha_{\ell}=-18$ and $n=8 \ldots \ldots 2$

3.34 Average execution time for $\alpha_{\ell}=-18$ and $n=8 \ldots \ldots 82$ 


\section{List of Tables}

3.1 Error rate and average time for $\alpha_{\ell}=-3$ and $n=1 \ldots 50$

3.2 Error rate and average time for $\alpha_{\ell}=-8$ and $n=1 \ldots \ldots 2$

3.3 Error rate and average time for $\alpha_{\ell}=-12$ and $n=1 \ldots \ldots 5$

3.4 Error rate and average time for $\alpha_{\ell}=-18$ and $n=1 \ldots 58$

3.5 Error rate and average time for $\alpha_{\ell}=-3$ and $n=3 \ldots 61$

3.6 Error rate and average time for $\alpha_{\ell}=-8$ and $n=3 \ldots 63$

3.7 Error rate and average time for $\alpha_{\ell}=-12$ and $n=3 \ldots 66$

3.8 Error rate and average time for $\alpha_{\ell}=-18$ and $n=3 \ldots 69$

3.9 Error rate and average time for $\alpha_{\ell}=-3$ and $n=8 \ldots \ldots 72$

3.10 Error rate and average time for $\alpha_{\ell}=-8$ and $n=8 \ldots \ldots 75$

3.11 Error rate and average time for $\alpha_{\ell}=-12$ and $n=8 \ldots \ldots 78$

3.12 Error rate and average time for $\alpha_{\ell}=-18$ and $n=8 \ldots \ldots 1$ 


\section{Chapter 1}

\section{Introduction}

\section{Resumo}

Nos últimos anos, o desenvolvimento de novas tecnologias de observação da terra a partir do espaço tem estimulado o interesse da sociedade em suas aplicações. Estas tecnologias permitiram que alguns dos países desenvolvidos começassem a corrida espacial, induzindo o desenvolvimento de novas técnicas que, com o tempo, foram denominadas "espaço de sensoriamento remoto".

As imagens de radar SAR ("Synthetic aperture Radar ") oferecem uma perspectiva única da terra, seus recursos e o impacto que sobre ela exercem os seres humanos. Imagens SAR têm demonstrado ser uma fonte de informação valiosa para várias aplicações, entre as quais é possível citar o planejamento urbano, o monitorização ambiental, a gestão dos cultivos, a prospecção de petróleo, a exploração mineral, a deteç̧ão de vida animal e muitas outras.

SAR é um radar de iluminação coerente de alta resolução que funciona utilizando uma antena sintética a bordo de uma plataforma aérea móvel, como um avião ou um satélite, cobrindo grandes superfícies e produzindo imagens de alta resolução. Ao contrário de um radar convencional, SAR utiliza o movimento da plataforma para obter uma antena sintética de maior dimensão e, por conseguinte, maior resolução do que a obtida a través antena real. 
Um sensor SAR emite e recebe sinais eletromagnéticos de natureza complexa, o sinal recebido podendo ser armazenado em diferentes formatos: complexo, intensidade e fase (Oliver and Quegan, 1998).

O radar ilumina uma cena com uma sucessão de pulsos e uma determinada freqüência. A energia é propagada em todas as direções e uma parte retorna à antena (este retorno é chamado eco). O sensor mede a intensidade e o atraso dos sinais emitidos e devolvidos à antena. A interpretação desses ecos permite a formação de imagens em termos de distâncias ao radar, ou seja, a imagem é formada em função da energia devolvida por qualquer ponto da superfície.

Algumas das características mais importantes que o sensor SAR apresenta são:

- O caráter ativo do instrumento o torna independente da iluminação solar, sendo capaz de recolher imagens a qualquer momento.

- As microondas são pouco afetadas pela presença de nuvens, o que torna possível a aquisição de imagens independentemente das condições meteorológicas e em regiões com cobertura freqüente.

- O sensor SAR permite obter imagens com resoluções de dezenas de centímetros a quilómetros de altura.

- As imagens SAR fornecem informações complementares às proporcionadas pelas imagens ópticas. A seleção da freqüência, da polarização e do ângulo de incidência do SAR permite discriminar diferentes propriedades da superfície.

Em uma imagem SAR é possível distinguir vários tipos de rugosidade ou textura:

Áreas homogêneas: Superfícies de pouca textura, por exemplo, zonas de cultivos, zonas com desmatamento, neve, água ou gelo, etc.

Áreas heterogêneas: Superfícies que apresentam certo grau de textura, por exemplo, florestas.

Áreas extremamente heterogêneas: Superfícies onde a textura é intensa, por exemplo, zonas urbanas, industriais, entre outros. 
Um fator importante que degrada a qualidade da imagem SAR é o ruído speckle, que aparece quando se usa iluminação coerente como é o caso de todas as tecnologias que utilizam microondas, Sonar, laser e ultra-som. Para reduzir o nível de ruído speckle em imagens SAR, uma técnica chamada "multilook" pode ser usada. Esta técnica consiste em subdividir o pulso emitido pela antena em vários setores independentes e combinar os dados obtidos em uma imagem final, de modo que esta imagem seja menos afetada pelo speckle.

Para encontrar os pontos de borda entre as diferentes regiões da imagem, os dados SAR são modelados com a distribuição $\mathcal{G}_{\mathrm{I}}^{0}$ sob o modelo multiplicativo. As regiões da imagem com diferentes graus de homogeneidade ficam caracterizadas pelos parâmetros da distribuição. Se um ponto pertence à borda, então numa vizinhança desse ponto existe uma mudança brusca nos parâmetros da distribuição.

$O$ modelo multiplicativo afirma que a variável aleatória $Z$ que descreve as observações, é o resultado do produto de duas variáveis aleatórias independentes, que não são observadas diretamente: $X$ e $Y$, a variável aleatória $X$ modela área de estudo (backscatter), enquanto que a variável aleatória $Y$ modela o ruído speckle.

O objetivo deste trabalho é estudar técnicas alternativas na deteç̧ão de imagens speckled, tomando como ponto de partida o trabalho de Gambini et al. (2006, 2008). Neste trabalho fornecemos evidências de que a técnica de M. Gambini pode ser substituída com sucesso pelo método Kruskal Wallis. O ganho reside em ter um algoritmo 1000 vezes mais rápido, sem compromisso da qualidade dos resultados.

Esta tese é composta pelos seguintes capítulos: o presente capítulo 1; o capítulo 2 apresenta o modelo multiplicativo que descreve as imagens SAR, a distribuição $\mathcal{G}_{\mathrm{I}}^{0} \mathrm{e}$ suas propriedades, e apresenta uma revisão de deteç̧ão de bordas em imagens SAR incluindo técnicas não-paramétrica e nossa proposta. Capítulo 3 apresenta resultados que permitem a comparação dos métodos sob avaliação. Capítulo 4 discute as conclusões extraídas dos resultados apresentados. 


\section{Introduction}

In the last years, the development of new technologies for Earth observation from space has stimulated the interest of the society on their applications. These technologies allowed some of the most powerful countries to begin the space race, inducing the development of new techniques that, with time, were denominated "space remote sensing".

SAR ("Synthetic Aperture Radar") imagery offers an unique Earth perspective, its resources and the impact that on its humans exert. SAR images have demonstrated to be a source of valuable information for numerous applications, among which it is possible to mention urban planning, monitoring of environment, management of crops, oil prospection, mining exploration, wind detection, detection of animal life and many others.

SAR is a coherent radar of high resolution that works on board using a synthetic antenna of a movable platform, like an airplane or a satellite, covering extended surfaces and producing images. Unlike a conventional radar, SAR uses the movement of the platform to obtain a synthetic antenna and, therefore, higher resolutions than the real antenna.

During the process of data acquisition, the target remains illuminated under the antenna beam during several instants, being observed by the radar from numerous positions caused by movement throughout the platform trajectory, prolonging in this way the real length of the antenna. The radar illuminates a scene with a succession of pulses in a certain frequency. The energy is propagated in all directions and returns partially to the antenna (this return is called echo). The sensor measures both the intensity and the delay of the emitted and returned signals to the antenna. The interpretation of these echoes allows the formation of images in terms of distances to the radar, the image being formed as function of the energy returned by every point of the surface.

Some of the most important characteristics that the SAR sensor presents for remote sensing are: 
- The active nature of the instrument makes it independent of other illumination sources, being able to gather images at any time.

- Microwaves are little affected by the presence of clouds, so image acquisition is possible regardless of the meteorological conditions and in regions with permanent cloud coverage.

- SAR images can have high spatial resolution, e.g. of less than one meter, allowing, thus, the study of small scale phenomena.

- SAR images contain complementary information to that provided by optical images. The selection of the frequency band, polarization and angle of incidence in SAR imagery allows discrimination of different surface properties.

A SAR sensor emits and receives electromagnetic waves of complex nature and, therefore, the received signal can be stored in different formats: complex, intensity, amplitude and phase (Oliver \& Quegan 1998).

In a SAR image it is possible to distinguish several types of roughness or texture, according to which it is possible to classify the different types of covers in:

Homogenous areas: Surfaces of very little texture, for example, zones of crops, zones with deforestation, snow, water or ice, etc.

Heterogeneous areas: Surfaces that present certain degree of texture, for example forest on not very pronounced relief, among others.

Extremely heterogeneous areas: Surfaces where the texture is intense, for example urban and industrial zones and of pronounced reliefs, among others.

"Texture", in the context of SAR imagery, should be understood as a measure of the number of objects in a cell of the size of the wavelength employed by the sensor. A fine texture is associated to a large number of objects per cell, while a coarse or extremely heterogeneous textures are those for which only a few objects are counted per cell. The Japanese Earth Resources Satellite JERS-1, for instance, operates on 
L-Band $(1.3 \mathrm{GHz}, 23.5 \mathrm{~cm}$ wavelength) and the European Remote Sensing Satellites ERS-1 and ERS-2 use C-Band ( $5.3 \mathrm{GHz}, 5.6 \mathrm{~cm}$ wavelength). The ERS1 is not ideal for forest discrimination, with less than $50 \%$ of the nonforest areas being correctly detected. This reflects the fact that even low vegetation canopies can have a backscattering coefficient similar to that of primary forest at C-band. Longer wavelengths are more appropriate to this application, such as the L-band data provided by JERS-1. A more complete temporal coverage of the region may have given better performance. Long time sequences of ERS images gathered over temperate forest, which also show very stable behavior, allow good forest discrimination using changedetection techniques. C-band systems are capable of good forest discrimination in the tropics if they have sufficient resolution (Oliver \& Quegan 1998).

A problem of fundamental importance in the analysis of images is the detection of edges. Edges characterize the limits of objects and, therefore, they are useful for segmentation, registration and identification of objects. Edge points can be thought as the locations of pixels where abrupt changes of intensity or other relevant property occur.

Segmentation is the process that divides an image in its constituent parts or objects. It is one of the most important steps in the whole process of image analysis. Its objective is to group image areas that have similar characteristics within different groups that represent parts of the image.

One of the basic principles in the segmentation process is the detection of discontinuities. The edges characterize the borders of the objects, and therefore they are very useful for the segmentation and identification of objects in scenes.

An important factor that degrades the quality of the SAR images is the speckle noise, that appears when coherent illumination is used. It is the case of all technologies that employ microwaves, sonar, laser and ultrasound; it is inherent to the coherent illumination, i.e., image formation where phase is recorded.

The noise is the main difficulty for the edge detection algorithms, because many of them find regions using local characteristics. In the case of detection of edges of objects in images with speckle noise, it is not possible in general to use pointwise 
information; it is necessary to analyze the image using sets of pixels that provide local information (Gambini et al. 2006).

To reduce the level of speckle noise in SAR images, a technology called "multilook" can be used. It consists of subdividing the antenna beam in several independent sectors and combining the resulting data in a final image, so that this image is less affected by speckle. Meanwhile, this type of processing reduces the spatial resolution proportionally to the number of looks.

Different approaches can be used in order to find edges of different regions, among them a statistical approach has been shown to be one of the most suited for speckled imagery (Gambini et al. 2008). In order to do this, the family of $\mathcal{G}$ distributions can be used to model data. This choice is based on the fact that this distribution presents the best results when used to describe areas with different degree of homogeneity (Frery et al. 1997, Mejail et al. 2001, 2003, Freitas et al. 2005).

The multiplicative model states that the random field $Z$ that describes the observations is the result of the product of two independent random fields, which are not observed directly: $X$ and $Y$.

The random field $X$ models the properties of the studied area (backscatter), whereas the random field $Y$ models the speckle noise associated to the mechanism of image formation inherent to coherent illumination. We shall only consider the intensity format in this thesis.

The phenomenon of speckle noise generation allows us to assume that each component of the field $Y$ follows a $\Gamma$ law (Goodman 1985). Several models can be used for the random field $X$, among them the $\Gamma$ distribution, which leads to $\mathcal{K}_{\mathrm{I}}$ distribution for the return Z (Jakeman \& Pusey 1976, Jao 1984, Oliver \& Quegan 1998). Nevertheless, this model fails in situations where the return represents extremely heterogeneous areas, like urban areas, the distribution being in addition difficult to deal with from the computational viewpoint.

Frery et al. (1997) propose a new class of distributions, $\mathcal{G}$, which has the $\mathcal{K}_{\mathrm{I}}$ distribution as a special case. Another special case is the $\mathcal{G}_{\mathrm{I}}^{0}$ distribution, which has as many parameters as the $\mathcal{K}_{\mathrm{I}}$ law, and allows modeling successfully extremely 
heterogeneous areas, such as urban zones, which cannot be adequately modeled by the $\mathcal{K}_{\mathrm{I}}$ distribution (Picco et al. (2007)).

The $\mathcal{G}_{\mathrm{I}}^{0}$ distribution is characterized by as many parameters as the $\mathcal{K}_{\mathrm{I}}$ distribution, namely: the number of looks $(n)$, the $(\gamma)$ parameter of scale and the parameter $(\alpha)$. Both $\mathcal{K}_{\mathrm{I}}$ and $\mathcal{G}_{\mathrm{I}}^{0}$ distributions allow the interpretation of their parameters. The roughness parameter is of interest in many applications, since it can be used as an indicator of are land type. The scale parameter $(\gamma)$ makes reference to the relative power between the reflected and incident signals (Frery et al. 1997).

Figure 1.1 presents the interpretation of the roughness parameter $\alpha$. Small values of $\alpha$ ( $\alpha<-10$, for instance) are associated with homogeneous areas, e.g. pastures. Values of $\alpha \in[-10,-4]$ characterize heterogeneous regions, for example forests, whereas bigger values of $\alpha$ (say $-4<\alpha<0$ ) are observed in extremely heterogeneous areas as is the case of cities (Bustos et al. 2002, Mejail et al. 2003, Pizarro 2003).

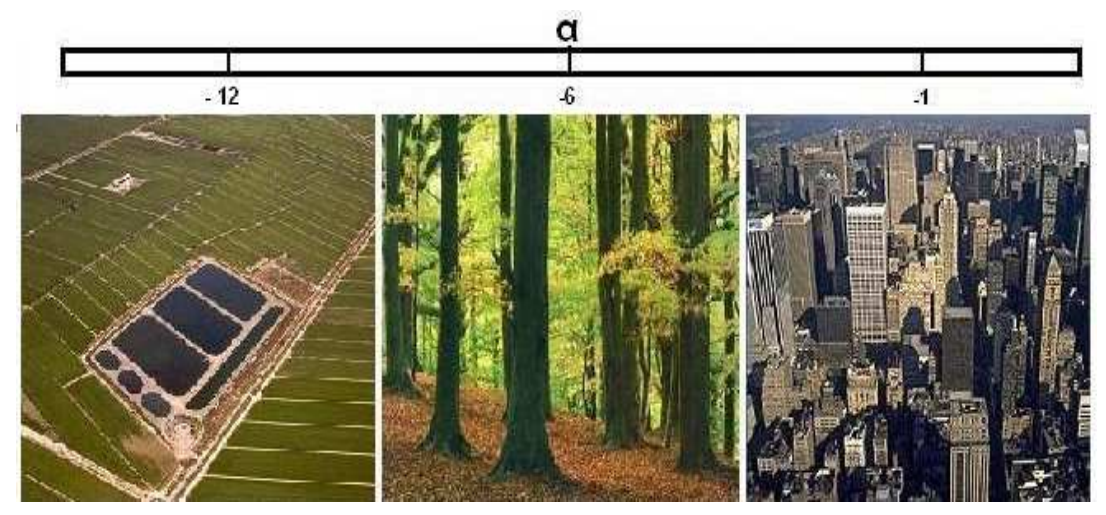

Figure 1.1: Interpretation of the roughness parameter

This thesis does not aim at combating speckle, but at taking advantage of its statistical properties for edge detection.

In this work we propose non-parametric methods for the detection of edges, and we compare them with existing ones to determine their advantages and disadvantages.

After proposing and analyzing different methods of edge detection, we evaluate and compare them using a Monte Carlo experiment. The function under assessment 
is a measure of error in fitting (estimating) an edge to known situations.

This thesis is composed of the following chapters: the present Chapter 1; Chapter 2 presents the multiplicative model for SAR image description, the $\mathcal{G}_{I}^{0}$ distribution and its properties, and a review of edge detection in SAR imagery including non-parametric techniques and our proposal. Chapter 3 presents the results that allow the comparison of the methods under assessment. Chapter 4 discusses the conclusions drawn from this approach. 


\section{Chapter 2}

\section{Methodology}

\section{Resumo}

O modelo multiplicativo é uma excelente ferramenta para explicar as características estatísticas dos dados provenientes de um sistema que emprega iluminação por radiação coerente como as imagens SAR.

Este modelo considera que o retorno, denotado como Z, pode ser modelado como o produto de duas variáveis aleatórias independentes, uma correspondente ao terreno $X$, também conhecida como backscatter, que descreve as propriedades intrínsecas da área, e outra correspondente ao ruído speckle $Y$, que degrada a qualidade da imagem e dificulta a sua visualização e interpretação.

O modelo multiplicativo "clássico" introduzido por Tur et al. (1982), afirma que o retorno de áreas não homogêneas segue uma distribuição $\mathcal{K}$. Quando a área é homogênea, a distribuição $\Gamma$ modela muito bem os dados por ser um caso particular da distribuição $\mathcal{K}$; no entanto, a distribuição $\mathcal{K}$ não modela adequadamente os dados provenientes de áreas extremamente heterogêneas.

Frery et al. (1997) propuseram uma nova classe de distribuições, $\mathcal{G}$, que tem a distribuição $\mathcal{K}$ como um caso particular. Outro caso especial desta família é a distribuição $\mathcal{G}^{0}$, que tem o mesmo número de parâmetros que a distribuição $\mathcal{K}$ e permite a modelagem de áreas extremamente heterogêneas, tais como as zonas urbanas que 
não são modeladas adequadamente pela distribuição $\mathcal{K}$.

Sob o modelo em formato intensidade n-look (Frery et al. 1997), o ruído speckle segue uma distribuição gamma, denotada por $Y_{I}^{(\mathfrak{n})} \sim \Gamma(n, n)$, cuja densidade é dada por

$$
f_{Y_{I}}(y)=\frac{n^{n}}{\Gamma(n)} y^{n-1} \exp (-n y), \quad n \geq 1, y>0,
$$

onde o número de looks $(n)$ indica a quantidade de imagens independentes que foram registradas na área.

A partir dos resultados apresentados em Frery et al. (1997) e Mejail (1999), o backscatter é considerado como uma variável aleatória com distribuição gaussiana inversa generalizada. Esta distribuição está caracterizada pela densidade

$$
f_{X}(x)=\frac{(\lambda / \gamma)^{\frac{\alpha}{2}}}{2 K_{\alpha}(\sqrt{\lambda \gamma})} x^{\alpha-1} \exp \left\{\frac{-1}{2}\left(\lambda x+\frac{\gamma}{x}\right)\right\}, \quad x>0
$$

onde $K_{\alpha}$ denota a função de Bessel modificada do terceiro tipo e ordem $\alpha$.

Se $X_{I} \sim N^{-1}(\alpha, \gamma, \lambda)$ e $Y_{I} \sim \Gamma(n, n)$ são variáveis aleatórias independentes, então o produto $Z_{I}=X_{I} Y_{I}$ tem distribuição $\mathcal{G}_{\mathcal{J}}(\alpha, \gamma, \lambda, n)$ e sua densidade é dada por Frery et al. (1997):

$$
f_{z_{1}}(z)=\frac{n^{n}(\lambda / \gamma)^{\alpha / 2}}{\Gamma(n) K_{\alpha}(2 \sqrt{\lambda \gamma})} z^{n-1}\left(\frac{\gamma+n z}{\lambda}\right)^{(\alpha-n) / 2} K_{\alpha-n}(2 \sqrt{\lambda(\gamma+n z)}),
$$

onde $n \geq 1, z>0$.

A distribuição $\mathcal{G}_{\mathrm{I}}^{0}$ é muito atraente para modelagem de dados com ruído speckle, devido a seu fácil manejo matemático e porque ela é capaz de modelar muito bem dados provenientes de qualquer tipo de área. Sua densidade é dada por Frery et al. (1997):

$$
f_{Z_{1}}(z)=\frac{n^{n} \Gamma(n-\alpha)}{\gamma^{\alpha} \Gamma(n) \Gamma(-\alpha)} \frac{z^{n-1}}{(\gamma+n z)^{n-\alpha}}, \quad z>0,
$$

onde $-\alpha>0$ é o parâmetro de rugosidade, $\gamma>0$ é o parâmetro de escala e $n \geq 1$ é o número de looks.

Detectores de bordas de imagens ruidosas baseados na teoria estatística foram 
descritos por diversos autores, como, por exemplo, Bovik et al. (1986). Os autores introduziram o uso da estatística não-paramétrica para a detecção de bordas com ruído gaussiano aditivo.

A detecção de bordas em imagens com ruído speckle tem sido estudada por diversos autores e uma variedade de técnicas é apresentada em Gambini et al. (2006, 2008). O algoritmo utilizado por Gambini et al. $(2006,2008)$ considera a imagem por regiões, em vez de considerar a imagem total, economizando tempo computacional. Se um ponto pertence à borda do objeto, então uma amostra retirada da sua vizinhança deverá exibir uma mudança nos parâmetros e, portanto, é considerado como ponto de transição.

Este capítulo apresenta uma introdução elementar a imagens SAR, o básico do modelo multiplicativo para speckled imagens, a distribuição $\mathrm{G}_{\mathrm{I}}^{0}$ e os quatro testes estatísticos. Faremos mais adiante uma avaliação dos desempenhos destas quatro técnicas, comparativamente ao método apresentado por Gambini et al. $(2006,2008)$. 


\section{Methodology}

The multiplicative model is an excellent tool for explaining the statistical characteristics of data obtained by systems which employ coherent illumination; such as sonar, laser, ultrasound-B and SAR imagery. This model considers that the intensity return, denoted $Z$, in every pixel, can be viewed as the product of two independent random variables, one corresponding to the terrain, $X$, also known as backscatter, that describes the intrinsic properties of the area, and another corresponding to the speckle noise $Y$, that degrades the quality of the image and hampers its visualization and interpretation. The distribution of $Z=X Y$ is determined by the distributions of $X$ and of $Y$.

The image format (complex, intensity or amplitude) determines the distribution of the variable $Y$, whereas the heterogeneity of the target determines the $X$ distribution. It is, therefore, possible to obtain different distributions to model the return $Z$, depending on the degree of target homogeneity.

The "classical" multiplicative model, introduced by Tur et al. (1982), states that the return from non-homogeneous areas follows the $\mathcal{K}$ distribution. When the area is homogeneous the $\Gamma$ distribution models the return data well and, being a particular case of the previous one, the validity of the $\mathcal{K}$ model is preserved. Nevertheless, the $\mathcal{K}$ distribution does not model adequately data from extremely heterogeneous areas.

Frery et al. (1997) proposed a new class of distributions, $\mathcal{G}$, which has the $\mathcal{K}$ distribution as a particular case. Another special case of this family is the $\mathcal{G}^{0}$ distribution, that has as many parameters as the $\mathcal{K}$ law, and allows the modeling of extremely heterogeneous areas, such as urban zones, which cannot be appropriately modeled by the $\mathcal{K}$ distribution.

In the following section, we will present a review of the multiplicative model, with emphasis on the information required for our proposal. 


\subsection{The multiplicative model}

Under the n-looks format model of intensity (Frery et al. 1997), the speckle noise follows a gamma distribution, denoted by $Y_{I}^{(\mathfrak{n})} \sim \Gamma(\mathfrak{n}, \mathfrak{n})$, whose density is given by:

$$
f_{Y_{I}}(y)=\frac{n^{n}}{\Gamma(n)} y^{n-1} \exp (-n y), \quad n \geq 1, y>0,
$$

where the number of looks $(n)$ denotes the quantity of independent images that were registered on the area. The moments of this distribution are given by

$$
E\left[Y_{I}^{r}\right]=\frac{1}{n^{r}} \frac{\Gamma(n+r)}{\Gamma(n)},
$$

where $r$ is the order of the moment.

In the modeling of SAR images, the minimum value of $n$ is 1 , which corresponds to images generated without multi-look processing. Such images are, thus, noisier, but they carry more information with respect to resolution. The number $n$ can be assumed to be known or estimated beforehand from the whole image. In this work we assume it is known.

Figure 2.1 shows four gamma densities corresponding to 1, 2, 4 and 8 looks. It is noticeable that the bigger $n$ the more symmetric the density. In fact, it is easy to show that the variance, the skewness and the kurtosis of this distribution converge to zero when $n \rightarrow \infty$ (see, for instance, Yanasse et al. 1995).

The backscatter may exhibit different degrees of homogeneity, and different models could be used to encompass this characteristic. Two main models have proved useful for modelling intensity backscatter: a gamma distributed random variable (for heterogeneous areas) and, more recently, a reciprocal of a gamma distributed random variable (for extremely heterogeneous areas). From the results presented in Frery et al. (1997) these two situations are unified by the generalized inverse Gaussian distribution, whose density function is given by

$$
f_{X}(x)=\frac{(\lambda / \gamma)^{\frac{\alpha}{2}}}{2 K_{\alpha}(\sqrt{\lambda \gamma})} x^{\alpha-1} \exp \left\{\frac{-1}{2}\left(\lambda x+\frac{\gamma}{x}\right)\right\}, \quad x>0
$$




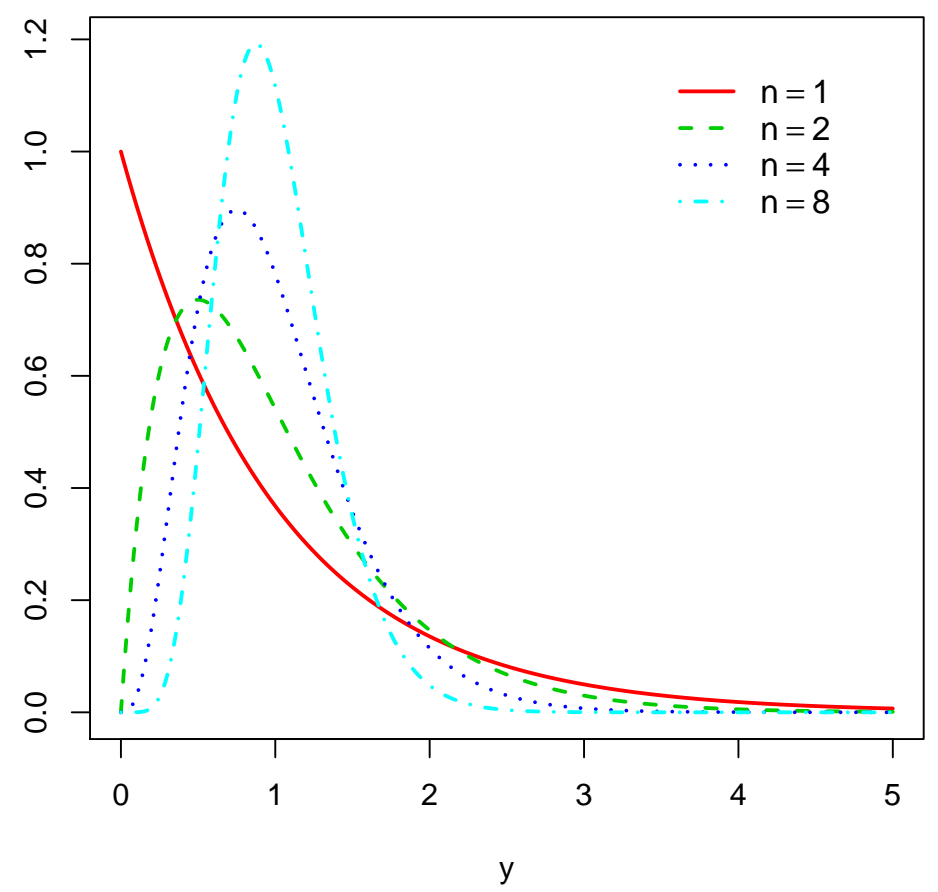

Figure 2.1: Densidade do speackle para 1, 2, 4 e 8 looks (Sólido, traços, pontos e pontos de traços respectivamente)

where $\mathrm{K}_{\alpha}$ denotes the modified Bessel function of the third kind and order $\alpha$ (Gradshteyn \& Ryzhik 1998) given by

$$
\mathrm{K}_{\alpha}(\sqrt{\lambda \gamma})=\frac{1}{2}\left(\frac{\lambda}{\gamma}\right)^{\frac{\alpha}{2}} \int_{0}^{\infty} \mathrm{t}^{\alpha-1} \exp \left\{-\frac{\gamma}{\mathrm{t}}-\lambda \mathrm{t}\right\} \mathrm{dt} .
$$

The parameter space is

$$
\begin{cases}\gamma>0, \lambda \geq 0, & \text { if } \alpha<0 \\ \gamma>0, \lambda>0, & \text { if } \alpha=0 \\ \gamma \geq 0, \lambda>0, & \text { if } \alpha>0 .\end{cases}
$$

The distribution induced by the density given in equation (2.2) is denoted as $\mathrm{X} \sim \mathrm{N}^{-1}(\alpha, \gamma, \lambda)$. This distribution can be reduced to several important particular 
cases, but the following two are of special interest in applications:

- the gamma distribution, when $\gamma=0$, denoted as $\Gamma(\alpha, \lambda)$;

- the distribution of the reciprocal of a gamma distributed random variable, when $\lambda=0$, denoted as $\Gamma^{-1}(\alpha, \gamma)$.

The aforementioned particular cases, i.e., the gamma and reciprocal of gamma laws, are obtained imposing restrictions on the parameter space. In order to make these derivations, two properties of that Bessel function have to be recalled:

1. for every $x>0, K_{-v}(x)=K_{v}(x)$, and

2. every $\mathrm{K}_{v}(\mathrm{x})$ can be approximated by $\Gamma(v) 2^{v-1} x^{-v}$ when $\mathrm{x} \downarrow 0$ and $v>0$.

The first distribution provides a model for studying surfaces which are fairly homogeneous and heterogeneous. The second, in addition to maintaining the skills of the first law, allows

A random variable $X$ is distributed as the reciprocal of a gamma, $X \sim \Gamma^{-1}(\alpha, \gamma)$, if its density function is

$$
f_{x}(x)=\frac{1}{\gamma^{\alpha} \Gamma(-\alpha)} x^{-\alpha-1} \exp \left\{-\frac{\gamma}{x}\right\}, \quad-\alpha, \gamma, x>0 .
$$

Figure 2.2 shows several $\Gamma^{-1}$ densities, according to the following parameters: $\gamma=1$ and $\alpha=(-0.5,-2,-4,-10)$. It is noteworthy that as the values of $\alpha$ are close to zero, the curve becomes flat, thus indicating that the variance increases with $\alpha$. Hence, this distribution is useful for modeling dispersed data, as is the case of very heterogeneous areas in SAR images, such as, for example, images from urban areas.

Under the multiplicative model, the return of intensity data $Z_{I}$ is the product of two independent variables: the intensity backscatter $X_{I}$ and the intensity speckle $Y_{I}$. Therefore, the return has a distribution that depends on the model chosen for the backscattering and noise speckle.

If $X_{I} \sim N^{-1}(\alpha, \gamma, \lambda)$ and $Y_{I} \sim \Gamma(n, n)$ are independent random variables, then the product $Z_{I}=X_{I} Y_{I}$ has a distribution which is called intensity $\mathcal{G}_{I}(\alpha, \gamma, \lambda, n)$ and its 


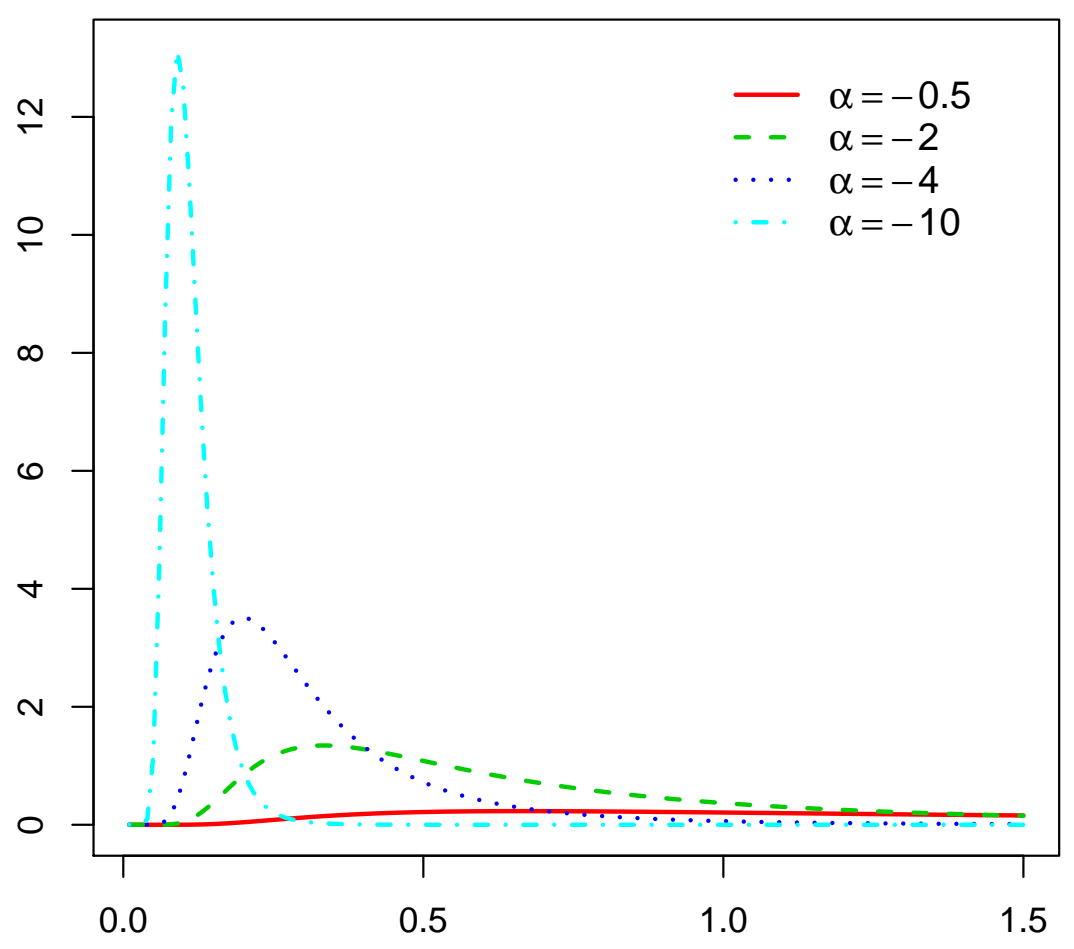

Figure 2.2: $\Gamma^{-1}$ densities for $\alpha=-0.5,-2,-4,-10$ (solid, dashes, dots and dotsdashes respectively)

density is given by Frery et al. (1997):

$$
f_{z_{1}}(z)=\frac{n^{n}(\lambda / \gamma)^{\alpha / 2}}{\Gamma(n) K_{\alpha}(2 \sqrt{\lambda \gamma})} z^{n-1}\left(\frac{\gamma+n z}{\lambda}\right)^{(\alpha-n) / 2} K_{\alpha-n}(2 \sqrt{\lambda(\gamma+n z)}),
$$

where $n \geq 1, z>0$. The space parameter of $(\alpha, \gamma, \lambda)$ is the same as in (2.3).

With this model for the return, it is possible to obtain closed form expressions for the densities of the return under the multiplicative model in, among others, the following cases:

- If $\alpha, \lambda>0$ and $\gamma \downarrow 0$, the $\mathcal{G}_{\mathrm{I}}(\alpha, \gamma, \lambda, n)$ distribution converges in distribution to distribution denoted as $\mathcal{K}_{\mathrm{I}}(\alpha, \lambda, n)$;

- If $-\alpha, \gamma>0$ and $\lambda \downarrow 0$, the $\mathcal{G}_{\mathrm{I}}(\alpha, \gamma, \lambda, \mathfrak{n})$ distribution converges in distribution to distribution denoted as $\mathcal{G}_{\mathrm{I}}^{0}(\alpha, \gamma, \mathrm{n})$. 
The parameters of the $\mathcal{G}_{\mathrm{I}}^{0}$ distribution have the same interpretation as those of the $\mathcal{K}_{\text {I }}$ distribution, but the first law has greater flexibility for modeling surfaces with different degrees of homogeneity. The $\mathcal{G}_{\mathrm{I}}^{0}$ law is numerically and computationally more manageable than the $\mathcal{K}_{\mathrm{I}}$ law, which makes it very attractive as an alternative for the analysis of SAR data. This distribution was developed for describing areas with extremely heterogeneous clutter by Frery et al. (1997), and was later proposed and evaluated as an universal model for data with speckle noise by Mejail et al. (2001). An extension for the polarimetric case is presented in Freitas et al. (2005), and its application to polarimetric SAR image classification is demonstrated in Frery et al. (2007).

Next section presents some useful properties of the distribution that will be used to describe the return in those images where we will look for edges.

\section{$2.2 \mathcal{G}_{\mathrm{I}}^{0}$ distribution: properties and estimation}

The $\mathcal{G}_{\mathrm{I}}^{0}$ distribution is very attractive for modeling data with speckle noise, due to its mathematical tractability and because it is able to model very well information from most types of area.

Let $X_{I}$ and $Y_{I}$ be two independent random variables such that $X_{I} \sim \Gamma^{-1}(\alpha, \gamma)$ and $Y_{I} \sim \Gamma(n, n)$ with $-\alpha, \gamma>0, n \geq 1$. Then, the random variable $Z_{I}=X_{I} Y_{I}$ follows a $\mathcal{G}_{\mathrm{I}}^{0}$ distribution: $Z_{\mathrm{I}} \sim \mathcal{G}_{\mathrm{I}}^{0}(\alpha, \gamma, n)$ (Frery et al. 1997), characterized by the density

$$
f_{Z_{I}}(z)=\frac{n^{n} \Gamma(n-\alpha)}{\gamma^{\alpha} \Gamma(n) \Gamma(-\alpha)} \frac{z^{n-1}}{(\gamma+n z)^{n-\alpha}}, \quad z>0,
$$

where $-\alpha>0$ is the roughness parameter, $\gamma>0$ is the scale parameter and $n \geq 1$ is the number of looks.

The moments of order $r$, are given by

$$
\mathrm{E}\left[Z_{\mathrm{I}}^{r}\right]=\left(\frac{\gamma}{n}\right)^{r} \frac{\Gamma(-\alpha-r) \Gamma(\mathrm{n}+\mathrm{r})}{\Gamma(-\alpha) \Gamma(\mathrm{n})}, \quad-\alpha>r / 2 .
$$


Using equation (2.5), the variance of the $\mathcal{G}_{\mathrm{I}}^{0}$ distribution can be computed as $\operatorname{Var}\left[Z_{\mathrm{I}}\right]= \begin{cases}\left(\frac{\gamma}{n}\right)^{2}\left[\frac{\Gamma(-\alpha) \Gamma(\mathrm{n}) \Gamma(-\alpha-2) \Gamma(\mathrm{n}+2)-\Gamma^{2}(-\alpha-1) \Gamma^{2}(\mathrm{n}+1)}{\Gamma^{2}(\mathrm{n}) \Gamma^{2}(-\alpha)}\right] & -\alpha>1, \\ \infty & 0<-\alpha \leq 1\end{cases}$

Figure 2.3 shows different $\mathcal{G}_{I}^{0}(\alpha, \gamma, n)$ densities for different values of $\alpha$; the parameters $\gamma=5$ and $n=3$ are fixed. It is noted that the variance increases when $\alpha$ approaches zero.

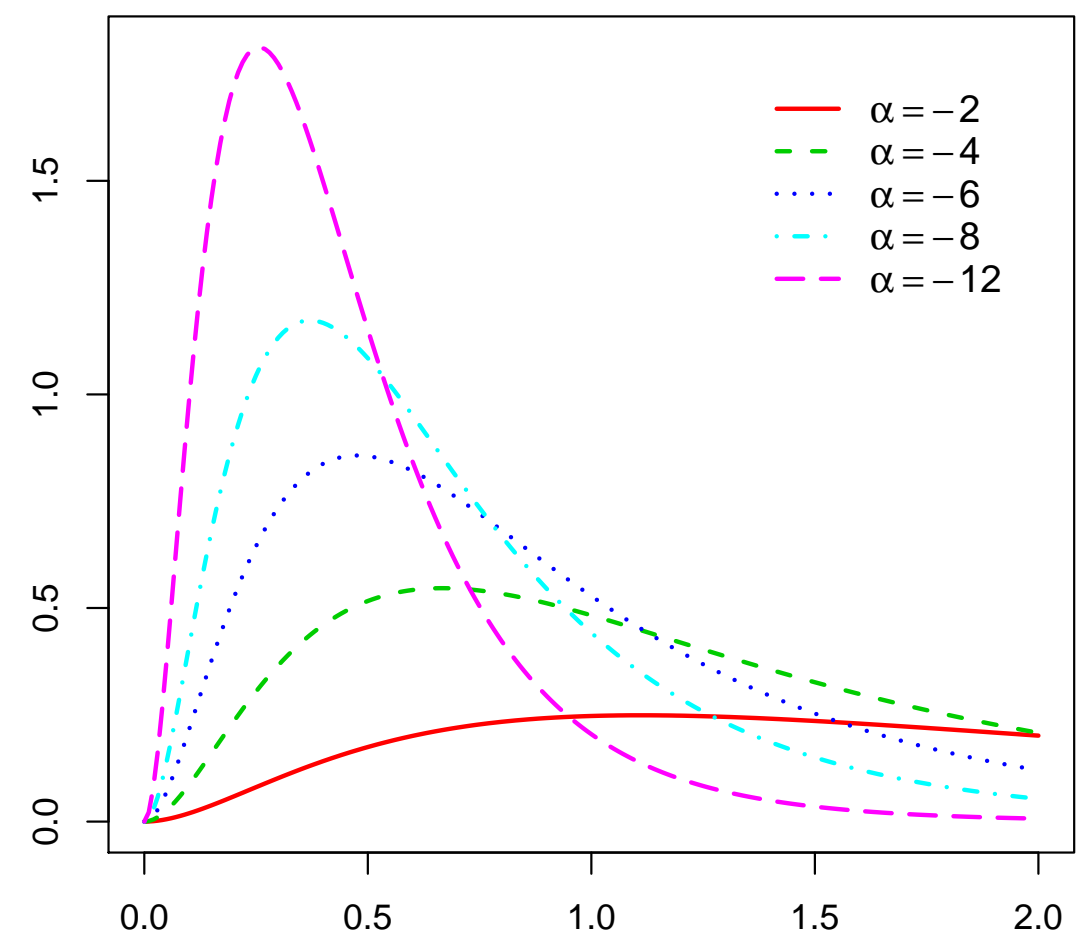

Figure 2.3: $\mathcal{G}_{\mathrm{I}}^{0}$ densities for $\alpha=-2,-4,-6,-8,-12$ (solid, dashes, dots, dots-dashes respectively, solid-solid)

The proposed model for the return in SAR images depends on three parameters: roughness $(\alpha)$, scale $(\gamma)$ and number of looks $(n)$. There are a number of techniques for estimating such parameters, the most commonly used being those based on the substitution method (Manski 1988), maximum likelihood methods (Casella \& Lehman 1998) and robust methods (Hampel et al. 1986). Besides those approaches, 
there are also proposals of improvement techniques based either on analytic correction or on re-sampling.

Cribari-Neto et al. (2002) evaluate the effectiveness of bootstrap methods in improving estimation of clutter properties in speckled imagery. The estimation is performed by maximum likelihood methods. They show that the estimators obtained in this way can be quite biased in finite samples, and develop bias correction schemes using bootstrap re-sampling. They propose, for numerically bias correcting the maximum likelihood point estimates, alternative estimators that can deliver substantial finite-sample improvement over the original maximum likelihood parameter estimates and over other bootstrap-based bias-corrected estimation procedures.

Vasconcellos et al. (2005) propose an analytical bias correction for the maximum likelihood estimators of the $\mathcal{G}_{\mathrm{I}}^{0}$ distribution. Comparing the performance of the corrected estimators with the corresponding original version, they observe that the maximum likelihood estimator and its corrected version are the preferred inference procedures with respect to bias. Also, they have verified that there is a wide range of practical situations for which the corrected estimator effectively reduces both bias and mean square error of the original maximum likelihood estimator.

Bustos et al. (2002) derive M-estimators for the parameters of the $\mathcal{G}_{\AA}^{0}$ distribution, and compare them with maximum likelihood estimators. They show that this robust technique is superior to the classical approach under the presence of corner reflectors, a common source of contamination in SAR images.

Allende et al. (2006) present the derivation of M-estimators with asymmetric influence functions, motivated by the $\mathcal{G}_{\mathrm{A}}^{0}$ distribution. They propose the asymmetric M-estimator (AM-estimator), an M-estimator with asymmetric redescending functions. The performance of AM estimators is assessed, and it is shown that they either compete with or outperform both maximum likelihood and Huber-type Mestimators.

In this section we present estimators for parameters of the $\mathcal{G}_{\mathrm{I}}^{0}$ distribution, assuming know number of looks and using the method of moments of orders $\frac{1}{2}$ and 1 . This was the approach used by Gambini et al. (2006, 2008), and since we aim at 
extending their work and comparing our proposal with theirs, we implemented the same approach they used.

Let $\left(Z_{1}, \ldots, Z_{n}\right)$ be a vector of independent and identically distributed random variables, with common $\mathcal{G}_{I}^{0}(\alpha, \gamma, n)$ distribution, $\alpha<-1, \gamma>0$ and $n$ known. Define the $r$-th sample moment as:

$$
\widehat{m}_{r}=\frac{1}{n} \sum_{i=1}^{n} Z_{i}^{r}
$$

with $r=\frac{1}{2}, 1$ (that is the reason why we assume $\alpha<-1$ rather than $\alpha<0$ ).

From equation (2.5) it is immediate that

$$
\mathrm{E}(\mathrm{Z})=\left(\frac{\gamma}{\mathrm{n}}\right) \frac{\Gamma(-\alpha-1) \Gamma(\mathrm{n}+1)}{\Gamma(-\alpha) \Gamma(\mathrm{n})}, \quad-\alpha>1 / 2
$$

and that

$$
\mathrm{E}\left(\mathrm{Z}^{\frac{1}{2}}\right)=\left(\frac{\gamma}{\mathrm{n}}\right)^{\frac{1}{2}} \frac{\Gamma\left(-\alpha-\frac{1}{2}\right) \Gamma\left(\mathrm{n}+\frac{1}{2}\right)}{\Gamma(-\alpha) \Gamma(\mathrm{n})}, \quad-\alpha>1 / 4 .
$$

Replacing the theoretical moments by the sample expressions, and the parameters by their estimators, we build a system of two equations:

$$
m_{1}=\left(\frac{\widehat{\gamma}}{n}\right) \frac{\Gamma(-\widehat{\alpha}-1) \Gamma(n+1)}{\Gamma(-\widehat{\alpha}) \Gamma(n)}, \quad-\widehat{\alpha}>1 / 2 .
$$

and

$$
m_{\frac{1}{2}}=\left(\frac{\widehat{\gamma}}{n}\right)^{\frac{1}{2}} \frac{\Gamma\left(-\widehat{\alpha}-\frac{1}{2}\right) \Gamma\left(n+\frac{1}{2}\right)}{\Gamma(-\widehat{\alpha}) \Gamma(n)}, \quad-\widehat{\alpha}>1 / 4 .
$$

clearing $\hat{\gamma}$ of both equations, we obtain

$$
\widehat{\gamma}=\frac{m_{1} \Gamma(-\widehat{\alpha}) \Gamma(n) n}{\Gamma(-\widehat{\alpha}-1) \Gamma(n+1)}
$$

and

$$
\widehat{\gamma}=\frac{m_{\frac{1}{2}}^{2} \Gamma^{2}(-\widehat{\alpha}) \Gamma^{2}(n) n}{\Gamma^{2}\left(-\widehat{\alpha}-\frac{1}{2}\right) \Gamma^{2}\left(n+\frac{1}{2}\right)} .
$$


From equations (2.7) and (2.8) we then obtain

$$
\frac{m_{1} \Gamma(-\widehat{\alpha}) \Gamma(n) n}{\Gamma(-\widehat{\alpha}-1) \Gamma(n+1)}=\frac{m_{\frac{1}{2}}^{2} \Gamma^{2}(-\widehat{\alpha}) \Gamma^{2}(n) n}{\Gamma^{2}\left(-\widehat{\alpha}-\frac{1}{2}\right) \Gamma^{2}\left(n+\frac{1}{2}\right)}
$$

The estimator of $\alpha$ is obtained by solving numerically the following equation

$$
g(\widehat{\alpha})-\zeta=0
$$

where

$$
g(\widehat{\alpha})=\frac{\Gamma^{2}\left(-\widehat{\alpha}-\frac{1}{2}\right)}{\Gamma(-\widehat{\alpha}) \Gamma(-\widehat{\alpha}-1)}
$$

and

$$
\zeta=\frac{m_{\frac{1}{2}}^{2}}{m_{1}} \frac{\Gamma(n+1) \Gamma(n)}{\Gamma^{2}\left(n+\frac{1}{2}\right)} .
$$

By plugging the value of $\widehat{\alpha}$ into equation (2.6) one finds the value of $\widehat{\gamma}$.

Next section presents a summary of the main techniques for edge detection in SAR imagery, with special emphasis on those that explicitly employ statistical models and techniques.

\subsection{Edge detection in SAR imagery}

Edge detectors based on the statistical theory of edges detection in noisy images have been described by, for example, Bovik et al. (1986). Those authors introduced nonparametric statistics for edge detection in Gaussian additive noise. They demonstrated the usefulness of the median and the Wilcoxon-Mann-Whitney tests for edge detection with the help of a sample image interpreted visually.

Fesharaki \& Hellestrand (1994) proposed an algorithm for detecting edges by using a t-test. Beauchemin et al. (1998) described an edge detection method which uses a nonparametric alternative based on the Wilcoxon-Mann-Whitney statistics for detecting changes in adjacent pixel neighborhoods with relatively distinct grey level values. They assumed that the neighborhoods are sufficiently homogeneous and 
changes in adjacent neighborhoods are detected by testing differences in location parameters such as means or medians. Although these tests may be appropriate for specific types of images, they may not detect changes in local grey level values in images with low signal-to-noise ratios, as is the case of SAR imagery.

Recently, Hoon Lim \& Ju Jang (2002) compared two-sample tests for edge detection in noisy images. Later, Lim (2006) describes a new edge detector based on the robust rank-order test which is a useful alternative to the Wilcoxon test, using $\ell \times \ell$ windows for detecting edges of all possible orientations in noisy images. This method is based on testing whether an $\ell \times \ell$ window is partitioned into two sub-regions having significant differences in local gray-level values between neighborhoods of a given pixel, using an edge-height model to extract edges of some sufficient brightness from images corrupted with noises.

The two main advantages of nonparametric tests are:

1. their statistical significance is independent of the distribution form, and

2. they are robust against the presence of extreme observations.

These features are of particular interest in the case at hand, namely, speckled imagery.

The detection of edges in images with speckle noise has been studied by many authors and a variety of techniques are presented in the work of Gambini et al. (2006, 2008).

This study is based on Juliana Gambini's doctoral thesis, who proposed a method of curve fitting with contours of objects and regions in images with speckle noise which displays excellent results, with an acceptable computational cost. The algorithms used by Gambini et al. (2006, 2008) consider the image region by region, instead of considering the whole image, saving computational time. In addition, this approach employs B-splines as the mathematical model for the contours; such curves depend on few parameters and are easily computed (Brigger et al. 2000).

In order to find edge points between different regions of the image, Gambini et al. $(2006,2008)$ used the assumption that the squared SAR data can be modeled by the 
$\mathcal{G}_{\mathrm{I}}^{0}$ distribution, i.e., the so-called $\mathcal{G}_{\mathrm{A}}^{0}$ distribution. Under this model, the regions of the image with different degrees of homogeneity are characterized by the parameters of the distribution. Hence, the relevant parameters are estimated, along straight segments arranged in an adequate surrounding of an initial curve. If a point belongs to the edge of the object, then in a neighborhood of this point there should be a sudden change in the estimated parameters of the distribution.

In this Chapter we describe five techniques for detecting edges in SAR images. One is the method of Gambini and four similar methods based on linear rank sums are described; specifically, the Wilcoxon-Mann-Whitney, Kruskal-Wallis, Variance test and a new statistical propose.

\subsubsection{Gambini algorithm for edge detection}

If a point belongs to an object edge, then a sample taken from its neighbourhood should exhibit a changes in the statistical parameters and, therefore, should be considered a transition point.

Consider $N$ segments of the image, $s^{(i)}, i \in\{1, \ldots, N\}$, of the form $s^{(i)}=\overline{C_{i}}$ where $C$ is the centroid of the initial region, the extreme $P_{i}$ is a point outside the region and $\theta_{i}=\angle\left(s^{(i)}, s^{(i+1)}\right)$ is the angle between two successive segments, as shown in Figure 2.4.

The segment $s^{(i)}$ is an array of $m$ elements coming from a discretization of the straight line on the image and is given by

$$
\mathrm{s}^{(i)}=\left(z_{1}^{(i)}, \ldots, z_{\mathrm{m}}^{(i)}\right) .
$$

For each segment $s^{(i)}, 1 \leq i \leq N$, the following partition is considered:

$$
\begin{array}{lr}
Z_{k}^{(i)} \sim \mathcal{G}_{\mathrm{I}}^{\mathrm{O}}\left(\alpha_{\ell}, \gamma_{\ell}\right), & \mathrm{k}=1, \ldots, \mathfrak{j}_{\mathrm{i}}, \\
\mathrm{Z}_{\mathrm{k}}^{(\mathrm{i})} \sim \mathcal{G}_{\mathrm{I}}^{\mathrm{O}}\left(\alpha_{\mathrm{r}}, \gamma_{\mathrm{r}}\right), & \mathrm{k}=\mathrm{j}_{\mathrm{i}}, \ldots, \mathrm{m},
\end{array}
$$

where, for each $k$, with $1 \leq k \leq m, z_{k}^{(i)}$ is the realization of the random variable 


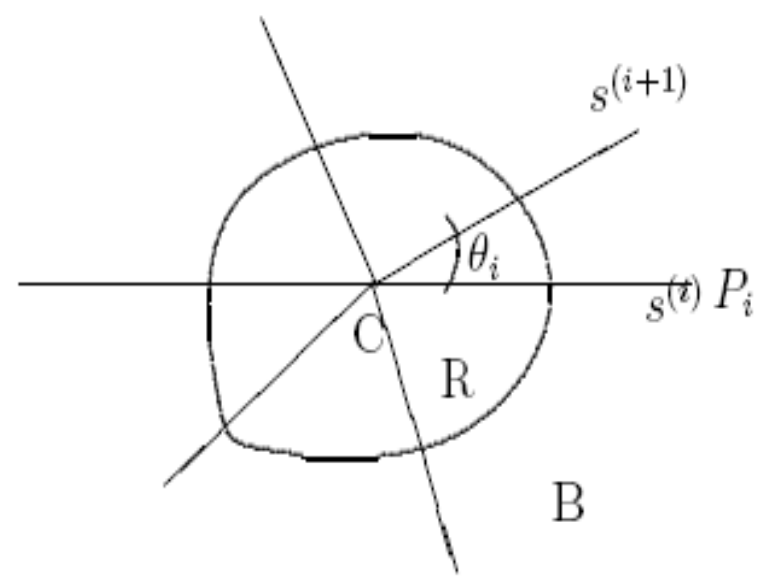

Figure 2.4: Radial straight lines projected from the centroid of $R$ to the exterior of the region, with a separation of $\theta_{i}$

$Z_{k}^{(i)}$. The parameters $\left(\alpha_{\ell}, \gamma_{\ell}\right)$ and $\left(\alpha_{r}, \gamma_{r}\right)$ characterize the region and its background, respectively, and they are estimated as explained in section 2.2 .

In order to find the transition point on each segment, $s^{(i)}$, an objective function is considered: the likelihood of the sample, which is given by

$$
l=\prod_{i=1}^{j} \operatorname{Pr}\left(z_{i} ; \widehat{\alpha}_{\ell}, \widehat{\gamma}_{\ell}\right) \prod_{i=j+1}^{m} \operatorname{Pr}\left(z_{i} ; \widehat{\alpha_{r}}, \widehat{\gamma_{r}}\right) .
$$

To find the transition point, we maximize $\mathrm{L}=\ln (l)$

$$
L=\ln (l)=\sum_{i=1}^{j} \ln \left(f_{\mathcal{S}_{1}^{0}}\left(z_{i} ; \widehat{\alpha}_{\ell}, \widehat{\gamma}_{\ell}\right)\right)+\sum_{i=j+1}^{m} \ln \left(f_{\mathcal{S}_{1}^{0}}\left(z_{i} ; \widehat{\alpha}_{r}, \widehat{\gamma}_{r}\right)\right)
$$

Then, using equations (2.4),

$$
\begin{aligned}
L= & \sum_{i=1}^{j} \ln \left(\frac{n^{n} \Gamma\left(n-\widehat{\alpha}_{\ell}\right) z_{i}^{n-1}}{\widehat{\gamma_{\ell}}{\widehat{\alpha_{\ell}}}^{n} \Gamma(n) \Gamma\left(-\widehat{\alpha}_{\ell}\right)\left(\widehat{\gamma_{\ell}}+n z_{i}\right)^{n-\widehat{\alpha_{\ell}}}}\right)+ \\
& \sum_{i=j+1}^{m} \ln \left(\frac{n^{n} \Gamma\left(n-\widehat{\alpha_{r}}\right) z_{i}^{n-1}}{\widehat{\gamma_{r}}{\widehat{\alpha_{r}}}^{n} \Gamma(n) \Gamma\left(-\widehat{\alpha_{r}}\right)\left(\widehat{\gamma_{r}}+n z_{i}\right)^{n-\widehat{\alpha_{r}}}}\right) .
\end{aligned}
$$


Finally, the estimated index on the segment that corresponds to the transition point, $\widehat{\jmath}$, is

$$
\hat{\jmath}=\arg \max _{j} L .
$$

Figure 2.5 shows typical values of the objective function, taken along a straight line segment. The corresponding position of the maximum is considered to be the point of transition between both regions, according to formula (2.9).

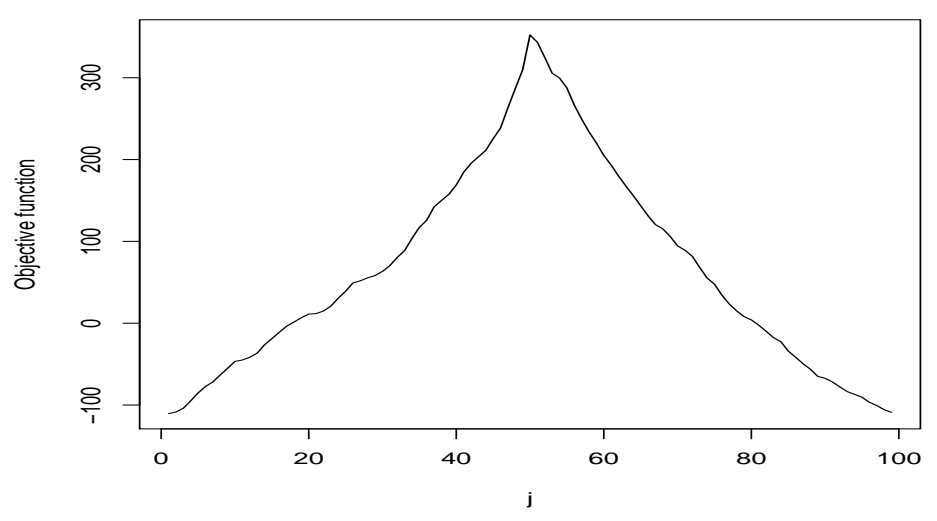

Figure 2.5: Values of the objective function for a segment of straight

The relevant parameters are estimated within a rectangular window, such that the direction of its major axis coincides with the segment being processed and such that it includes a sample from the region and a sample from the background. These samples are used to estimate the $\left(\alpha_{\ell}, \gamma_{\ell}\right)$ and $\left(\alpha_{r}, \gamma_{r}\right)$ parameters, respectively.

Estimation of the parameters that index the $\mathcal{G}_{\mathrm{I}}^{0}$ distribution was discussed in Section 2.2. Next section will present non-parametric alternatives to edge detection, that will lead to the main proposal of this work.

\subsubsection{Non-parametric edge detection}

The usual two-sample situation is that one for which the experimenter has obtained two samples from possibly different populations and wishes to use a statistical test to check if the null hypothesis that the two populations are identical can be rejected. 
That is, the experimenter wishes to detect differences between the two populations on the basis of random samples from those populations. If the samples consist of ordinal-type data, the most interesting difference is a difference in the locations of the two populations.

An intuitive approach to the two-sample problem is to combine both samples into a single ordered sample and assign ranks to the sample values from the smallest value to the largest, regardless the population each value came from. Then, the test statistic can be computed as the sum of the ranks assigned to those values from one of the populations. If the sum is too small (or too large), there is indication that the values from that population tend to be smaller (or larger, as the case may be) than the values from the other population. Hence, the null hypothesis of no differences between populations may be rejected if the ranks associated with one sample tend to be larger than those of the other sample.

Ranks may be preferable to the actual data for several reasons. First, if the numbers assigned to the observations have no meaning by themselves but attain meaning only in an ordinal comparison with the other observations, the numbers contain no more information than the ranks contain. Such is the nature of ordinal data. Second, even if the numbers have meaning but the distribution is not a Gaussian distribution function, the theory is usually beyond our reach when the test statistic is based on the actual data. The probability theory of statistics based on ranks is relatively simple and, in many cases, it does not depend on the underlying distribution. A third reason for preferring ranks is that the asymptotic relative efficiency of the Mann-Whitney test below is never low when compared with the two-sample $t$ test, the usual parametric counterpart. And yet the contrary is not true; the asymptotic relative efficiency of the $t$ test compared to the Mann-Whitney test may be as small as zero, or "infinitely bad." So, the Mann-Whitney test is a safer test to use (Conover 1980).

In this paper we will use test statistical for each non-parametric method, and does not take decision on the hypothesis, for that reason not to follow rules of decision. 


\subsubsection{The Mann-Whitney test}

The data consist of samples from two different populations. Let $X_{1}, X_{2}, \ldots, X_{n}$ denote the random variables representing a sample of size $n$ from population $A$ and let $Y_{1}, Y_{2}, \ldots, Y_{m}$ denote the random variables representing a sample of size $m$ from population B. Assign ranks 1 to $n+m$. Let $R\left(X_{i}\right)$ and $R\left(Y_{j}\right)$ denote the ranks assigned to $X_{i}$ and $Y_{j}$ for all $i$ and $j$. For convenience, let $N=n+m$.

If several sample values are exactly equal to each other (tied), assign to each the average of the ranks that would have been assigned to them had there been no ties.

\section{Assumptions}

- Both samples are random samples from the respective populations.

- In addition to independence within each sample, there is mutual independence between the two samples.

- The measurement scale is at least ordinal.

\section{Hypotheses}

Let $F(x)$ and $G(x)$ be the distribution functions of $X$ and $Y$ corresponding to populations $A$ and $B$, respectively. Then, the hypotheses may be stated as follows:

$$
\begin{aligned}
& H_{0}: F(x)=G(x) \\
& H_{1}: F(x) \neq G(x)
\end{aligned}
$$

In many real situations, as is our case in edge detection, differences between distributions imply that $\operatorname{Pr}(X<Y)$ is no longer equal to $1 / 2$. Therefore, the following 
set of hypotheses is often used instead of the above.

$$
\begin{aligned}
& \mathrm{H}_{0}: \operatorname{Pr}(\mathrm{X}<\mathrm{Y})=\frac{1}{2} \\
& \mathrm{H}_{1}: \operatorname{Pr}(\mathrm{X}<\mathrm{Y}) \neq \frac{1}{2}
\end{aligned}
$$

The Mann-Whitney test is unbiased and consistent when testing the preceding hypotheses involving $\operatorname{Pr}(\mathrm{X}<\mathrm{Y})$.

\section{Test Statistic}

If there are no or just a few ties, the sum of the ranks assigned to the sample from population $A$ can be used as a test statistic:

$$
\mathrm{T}=\sum_{i=1}^{n} \mathrm{R}\left(\mathrm{X}_{i}\right)
$$

If there are many ties, subtract the mean from $T$ and divide by the standard deviation to get

$$
T_{1}=\left|\frac{T-n \frac{N+1}{2}}{\sqrt{\frac{n m}{N(N-1)} \sum_{i=1}^{N} R_{i}^{2}-\frac{n m(N+1)^{2}}{4(N-1)}}}\right| .
$$

where $\sum_{i=1}^{N} R_{i}^{2}$ refers to the sum of the squares of all $N$ of the ranks or average ranks actually used in both samples.

\subsubsection{The Kruskal-Wallis test}

The Mann-Whitney test for two independent samples was extended to the problem of analyzing $k$ independent samples, for $k \geq 2$, by Kruskal \& Wallis (1952). The experimental situation is one where $k$ random samples have been obtained, one from each of $k$ possible different populations, and we want to test the null hypothesis that all populations are identical against the alternative that some of the populations tend to yield greater observed values than others. The term "greater" applies to observations from random variables, but actually any observations that may be 
arranged in increasing order according to some property such as quality, value, and the like may be analyzed using the Kruskal-Wallis test in a manner analogous to the analysis of nonnumeric data using the Mann-Whitney test.

The Kruskal-Wallis test statistic is a function of the ranks of the observations in the combined sample, in a similar fashion to the Mann-Whitney test.

\section{Data}

The data consist of $k$ random samples of possibly different sizes. Denote the $i$-th random sample of size $n_{i}$ by $X_{i 1}, X_{i 2}, \ldots, X_{i n_{i}}$. Then, the data may be arranged into columns:

$\begin{array}{cccc}\text { Sample 1 } & \text { Sample 2 } & \cdots & \text { Sample k } \\ \mathrm{X}_{1,1} & \mathrm{X}_{2,1} & & \mathrm{X}_{k, 1} \\ \mathrm{X}_{1,2} & \mathrm{X}_{2,2} & & \mathrm{X}_{k, 2} \\ \vdots & \vdots & \ddots & \vdots \\ \mathrm{X}_{1, \mathfrak{n}_{1}} & \mathrm{X}_{2, \mathrm{n}_{2}} & & \mathrm{X}_{k, \mathfrak{n}_{k}}\end{array}$

Let $\mathrm{N}$ denote the total number of observations:

$$
\mathrm{N}=\sum_{i=1}^{k} n_{i}
$$

Assign rank 1 to the smallest of the total of $\mathrm{N}$ observations, rank 2 to the second smallest, and so on until the largest of the all $\mathrm{N}$ observations, which receives rank assigned to $X_{i j}$. Let $R_{i}$ be the sum of the ranks assigned to the $i$ th sample:

$$
R_{i}=\sum_{j=1}^{n_{i}} R\left(X_{i j}\right) \quad i=1,2, \ldots, k
$$

Compute $R_{i}$ for each sample. When the ranks can be assigned in several different ways because several observations are tied, assign the average rank to each of the tied observations, as in the previous test. 


\section{Assumptions}

- All samples are random samples from the respective populations.

- In addition to independence within each sample, there is mutual independence among the various samples.

- The measurement scale is at least ordinal.

- Either the $\mathrm{k}$ population distribution functions are identical, or some of the populations tend to yield larger values than other populations do.

\section{Hypotheses}

The following hypotheses are covered by this test:

$\mathrm{H}_{0}$ : All $\mathrm{k}$ population distribution functions are identical

$\mathrm{H}_{1}$ : At least one population tends to yield larger observations than at least one of the other populations

Because the Kruskal-Wallis test is designed to be sensitive against differences among means in the $k$ populations, the alternative hypothesis is sometimes stated as follows.

$H_{1}: k$ populations do not have identical means.

\section{Test Statistic}

The test statistic $T$ is defined as

$$
\mathrm{T}=\frac{1}{\mathrm{~S}^{2}}\left(\sum_{i=1}^{k} \frac{\mathrm{R}_{i}^{2}}{\mathrm{n}_{i}}-\frac{\mathrm{N}(\mathrm{N}+1)^{2}}{4}\right),
$$


where $N$ and $R_{i}$ are defined by equations (2.10) and (2.11), respectively, and where

$$
S^{2}=\frac{1}{N-1}\left(\sum_{\text {all ranks }} R\left(x_{i j}\right)^{2}-\frac{N(N+1)^{2}}{4}\right) .
$$

If there are no ties, $S^{2}$ simplifies to $N(N+1) / 12$, and the test statistic reduces to

$$
\mathrm{T}_{k}=\frac{12}{\mathrm{~N}(\mathrm{~N}+1)} \sum_{i=1}^{k} \frac{\mathrm{R}_{i}^{2}}{\mathrm{n}_{\mathrm{i}}}-3(\mathrm{~N}+1) .
$$

If the number of ties is moderate there will be very little difference between equations (2.12) and (2.13), so the simpler equations (2.13) may be preferred in practice.

\subsubsection{The Squared Ranks test for variances}

The usual standard of comparison for several populations is based on the means or others measures of location of the population. However, in some situations the variances of the populations may be the quantity of interest. The squared ranks test can be used to assess equality of variance across two or more independent random samples which have been measured using a scale that is at least interval (Conover 1980).

Interval measurement assigned to objects have all the features of ordinal measurements, and in addition equal differences between measurements represent equivalent intervals. That is, differences between arbitrary pairs of measurements can be meaningfully compared. Operations such as addition and subtraction are therefore meaningful. The zero point on the scale is arbitrary; negative values can be used.

\section{Data}

The data consist of the two random samples. Let $X_{1}, X_{2}, \ldots, X_{n}$ denote the random sample of size $n$ from population $A$ and let $Y_{1}, Y_{2}, \ldots, Y_{m}$ denote the random sample of size $m$ from population B. Convert each $X_{i}$ and $Y_{j}$ to its absolute deviation from 
the mean using

$$
u_{i}=\left|X_{i}-\bar{X}_{1}\right|, \quad i=1, \ldots, n,
$$

and

$$
\mathrm{V}_{j}=\left|\mathrm{Y}_{j}-\overline{\mathrm{X}}_{2}\right|, \quad j=1, \ldots, \mathrm{m},
$$

where $\bar{X}_{1}$ and $\bar{X}_{2}$ are the sample means for populations $A$ and $B$.

Assign ranks 1 to $n+m$ to the combined sample for $U s$ and $V s$ in the usual way. If several values of $U$ and/or $V$ are exactly equal to each other (ties), assign to each the average of the ranks that would have been assigned to them had there been no ties.

\section{Assumptions}

- Both samples are random samples from their respective populations.

- In addition to independence within each sample there is mutual independence between the two samples.

- The measurement scale is at least interval.

\section{Hypotheses}

$H_{0}: X$ and $Y$ are identically distributed, except for possibly different means. $\mathrm{H}_{1}$ :

$$
\begin{aligned}
& \operatorname{Var}(\mathrm{X}) \neq \operatorname{Var}(\mathrm{Y}) \quad \text { or } \\
& \operatorname{Var}(\mathrm{X})<\operatorname{Var}(\mathrm{Y}) \quad \text { or } \\
& \operatorname{Var}(\mathrm{X})>\operatorname{Var}(\mathrm{Y})
\end{aligned}
$$




\section{Test Statistic}

If there are no values of $U$ tied with values of $V$, the sum of the squares of the ranks assigned to population $A$ can be used as the test statistic

$$
\mathrm{T}=\sum_{i=1}^{n}\left[R\left(\mathrm{U}_{\mathrm{i}}\right)\right]^{2}
$$

If there are ties, subtract the mean from $\mathrm{T}$ and divide by the standard deviation to get

$$
\mathrm{T}_{v}=\frac{\mathrm{T}-n \overline{\mathrm{R}^{2}}}{\left[\frac{n \mathrm{~m}}{\mathrm{~N}(\mathrm{~N}-1)} \sum_{i=1}^{\mathrm{N}} \mathrm{R}_{i}^{4}-\frac{n \mathrm{~m}}{\mathrm{~N}-1}\left(\overline{\mathrm{R}^{2}}\right)^{2}\right]^{\frac{1}{2}}},
$$

where $N=n+m$, and $\overline{R^{2}}$ represents the average of the squared ranks of both samples combined, i.e,

$$
\overline{R^{2}}=\frac{1}{N}\left\{\sum_{i=1}^{n}\left[R\left(U_{i}\right)\right]^{2}+\sum_{j=1}^{m}\left[R\left(V_{j}\right)\right]^{2}\right\}
$$

and $\sum_{i=1}^{N} R_{i}^{4}$ represents the sum of the ranks raised to the fourth power:

$$
\sum_{i=1}^{N} R_{i}^{4}=\sum_{i=1}^{n}\left[R\left(U_{i}\right)\right]^{4}+\sum_{j=1}^{m}\left[R\left(V_{j}\right)\right]^{4}
$$

\subsubsection{The TPE empirical statistic}

The empirical statistic TPE was designed based on non-parametric statistics based on ranges, which have good performance in situations where one wants to test whether two samples have means and/or different variances, as is the case with Kruskal-Wallis and Mann-Whitney statistics and the Squared Rank test for variances.

The data consist of the two random samples. Let $X_{1}, X_{2}, \ldots, X_{n}$ denote the random sample of size $n$ from population $A$ and let $Y_{1}, Y_{2}, \ldots, Y_{m}$ denote the random sample of size $m$ from population $B$. Assign ranks 1 to $N=n+m$.

Taking as the main idea the use of the ranges of the combined sample, the em- 
pirical statistic TPE compares the average of overall ranks of the combined sample $\mu=(N+1) / 2$ with the difference between the average ranks of the two populations $D_{E}=|\bar{x}-\bar{y}|$, obtaining in this way the empirical statistics $E$ :

$$
E=\left|D_{E}-\mu\right|
$$

\subsection{Proposal}

We have presented three classical and an empirical non-parametrical test that may be used for edge detection in speckled imagery. In this section we will discuss how to use them in practice.

In order to find the transition point on each segment, $s^{(i)}$, take a number of elements $j_{1}, \ldots, j_{k}$ on the segment, separated by an arbitrary length. For each element, form two rectangular windows whose division is in this point, as shown in Figure 2.6. The window to the left of $j_{i}$ contains information on the ranks of population $A$, and, to the right of $j_{i}$, the window contains the ranks of population $B$. The candidate edge, namely $j_{i}$, will be displaced and at each location objective functions will be calculated.

C

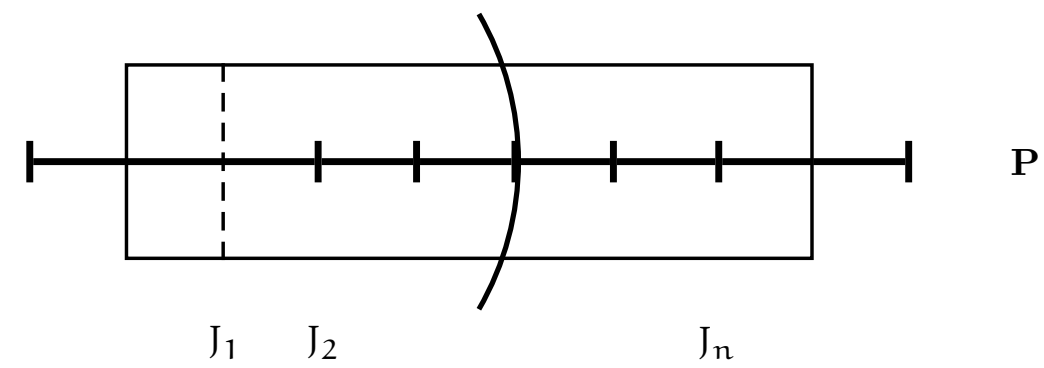

C

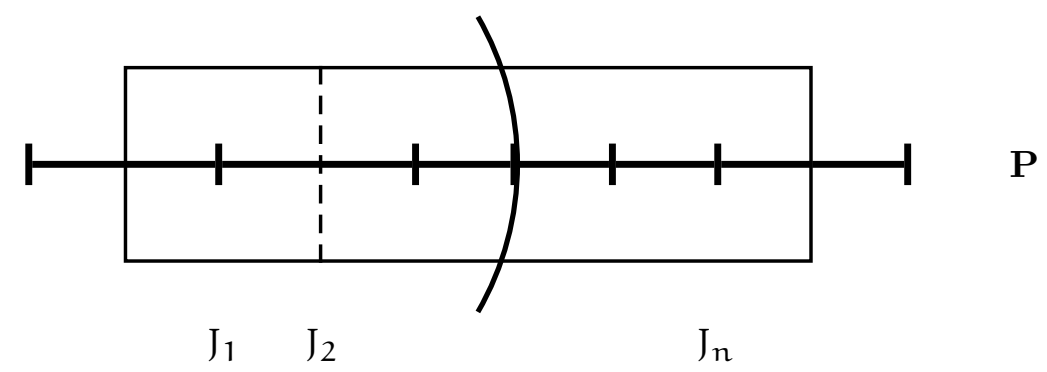

Figure 2.6: Displacement of a rectangular window on a straight segment 
Finally, the estimate of the index $\hat{\jmath}$ corresponding to point edge $b_{i}$ on the segment $s^{(i)}$ is given by:

- The Mann-Whitney Test:

$$
\widehat{\jmath}=\arg \max _{j} T_{1} ;
$$

- The Kruskal-Wallis Test:

$$
\widehat{\jmath}=\arg \max _{j} T_{k} ;
$$

- The squared Ranks Test for Variances:

$$
\widehat{\jmath}=\arg \max _{j} T_{v} ;
$$

- The TPE Empirical statistic:

$$
\widehat{\jmath}=\arg \min _{j} E .
$$

Figure 2.7 shows typical values of the statistics of the Mann-Whitney test, KruskalWallis test, squared ranks test for variances and the TPE empirical statistic taken along a straight line segment. The corresponding position of the maximum (MannWhitney, Kruskal, T. Variance) or the minimum (TPE) is considered to be the point of transition between both regions. In this figure, the true edge is at position 50 along the abscissas; it is noted that the maximum value that the Mann-Whitney, Kruskal-Wallis, squared Ranks for Variances test statistics, and TPE's minimum coincides with the point of edge, suggesting, thus, that our proposal is sensible.

This Chapter presented an elementary introduction to SAR imagery, the basics of
the Multiplicative Model for speckled imagery, the $\mathrm{G}_{\mathrm{I}}^{O}$ distribution and the four test
statistics. In order to make a quantitative assessment of the performance of these
four techniques, and to compare them with the one claimed by Gambini et al. (2006,
2008), a Monte Carlo experience is described in the next Chapter.



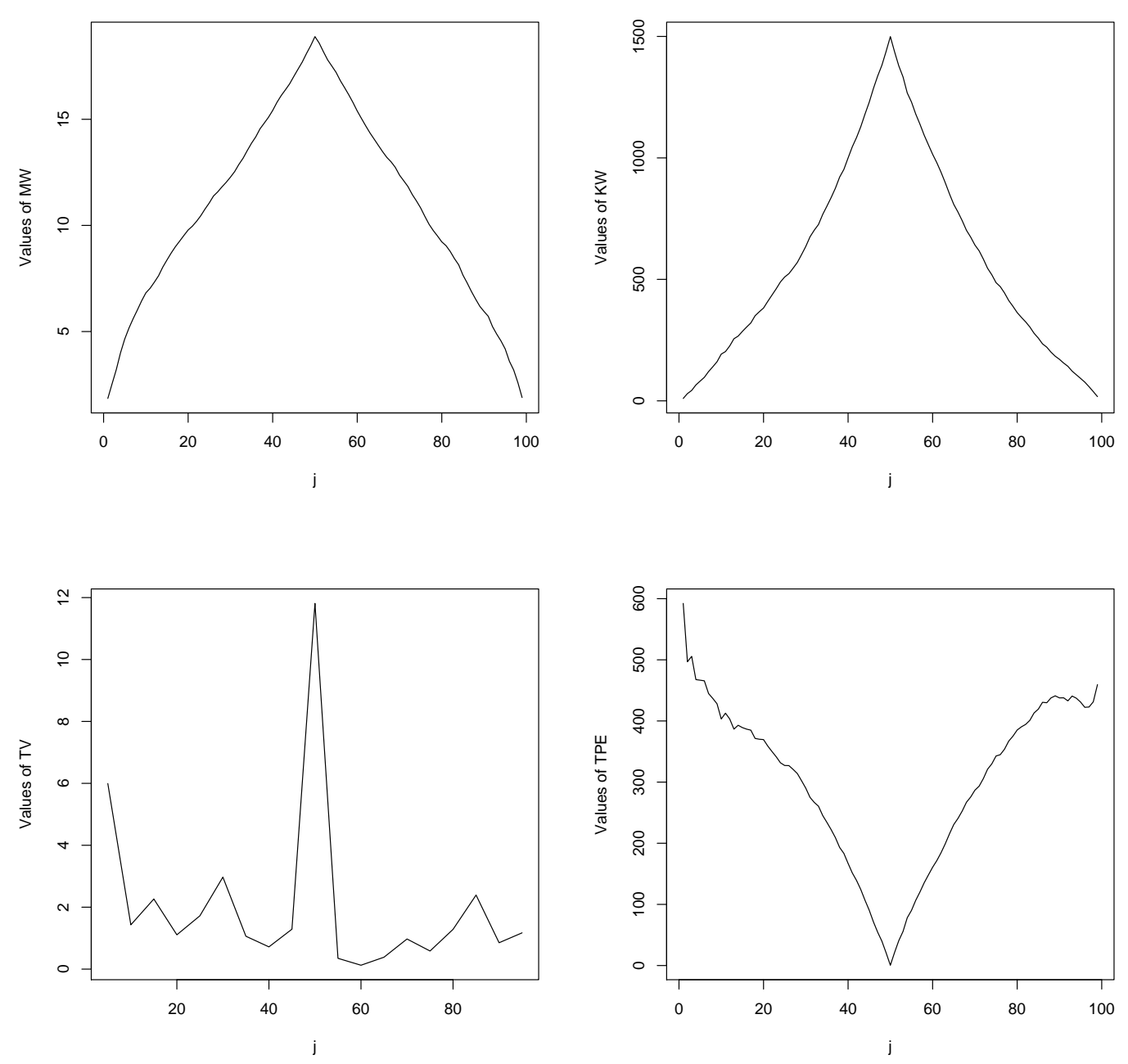

Figure 2.7: Typical values of the Mann-Whitney, Kruskal-Wallis Test, T. Variances statistics and TPE for a straight segment 


\section{Chapter 3}

\section{Results}

\section{Resumo}

Este capítulo descreve as simulações realizadas com o intuito de avaliar os desempenhos das diferentes técnicas de detecção de bordas, o capítulo inclui ainda uma análise dos resultados obtidos por meio de um experimento Monte Carlo.

Todas as simulações foram realizadas em computadores Intel (C) Pentium(C) IV CPUs de $3.20 \mathrm{GHz}$ sob o sistema operacional Windows XP, usando a linguagem matricial Ox versão 4.10 (Doornik 2002), os gráficos tendo sido produzidos com o programa $R$ versão 2.6.1

Os métodos estatísticos considerados nesta tese são projetados para avaliar a precisão na procura de uma borda conhecida num vetor com dados speckled. Neste capítulo nós avaliamos o erro cometido ao estimar o ponto borda (erro local), para cada um dos métodos descritos no capítulo 2 .

Nós calculamos o erro que se comete ao encontrar o ponto de transição num segmento de reta. Varias situações são consideradas, e para cada situação são simuladas 1000 janelas retangulares de tamanho $20 \times 100$ geradas com a distribuição $\mathcal{G}_{\mathrm{I}}^{0}(\alpha, \gamma, n)$.

Cada janela é composta de duas partes e cada situação corresponde a considerar $-\alpha_{\ell} \in\{3,4,6,8,10,12,14,16,18,20\}, \mathrm{e}-\alpha_{\mathrm{r}} \in\{2,3,4,5,6,7,8,9,10$, 
$11,12,13,14,15,16,17,18,19,20\}$.

O número de looks em nosso experimento, para cada situação, é $n \in\{1,3,8\}$; esses valores abrangem uma variedade de imagens freqüentemente encontradas na prática, a partir de apenas um look até suavizados multi-looks. 


\section{Results}

This Chapter describes the simulations performed to obtain a quantitative assessment of the performance of the techniques under evaluation, in addition to the analysis of results obtained by such Monte Carlo experiment. All simulations were performed on personal computers with Intel(C) Pentium(C) IV CPUs of $3.20 \mathrm{GHz}$ running Windows XP operating system, and using the matrix language program $\mathrm{Ox}$ version 4.10 (for details, see Doornik 2002). Graphical outputs were obtained in $R$ version 2.6.1 (Venables \& Ripley 2002).

A widely used tool in statistics is Monte-Carlo simulation. Monte-Carlo techniques are based on the generation of a large number of samples from random variables with specific distributions of interest and then using them to make inferences and draw conclusions.

The statistical methods considered in this thesis are designed to assess the accuracy in finding an edge known to be present on an array of speckled data. In this chapter we evaluate the error when estimating the point edge (local error), for each of the methods described in Chapter 2.

We estimate the error in finding the transition point on a straight segment, according to the process described below. Several parametric situations are considered and for each situation 1000 simulated rectangular windows of size $20 \times 100$ (20 rows, 100 columns) are filled with samples from the $\mathcal{G}_{\mathrm{I}}^{O}(\alpha, \gamma, n)$ distribution.

Each window is composed of two halves, and each situation corresponds to considering $-\alpha_{\ell} \in\{3,4,6,8,10,12,14,16,18,20\}$, and $-\alpha_{r} \in\{2,3,4,5,6,7,8,9,10$, $11,12,13,14,15,16,17,18,19,20\}$. The number of looks in our experience, for each situation, is $n \in\{1,3,8\}$; these values span a variety of images often encountered in practice, from single-look to smoothed multi-look. The scale parameter $\gamma$ assumes the values resulting from replacing $n$ and $\alpha$ in the expression

$$
\gamma_{\alpha, n}=\frac{\Gamma(-\alpha) \Gamma(n) n}{\Gamma(-\alpha-1) \Gamma(n+1)},
$$

in order to guarantee unitary mean. It is noteworthy that we opted for testing 
the edge detection algorithms in a difficult situation, namely, in a case where the areas have the same mean value (granted by $\gamma_{\alpha, n}$ ) and differ only by the texture. Figure 3.1 shows a scheme of the form that has each of the rectangular samples.

\begin{tabular}{c|c|}
\hline $\mathcal{G}_{\mathrm{I}}^{\mathrm{O}}\left(\alpha_{\ell}, \gamma_{\alpha_{\ell}, n}, n\right)$ & $\mathcal{G}_{\mathrm{I}}^{\mathrm{O}}\left(\alpha_{\mathrm{r}}, \gamma_{\alpha_{r}, n}, n\right)$ \\
\hline & $=50$
\end{tabular}

Figure 3.1: Scheme of a rectangular window on a straight segment

Situations for which $\alpha_{\ell}=\alpha_{r}$ are not considered, since in those 10 cases there is no edge. In this manner, we consider $((10 \times 19)-10) \times 3=540\left(\alpha_{\ell}, \alpha_{r}\right.$ and n) situations, and 1000 windows are simulated for each of them. In each of these 540, 000 windows, the edge is detected by the five techniques already described, and the error is calculated as the absolute difference between the detected edge and the true edge, located at position 50.

The errors are stored in an 1000-dimensional array $D_{M}(j)$, with $N=1000$, defined in the following way:

$$
\mathrm{D}_{\mathrm{M}}(\mathfrak{j})=\left|\mathrm{P}_{\mathrm{V}}-\mathrm{P}_{\mathrm{T}}(\mathfrak{j})\right| \quad \mathfrak{j}=1,2, \ldots, 1000
$$

where $P_{V}=50$ is the true edge or transition point and $P_{T}(j), j=1, \ldots, 1000$ is the transition point found by the method under evaluation assessment, correspondent to the $j-$ th sample. Note that $M$ ranges in the set $\{M$. Gambini, T. Kruskal, T. Mann-Whitney, T. Variance, TPE\}, where M. Gambini denotes the method that maximizes a likelihood function of Gambini et al. (2006), T. Kruskal the method Kruskal Wallis, T. Mann-Whitney denotes the Mann-Whitney Test, T. Variance the Squared Ranks Test for Variances and TPE the Empirical Statistics TPE.

Here, $f(M)$ is the proportion of times that the difference between the estimated 
point and the true point is greater than 5 pixels, using method $M$ :

$$
f(M)=\frac{\#\left\{j \in\{1, \ldots, 1000\}: D_{M}(j)>5\right\}}{1000} .
$$

Method $M_{i}$ is more efficient than method $M_{j}(i \neq j)$ whenever $f\left(M_{i}\right)<f\left(M_{j}\right)$, i.e., if the proportion of errors of method $M_{i}$ is smaller that of method $M_{j}$.

Instead of showing the results of all 540 situations, only the ones we identified as the most relevant are discussed in detail. This chapter presents a detailed analysis of $((4 \times 19)-4) \times 3=216$ situations, namely for each of the 3 looks and each of the 19 values of $\alpha_{r}$, but only for 4 values of $\alpha_{\ell}$ : extremely heterogenous areas $\left(\alpha_{\ell}=-3\right)$, heterogeneous areas $\left(\alpha_{\ell}=-8\right)$ and two completely homogeneous areas $\left(\alpha_{\ell}=-12,-18\right)$. Four situations for which $\alpha_{r}=\alpha_{\ell}$ were not considered. The data from the remaining $540-216=324$ situations, though not analyzed in detail, are presented in Appendices A, B and C.

It is shown that the M. Gambini method and the Kruskal-Wallis and MannWhitney statistics are the best choices in our case studies.

The execution time of each method is also computed and assessed, and the Monte Carlo experience provides strong evidence that the Kruskal-Wallis approach is approximately three orders of magnitude faster than the M. Gambini method. 


\subsection{Extremely heterogeneous areas with $n=1$ and} $\alpha_{\ell}=-3$

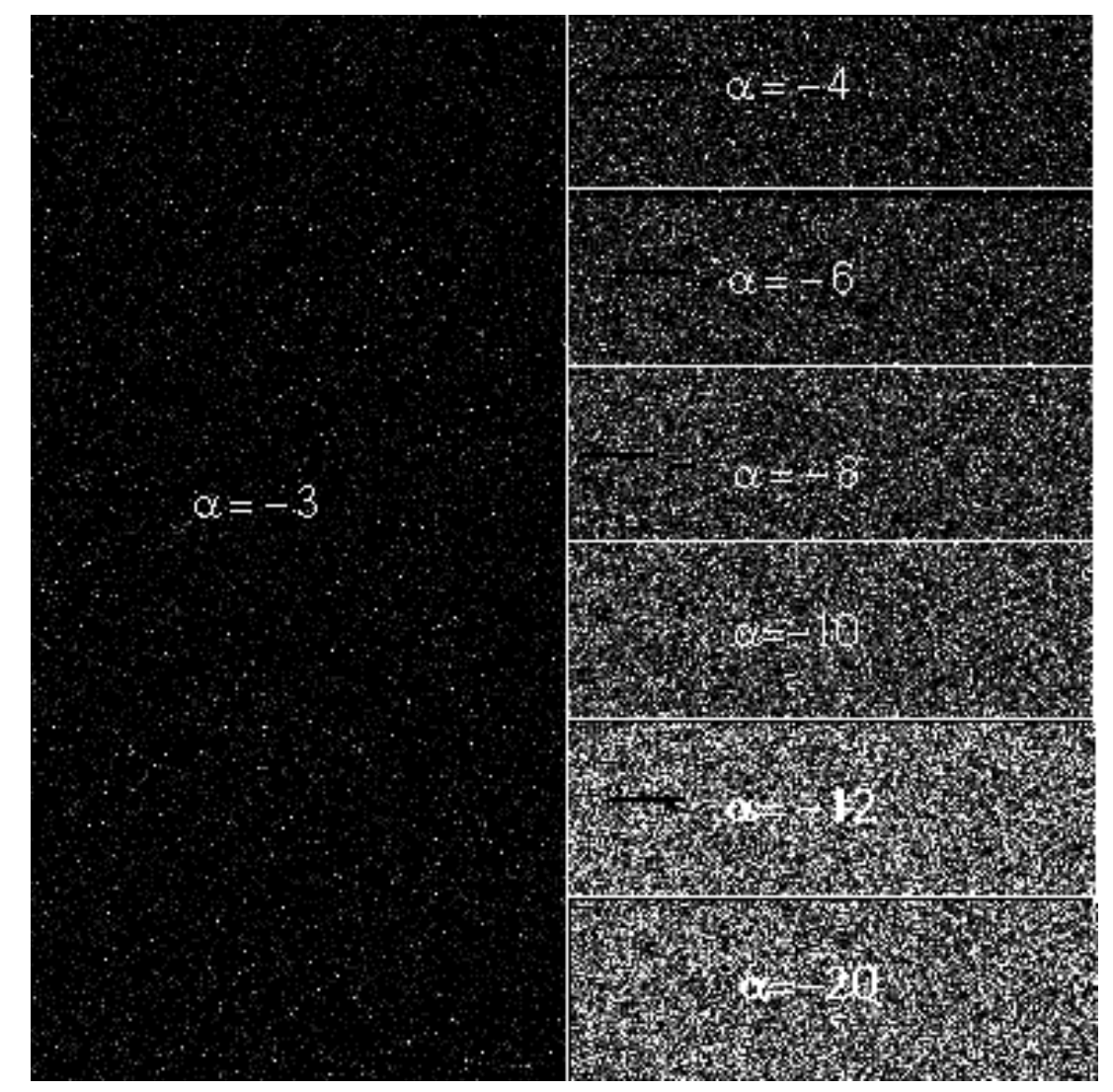

Figure 3.2: Synthetic images $\mathcal{G}_{\mathrm{I}}^{\mathrm{O}}(\alpha, 1,1), \gamma=1$ and $\alpha_{\ell}=-3$ to the left against $\alpha_{\mathrm{r}}=\{-4,-6,-8,-10,-12,-20\}$ to the right

Figure 3.2 presents samples generated from the $\mathcal{G}_{\mathrm{I}}^{0}(\alpha, 1,1)$ distribution using different values of $\alpha$ and $\gamma=1$. These samples correspond to different degrees of homogeneity. It can be noted that when the parameter $\alpha$ is close to zero, the variance increases and, therefore, a higher degree of heterogeneity is observed. To the left side of this figure there is an image generated from $\mathcal{G}_{\mathrm{I}}^{0}(-3,1,1)$, which represents extremely heterogeneous areas, and to the right there are images generated with the $\mathcal{G}_{\mathrm{I}}^{0}(\alpha, 1,1)$ whit $\alpha=-4$ up to $\alpha=-20$, that represent areas with different degrees of roughness. 
In this and in all subsequent figures, each patch of data with same distribution was scaled independently of the others, in order to provide an acceptable contrast of the whole compound image, these images are generated with $\gamma$ fixed equal to 1. These images are a graphic representation of changes in texture when varies $\alpha$, are not generated with the data used to detect edges, since the data generated dependent the $\alpha$ and $\gamma$, and the latter depends of the first.

Table 3.1 presents the error rate and average time for $\alpha_{\ell}=-3$ versus $\alpha_{r} \in$ $\{-2,-4, \ldots,-20\}$. It is noted that from $\alpha_{r}=-6$ up to $\alpha_{r}=-20$ all methods display an error rate of $0 \%$, and that as $\alpha_{r}$ becomes closer to $\alpha_{\ell}$ the error rate increases considerably for the methods TPE and T. Variance. The error rate of the M. Gambini is only $0.1 \%$ with $\alpha_{r}=-4$. T. Kruskal and T. MannWhitney have the best performance since the percentage of error is $0 \%$ for all different values of $\alpha_{r}$. The different execution times between the non-parametric and the M. Gambini methods are noticeable, the latter being approximately 74 times slower than T. Variance, which presents the slowest times among the nonparametric methods.

Figure 3.3, left, shows that the average execution time of M. Gambini diminishes as the value of $\alpha_{r}$ increases. Figure 3.3, right, shows the behavior of the average times of the non-parametric methods, which were always less than a second, being T. Kruskal the one exhibiting the shortest execution times followed by T. MannWhitney. 


\begin{tabular}{|c|c|c|c|c|c|c|c|c|c|c|}
\hline & \multicolumn{2}{|c|}{ M. Gambini } & \multicolumn{2}{c|}{ TPE } & \multicolumn{2}{c|}{ T. Kruskal } & \multicolumn{2}{|c|}{ T. Variance } & \multicolumn{2}{c|}{ T. M-Whitney } \\
\hline$\alpha_{r}$ & $\begin{array}{r}\text { Error } \\
\text { rate }\end{array}$ & Time & $\begin{array}{r}\text { Error } \\
\text { rate }\end{array}$ & Time & $\begin{array}{r}\text { Error } \\
\text { rate }\end{array}$ & Time & $\begin{array}{r}\text { Error } \\
\text { rate }\end{array}$ & $\begin{array}{r}\text { Time } \\
\text { Error } \\
\text { rate }\end{array}$ & Time \\
\hline-20 & $0.00 \%$ & 1.415 & $0.00 \%$ & 0.012 & $0.00 \%$ & 0.002 & $0.00 \%$ & 0.015 & $0.00 \%$ & 0.003 \\
\hline-19 & $0.00 \%$ & 1.401 & $0.00 \%$ & 0.012 & $0.00 \%$ & 0.002 & $0.00 \%$ & 0.015 & $0.00 \%$ & 0.003 \\
\hline-18 & $0.00 \%$ & 1.376 & $0.00 \%$ & 0.012 & $0.00 \%$ & 0.002 & $0.00 \%$ & 0.015 & $0.00 \%$ & 0.003 \\
\hline-17 & $0.00 \%$ & 1.362 & $0.00 \%$ & 0.012 & $0.00 \%$ & 0.002 & $0.00 \%$ & 0.015 & $0.00 \%$ & 0.003 \\
\hline-16 & $0.00 \%$ & 1.352 & $0.00 \%$ & 0.012 & $0.00 \%$ & 0.002 & $0.00 \%$ & 0.015 & $0.00 \%$ & 0.003 \\
\hline-15 & $0.00 \%$ & 1.338 & $0.00 \%$ & 0.012 & $0.00 \%$ & 0.002 & $0.00 \%$ & 0.015 & $0.00 \%$ & 0.003 \\
\hline-14 & $0.00 \%$ & 1.307 & $0.00 \%$ & 0.012 & $0.00 \%$ & 0.002 & $0.00 \%$ & 0.015 & $0.00 \%$ & 0.003 \\
\hline-13 & $0.00 \%$ & 1.287 & $0.00 \%$ & 0.012 & $0.00 \%$ & 0.002 & $0.00 \%$ & 0.015 & $0.00 \%$ & 0.003 \\
\hline-12 & $0.00 \%$ & 1.275 & $0.00 \%$ & 0.012 & $0.00 \%$ & 0.002 & $0.00 \%$ & 0.015 & $0.00 \%$ & 0.003 \\
\hline-11 & $0.00 \%$ & 1.257 & $0.00 \%$ & 0.012 & $0.00 \%$ & 0.002 & $0.00 \%$ & 0.015 & $0.00 \%$ & 0.003 \\
\hline-10 & $0.00 \%$ & 1.238 & $0.00 \%$ & 0.012 & $0.00 \%$ & 0.002 & $0.00 \%$ & 0.015 & $0.00 \%$ & 0.003 \\
\hline-9 & $0.00 \%$ & 1.221 & $0.00 \%$ & 0.012 & $0.00 \%$ & 0.002 & $0.00 \%$ & 0.015 & $0.00 \%$ & 0.003 \\
\hline-8 & $0.00 \%$ & 1.198 & $0.00 \%$ & 0.012 & $0.00 \%$ & 0.002 & $0.00 \%$ & 0.015 & $0.00 \%$ & 0.003 \\
\hline-7 & $0.00 \%$ & 1.189 & $0.10 \%$ & 0.012 & $0.00 \%$ & 0.002 & $0.00 \%$ & 0.015 & $0.00 \%$ & 0.003 \\
\hline-6 & $0.00 \%$ & 1.168 & $0.00 \%$ & 0.012 & $0.00 \%$ & 0.002 & $0.00 \%$ & 0.015 & $0.00 \%$ & 0.003 \\
\hline-5 & $0.00 \%$ & 1.158 & $0.40 \%$ & 0.012 & $0.00 \%$ & 0.002 & $0.60 \%$ & 0.015 & $0.00 \%$ & 0.003 \\
\hline-4 & $0.10 \%$ & 1.140 & $15.40 \%$ & 0.012 & $0.00 \%$ & 0.002 & $16.90 \%$ & 0.015 & $0.00 \%$ & 0.003 \\
\hline-2 & $0.00 \%$ & 1.101 & $2.80 \%$ & 0.012 & $0.00 \%$ & 0.002 & $9.30 \%$ & 0.015 & $0.00 \%$ & 0.003 \\
\hline
\end{tabular}

Table 3.1: Error rate and average time for $\alpha_{\ell}=-3$ vs. $\alpha_{r} \in$ $\{-2,-4,-5, \ldots,-19,-20\}$ when $n=1$
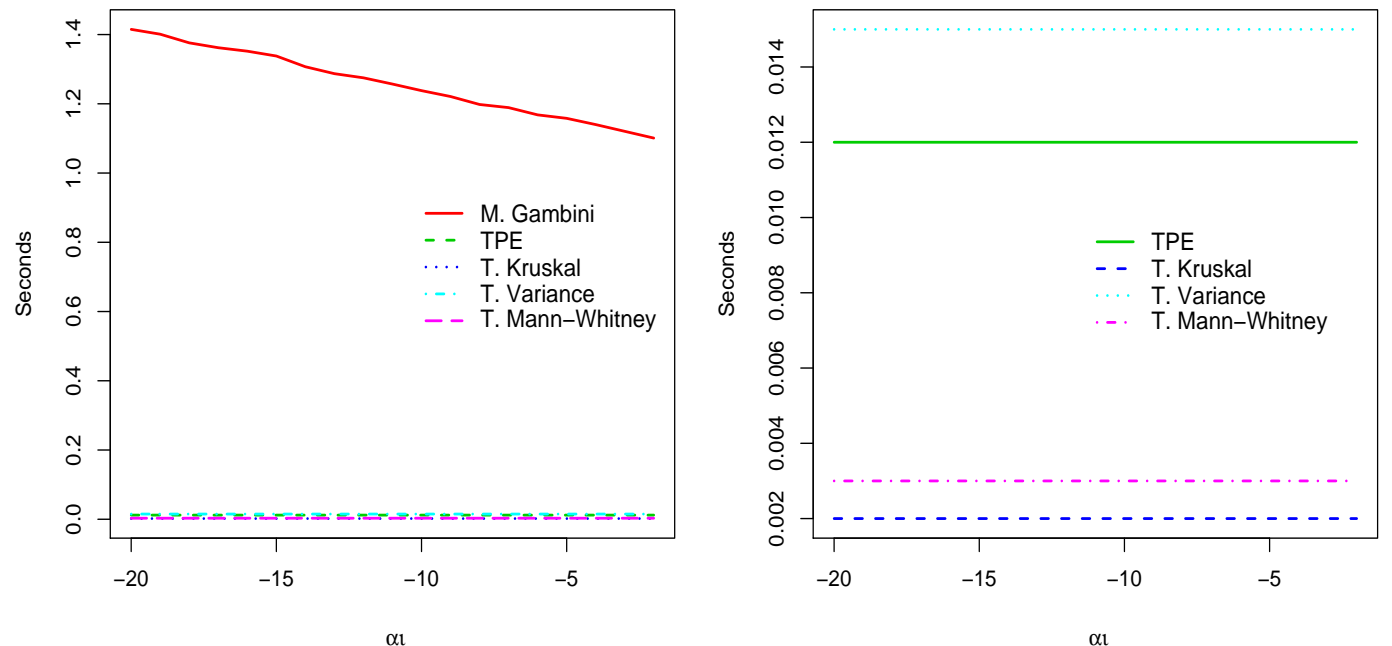

Figure 3.3: Average execution time in seconds for Gambini, Kruskal, Mann-Whitney, Variance and TPE, $\alpha_{\ell}=-3$ vs. $\alpha_{r} \in\{-2,-4,-5, \ldots,-19,-20\}$ with $n=1$ 


\subsection{Heterogeneous areas with $n=1$ and $\alpha_{\ell}=-8$}

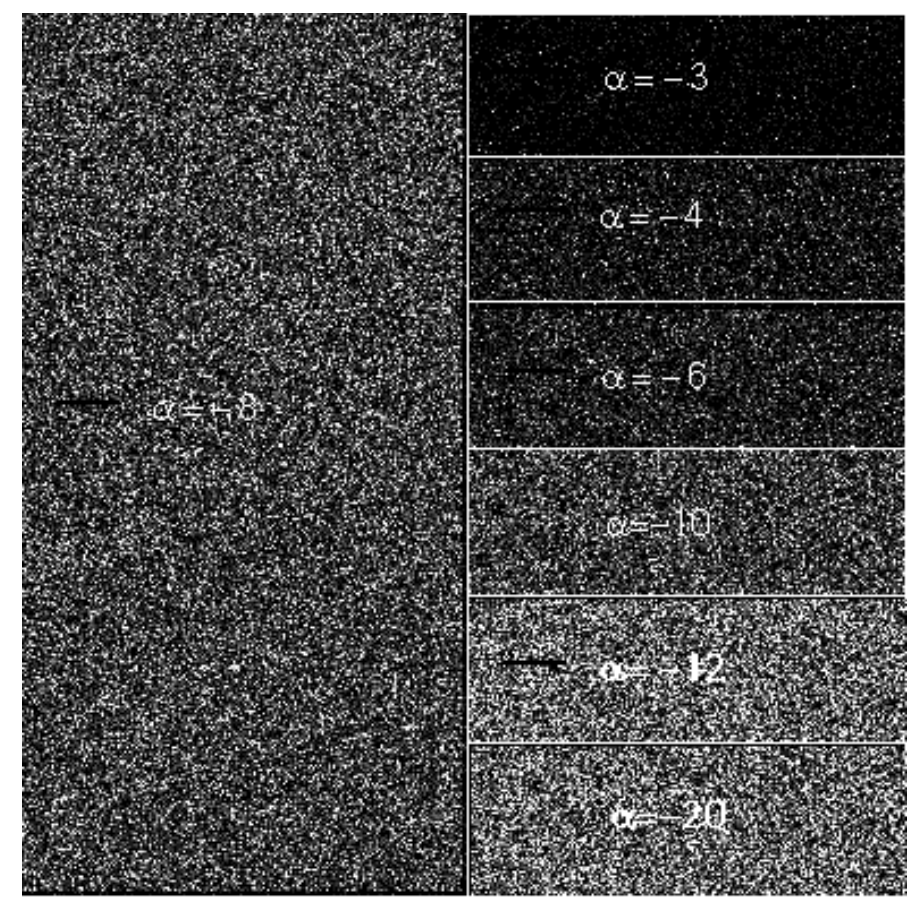

Figure 3.4: Synthetic images from $\mathcal{G}_{\mathrm{I}}^{0}(\alpha, 1,1), \gamma=1$ and $\alpha_{\ell}=-8$ to the left against $\alpha_{\mathrm{r}}=\{-3,-4,-6,-10,-12,-20\}$ to the right

Figure 3.4, left, is an image formed by samples from the $\mathcal{G}_{\mathrm{I}}^{O}(-8,1,1)$, representing heterogeneous areas. Figure 3.4, right, presents samples from the $\mathcal{G}_{\mathcal{J}}^{0}\left(\alpha_{r}, 1,1\right)$ distribution with $\alpha_{r}=-4$ up to $\alpha_{r}=-20$ representing areas with different degrees of roughness.

Table 3.2 presents the error rate and average time of the different methods for $\mathrm{n}=1, \alpha_{\ell}=-8$. Note that the percentages achieved by TPE and T. Variance are greater than zero when $\alpha_{\mathrm{r}}$ comes closer to $\alpha_{\ell}$, reaching the greatest value when $\alpha_{\mathrm{r}}=$ -9 (81.0\% TPE and 64.5\% T. Variance). Regarding the Average execution time, we see that the difference between M. Gambini and the non-parametric methods is kept as described in Section 3.1. 


\begin{tabular}{|c|r|r|r|r|r|r|r|r|r|r|}
\hline & \multicolumn{2}{|c|}{ M. Gambini } & \multicolumn{2}{|c|}{ TPE } & \multicolumn{2}{c|}{ T. Kruskal } & \multicolumn{2}{|c|}{ T. Variance } & \multicolumn{2}{|c|}{ T. M-Whitney } \\
\hline$\alpha_{r}$ & $\begin{array}{r}\text { Error } \\
\text { rate }\end{array}$ & Time & $\begin{array}{r}\text { Error } \\
\text { rate }\end{array}$ & Time & $\begin{array}{r}\text { Error } \\
\text { rate }\end{array}$ & Time & $\begin{array}{r}\text { Error } \\
\text { rate }\end{array}$ & $\begin{array}{r}\text { Time } \\
\text { Error } \\
\text { rate }\end{array}$ & Time \\
\hline-20 & $0.00 \%$ & 1.513 & $0.00 \%$ & 0.012 & $0.00 \%$ & 0.002 & $0.00 \%$ & 0.015 & $0.00 \%$ & 0.003 \\
\hline-19 & $0.00 \%$ & 1.519 & $0.00 \%$ & 0.012 & $0.00 \%$ & 0.002 & $0.00 \%$ & 0.015 & $0.00 \%$ & 0.003 \\
\hline-18 & $0.00 \%$ & 1.502 & $0.00 \%$ & 0.012 & $0.00 \%$ & 0.002 & $0.00 \%$ & 0.015 & $0.00 \%$ & 0.003 \\
\hline-17 & $0.00 \%$ & 1.469 & $0.00 \%$ & 0.012 & $0.00 \%$ & 0.002 & $0.00 \%$ & 0.015 & $0.00 \%$ & 0.003 \\
\hline-16 & $0.00 \%$ & 1.449 & $0.00 \%$ & 0.012 & $0.00 \%$ & 0.002 & $0.00 \%$ & 0.015 & $0.00 \%$ & 0.003 \\
\hline-15 & $0.00 \%$ & 1.440 & $0.20 \%$ & 0.012 & $0.00 \%$ & 0.002 & $0.00 \%$ & 0.015 & $0.00 \%$ & 0.003 \\
\hline-14 & $0.00 \%$ & 1.414 & $0.50 \%$ & 0.012 & $0.00 \%$ & 0.002 & $0.00 \%$ & 0.014 & $0.00 \%$ & 0.003 \\
\hline-13 & $0.00 \%$ & 1.419 & $2.70 \%$ & 0.012 & $0.00 \%$ & 0.002 & $0.20 \%$ & 0.015 & $0.00 \%$ & 0.003 \\
\hline-12 & $0.00 \%$ & 1.396 & $6.50 \%$ & 0.012 & $0.00 \%$ & 0.002 & $1.20 \%$ & 0.015 & $0.00 \%$ & 0.003 \\
\hline-11 & $0.10 \%$ & 1.385 & $14.20 \%$ & 0.012 & $0.20 \%$ & 0.002 & $6.20 \%$ & 0.015 & $0.20 \%$ & 0.003 \\
\hline-10 & $0.50 \%$ & 1.406 & $33.80 \%$ & 0.012 & $1.60 \%$ & 0.002 & $26.50 \%$ & 0.015 & $1.60 \%$ & 0.003 \\
\hline-9 & $16.20 \%$ & 1.389 & $81.00 \%$ & 0.012 & $22.40 \%$ & 0.002 & $64.50 \%$ & 0.015 & $22.40 \%$ & 0.003 \\
\hline-7 & $11.20 \%$ & 1.353 & $73.30 \%$ & 0.012 & $12.20 \%$ & 0.002 & $61.30 \%$ & 0.015 & $12.80 \%$ & 0.003 \\
\hline-6 & $0.00 \%$ & 1.292 & $21.60 \%$ & 0.012 & $0.50 \%$ & 0.002 & $11.40 \%$ & 0.015 & $0.50 \%$ & 0.003 \\
\hline-5 & $0.00 \%$ & 1.242 & $3.80 \%$ & 0.012 & $0.00 \%$ & 0.002 & $0.60 \%$ & 0.015 & $0.00 \%$ & 0.003 \\
\hline-4 & $0.00 \%$ & 1.214 & $0.10 \%$ & 0.012 & $0.00 \%$ & 0.002 & $0.00 \%$ & 0.015 & $0.00 \%$ & 0.003 \\
\hline-3 & $0.00 \%$ & 1.196 & $0.00 \%$ & 0.012 & $0.00 \%$ & 0.002 & $0.00 \%$ & 0.014 & $0.00 \%$ & 0.003 \\
\hline-2 & $0.00 \%$ & 1.175 & $0.00 \%$ & 0.012 & $0.00 \%$ & 0.002 & $0.10 \%$ & 0.015 & $0.00 \%$ & 0.003 \\
\hline
\end{tabular}

Table 3.2: Error rate and average time for, $\alpha_{\ell}=-8$ vs. $\alpha_{\mathrm{r}} \in$ $\{-2,-3,-5, \ldots,-19,-20\}$ with $n=1$

The performance of M. Gambini, T. Kruskal and T. Mann-Whitney are similar regarding their error rates, e.g., they are equal to $0 \%$ when $\alpha_{r} \leq-12$ and when $\alpha_{r}>-6$. Their error rates increase when $\alpha_{r}$ approaches $\alpha_{\ell}$, up to $16.2 \%$ for M. Gambini and $22.4 \%$ for T. Kruskal and T. Mann-Whitney, when $\alpha_{r}=-9$. These three methods present the best behavior for $n=1$ and $\alpha_{\ell}=-8$ with respect to error.

Figure 3.5 shows the behavior of the error generated by different methods under consideration. Note that the smallest percentages are generated by M. Gambini, T. Kruskal and T. Mann-Whitney.

Figure 3.6, left, shows that the average time of the execution of M. Gambini has the same behavior observed in the $\alpha_{\ell}=-3$ situation (Section 3.1). The plot to the right of Figure 3.6 presents the behavior of the average times of the non-parametrics methods, which continue being shorter than the former second. T. Kruskal is the 


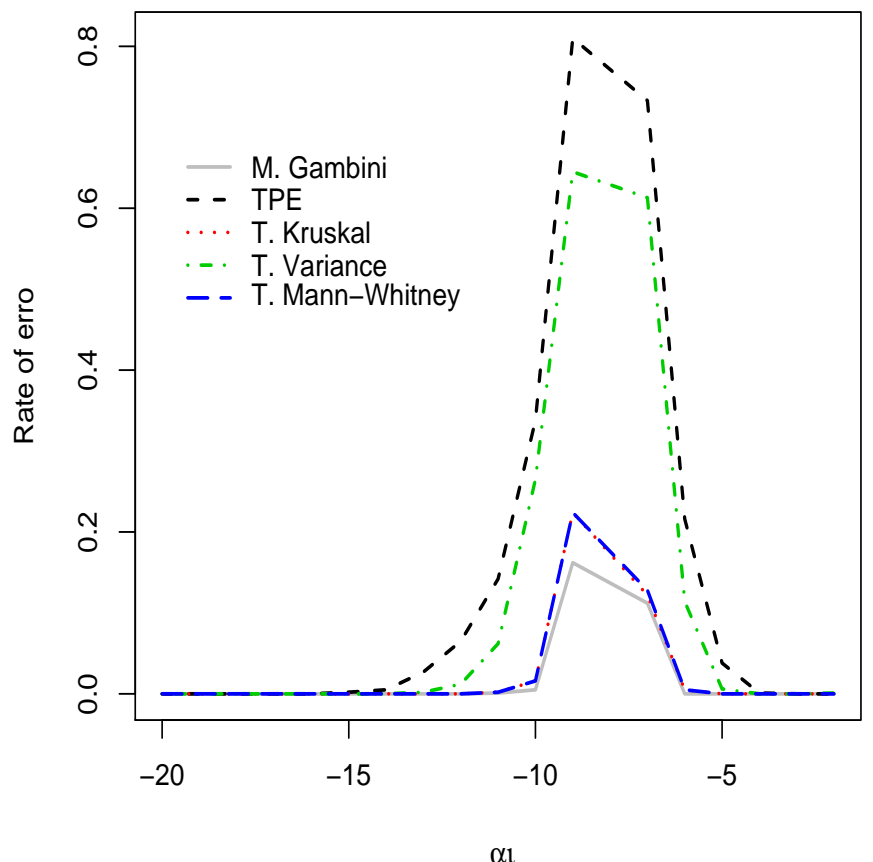

Figure 3.5: Error rate in edge detection for Gambini, Kruskal, Mann-Whitney, Variance and TPE, $\alpha_{\ell}=-8$ vs. $\alpha_{r} \in\{-2,-4,-5, \ldots,-19,-20\}$ with $n=1$

method that obtains the shortest execution times, followed by Mann-Whitney.
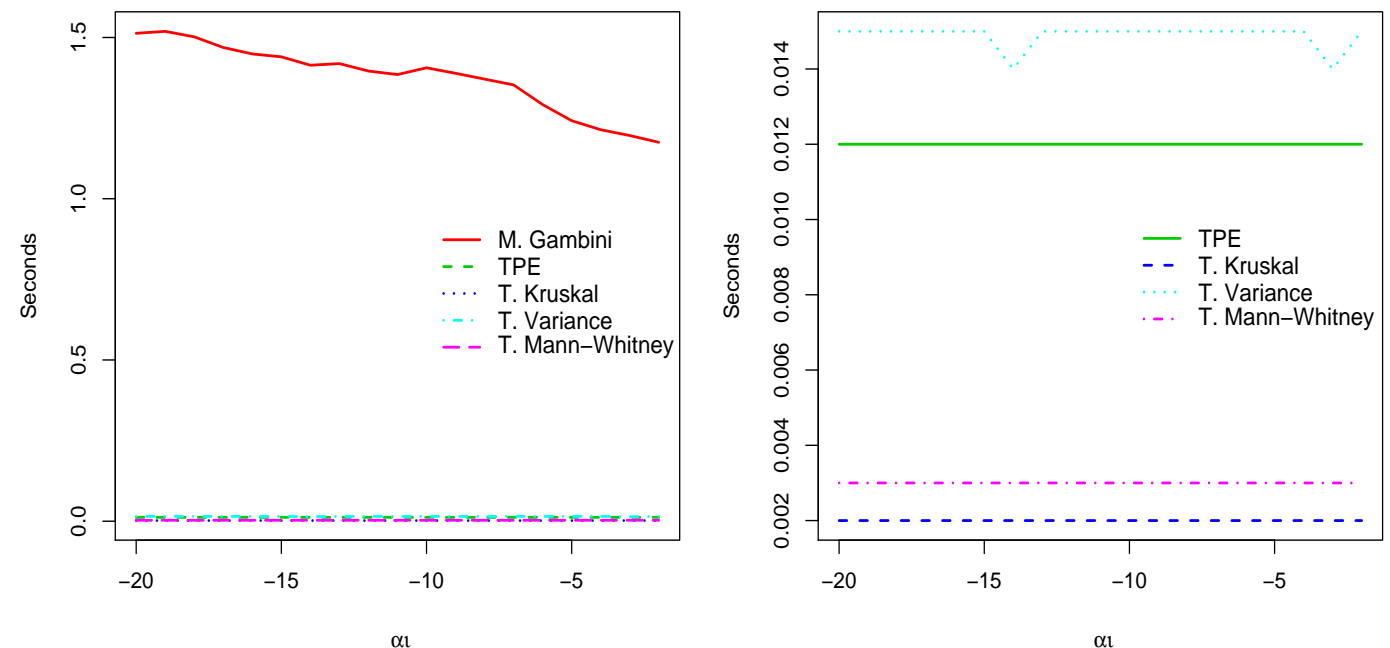

Figure 3.6: Average execution time in seconds for Gambini, Kruskal, Mann-Whitney, Variance and TPE, $\alpha_{\ell}=-8$ vs. $\alpha_{r} \in\{-2,-4,-5, \ldots,-19,-20\}$ with $n=1$ 


\subsection{Homogeneous areas with $n=1$ and $\alpha_{\ell}=-12$}

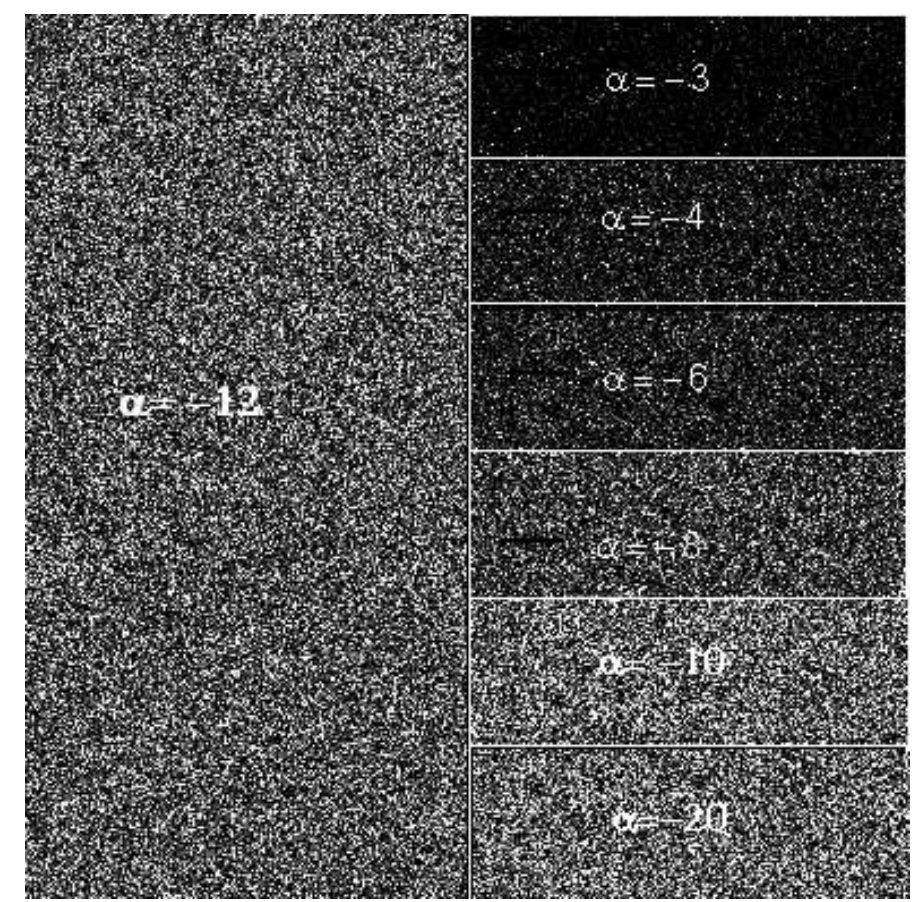

Figure 3.7: Synthetic images from $\mathcal{G}_{\mathrm{I}}^{0}(\alpha, 1,1), \gamma=1$ and $\alpha_{\ell}=-12$ to the left against $\alpha_{r}=\{-3,-4,-6,-8,-10,-20\}$ to the right

Figure 3.7, left, is an image formed by samples from the $\mathcal{G}_{\mathrm{I}}^{O}(-12,1,1)$, representing homogeneous areas. Figure 3.7, right, presents samples from the $\mathcal{G}_{\mathcal{J}}^{0}\left(\alpha_{r}, 1,1\right)$ distribution with $\alpha_{r}=-3$ up to $\alpha_{r}=-20$ representing areas with different degrees of roughness. Table 3.3 contain the percentages of error and average time for $n=1$, $\alpha_{\ell}=-12$. We note that the TPE method presents high rates of error for almost all values of $\alpha_{r}$ and that it only gets an error rate equal to zero when $\alpha_{r} \geq-5$. M. Gambini, T. Kruskal and T. Mann-Whitney display similar behaviors, but M. Gambini presents smaller percentages of error. When $\alpha_{r}=-11$ the method with greater percentage of error is TPE with $90.6 \%$, the method with the smallest percentage of error is M. Gambini with (40.3\%). In the average execution time we noted the difference in the times of execution between the non-parametrics methods and M. Gambini, the latter being approximately 626 times slower than by 
T. Kruskal for $\alpha_{r}=-2$, and 823 times slower for $\alpha_{r}=-20$.

\begin{tabular}{|c|r|r|r|r|r|r|r|r|r|r|}
\hline & \multicolumn{2}{|c|}{ M. Gambini } & \multicolumn{2}{|c|}{ TPE } & \multicolumn{2}{c|}{ T. Kruskal } & \multicolumn{2}{|c|}{ T. Variance } & \multicolumn{2}{|c|}{ T. M-Whitney } \\
\hline$\alpha_{r}$ & $\begin{array}{r}\text { Error } \\
\text { rate }\end{array}$ & Time & $\begin{array}{r}\text { Error } \\
\text { rate }\end{array}$ & Time & $\begin{array}{r}\text { Error } \\
\text { rate }\end{array}$ & Time & $\begin{array}{r}\text { Error } \\
\text { rate }\end{array}$ & $\begin{array}{r}\text { Time } \\
\text { rate }\end{array}$ & $\begin{array}{r}\text { Time } \\
\text { rater }\end{array}$ \\
\hline-19 & $0.00 \%$ & 1.646 & $1.10 \%$ & 0.012 & $0.00 \%$ & 0.002 & $0.00 \%$ & 0.015 & $0.00 \%$ & 0.003 \\
\hline-18 & $0.00 \%$ & 1.640 & $3.00 \%$ & 0.012 & $0.00 \%$ & 0.002 & $0.20 \%$ & 0.015 & $0.00 \%$ & 0.003 \\
\hline-17 & $0.00 \%$ & 1.612 & $7.10 \%$ & 0.012 & $0.00 \%$ & 0.002 & $0.60 \%$ & 0.015 & $0.00 \%$ & 0.003 \\
\hline-16 & $0.00 \%$ & 1.634 & $23.50 \%$ & 0.012 & $0.20 \%$ & 0.002 & $4.40 \%$ & 0.015 & $0.20 \%$ & 0.003 \\
\hline-15 & $0.80 \%$ & 1.608 & $39.00 \%$ & 0.012 & $0.40 \%$ & 0.002 & $12.50 \%$ & 0.015 & $0.40 \%$ & 0.003 \\
\hline-14 & $6.90 \%$ & 1.598 & $67.70 \%$ & 0.012 & $11.30 \%$ & 0.002 & $48.30 \%$ & 0.015 & $11.30 \%$ & 0.003 \\
\hline-13 & $40.30 \%$ & 1.622 & $92.50 \%$ & 0.012 & $45.90 \%$ & 0.002 & $75.90 \%$ & 0.015 & $45.40 \%$ & 0.003 \\
\hline-11 & $38.30 \%$ & 1.544 & $90.60 \%$ & 0.012 & $40.70 \%$ & 0.002 & $76.00 \%$ & 0.015 & $41.20 \%$ & 0.003 \\
\hline-10 & $3.20 \%$ & 1.512 & $53.90 \%$ & 0.012 & $5.80 \%$ & 0.002 & $45.10 \%$ & 0.015 & $5.80 \%$ & 0.003 \\
\hline-9 & $0.00 \%$ & 1.469 & $23.90 \%$ & 0.012 & $0.20 \%$ & 0.002 & $11.80 \%$ & 0.015 & $0.20 \%$ & 0.003 \\
\hline-8 & $0.00 \%$ & 1.399 & $9.00 \%$ & 0.012 & $0.00 \%$ & 0.002 & $1.30 \%$ & 0.014 & $0.00 \%$ & 0.003 \\
\hline-7 & $0.00 \%$ & 1.387 & $2.10 \%$ & 0.012 & $0.00 \%$ & 0.002 & $0.00 \%$ & 0.015 & $0.00 \%$ & 0.003 \\
\hline-6 & $0.00 \%$ & 1.343 & $0.20 \%$ & 0.012 & $0.00 \%$ & 0.002 & $0.00 \%$ & 0.015 & $0.00 \%$ & 0.003 \\
\hline-5 & $0.00 \%$ & 1.315 & $0.00 \%$ & 0.012 & $0.00 \%$ & 0.002 & $0.00 \%$ & 0.015 & $0.00 \%$ & 0.003 \\
\hline-4 & $0.00 \%$ & 1.281 & $0.00 \%$ & 0.012 & $0.00 \%$ & 0.002 & $0.00 \%$ & 0.015 & $0.00 \%$ & 0.003 \\
\hline-3 & $0.00 \%$ & 1.277 & $0.00 \%$ & 0.012 & $0.00 \%$ & 0.002 & $0.00 \%$ & 0.015 & $0.00 \%$ & 0.003 \\
\hline-2 & $0.00 \%$ & 1.252 & $0.00 \%$ & 0.012 & $0.00 \%$ & 0.002 & $0.00 \%$ & 0.015 & $0.00 \%$ & 0.003 \\
\hline
\end{tabular}

Table 3.3: Error rate and average time for $\alpha_{\ell}=-12$ vs. $\alpha_{r} \in$ $\{-2,-3,-5, \ldots,-19,-20\}$ with $n=1$

Figure 3.8 shows the behavior of the percentages of error generated by different methods under consideration for $\alpha_{\ell}=-12$ and $n=1$; it is observed that the greater percentages of error are generated by TPE and T. Variance.

M. Gambini, T. Kruskal and Mann-Whitney have similar behaviors, and differ when $\alpha_{r}$ is near $\alpha_{\ell}$.

Figure 3.9, left, shows that the average execution time of the M. Gambini diminishes as the value of $\alpha_{r}$ increases. Figure 3.9, right, shows the behavior of the average execution times of the non-parametrics methods. The T. Kruskal has the smallest execution time followed by T. Mann-Whitney, the execution time of the non-parametrics methods are not sensitive to the value of $\alpha_{r}$. 


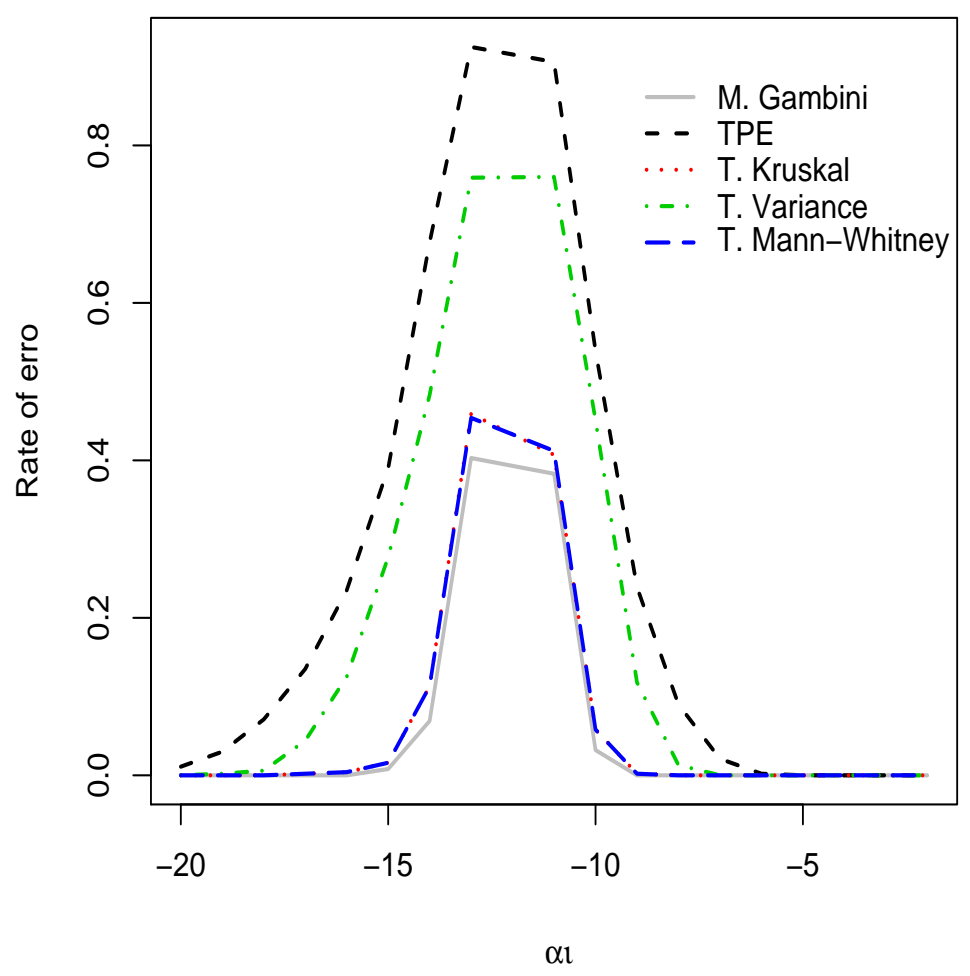

Figure 3.8: Error rate in edge detection for Gambini, Kruskal, Mann-Whitney, Variance and TPE, $\alpha_{\ell}=-12$ vs. $\alpha_{r} \in\{-2,-4,-5, \ldots,-19,-20\}$ with $n=1$
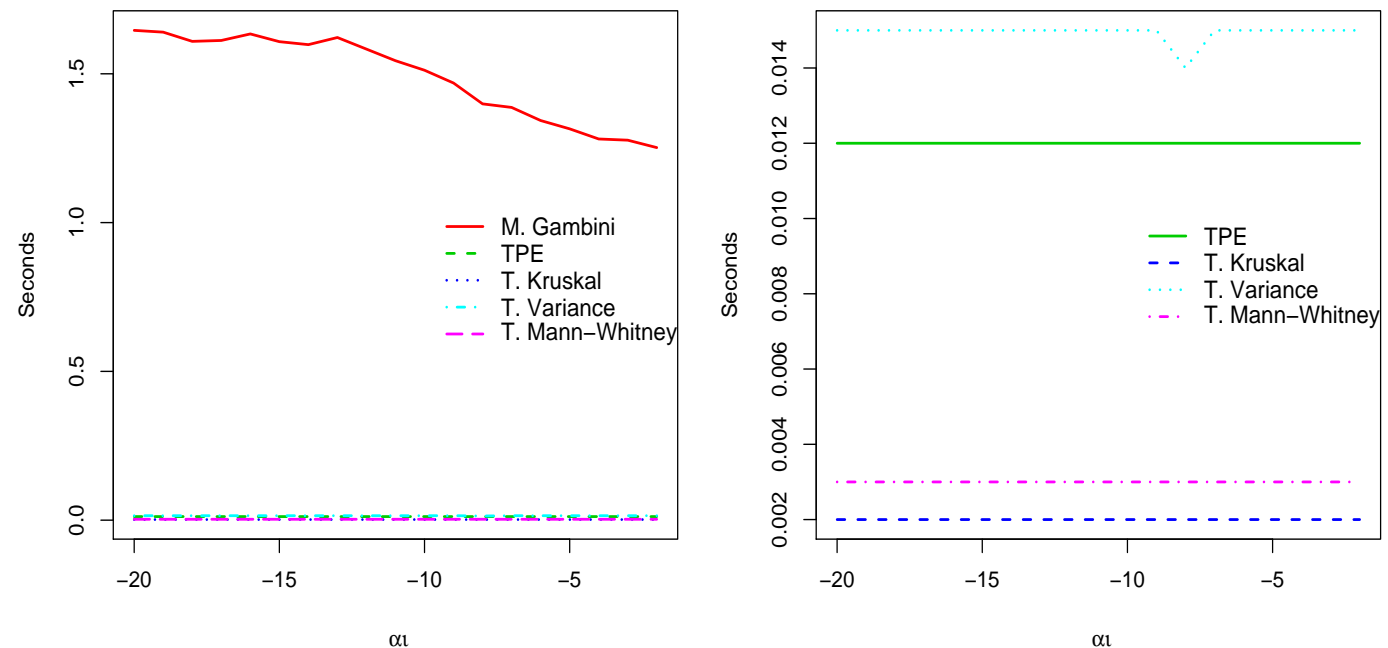

Figure 3.9: Average execution time in seconds for Gambini, Kruskal, Mann-Whitney, Variance and TPE, $\alpha_{\ell}=-12$ vs. $\alpha_{r} \in\{-2,-4,-5, \ldots,-19,-20\}$ with $n=1$ 


\subsection{Homogeneous areas with $n=1$ and $\alpha_{\ell}=-18$}

In the left side of Figure 3.10 we find an image generated from $\mathcal{G}_{\mathrm{I}}^{\mathrm{O}}(-18,1,1)$, which represents homogeneous areas, and on the right side there are images generated with $\alpha_{r}=-4$ up to $\alpha_{r}=-20$, that represent areas with different degrees of roughness.

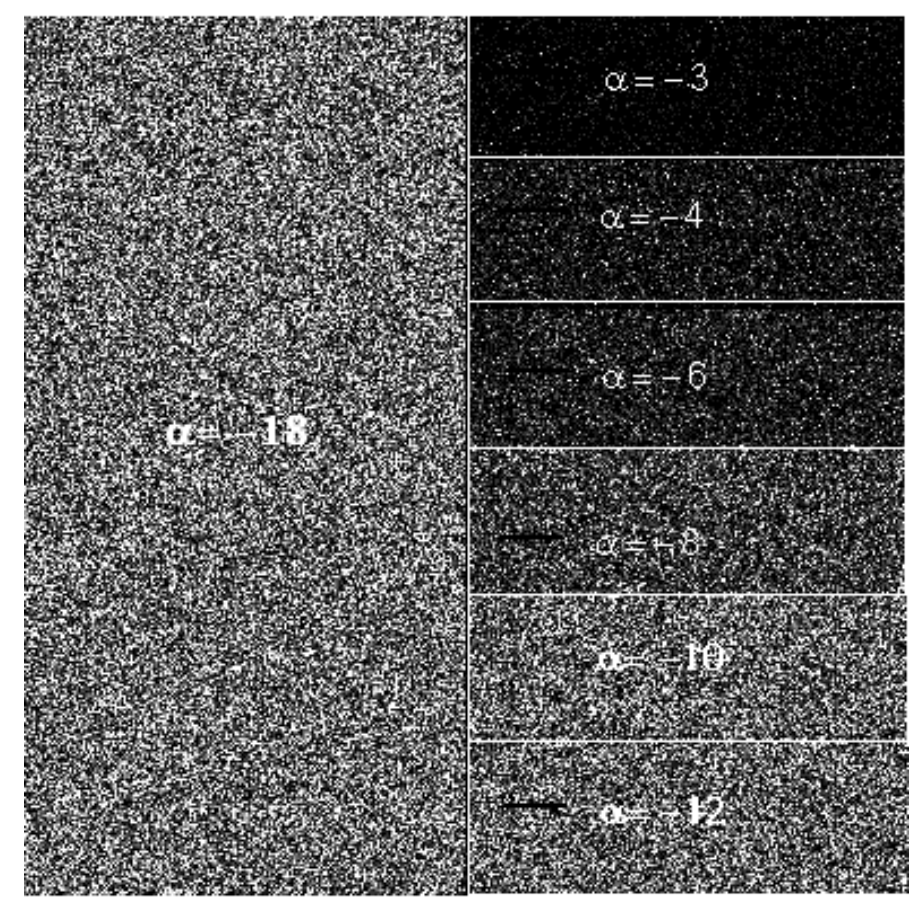

Figure 3.10: Synthetic images $\mathcal{G}_{\mathrm{I}}^{0}(\alpha, 1,1), \gamma=1$ and $\alpha_{\ell}=-18$ to the left against $\alpha_{r}=\{-3,-4,-6,-8,-10,-12\}$ to the right

Table 3.4 contains the error rate and average time of the methods under evaluation for $\alpha_{\ell}=-18$. We note that M. Gambini, T. Kruskal and T. Mann-Whitney present percentage of error zero in the cases for which the image to the right of the edge is generated from $\alpha_{r}=>-13$; the error rate increases as $\alpha_{r}$ approaches $\alpha_{\ell}$. Note also that the highest percentage of error of these methods occurs for $\alpha_{r}=-17$ and $\alpha_{r}=-19$, however, this error rate is lower in comparison with $\mathbf{T}$. Variance and TPE.

TPE presents zero error rate when $\alpha_{r}$ is a distant from $\alpha_{\ell}$, but this percentage begins to increase when $\alpha_{r}$ approaches $\alpha_{\ell}=-18$, reaching $98 \%$ when $\alpha_{r}=-17$. 
T. Variance behaves similarly to TPE. The T. Mann-Whitney presented error rate similarly to $\mathbf{T}$. Kruskal.

Note that the average execution time of T. Kruskal is approximately 1000 times smaller than that of M. Gambini when $\alpha_{r}=-19$. Figure 3.12 shows that the runtime of M.Gambini decreases when $\alpha_{r}$ is close to zero, but it does not get close to the times of the non-parametrics methods. The faster method is T. Kruskal followed by T. Mann-Whitney; the slower method is T. Variance, which, however, never exceeds 0,015 second.

\begin{tabular}{|c|c|c|c|c|c|c|c|c|c|c|}
\hline & \multicolumn{2}{|c|}{ M. Gambini } & \multicolumn{2}{|c|}{ TPE } & \multicolumn{2}{|c|}{ T. Kruskal } & \multicolumn{2}{|c|}{ T. Variance } & \multicolumn{2}{|c|}{ T. M-Whitney } \\
\hline$\alpha_{r}$ & $\begin{array}{r}\text { Error } \\
\text { rate }\end{array}$ & Time & $\begin{array}{r}\text { Error } \\
\text { rate }\end{array}$ & Time & $\begin{array}{r}\text { Error } \\
\text { rate }\end{array}$ & Time & $\begin{array}{r}\text { Error } \\
\text { rate }\end{array}$ & Time & $\begin{array}{r}\text { Error } \\
\text { rate }\end{array}$ & me \\
\hline-20 & $23.80 \%$ & 95 & $84.40 \%$ & 2 & $24.20 \%$ & 02 & $67.50 \%$ & 5 & $24.20 \%$ & 03 \\
\hline-19 & $1.40 \%$ & 013 & $7.50 \%$ & $\overline{12}$ & $5.00 \%$ & $\overline{002}$ & $9.40 \%$ & 5 & $4.90 \%$ & 003 \\
\hline-17 & $62.70 \%$ & 1.893 & $8.00 \%$ & 0.012 & $3.60 \%$ & 0.002 & $79.60 \%$ & 15 & $63.80 \%$ & .003 \\
\hline-16 & $9.70 \%$ & 853 & $.50 \%$ & 0.012 & $1.40 \%$ & 002 & $2.10 \%$ & 5 & $1.40 \%$ & .003 \\
\hline-15 & $2.60 \%$ & 1.777 & $56.30 \%$ & .012 & $4.00 \%$ & 0.002 & $39.40 \%$ & 15 & $4.10 \%$ & .003 \\
\hline-14 & $0.30 \%$ & 1.746 & $33.30 \%$ & 0.012 & $0.90 \%$ & 0.002 & $18.80 \%$ & 0.015 & $0.90 \%$ & 0.003 \\
\hline-13 & $0.00 \%$ & 669 & $17.50 \%$ & 0.012 & $0.00 \%$ & .002 & $4.10 \%$ & 015 & $0.00 \%$ & 0.003 \\
\hline-12 & $0.00 \%$ & 1.638 & $7.00 \%$ & 0.012 & $0.00 \%$ & 0.002 & $1.00 \%$ & .015 & $0.00 \%$ & 0.003 \\
\hline-11 & $0.00 \%$ & 1.600 & $2.70 \%$ & 0.012 & $0.00 \%$ & 0.002 & $0.20 \%$ & 0.015 & $0.00 \%$ & 0.003 \\
\hline-10 & $0.00 \%$ & 564 & $0.40 \%$ & 0.012 & $0.00 \%$ & .002 & $0.00 \%$ & 0.015 & $0.00 \%$ & 0.003 \\
\hline-9 & $0.00 \%$ & 1.538 & $0.50 \%$ & 0.012 & $0.00 \%$ & 0.002 & $0.00 \%$ & .015 & $0.00 \%$ & 0.003 \\
\hline-8 & $0.00 \%$ & 1.508 & $0.00 \%$ & 0.012 & $0.00 \%$ & 0.002 & $0.00 \%$ & 0.015 & $0.00 \%$ & 0.003 \\
\hline-7 & $0.00 \%$ & 1.495 & $0.00 \%$ & 0.012 & $0.00 \%$ & 0.002 & $0.00 \%$ & 0.015 & $0.00 \%$ & 0.003 \\
\hline-6 & $0.00 \%$ & 1.461 & $0.00 \%$ & 0.012 & $0.00 \%$ & 0.002 & $0.00 \%$ & 0.015 & $0.00 \%$ & 0.003 \\
\hline-5 & $0.00 \%$ & 1.436 & $0.00 \%$ & 0.012 & $0.00 \%$ & 0.002 & $0.00 \%$ & 0.015 & $0.00 \%$ & 0.003 \\
\hline-4 & $0.00 \%$ & 1.406 & $0.00 \%$ & 0.012 & $0.00 \%$ & 0.002 & $0.00 \%$ & 0.015 & $0.00 \%$ & 0.003 \\
\hline-3 & $0.00 \%$ & 1.404 & $0.00 \%$ & 0.012 & $0.00 \%$ & 0.002 & $0.00 \%$ & 0.015 & $0.00 \%$ & 0.003 \\
\hline-2 & $0.00 \%$ & 1.387 & $0.00 \%$ & 0.012 & $0.00 \%$ & 0.002 & $0.00 \%$ & 0.015 & $0.00 \%$ & 0.003 \\
\hline
\end{tabular}

Table 3.4: Error rate and average time for, $\alpha_{\ell}=-18$ vs. $\alpha_{r} \in$ $\{-2,-3,-5, \ldots,-19,-20\}$ with $n=1$

Figure 3.11 shows T. Kruskal and T. Mann-Whitney behaves similarly to M. Gambini, these three methods are the best performing over. All methods present error in the detection of the edge when the generated images come from distributions with very nearby parameters of roughness. 


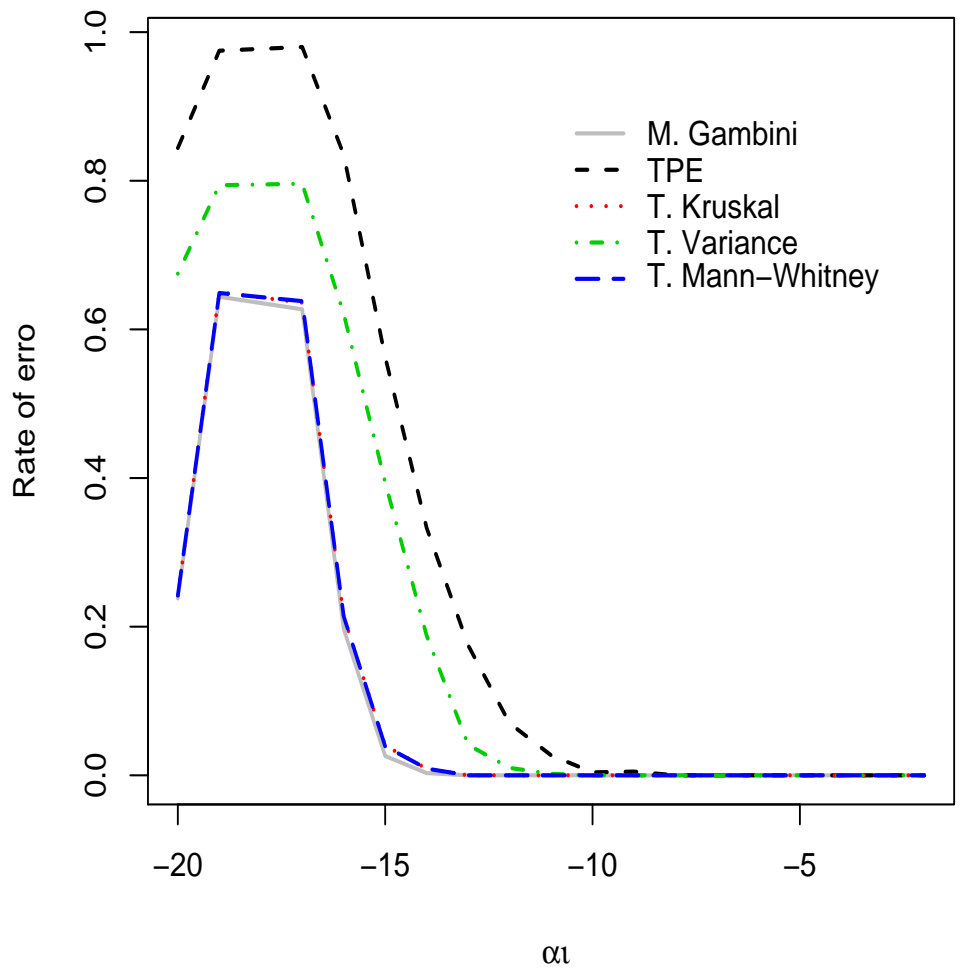

Figure 3.11: Error rate for Gambini, Kruskal, Mann-Whitney, Variance and TPE, $\alpha_{\ell}=-18$ vs. $\alpha_{r} \in\{-2,-4,-5, \ldots,-19,-20\}$ with $n=1$
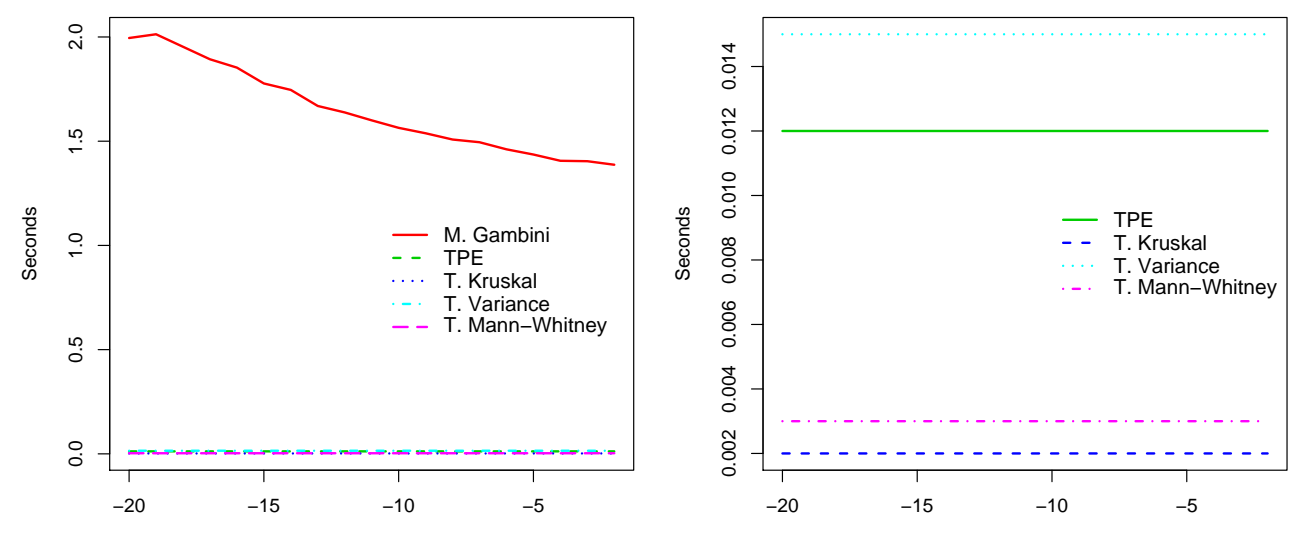

Figure 3.12: Average execution time in seconds for Gambini, Kruskal, MannWhitney, Variance and TPE, $\alpha_{\ell}=-18$ vs. $\alpha_{r} \in\{-2,-4,-5, \ldots,-19,-20\}$ with $\mathrm{n}=1$ 


\subsection{Extremely heterogeneous areas with $n=3$ and} $\alpha_{\ell}=-3$

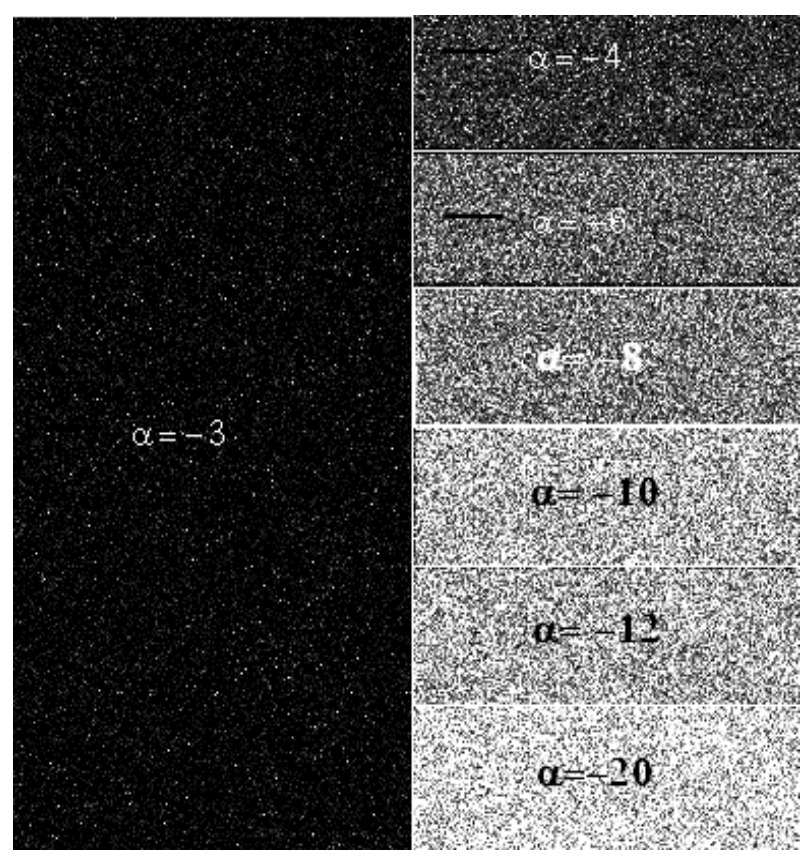

Figure 3.13: Synthetic images $\mathcal{G}_{\mathrm{I}}^{0}(\alpha, 1,3), \gamma=1$ and $\alpha_{\ell}=-3$ to the left against $\alpha_{r}=\{-4,-6,-8,-10,-12,-20\}$ to the right

Figure 3.13 shows images of samples generated from $\mathcal{G}_{I}^{0}(\alpha, 1,3)$ with different values of $\alpha$. On the left side of the figure we find an image generated from $\mathcal{G}_{I}^{0}(-3,1,3)$.

Table 3.5 presents the error rate and average time obtained by the methods used in the simulation. Note that the percentages of errors of all methods are zero except for method T. Variance which presents error rates of $5.9 \%, 3.4 \%$ and $0.3 \%$ for $\alpha_{r}=$ $-5,-4$ and -2 , respectively. In Table 3.5 it is noteworthy the difference in execution times between non-parametrics methods and M. Gambini. The T. Kruskal is 545 times faster than M. Gambini, for $\alpha_{r}=-2$. Figure 3.14, left, shows that the average execution time of the M. Gambini decreases as the value of $\alpha_{r}$ increases.

Figure 3.14, right, shows that T. Kruskal has the smaller execution times, followed by the method of T. Mann-Whitney. 


\begin{tabular}{|c|c|c|c|c|c|c|c|c|c|r|}
\hline & \multicolumn{2}{|c|}{ M. Gambini } & \multicolumn{2}{|c|}{ TPE } & \multicolumn{2}{|c|}{ T. Kruskal } & \multicolumn{2}{|c|}{ T. Variance } & \multicolumn{2}{|c|}{ T. M-Whitney } \\
\hline$\alpha_{\mathrm{r}}$ & $\begin{array}{r}\text { Error } \\
\text { rate }\end{array}$ & Time & $\begin{array}{r}\text { Error } \\
\text { rate }\end{array}$ & Time & $\begin{array}{r}\text { Error } \\
\text { rate }\end{array}$ & Time & $\begin{array}{r}\text { Error } \\
\text { rate }\end{array}$ & Time & $\begin{array}{r}\text { Error } \\
\text { rate }\end{array}$ & Time \\
\hline-20 & $0.00 \%$ & 1.252 & $0.00 \%$ & 0.012 & $0.00 \%$ & 0.002 & $0.00 \%$ & 0.015 & $0.00 \%$ & 0.003 \\
\hline-19 & $0.00 \%$ & 1.216 & $0.00 \%$ & 0.012 & $0.00 \%$ & 0.002 & $0.00 \%$ & 0.015 & $0.00 \%$ & 0.003 \\
\hline-18 & $0.00 \%$ & 1.205 & $0.00 \%$ & 0.012 & $0.00 \%$ & 0.002 & $0.00 \%$ & 0.014 & $0.00 \%$ & 0.003 \\
\hline-17 & $0.00 \%$ & 1.355 & $0.00 \%$ & 0.012 & $0.00 \%$ & 0.002 & $0.00 \%$ & 0.015 & $0.00 \%$ & 0.003 \\
\hline-16 & $0.00 \%$ & 1.144 & $0.00 \%$ & 0.012 & $0.00 \%$ & 0.002 & $0.00 \%$ & 0.015 & $0.00 \%$ & 0.003 \\
\hline-15 & $0.00 \%$ & 1.136 & $0.00 \%$ & 0.012 & $0.00 \%$ & 0.002 & $0.00 \%$ & 0.015 & $0.00 \%$ & 0.003 \\
\hline-14 & $0.00 \%$ & 1.132 & $0.00 \%$ & 0.012 & $0.00 \%$ & 0.002 & $0.00 \%$ & 0.015 & $0.00 \%$ & 0.003 \\
\hline-13 & $0.00 \%$ & 1.141 & $0.00 \%$ & 0.012 & $0.00 \%$ & 0.002 & $0.00 \%$ & 0.015 & $0.00 \%$ & 0.003 \\
\hline-12 & $0.00 \%$ & 1.151 & $0.00 \%$ & 0.012 & $0.00 \%$ & 0.002 & $0.00 \%$ & 0.015 & $0.00 \%$ & 0.003 \\
\hline-11 & $0.00 \%$ & 1.137 & $0.00 \%$ & 0.012 & $0.00 \%$ & 0.002 & $0.00 \%$ & 0.015 & $0.00 \%$ & 0.003 \\
\hline-10 & $0.00 \%$ & 1.127 & $0.00 \%$ & 0.012 & $0.00 \%$ & 0.002 & $0.00 \%$ & 0.014 & $0.00 \%$ & 0.003 \\
\hline-9 & $0.00 \%$ & 1.127 & $0.00 \%$ & 0.012 & $0.00 \%$ & 0.002 & $0.00 \%$ & 0.015 & $0.00 \%$ & 0.003 \\
\hline-8 & $0.00 \%$ & 1.149 & $0.00 \%$ & 0.012 & $0.00 \%$ & 0.002 & $0.00 \%$ & 0.015 & $0.00 \%$ & 0.003 \\
\hline-7 & $0.00 \%$ & 1.142 & $0.00 \%$ & 0.012 & $0.00 \%$ & 0.002 & $0.00 \%$ & 0.015 & $0.00 \%$ & 0.003 \\
\hline-6 & $0.00 \%$ & 1.127 & $0.00 \%$ & 0.012 & $0.00 \%$ & 0.002 & $0.00 \%$ & 0.015 & $0.00 \%$ & 0.003 \\
\hline-5 & $0.00 \%$ & 1.137 & $0.00 \%$ & 0.012 & $0.00 \%$ & 0.002 & $0.30 \%$ & 0.015 & $0.00 \%$ & 0.003 \\
\hline-4 & $0.00 \%$ & 1.117 & $0.00 \%$ & 0.012 & $0.00 \%$ & 0.002 & $3.40 \%$ & 0.015 & $0.00 \%$ & 0.003 \\
\hline-2 & $0.00 \%$ & 1.090 & $0.00 \%$ & 0.012 & $0.00 \%$ & 0.002 & $5.90 \%$ & 0.015 & $0.00 \%$ & 0.003 \\
\hline
\end{tabular}

Table 3.5: Error rate and average time for, $\alpha_{\ell}=-3$ vs. $\alpha_{\mathrm{r}} \in$ $\{-2,-4,-5, \ldots,-19,-20\}$ with $n=3$
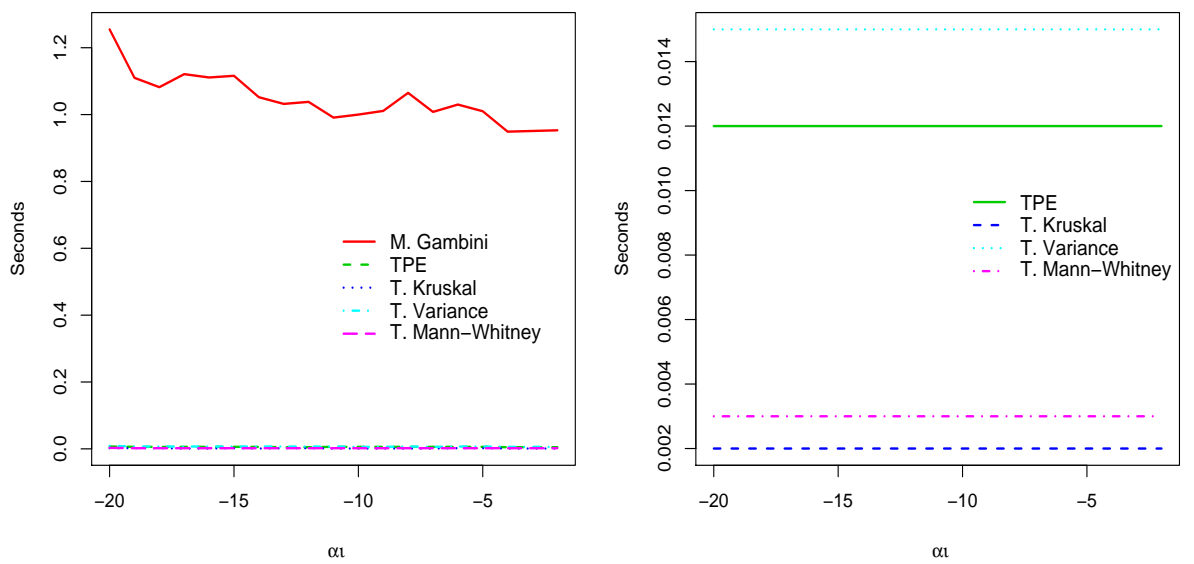

Figure 3.14: Average execution time for Gambini, Kruskal, Mann-Whitney, Variance and TPE, $\alpha_{\ell}=-3$ vs. $\alpha_{r} \in\{-2,-4,-5, \ldots,-19,-20\}$ with $n=3$ 


\subsection{Heterogeneous areas with $n=3$ and $\alpha_{\ell}=-8$}

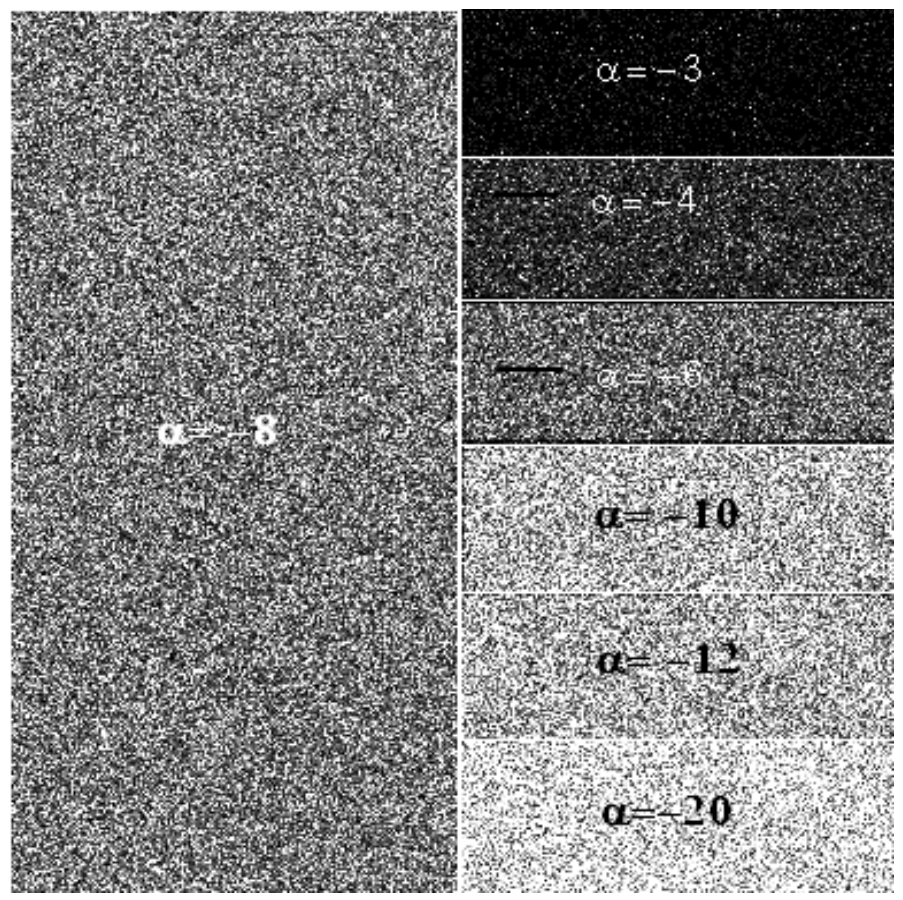

Figure 3.15: Synthetic images $\mathcal{G}_{\mathrm{I}}^{0}(\alpha, 1,3), \gamma=1$ and $\alpha_{\ell}=-8$ to the left against $\alpha_{\mathrm{r}}=\{-3,-4,-6,-10,-12,-20\}$ to the right

Table 3.6 contains the percentages of error and average time for $\alpha_{\ell}=-8, n=3$. We note that T. Kruskal, T. Mann-Whitney and M. Gambini do not present errors for any $\alpha_{\mathrm{r}}$, which makes the best behavior. TPE has $58 \%$ of error for $\alpha_{\mathrm{r}}=9$ and $12 \%$ for $\alpha_{r}=-7$; for the other values of $\alpha_{r}$ the percentage of error is zero; the method TPE has difficulties in finding the edge when $\alpha_{r}$ is very close to $\alpha_{\ell}$. The method T. Variance presents large percentages of error around $\alpha_{\ell}$.

Figure 3.16 compares the behavior of the percentages of error generated by the different methods in study. Note that the greater percentages of error are generated by TPE and T. Variance. The methods with better behavior are M. Gambini, T. Kruskal and T. Mann-Whitney because they have zero error rate.

Table 3.6 shows that M. Gambini continues to display the largest execution times. T. Kruskal is approximately 578 times faster that the M. Gambini for 


\begin{tabular}{|c|c|c|c|c|c|c|c|c|c|c|}
\hline & \multicolumn{2}{|c|}{ M. Gambini } & \multicolumn{2}{|c|}{ TPE } & \multicolumn{2}{|c|}{ T. Kruskal } & \multicolumn{2}{|c|}{ T. Variance } & \multicolumn{2}{|c|}{ T. M-Whitney } \\
\hline$\alpha_{r}$ & $\begin{array}{r}\text { Error } \\
\text { rate }\end{array}$ & Time & $\begin{array}{r}\text { Error } \\
\text { rate }\end{array}$ & Time & $\begin{array}{r}\text { Error } \\
\text { rate }\end{array}$ & $\begin{array}{r}\text { Time } \\
\text { rate }\end{array}$ & $\begin{array}{r}\text { Error } \\
\text { rate }\end{array}$ & Time \\
\hline-20 & $0.00 \%$ & 1.351 & $0.00 \%$ & 0.012 & $0.00 \%$ & 0.002 & $0.00 \%$ & 0.015 & $0.00 \%$ & 0.003 \\
\hline-19 & $0.00 \%$ & 1.186 & $0.00 \%$ & 0.012 & $0.00 \%$ & 0.002 & $0.00 \%$ & 0.015 & $0.00 \%$ & 0.003 \\
\hline-18 & $0.00 \%$ & 1.229 & $0.00 \%$ & 0.012 & $0.00 \%$ & 0.002 & $0.00 \%$ & 0.015 & $0.00 \%$ & 0.003 \\
\hline-17 & $0.00 \%$ & 1.277 & $0.00 \%$ & 0.012 & $0.00 \%$ & 0.002 & $0.00 \%$ & 0.015 & $0.00 \%$ & 0.003 \\
\hline-16 & $0.00 \%$ & 1.268 & $0.00 \%$ & 0.012 & $0.00 \%$ & 0.002 & $0.00 \%$ & 0.015 & $0.00 \%$ & 0.003 \\
\hline-15 & $0.00 \%$ & 1.506 & $0.00 \%$ & 0.012 & $0.00 \%$ & 0.002 & $0.00 \%$ & 0.015 & $0.00 \%$ & 0.003 \\
\hline-14 & $0.00 \%$ & 1.231 & $0.00 \%$ & 0.012 & $0.00 \%$ & 0.002 & $0.00 \%$ & 0.015 & $0.00 \%$ & 0.003 \\
\hline-13 & $0.00 \%$ & 1.196 & $0.00 \%$ & 0.012 & $0.00 \%$ & 0.002 & $0.00 \%$ & 0.015 & $0.00 \%$ & 0.003 \\
\hline-12 & $0.00 \%$ & 1.232 & $0.00 \%$ & 0.012 & $0.00 \%$ & 0.002 & $0.00 \%$ & 0.015 & $0.00 \%$ & 0.003 \\
\hline-11 & $0.00 \%$ & 1.262 & $0.00 \%$ & 0.012 & $0.00 \%$ & 0.002 & $0.40 \%$ & 0.015 & $0.00 \%$ & 0.003 \\
\hline-10 & $0.00 \%$ & 1.252 & $0.00 \%$ & 0.012 & $0.00 \%$ & 0.002 & $20.90 \%$ & 0.015 & $0.00 \%$ & 0.003 \\
\hline-9 & $0.00 \%$ & 1.279 & $57.90 \%$ & 0.012 & $0.00 \%$ & 0.002 & $32.20 \%$ & 0.015 & $0.00 \%$ & 0.003 \\
\hline-7 & $0.00 \%$ & 1.269 & $11.90 \%$ & 0.012 & $0.00 \%$ & 0.002 & $48.80 \%$ & 0.015 & $0.00 \%$ & 0.003 \\
\hline-6 & $0.00 \%$ & 1.237 & $0.00 \%$ & 0.012 & $0.00 \%$ & 0.002 & $3.00 \%$ & 0.015 & $0.00 \%$ & 0.003 \\
\hline-5 & $0.00 \%$ & 1.172 & $0.00 \%$ & 0.012 & $0.00 \%$ & 0.002 & $0.00 \%$ & 0.015 & $0.00 \%$ & 0.003 \\
\hline-4 & $0.00 \%$ & 1.141 & $0.00 \%$ & 0.012 & $0.00 \%$ & 0.002 & $0.00 \%$ & 0.015 & $0.00 \%$ & 0.003 \\
\hline-3 & $0.00 \%$ & 1.136 & $0.00 \%$ & 0.012 & $0.00 \%$ & 0.002 & $0.00 \%$ & 0.015 & $0.00 \%$ & 0.003 \\
\hline-2 & $0.00 \%$ & 1.157 & $0.00 \%$ & 0.012 & $0.00 \%$ & 0.002 & $0.20 \%$ & 0.015 & $0.00 \%$ & 0.003 \\
\hline
\end{tabular}

Table 3.6: Error rate and average time for, $\alpha_{\ell}=-8$ vs. $\alpha_{\mathrm{r}} \in$ $\{-2,-4,-5, \ldots,-19,-20\}$ with $n=3$

$\alpha_{\mathrm{r}}=-2$ and 675 times faster when $\alpha_{\mathrm{r}}=-20$.

Figure 3.17 corroborates the behavior of the execution times of M. Gambini. The execution times of the non-parametric methods are almost constant when $\alpha_{r}$ varies, the fastest method being T. Kruskal, followed by the method of T. MannWhitney. 


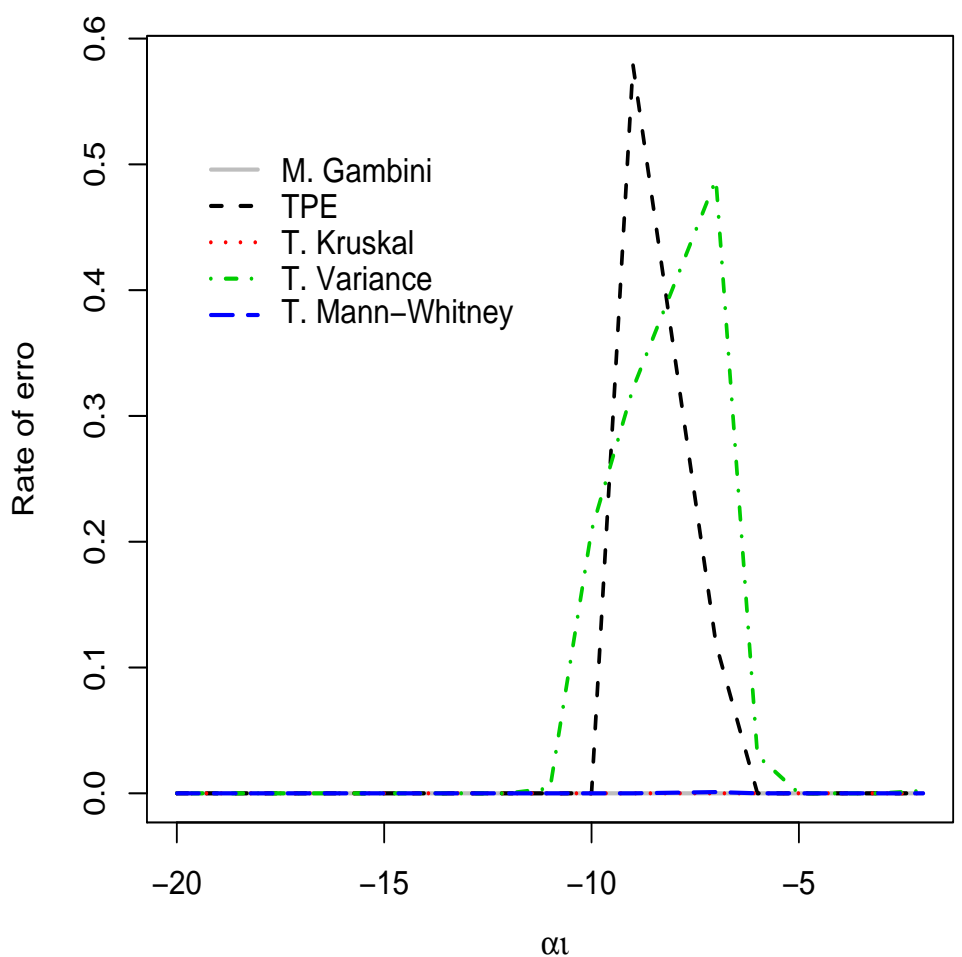

Figure 3.16: Error rate in edge detection for Gambini, Kruskal, Mann-Whitney, Variance and TPE, $\alpha_{\ell}=-8$ vs. $\alpha_{r} \in\{-2,-4,-5, \ldots,-19,-20\}$ with $n=3$
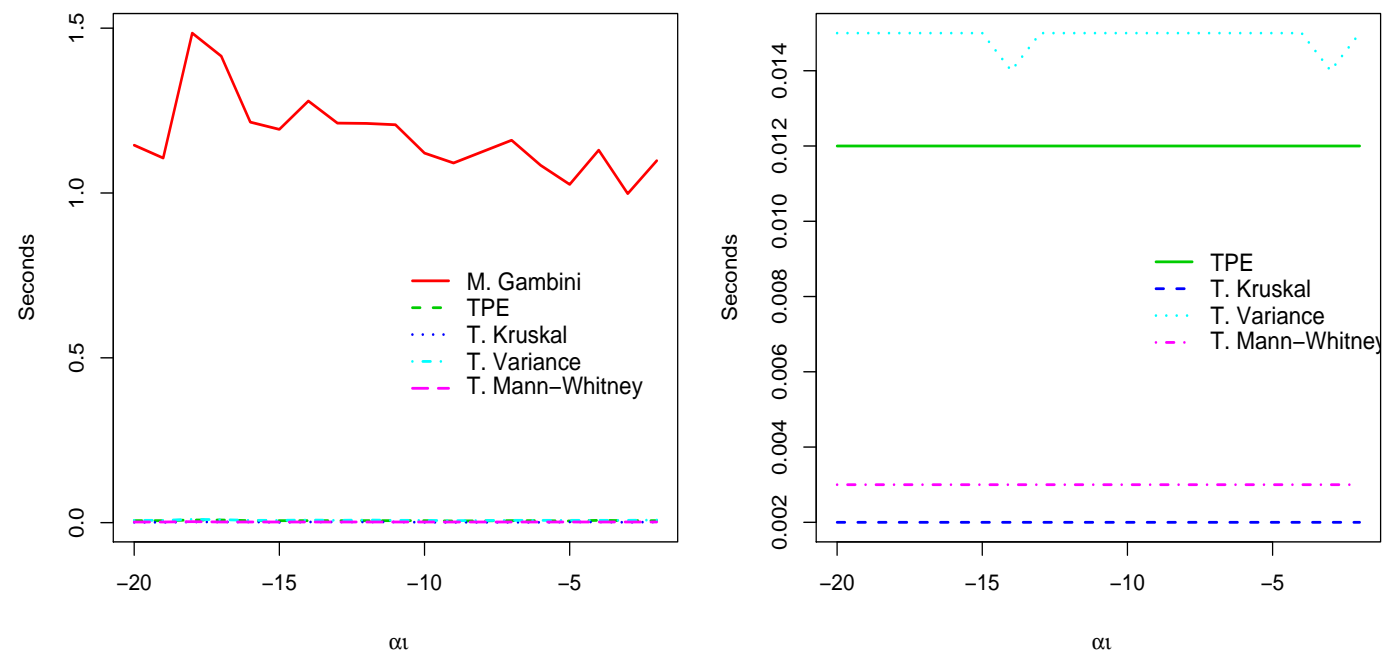

Figure 3.17: Average execution time in seconds for Gambini, Kruskal, MannWhitney, Variance and TPE, $\alpha_{\ell}=-8$ vs. $\alpha_{r} \in\{-2,-4,-5, \ldots,-19,-20\}$ with $\mathrm{n}=3$ 


\subsection{Homogeneous areas with $n=3$ and $\alpha_{\ell}=-12$}

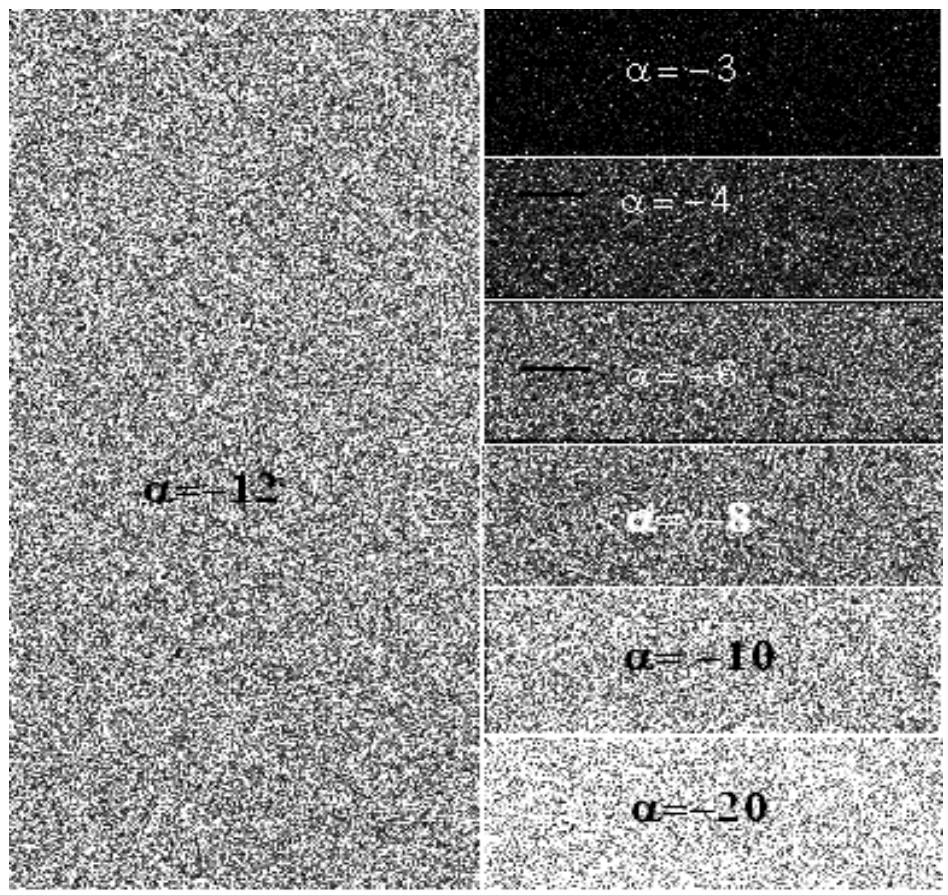

Figure 3.18: Synthetic images from $\mathcal{G}_{\mathrm{I}}^{\circ}(\alpha, 1,3), \gamma=1$ and $\alpha_{\ell}=-12$ to the left against $\alpha_{r}=\{-3,-4,-6,-8,-10,-20\}$ to the right

Figure 3.18 shows images of samples generated from $\mathcal{G}_{\mathrm{I}}^{0}(\alpha, 1,3)$ and different values of the parameter $\alpha$ and $\gamma=1$. The image at the left side of the figure generated from $\mathcal{G}_{\mathrm{I}}^{\mathrm{O}}(-12,1,3)$ which represents homogeneous areas.

The table 3.7 contains the error rate and average time for $\alpha_{\ell}=-12, n=3$ and different values of $\alpha_{r}$. Note that M. Gambini, T. Kruskal and T. Mann-Whitney are the best performing over. The M. Gambini has the smallest percentage of error when $\alpha_{r}=-13$, and the largest percentage of error when $\alpha_{r}=-11$ with 26\%. For $\alpha_{r}=-14$, the methods with the best behavior are T. Kruskal and M. Gambini followed by T. Mann-Whitney. The T. Variance presents $89 \%$ of error when $\alpha_{r}=-11$ and $50 \%$ when $\alpha_{r}=-13$, with which this method presents under performance. 


\begin{tabular}{|c|c|c|c|c|c|c|c|c|c|c|}
\hline & \multicolumn{2}{|c|}{ M. Gambini } & \multicolumn{2}{|c|}{ TPE } & \multicolumn{2}{|c|}{ T. Kruskal } & \multicolumn{2}{|c|}{ T. Variance } & \multicolumn{2}{|c|}{ T. M-Whitney } \\
\hline$\alpha_{r}$ & $\begin{array}{r}\text { Error } \\
\text { rate }\end{array}$ & Time & $\begin{array}{r}\text { Error } \\
\text { rate }\end{array}$ & $\overline{\mathrm{Ti}}$ & $\begin{array}{r}\text { Error } \\
\text { rate }\end{array}$ & Time & $\begin{array}{r}\text { Error } \\
\text { rate }\end{array}$ & Time & $\begin{array}{r}\text { Error } \\
\text { rate }\end{array}$ & Time \\
\hline-20 & $0.00 \%$ & & $0.00 \%$ & & $0.00 \%$ & 00 & $0.00 \%$ & & $0.00 \%$ & 102 \\
\hline-19 & $0.00 \%$ & 963 & $00 \%$ & 0.0 & $0.00 \%$ & 0.001 & $0.00 \%$ & 0.007 & $.00 \%$ & $\overline{002}$ \\
\hline-18 & $0.00 \%$ & 509 & $00 \%$ & 0.006 & $0.00 \%$ & .002 & $0.00 \%$ & 0.008 & $0.00 \%$ & 0.002 \\
\hline-17 & $0 \%$ & 98 & $00 \%$ & 007 & $.00 \%$ & 002 & $.00 \%$ & $\overline{99}$ & $.00 \%$ & 003 \\
\hline-16 & $0.00 \%$ & 639 & $00 \%$ & 0.008 & $0.00 \%$ & 0.002 & $0.00 \%$ & 0.009 & $0.00 \%$ & 0.003 \\
\hline-15 & $0.00 \%$ & 636 & $2.00 \%$ & 0.007 & $0.00 \%$ & 0.002 & $21.50 \%$ & 0.008 & $0.00 \%$ & 0.002 \\
\hline-14 & $0.40 \%$ & 452 & $50 \%$ & .007 & $0.10 \%$ & 0.002 & $2.50 \%$ & 0.009 & $0.10 \%$ & $\overline{002}$ \\
\hline-13 & $1.90 \%$ & 430 & $.50 \%$ & 0.007 & $1.50 \%$ & 0.002 & $50.30 \%$ & 0.008 & $31.60 \%$ & 0.002 \\
\hline-11 & $26.40 \%$ & 1.491 & $70 \%$ & 0.007 & $24.50 \%$ & 0.002 & $8.80 \%$ & 0.008 & $25.20 \%$ & $\overline{0.002}$ \\
\hline-10 & $0 \%$ & 417 & $20 \%$ & 0.006 & $0.00 \%$ & 0.002 & $16.40 \%$ & 0.008 & $0.00 \%$ & $\overline{0.002}$ \\
\hline-9 & $0.00 \%$ & 448 & $00 \%$ & 0.006 & $0.00 \%$ & 0.001 & $0.00 \%$ & 0.008 & $0.00 \%$ & 0.002 \\
\hline-8 & $00 \%$ & 405 & $00 \%$ & 0.007 & $0.00 \%$ & 0.002 & $0.10 \%$ & 0.009 & $0.00 \%$ & 0.002 \\
\hline-7 & $0.00 \%$ & 1.315 & $00 \%$ & 0.007 & $0.00 \%$ & 0.002 & $0.00 \%$ & 0.008 & $0.00 \%$ & 0.002 \\
\hline-6 & $0.00 \%$ & 1.098 & $0.00 \%$ & 0.005 & $0.00 \%$ & 0.002 & $0.00 \%$ & 0.007 & $0.00 \%$ & 0.002 \\
\hline-5 & $00 \%$ & 1.038 & $00 \%$ & 0.005 & $0.00 \%$ & 0.001 & $0.00 \%$ & 0.006 & $0.00 \%$ & 0.002 \\
\hline-4 & $0.00 \%$ & 1.074 & $0.00 \%$ & 0.005 & $0.00 \%$ & 0.001 & $0.00 \%$ & 0.006 & $0.00 \%$ & 0.002 \\
\hline-3 & $0.00 \%$ & 0.982 & $0.00 \%$ & 0.005 & $0.00 \%$ & 0.002 & $0.00 \%$ & 0.006 & $0.00 \%$ & 0.002 \\
\hline-2 & $0.00 \%$ & 0.938 & $0.00 \%$ & 0.006 & $0.00 \%$ & 0.001 & $0.10 \%$ & 0.006 & $0.00 \%$ & 0.002 \\
\hline
\end{tabular}

Table 3.7: Error rate and average time for, $\alpha_{\ell}=-12$ vs. $\alpha_{r} \in$ $\{-2,-4,-5, \ldots,-19,-20\}$ with $n=3$

Figure 3.19 shows the behavior of the different methods according to the percentage of error generated in the detection of edges. Note that the method with the best behavior is the M. Gambini followed by T. Kruskal and T. Mann-Whitney.

The average execution time of the methods display the same behavior as before, that for $(n=1)$; the non-parametrics methods are faster that M. Gambini; T. Kruskal is 938 times faster than M. Gambini for $\alpha_{r}=-2$ and 1963 times faster for $\alpha_{r}=-19$, as presented in Table 3.7 and Figure 3.20 


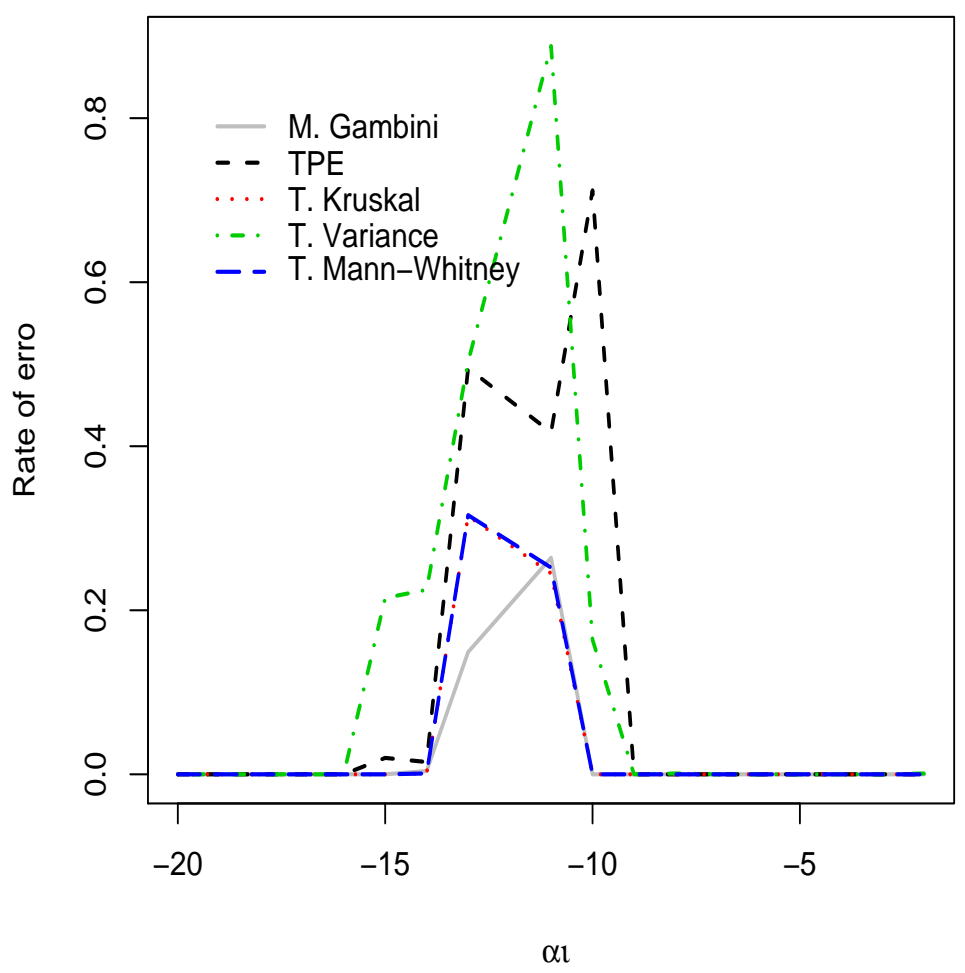

Figure 3.19: Error rate in edge detection for Gambini, Kruskal, Mann-Whitney, Variance and TPE, $\alpha_{\ell}=-12$ vs. $\alpha_{r} \in\{-2,-4,-5, \ldots,-19,-20\}$ with $n=3$
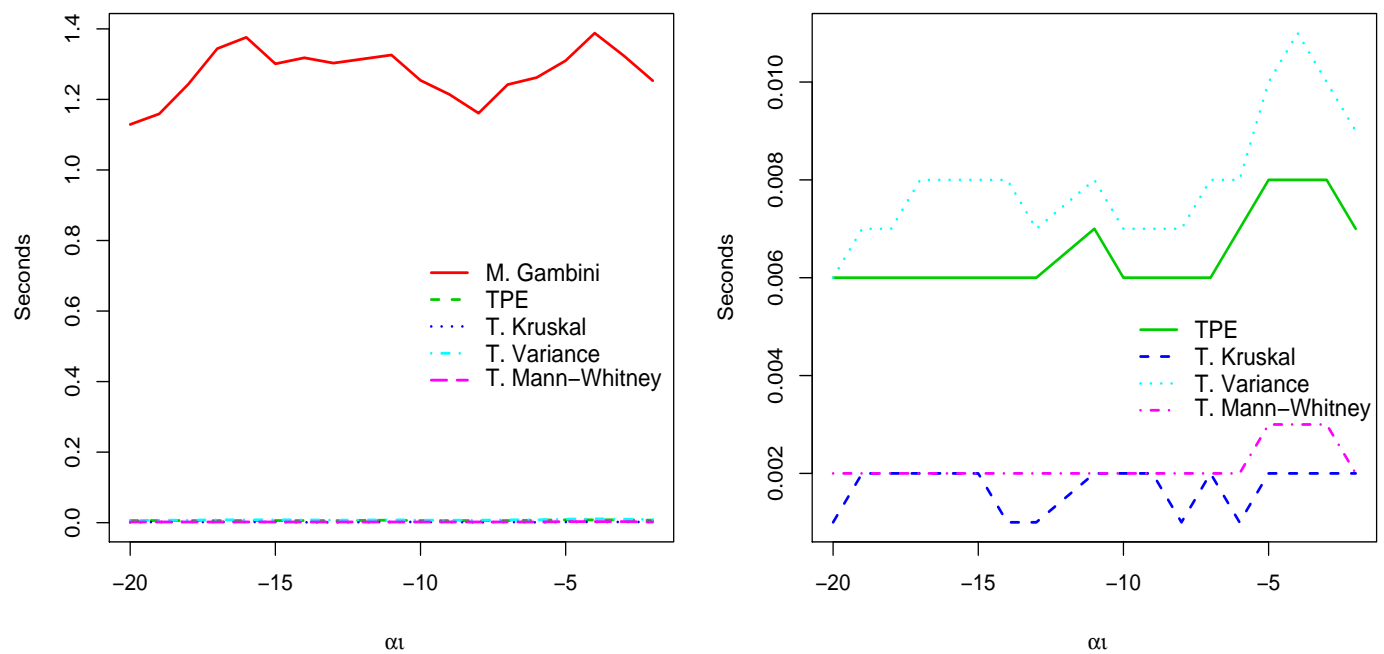

Figure 3.20: Average execution time in seconds for Gambini, Kruskal, MannWhitney, Variance and TPE, $\alpha_{\ell}=-12$ vs. $\alpha_{r} \in\{-2,-4,-5, \ldots,-19,-20\}$ with $\mathrm{n}=3$ 


\subsection{Homogeneous areas with $n=3$ and $\alpha_{\ell}=-18$}

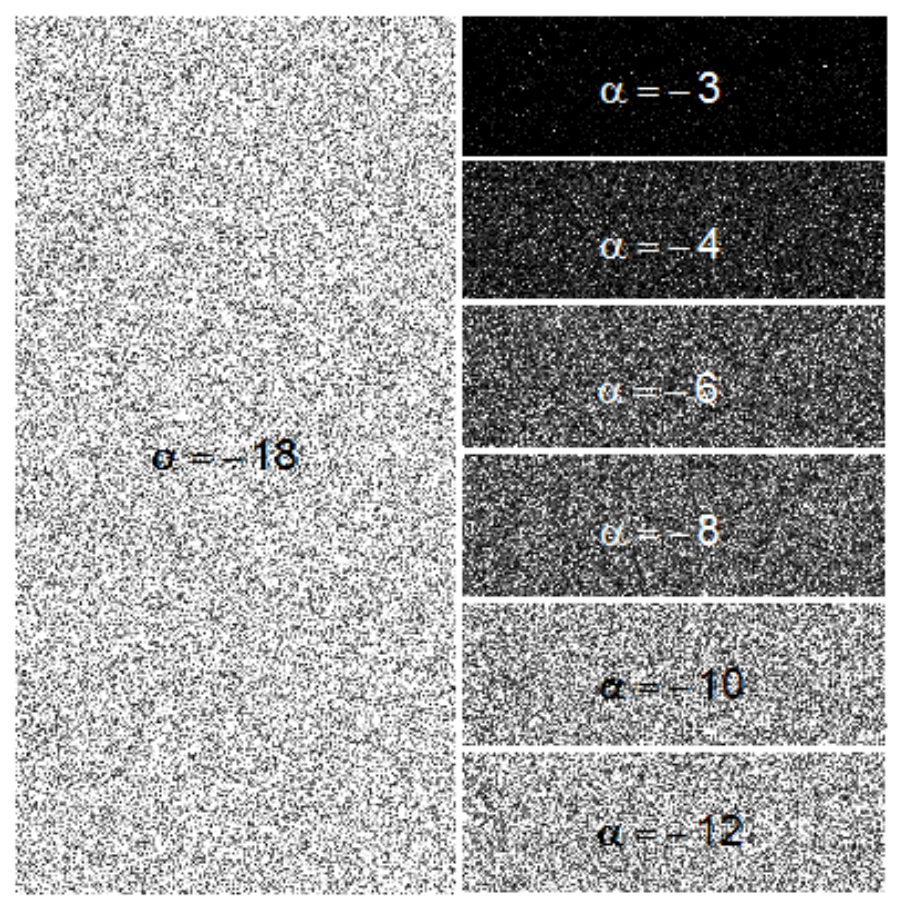

Figure 3.21: Synthetic images $\mathcal{G}_{\mathrm{I}}^{0}(\alpha, 1,3), \gamma=1$ and $\alpha_{\ell}=-18$ to the left against $\alpha_{r}=\{-3,-4,-6,-8,-10,-20\}$ to the right

Table 3.8 contains the error rate and average execution times of the methods under study when detecting the edge in a $20 \times 100$ image generated with $\alpha_{\ell}=-18$ and $\mathrm{n}=3$. We note that the M. Gambini, T. Kruskal and T. Mann-Whitney present percentages of error equal to zero in the cases where $\alpha_{r} \geq-16$. The T. Kruskal and T. Mann-Whitney presents smaller percentages of error in comparison with M. Gambini for $\alpha_{r}=-17,-19,-20$; T. Kruskal and T. Mann-Whitney appears to be the methods with the smaller percentages of error in the detection of edges when $\alpha_{\ell}=-18$ and $n=3$. The TPE presents percentage of error zero when $\alpha_{r}$ is distant enough from $\alpha_{\ell}$, but this percentage begins to increase as $\alpha_{r}$ approaches $\alpha_{\ell}=-18$, obtaining $99.5 \%$ of error when $\alpha_{\mathrm{r}}=-17$. The $\mathbf{T}$. Variance presents behavior similar to the TPE. 


\begin{tabular}{|c|r|r|r|r|r|r|r|r|r|r|}
\hline & \multicolumn{2}{|c|}{ M. Gambini } & \multicolumn{2}{|c|}{ TPE } & \multicolumn{2}{c|}{ T. Kruskal } & \multicolumn{2}{|c|}{ T. Variance } & \multicolumn{2}{|c|}{ T. M-Whitney } \\
\hline$\alpha_{r}$ & $\begin{array}{r}\text { Error } \\
\text { rate }\end{array}$ & Time & $\begin{array}{r}\text { Error } \\
\text { rate }\end{array}$ & Time & $\begin{array}{r}\text { Error } \\
\text { rate }\end{array}$ & Time & $\begin{array}{r}\text { Error } \\
\text { rate }\end{array}$ & $\begin{array}{r}\text { Time } \\
\text { rrote }\end{array}$ & $\begin{array}{r}\text { Time } \\
\text { rate }\end{array}$ \\
\hline-20 & $0.30 \%$ & 1.866 & $7.50 \%$ & 0.005 & $0.50 \%$ & 0.001 & $76.80 \%$ & 0.006 & $0.50 \%$ & 0.002 \\
\hline-19 & $15.70 \%$ & 1.417 & $33.30 \%$ & 0.005 & $13.10 \%$ & 0.001 & $83.20 \%$ & 0.006 & $13.10 \%$ & 0.002 \\
\hline-17 & $31.30 \%$ & 1.324 & $99.50 \%$ & 0.006 & $11.20 \%$ & 0.001 & $87.00 \%$ & 0.006 & $11.20 \%$ & 0.002 \\
\hline-16 & $0.00 \%$ & 1.278 & $2.90 \%$ & 0.005 & $0.00 \%$ & 0.002 & $20.00 \%$ & 0.006 & $0.00 \%$ & 0.002 \\
\hline-15 & $0.00 \%$ & 1.206 & $0.00 \%$ & 0.005 & $0.00 \%$ & 0.001 & $13.30 \%$ & 0.006 & $0.00 \%$ & 0.002 \\
\hline-14 & $0.00 \%$ & 1.351 & $6.10 \%$ & 0.005 & $0.00 \%$ & 0.002 & $17.20 \%$ & 0.007 & $0.00 \%$ & 0.002 \\
\hline-13 & $0.00 \%$ & 1.182 & $0.00 \%$ & 0.006 & $0.00 \%$ & 0.001 & $0.00 \%$ & 0.006 & $0.00 \%$ & 0.002 \\
\hline-12 & $0.00 \%$ & 1.097 & $0.00 \%$ & 0.006 & $0.00 \%$ & 0.001 & $0.00 \%$ & 0.006 & $0.00 \%$ & 0.002 \\
\hline-11 & $0.00 \%$ & 1.303 & $0.00 \%$ & 0.005 & $0.00 \%$ & 0.001 & $0.00 \%$ & 0.007 & $0.00 \%$ & 0.002 \\
\hline-10 & $0.00 \%$ & 1.264 & $0.00 \%$ & 0.005 & $0.00 \%$ & 0.001 & $0.00 \%$ & 0.007 & $0.00 \%$ & 0.002 \\
\hline-9 & $0.00 \%$ & 1.133 & $0.00 \%$ & 0.005 & $0.00 \%$ & 0.001 & $0.00 \%$ & 0.007 & $0.00 \%$ & 0.002 \\
\hline-8 & $0.00 \%$ & 1.046 & $0.00 \%$ & 0.005 & $0.00 \%$ & 0.001 & $0.00 \%$ & 0.006 & $0.00 \%$ & 0.002 \\
\hline-7 & $0.00 \%$ & 1.378 & $0.00 \%$ & 0.005 & $0.00 \%$ & 0.001 & $0.00 \%$ & 0.006 & $0.00 \%$ & 0.002 \\
\hline-6 & $0.00 \%$ & 1.097 & $0.00 \%$ & 0.005 & $0.00 \%$ & 0.001 & $0.00 \%$ & 0.006 & $0.00 \%$ & 0.002 \\
\hline-5 & $0.00 \%$ & 1.062 & $0.00 \%$ & 0.005 & $0.00 \%$ & 0.001 & $0.00 \%$ & 0.006 & $0.00 \%$ & 0.002 \\
\hline-4 & $0.00 \%$ & 1.056 & $0.00 \%$ & 0.005 & $0.00 \%$ & 0.001 & $0.00 \%$ & 0.006 & $0.00 \%$ & 0.002 \\
\hline-3 & $0.00 \%$ & 1.055 & $0.00 \%$ & 0.005 & $0.00 \%$ & 0.001 & $0.00 \%$ & 0.006 & $0.00 \%$ & 0.002 \\
\hline-2 & $0.00 \%$ & 1.021 & $0.00 \%$ & 0.005 & $0.00 \%$ & 0.001 & $0.00 \%$ & 0.006 & $0.00 \%$ & 0.002 \\
\hline
\end{tabular}

Table 3.8: Error rate and average time for $\alpha_{\ell}=-18$ vs. $\alpha_{\mathrm{r}} \in$ $\{-2,-4,-5, \ldots,-19,-20\}$ with $n=3$

Figure 3.22 shows that T. Kruskal and T. Mann-Whitney presents the lowest error rate in detecting edges, followed by M. Gambini. All methods present error greater than zero when the generated images were obtained from distributions with roughness parameters very close in value.

The average time of the T. Kruskal is approximately 1000 times smaller than that of M. Gambini when $\alpha_{r}=-2$ and 1866 times faster when $\alpha_{r}=-20$, as it is observed in the Table 3.8.

Figure 3.23 shows that the M. Gambini runtime decreases when $\alpha_{r}$ is close to zero, but this time is never less than 1 second. Among the non-parametric methods, the fastest is T. Kruskal followed by T. Mann-Whitney; lower is the T. Variance although that it never surpasses 0.010 seconds. 


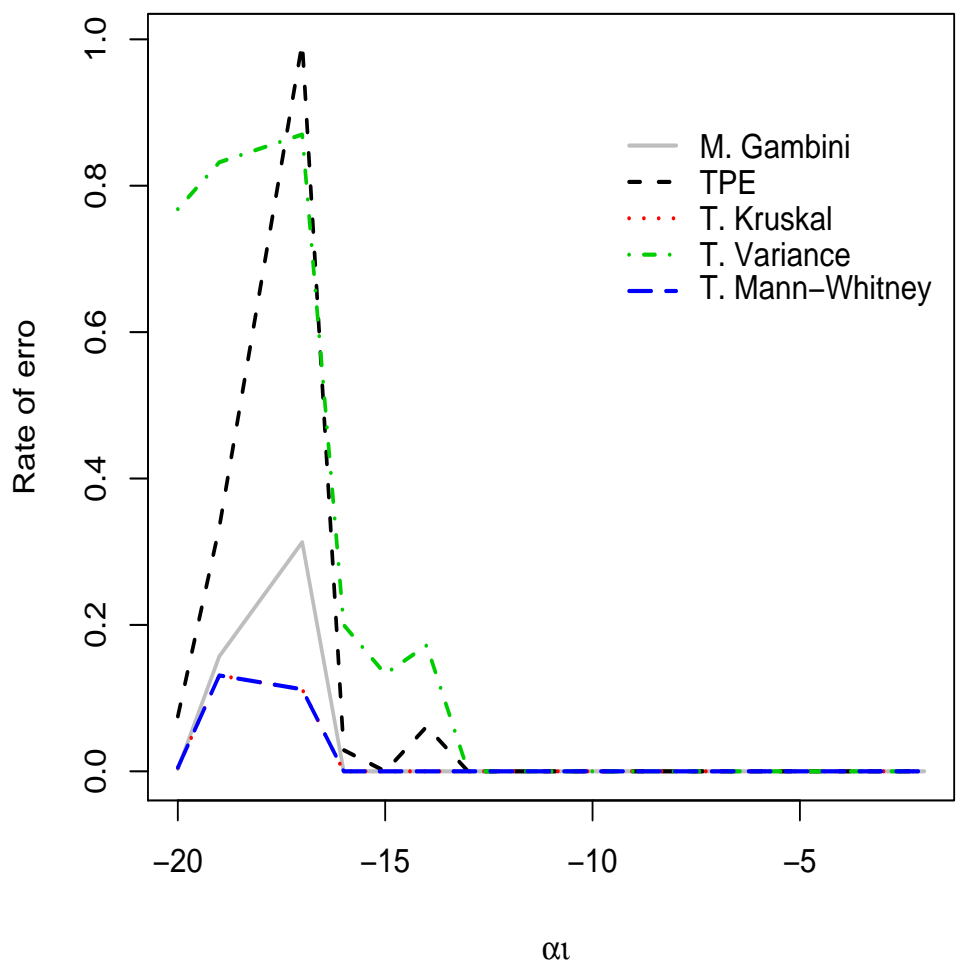

Figure 3.22: Error rate in edge detection for Gambini, Kruskal, Mann-Whitney, Variance and TPE, $\alpha_{\ell}=-18$ vs. $\alpha_{r} \in\{-2,-4,-5, \ldots,-19,-20\}$ with $n=3$
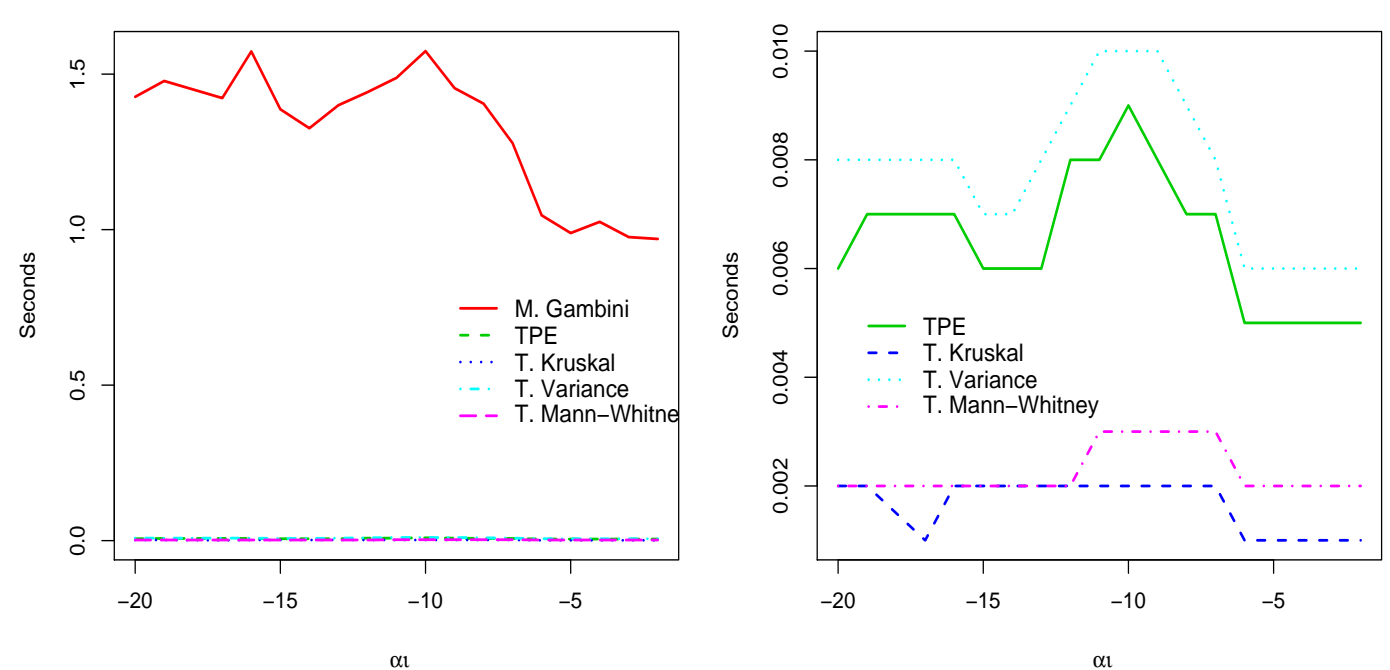

Figure 3.23: Average execution time in seconds for Gambini, Kruskal, MannWhitney, Variance and TPE, $\alpha_{\ell}=-18$ vs. $\alpha_{r} \in\{-2,-4,-5, \ldots,-19,-20\}$ with $\mathrm{n}=3$ 


\subsection{Extremely heterogeneous areas with $n=8$ and}

$$
\alpha_{\ell}=-3
$$
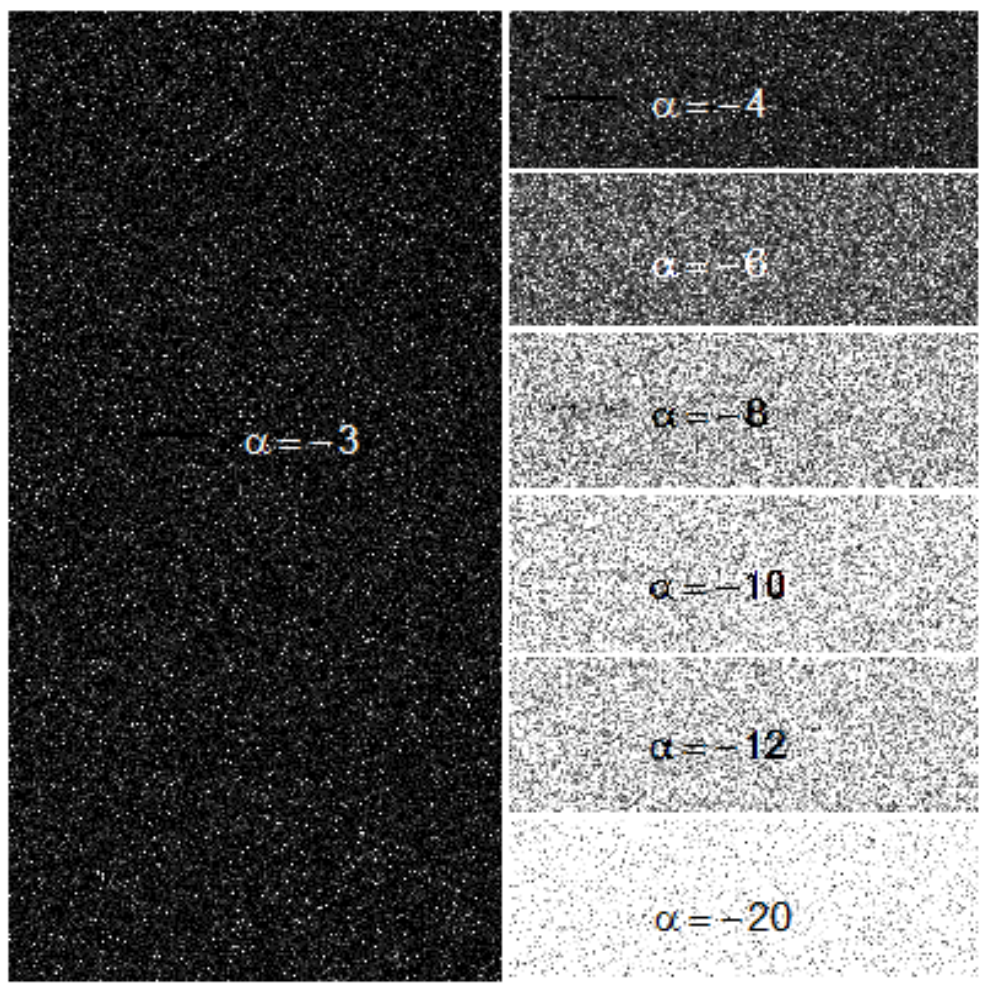

Figure 3.24: Synthetic images $\mathcal{G}_{\mathrm{I}}^{0}(\alpha, 1,8), \gamma=1$ and $\alpha_{\ell}=-3$ to the left against $\alpha_{r}=\{-4,-6,-8,-10,-12,-20\}$ to the right

Figure 3.24, left, show an image generated from $\mathcal{G}_{\mathrm{I}}^{0}(-3,1,8)$ which represents extremely heterogeneous areas. Figure 3.24, right, we have images generated with $\alpha_{r}=-4$ until $\alpha_{r}=-20$ that represent areas with different degrees of roughness.

The table 3.9 presents the percentages of errors and average time obtained by the methods considered in the simulation. Note that the error rate of all methods are zero, except for T. Variance that presents percentages of error of $6.2 \%$ and $3.6 \%$ for $\alpha_{\mathrm{r}}=-2$ and $\alpha_{\mathrm{r}}=-4$, respectively. All methods present excellent behavior in the detection of edges when $\alpha_{\ell}=-3$ and $n=8$.

The Table 3.9 contains the average execution time for $\alpha_{\ell}=-3$ and $n=8$. The 


\begin{tabular}{|c|c|c|c|c|c|c|c|c|c|c|}
\hline & \multicolumn{2}{|c|}{ M. Gambini } & \multicolumn{2}{c|}{ TPE } & \multicolumn{2}{c|}{ T. Kruskal } & \multicolumn{2}{|c|}{ T. Variance } & \multicolumn{2}{|c|}{ T. M-Whitney } \\
\hline$\alpha_{r}$ & $\begin{array}{r}\text { Error } \\
\text { rate }\end{array}$ & Time & $\begin{array}{r}\text { Error } \\
\text { rate }\end{array}$ & Time & $\begin{array}{r}\text { Error } \\
\text { rate }\end{array}$ & Time & $\begin{array}{r}\text { Error } \\
\text { rate }\end{array}$ & $\begin{array}{r}\text { Time } \\
\text { rate }\end{array}$ & Time \\
\hline-20 & $0.00 \%$ & 1.255 & $0.00 \%$ & 0.007 & $0.00 \%$ & 0.002 & $0.00 \%$ & 0.009 & $0.00 \%$ & 0.003 \\
\hline-19 & $0.00 \%$ & 1.110 & $0.00 \%$ & 0.006 & $0.00 \%$ & 0.002 & $0.00 \%$ & 0.007 & $0.00 \%$ & 0.002 \\
\hline-18 & $0.00 \%$ & 1.082 & $0.00 \%$ & 0.006 & $0.00 \%$ & 0.002 & $0.00 \%$ & 0.007 & $0.00 \%$ & 0.002 \\
\hline-17 & $0.00 \%$ & 1.121 & $0.00 \%$ & 0.006 & $0.00 \%$ & 0.001 & $0.00 \%$ & 0.007 & $0.00 \%$ & 0.002 \\
\hline-16 & $0.00 \%$ & 1.111 & $0.00 \%$ & 0.006 & $0.00 \%$ & 0.001 & $0.00 \%$ & 0.007 & $0.00 \%$ & 0.002 \\
\hline-15 & $0.00 \%$ & 1.116 & $0.00 \%$ & 0.006 & $0.00 \%$ & 0.002 & $0.00 \%$ & 0.007 & $0.00 \%$ & 0.002 \\
\hline-14 & $0.00 \%$ & 1.052 & $0.00 \%$ & 0.006 & $0.00 \%$ & 0.001 & $0.00 \%$ & 0.007 & $0.00 \%$ & 0.002 \\
\hline-13 & $0.00 \%$ & 1.032 & $0.00 \%$ & 0.005 & $0.00 \%$ & 0.002 & $0.00 \%$ & 0.007 & $0.00 \%$ & 0.002 \\
\hline-12 & $0.00 \%$ & 1.038 & $0.00 \%$ & 0.005 & $0.00 \%$ & 0.002 & $0.00 \%$ & 0.007 & $0.00 \%$ & 0.002 \\
\hline-11 & $0.00 \%$ & 0.991 & $0.00 \%$ & 0.006 & $0.00 \%$ & 0.001 & $0.10 \%$ & 0.007 & $0.00 \%$ & 0.002 \\
\hline-10 & $0.00 \%$ & 1.000 & $0.00 \%$ & 0.006 & $0.00 \%$ & 0.001 & $0.00 \%$ & 0.006 & $0.00 \%$ & 0.002 \\
\hline-9 & $0.00 \%$ & 1.011 & $0.00 \%$ & 0.006 & $0.00 \%$ & 0.001 & $0.00 \%$ & 0.006 & $0.00 \%$ & 0.002 \\
\hline-8 & $0.00 \%$ & 1.065 & $0.00 \%$ & 0.006 & $0.00 \%$ & 0.001 & $0.00 \%$ & 0.007 & $0.00 \%$ & 0.002 \\
\hline-7 & $0.00 \%$ & 1.008 & $0.00 \%$ & 0.006 & $0.00 \%$ & 0.001 & $0.00 \%$ & 0.006 & $0.00 \%$ & 0.002 \\
\hline-6 & $0.00 \%$ & 1.030 & $0.00 \%$ & 0.006 & $0.00 \%$ & 0.002 & $0.00 \%$ & 0.007 & $0.00 \%$ & 0.002 \\
\hline-5 & $0.00 \%$ & 1.010 & $0.00 \%$ & 0.006 & $0.00 \%$ & 0.002 & $0.10 \%$ & 0.007 & $0.00 \%$ & 0.002 \\
\hline-4 & $0.00 \%$ & 0.949 & $0.10 \%$ & 0.005 & $0.00 \%$ & 0.001 & $3.60 \%$ & 0.006 & $0.00 \%$ & 0.002 \\
\hline-2 & $0.00 \%$ & 0.953 & $0.00 \%$ & 0.005 & $0.00 \%$ & 0.001 & $6.20 \%$ & 0.006 & $0.00 \%$ & 0.002 \\
\hline
\end{tabular}

Table 3.9: Error rate and average time for $\alpha_{\ell}=-3$ vs. $\alpha_{r} \in$ $\{-2,-4,-5, \ldots,-19,-20\}$ with $n=8$

difference between the runtimes of the non-parametrics methods and that of $\mathbf{M}$. Gambini method remain. The Kruskal Wallis is 953 times faster than M. Gambini for $\alpha_{\mathrm{r}}=-2$.

In figure 3.25, left, it is noted that the average execution time of M. Gambini diminishes as the value of $\alpha_{r}$ increases. In figure 3.25, right, it is noted that T. Kruskal yield the smallest runtimes followed by the T. Mann-Whitney method. 

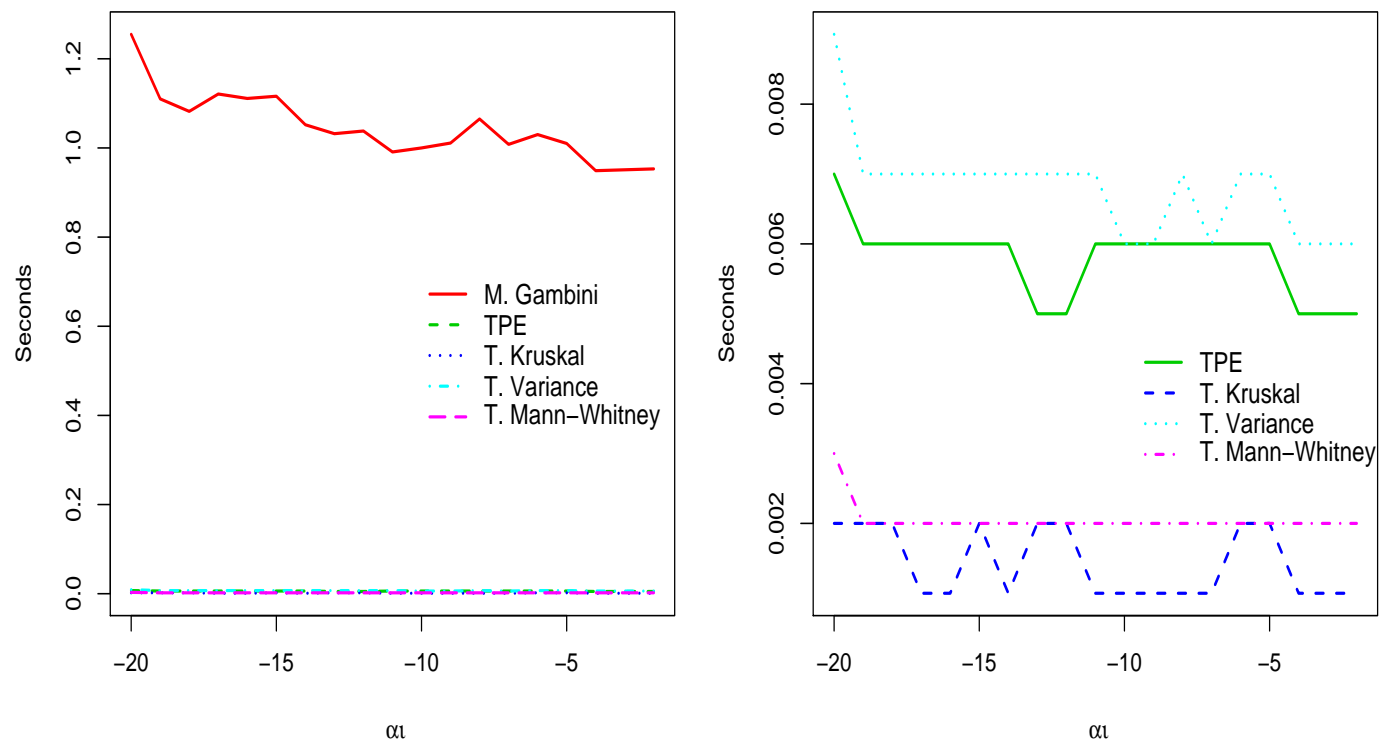

Figure 3.25: Average execution time in seconds for Gambini, Kruskal, MannWhitney, Variance and TPE, $\alpha_{\ell}=-3$ vs. $\alpha_{r} \in\{-2,-4,-5, \ldots,-19,-20\}$ with $\mathrm{n}=8$ 


\subsection{Heterogeneous areas with $n=8$ and $\alpha_{\ell}=-8$}

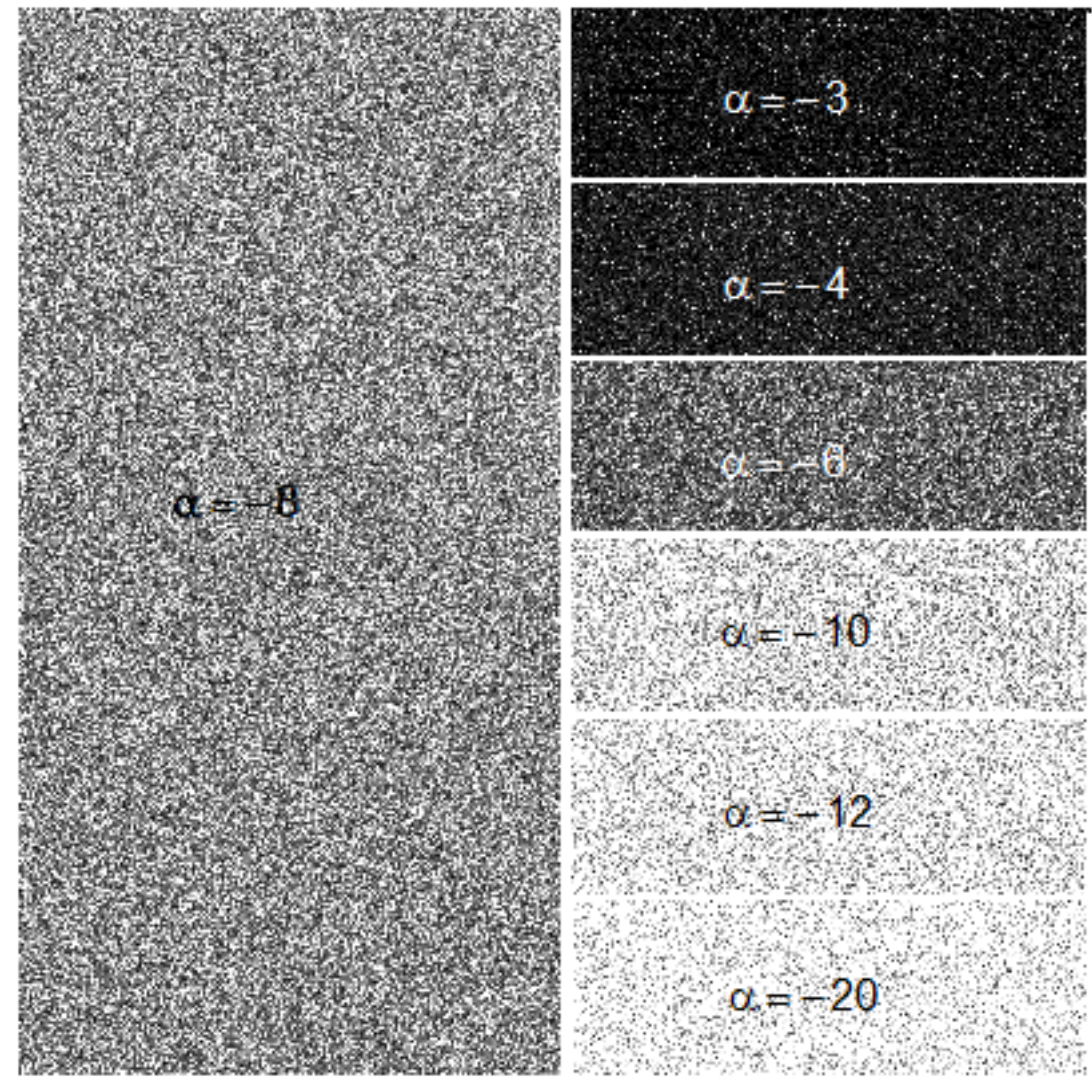

Figure 3.26: Synthetic images $\mathcal{G}_{\mathrm{I}}^{0}(\alpha, 1,8), \gamma=1$ and $\alpha_{\ell}=-8$ to the left against $\alpha_{r}=\{-3,-4,-6,-10,-12,-20\}$ to the right

Table 3.10 contains the error rate and average time for $\alpha_{\ell}=-8, n=8$ and different values of the $\alpha_{r}$. Note that T. Kruskal does not present errors in the detection of edges for any value of $\alpha_{r}$. M. Gambini and T. Mann-Whitney methods have the same behavior as T. Kruskal method except for $\alpha_{r}=-7$ where its percentage of error is $0.2 \%$ and $0.1 \%$ respectively. These three methods achieve the best results when $\alpha_{\ell}=-8$ and $n=8$.

TPE method reaches $66 \%$ of error when $\alpha_{r}=-7$ and 10,3\% when $\alpha_{r}=-9$, for the other values of $\alpha_{r}$ the percentage of error is zero. T. Variance method display high percentage of errors when $\alpha_{\ell}$ is close to $\alpha_{r}$. 


\begin{tabular}{|c|r|r|r|r|r|r|r|r|r|r|}
\hline & \multicolumn{2}{|c|}{ M. Gambini } & \multicolumn{2}{c|}{ TPE } & \multicolumn{2}{|c|}{ T. Kruskal } & \multicolumn{2}{|c|}{ T. Variance } & \multicolumn{2}{c|}{ T. M-Whitney } \\
\hline$\alpha_{r}$ & $\begin{array}{r}\text { Error } \\
\text { rate }\end{array}$ & Time & $\begin{array}{r}\text { Error } \\
\text { rate }\end{array}$ & Time & $\begin{array}{r}\text { Error } \\
\text { rate }\end{array}$ & Time & $\begin{array}{r}\text { Error } \\
\text { rate }\end{array}$ & $\begin{array}{r}\text { Time } \\
\text { rate }\end{array}$ & Time \\
\hline-20 & $0.00 \%$ & 1.145 & $0.00 \%$ & 0.006 & $0.00 \%$ & 0.001 & $0.00 \%$ & 0.007 & $0.00 \%$ & 0.002 \\
\hline-19 & $0.00 \%$ & 1.106 & $0.00 \%$ & 0.006 & $0.00 \%$ & 0.001 & $0.00 \%$ & 0.007 & $0.00 \%$ & 0.002 \\
\hline-18 & $0.00 \%$ & 1.485 & $0.00 \%$ & 0.008 & $0.00 \%$ & 0.002 & $0.00 \%$ & 0.010 & $0.00 \%$ & 0.003 \\
\hline-17 & $0.00 \%$ & 1.415 & $0.00 \%$ & 0.008 & $0.00 \%$ & 0.002 & $0.00 \%$ & 0.009 & $0.00 \%$ & 0.002 \\
\hline-16 & $0.00 \%$ & 1.215 & $0.00 \%$ & 0.006 & $0.00 \%$ & 0.002 & $0.00 \%$ & 0.007 & $0.00 \%$ & 0.002 \\
\hline-15 & $0.00 \%$ & 1.193 & $0.00 \%$ & 0.006 & $0.00 \%$ & 0.001 & $0.00 \%$ & 0.007 & $0.00 \%$ & 0.002 \\
\hline-14 & $0.00 \%$ & 1.279 & $0.00 \%$ & 0.006 & $0.00 \%$ & 0.002 & $0.00 \%$ & 0.008 & $0.00 \%$ & 0.002 \\
\hline-13 & $0.00 \%$ & 1.212 & $0.00 \%$ & 0.006 & $0.00 \%$ & 0.002 & $0.00 \%$ & 0.007 & $0.00 \%$ & 0.002 \\
\hline-12 & $0.00 \%$ & 1.211 & $0.00 \%$ & 0.006 & $0.00 \%$ & 0.002 & $0.10 \%$ & 0.008 & $0.00 \%$ & 0.002 \\
\hline-11 & $0.00 \%$ & 1.207 & $0.00 \%$ & 0.006 & $0.00 \%$ & 0.002 & $0.70 \%$ & 0.007 & $0.00 \%$ & 0.002 \\
\hline-10 & $0.00 \%$ & 1.121 & $0.00 \%$ & 0.006 & $0.00 \%$ & 0.001 & $4.40 \%$ & 0.007 & $0.00 \%$ & 0.002 \\
\hline-9 & $0.00 \%$ & 1.091 & $10.30 \%$ & 0.005 & $0.00 \%$ & 0.001 & $41.50 \%$ & 0.006 & $0.00 \%$ & 0.002 \\
\hline-7 & $0.20 \%$ & 1.160 & $66.50 \%$ & 0.006 & $0.00 \%$ & 0.001 & $58.00 \%$ & 0.007 & $0.10 \%$ & 0.002 \\
\hline-6 & $0.00 \%$ & 1.084 & $0.00 \%$ & 0.006 & $0.00 \%$ & 0.001 & $1.20 \%$ & 0.007 & $0.00 \%$ & 0.002 \\
\hline-5 & $0.00 \%$ & 1.026 & $0.00 \%$ & 0.005 & $0.00 \%$ & 0.002 & $0.00 \%$ & 0.007 & $0.00 \%$ & 0.002 \\
\hline-4 & $0.00 \%$ & 1.130 & $0.00 \%$ & 0.007 & $0.00 \%$ & 0.002 & $0.00 \%$ & 0.007 & $0.00 \%$ & 0.002 \\
\hline-3 & $0.00 \%$ & 0.998 & $0.00 \%$ & 0.006 & $0.00 \%$ & 0.001 & $0.00 \%$ & 0.007 & $0.00 \%$ & 0.002 \\
\hline-2 & $0.00 \%$ & 1.098 & $0.00 \%$ & 0.006 & $0.00 \%$ & 0.002 & $0.10 \%$ & 0.008 & $0.00 \%$ & 0.002 \\
\hline
\end{tabular}

Table 3.10: Error rate and average time for $\alpha_{\ell}=-8$ vs. $\alpha_{r} \in$ $\{-2,-4,-5, \ldots,-19,-20\}$ with $n=8$

Figure 3.27 compares the behavior of the percentages of error generated by the different methods under study. We observe that the largest percentages of error are generated by TPE and T. Variance.

Regarding runtime, the Table 3.10 shows that M. Gambini is the slowest method. T. Kruskal is approximately 550 times faster than M. Gambini for $\alpha_{r}=-2$ and 1145 times faster when $\alpha_{r}=-20$. Figure 3.28 corroborates the behavior of the times of M. Gambini. The execution times of non-parametric methods are smaller than 0.010 seconds, being T. Kruskal the fastest method, whose execution time does not exceed 0.02 second in any situation. 


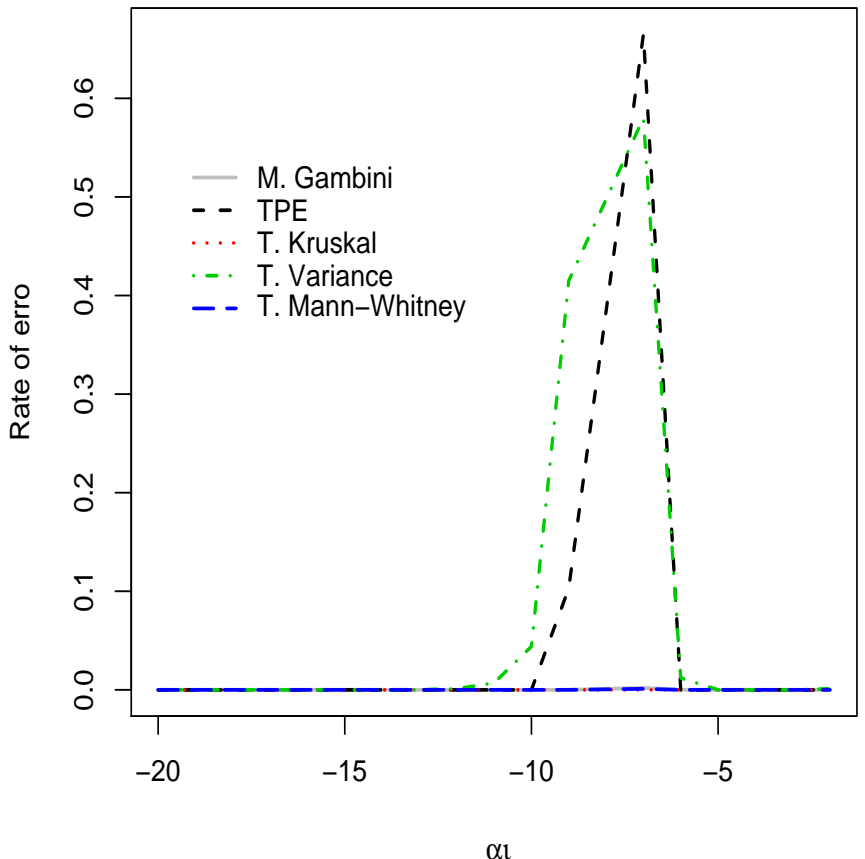

Figure 3.27: Error rate in edge detection for Gambini, Kruskal, Mann-Whitney, Variance and TPE, $\alpha_{\ell}=-8$ vs. $\alpha_{r} \in\{-2,-4,-5, \ldots,-19,-20\}$ with $n=8$
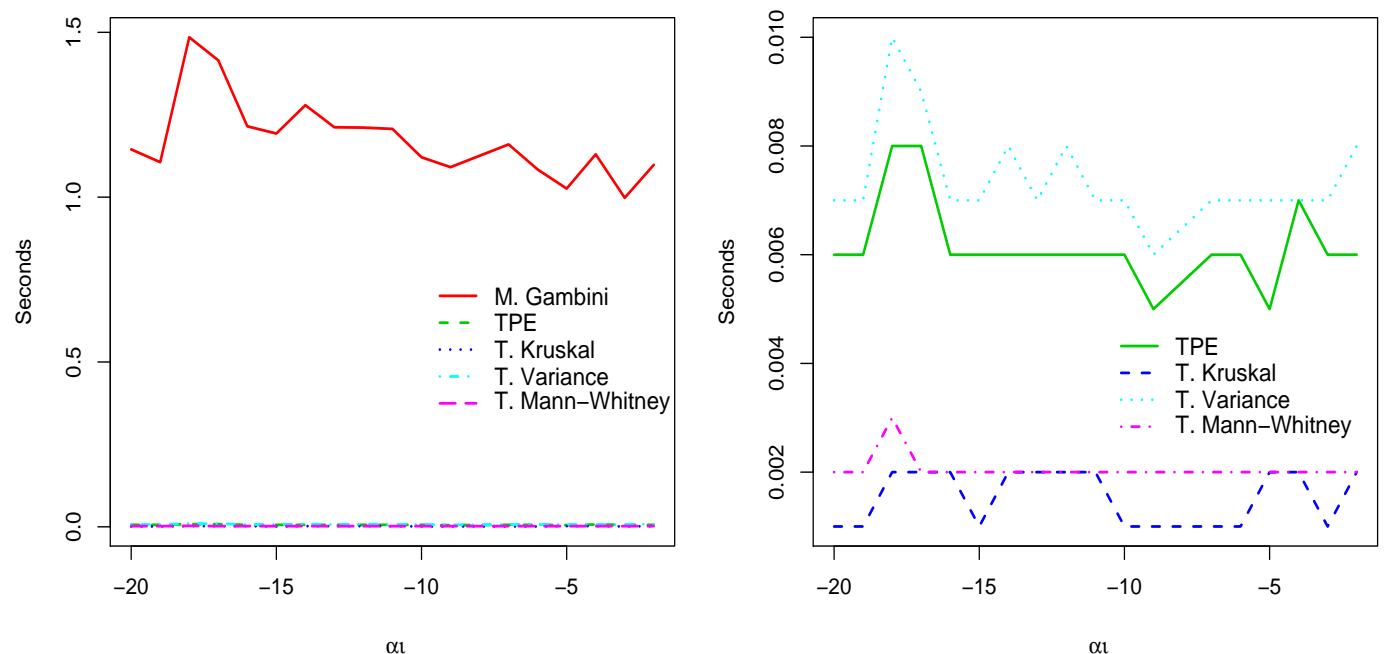

Figure 3.28: Average execution time in seconds for Gambini, Kruskal, MannWhitney, Variance and TPE, $\alpha_{\ell}=-8$ vs. $\alpha_{r} \in\{-2,-4,-5, \ldots,-19,-20\}$ with $n=8$ 


\subsection{Homogeneous areas with $n=8$ and $\alpha_{\ell}=-12$}

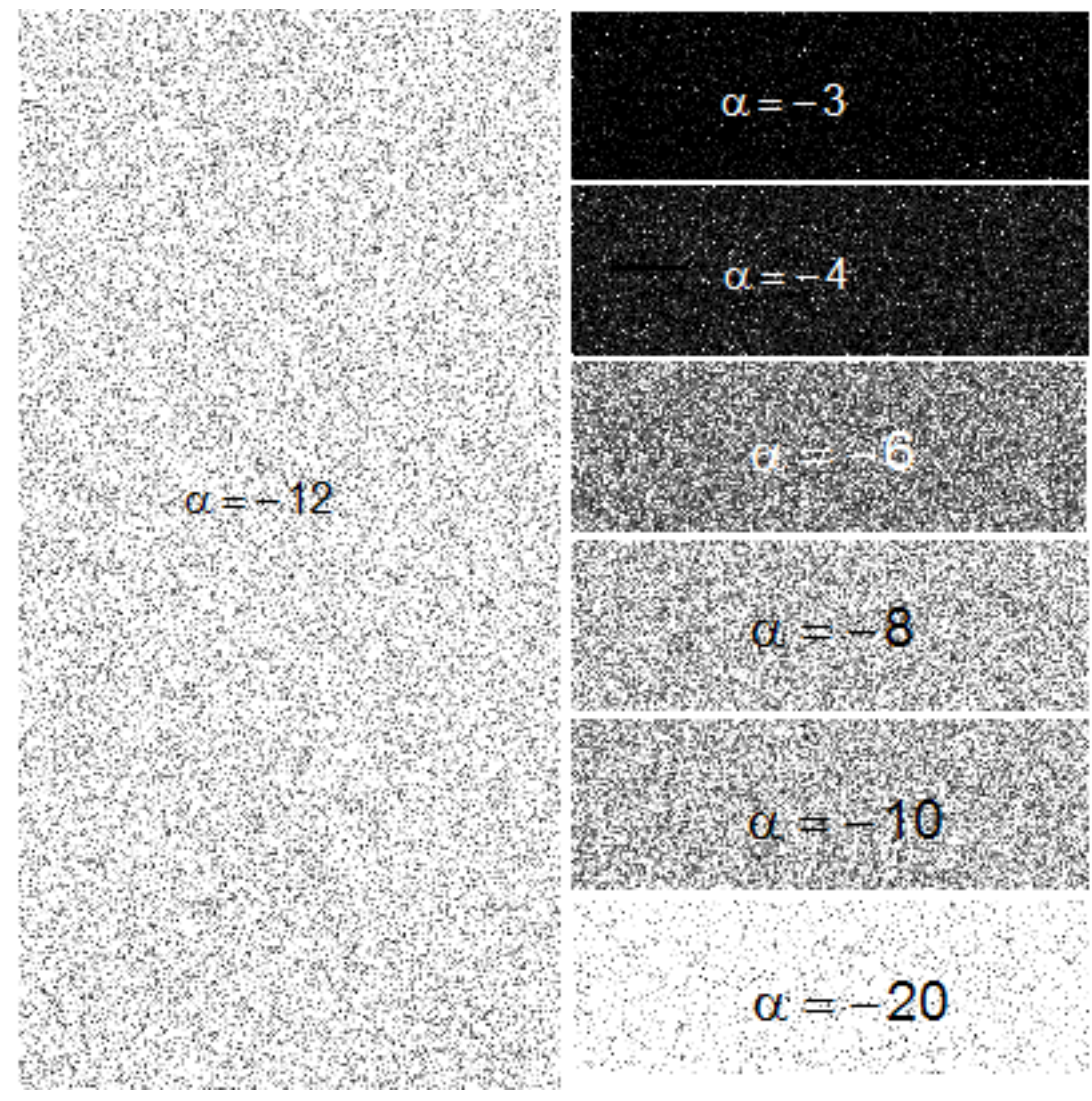

Figure 3.29: Synthetic images $\mathcal{G}_{\mathrm{I}}^{0}(\alpha, 1,8), \gamma=1$ and $\alpha_{\ell}=-12$ to the left against $\alpha_{r}=\{-3,-4,-6,-8,-10,-20\}$ to the right

Table 3.11 presents the error rates and average execution times achieved by the different methods in the simulation, with $n=8$ and $\alpha_{\ell}=-12$. We note that T. Variance obtains errors between $35.5 \%$ and $67.9 \%$ when $\alpha_{r}$ is between -14 and -9. TPE obtains errors between $17.7 \%$ and $37.3 \%$ when $\alpha_{\mathrm{r}}$ is between -13 and -10 . T. Mann-Whitney detects satisfactorily the edge when $\alpha_{\mathrm{r}} \leq-14$; it obtains $0.4 \%$ of error when $\alpha_{r}=-13$ and for $\alpha_{r} \geq-11$ it obtains $0 \%$ of error in edge detection. T. Kruskal and M. Gambini behave similarly, obtaining $0.4 \%$ and $0.3 \%$ errors, respectively, when $\alpha_{r}=-13$; the maximum error that these methods generate are $1.2 \%$ and $1.3 \%$ when $\alpha_{r}$ is equal to -11 . 


\begin{tabular}{|c|r|r|r|r|r|r|r|r|r|r|}
\hline & \multicolumn{2}{|c|}{ M. Gambini } & \multicolumn{2}{c|}{ TPE } & \multicolumn{2}{|c|}{ T. Kruskal } & \multicolumn{2}{|c|}{ T. Variance } & \multicolumn{2}{|c|}{ T. M-Whitney } \\
\hline$\alpha_{r}$ & $\begin{array}{r}\text { Error } \\
\text { rate }\end{array}$ & Time & $\begin{array}{r}\text { Error } \\
\text { rate }\end{array}$ & Time & $\begin{array}{r}\text { Error } \\
\text { rate }\end{array}$ & Time & $\begin{array}{r}\text { Error } \\
\text { rate }\end{array}$ & $\begin{array}{r}\text { Time } \\
\text { rate }\end{array}$ & Time \\
\hline-20 & $0.00 \%$ & 1.129 & $0.00 \%$ & 0.006 & $0.00 \%$ & 0.001 & $0.00 \%$ & 0.006 & $0.00 \%$ & 0.002 \\
\hline-19 & $0.00 \%$ & 1.159 & $0.00 \%$ & 0.006 & $0.00 \%$ & 0.002 & $0.00 \%$ & 0.007 & $0.00 \%$ & 0.002 \\
\hline-18 & $0.00 \%$ & 1.243 & $0.00 \%$ & 0.006 & $0.00 \%$ & 0.002 & $0.10 \%$ & 0.007 & $0.00 \%$ & 0.002 \\
\hline-17 & $0.00 \%$ & 1.344 & $0.00 \%$ & 0.006 & $0.00 \%$ & 0.002 & $0.00 \%$ & 0.008 & $0.00 \%$ & 0.002 \\
\hline-16 & $0.00 \%$ & 1.376 & $0.00 \%$ & 0.006 & $0.00 \%$ & 0.002 & $0.20 \%$ & 0.008 & $0.00 \%$ & 0.002 \\
\hline-15 & $0.00 \%$ & 1.301 & $0.00 \%$ & 0.006 & $0.00 \%$ & 0.002 & $0.50 \%$ & 0.008 & $0.00 \%$ & 0.002 \\
\hline-14 & $0.00 \%$ & 1.318 & $0.00 \%$ & 0.006 & $0.00 \%$ & 0.001 & $35.50 \%$ & 0.008 & $0.00 \%$ & 0.002 \\
\hline-13 & $0.30 \%$ & 1.303 & $37.30 \%$ & 0.006 & $0.40 \%$ & 0.001 & $47.10 \%$ & 0.007 & $0.40 \%$ & 0.002 \\
\hline-11 & $1.20 \%$ & 1.326 & $11.70 \%$ & 0.007 & $1.30 \%$ & 0.002 & $67.90 \%$ & 0.008 & $1.30 \%$ & 0.002 \\
\hline-10 & $0.00 \%$ & 1.254 & $17.70 \%$ & 0.006 & $0.00 \%$ & 0.002 & $5.90 \%$ & 0.007 & $0.00 \%$ & 0.002 \\
\hline-9 & $0.00 \%$ & 1.214 & $0.00 \%$ & 0.006 & $0.00 \%$ & 0.002 & $0.60 \%$ & 0.007 & $0.00 \%$ & 0.002 \\
\hline-8 & $0.00 \%$ & 1.161 & $0.00 \%$ & 0.006 & $0.00 \%$ & 0.001 & $0.00 \%$ & 0.007 & $0.00 \%$ & 0.002 \\
\hline-7 & $0.00 \%$ & 1.242 & $0.00 \%$ & 0.006 & $0.00 \%$ & 0.002 & $0.00 \%$ & 0.008 & $0.00 \%$ & 0.002 \\
\hline-6 & $0.00 \%$ & 1.262 & $0.00 \%$ & 0.007 & $0.00 \%$ & 0.001 & $0.00 \%$ & 0.008 & $0.00 \%$ & 0.002 \\
\hline-5 & $0.00 \%$ & 1.310 & $0.00 \%$ & 0.008 & $0.00 \%$ & 0.002 & $0.00 \%$ & 0.010 & $0.00 \%$ & 0.003 \\
\hline-4 & $0.00 \%$ & 1.388 & $0.00 \%$ & 0.008 & $0.00 \%$ & 0.002 & $0.00 \%$ & 0.011 & $0.00 \%$ & 0.003 \\
\hline-3 & $0.00 \%$ & 1.324 & $0.00 \%$ & 0.008 & $0.00 \%$ & 0.002 & $0.00 \%$ & 0.010 & $0.00 \%$ & 0.003 \\
\hline-2 & $0.00 \%$ & 1.253 & $0.00 \%$ & 0.007 & $0.00 \%$ & 0.002 & $0.00 \%$ & 0.009 & $0.00 \%$ & 0.002 \\
\hline
\end{tabular}

Table 3.11: Error rate and average time for $\alpha_{\ell}=-12$ vs. $\alpha_{\mathrm{r}} \in$ $\{-2,-4,-5, \ldots,-19,-20\}$ with $n=8$

Figure 3.30 shows that M. Gambini, T. Kruskal and T. Mann-Whitney have the same behavior and widely surpass the performance of the other methods.

Table 3.11 shows that the execution time in seconds required by M. Gambini is approximately 1000 times slower than the one required by any of the rank-based methods; this feature is also shown in the graph on the left of figure 3.31. In the graphic to the right, we compare the runtimes of the non-parametrics methods. We note that T. Kruskal and T. Mann-Whitney are the fastest methods. Therefore, T. Kruskal achieves the smallest errors in the detection of edges with the smallest computing time. 


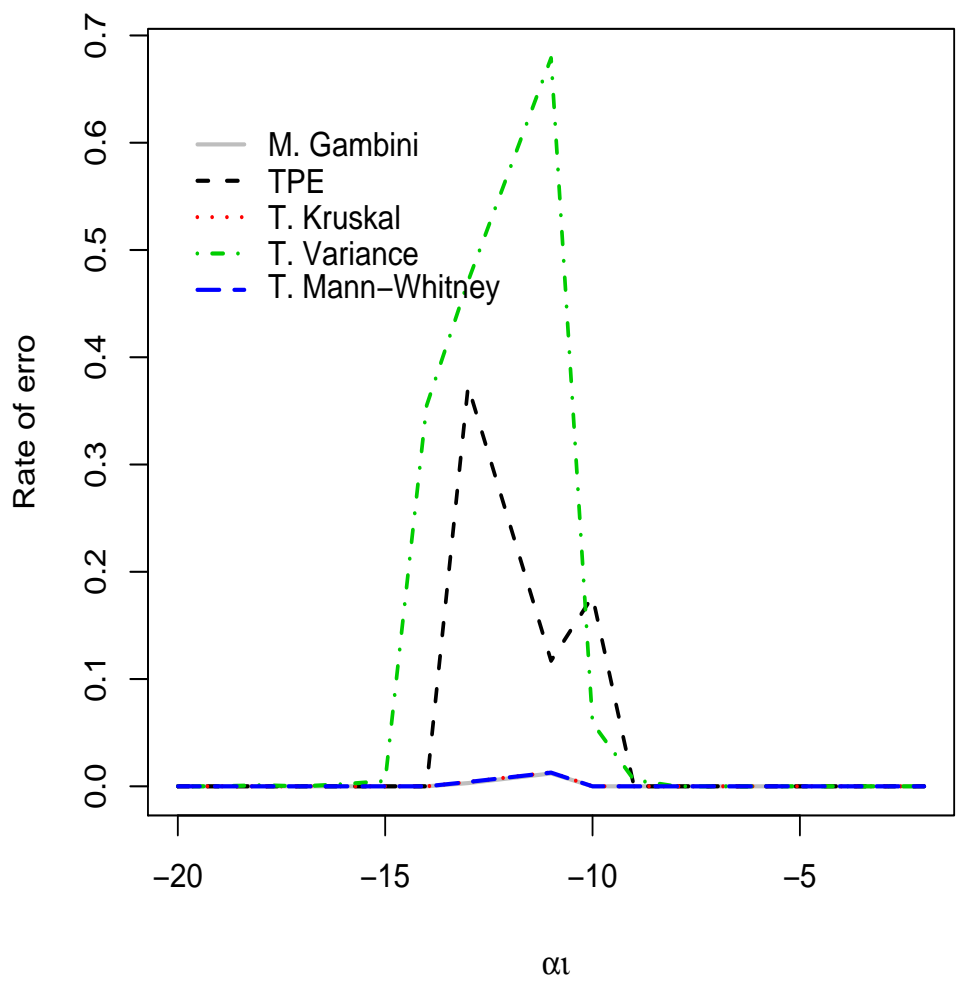

Figure 3.30: Error rate in detection of edge for Gambini, Kruskal, Mann-Whitney, Variance and TPE, $\alpha_{\ell}=-12$ vs. $\alpha_{r} \in\{-2,-4,-5, \ldots,-19,-20\}$ with $n=8$
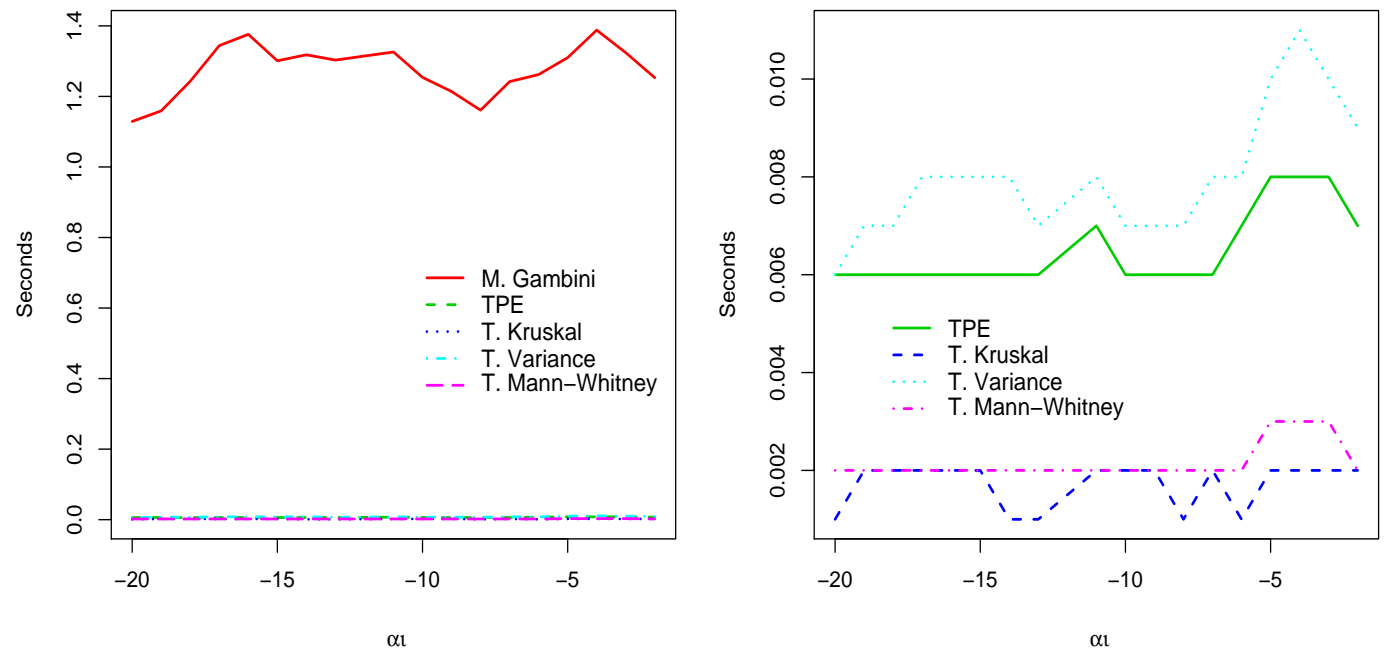

Figure 3.31: Average execution time in seconds for Gambini, Kruskal, MannWhitney, Variance and TPE, $\alpha_{\ell}=-12$ vs. $\alpha_{r} \in\{-2,-4,-5, \ldots,-19,-20\}$ with $\mathrm{n}=8$ 


\subsection{Homogeneous areas with $n=8 \alpha_{\ell}=-18$}

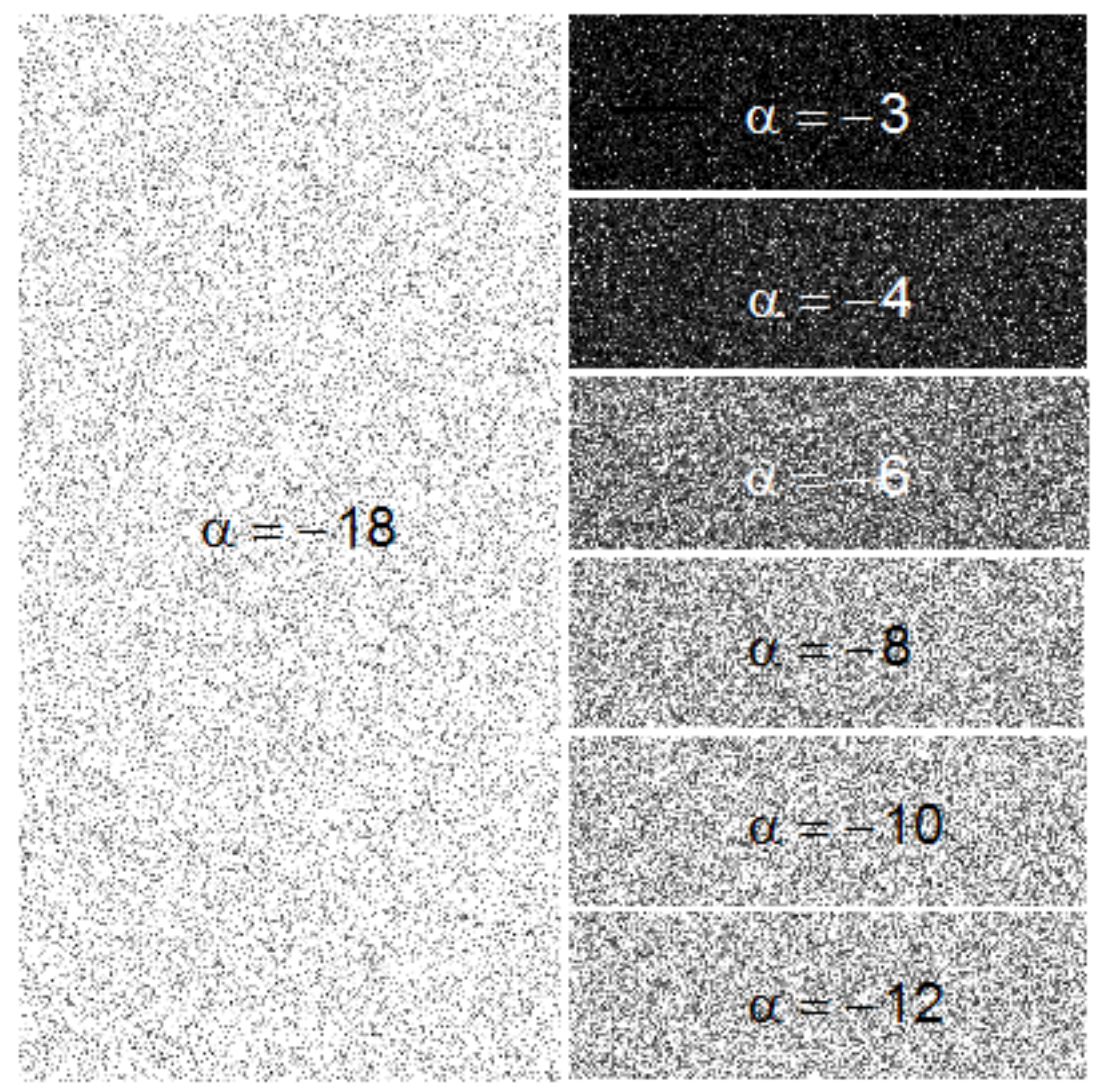

Figure 3.32: Synthetic images $\mathcal{G}_{\mathrm{I}}^{0}(\alpha, 1,8), \gamma=1$ and $\alpha_{\ell}=-18$ to the left against $\alpha_{r}=\{-3,-4,-6,-8,-10,-20\}$ to the right

Figure 3.32 depicts a typical sample of the situation considered in this section.

Table 3.12 presents the errors of the different methods, with $n=8$ and $\alpha_{\ell}=$ -18 , it can be seen that the percentages error of T. Variance exceeds $11 \%$ when $\alpha_{r}<-15$, while TPE obtains errors of $38.3 \%, 34 \%$ and $64 \%$ when $\alpha_{r}$ takes values $-17,-19$ and -20 , respectively. T. Mann-Whitney obtains $0 \%$ of error for $\alpha_{\mathrm{r}}=$ $-20,3.4 \%$ when $\alpha_{r}=-19$ and $0.30 \%$ for $\alpha_{r}=-16$; for $\alpha_{r} \geq-15$, it obtains $0 \%$ of error. T. Kruskal and M. Gambini behave similarly, obtaining errors of $3.1 \%$ and $3.4 \%$, respectively, when $\alpha_{r}=-19$; for $\alpha_{r}>-15$, these two methods always find the edge and, thus, obtain $0 \%$ of error. 


\begin{tabular}{|c|r|r|r|r|r|r|r|r|r|r|}
\hline & \multicolumn{2}{|c|}{ M. Gambini } & \multicolumn{2}{c|}{ TPE } & \multicolumn{2}{c|}{ T. Kruskal } & \multicolumn{2}{|c|}{ T. Variance } & \multicolumn{2}{|c|}{ T. M-Whitney } \\
\hline$\alpha_{r}$ & $\begin{array}{r}\text { Error } \\
\text { rate }\end{array}$ & Time & $\begin{array}{r}\text { Error } \\
\text { rate }\end{array}$ & Time & $\begin{array}{r}\text { Error } \\
\text { rate }\end{array}$ & Time & $\begin{array}{r}\text { Error } \\
\text { rate }\end{array}$ & $\begin{array}{r}\text { Time } \\
\text { rate }\end{array}$ & Time \\
\hline-20 & $0.00 \%$ & 1.427 & $63.70 \%$ & 0.006 & $0.00 \%$ & 0.002 & $60.40 \%$ & 0.008 & $0.00 \%$ & 0.002 \\
\hline-19 & $3.10 \%$ & 1.478 & $34.90 \%$ & 0.007 & $3.40 \%$ & 0.002 & $43.70 \%$ & 0.008 & $3.40 \%$ & 0.002 \\
\hline-17 & $1.70 \%$ & 1.423 & $38.30 \%$ & 0.007 & $1.50 \%$ & 0.001 & $66.40 \%$ & 0.008 & $1.60 \%$ & 0.002 \\
\hline-16 & $0.20 \%$ & 1.573 & $1.90 \%$ & 0.007 & $0.30 \%$ & 0.002 & $69.60 \%$ & 0.008 & $0.30 \%$ & 0.002 \\
\hline-15 & $0.00 \%$ & 1.387 & $0.10 \%$ & 0.006 & $0.00 \%$ & 0.002 & $11.50 \%$ & 0.007 & $0.00 \%$ & 0.002 \\
\hline-14 & $0.00 \%$ & 1.326 & $0.00 \%$ & 0.006 & $0.00 \%$ & 0.002 & $0.50 \%$ & 0.007 & $0.00 \%$ & 0.002 \\
\hline-13 & $0.00 \%$ & 1.400 & $0.00 \%$ & 0.006 & $0.00 \%$ & 0.002 & $0.00 \%$ & 0.008 & $0.00 \%$ & 0.002 \\
\hline-12 & $0.00 \%$ & 1.442 & $0.00 \%$ & 0.008 & $0.00 \%$ & 0.002 & $0.00 \%$ & 0.009 & $0.00 \%$ & 0.002 \\
\hline-11 & $0.00 \%$ & 1.488 & $0.00 \%$ & 0.008 & $0.00 \%$ & 0.002 & $0.00 \%$ & 0.010 & $0.00 \%$ & 0.003 \\
\hline-10 & $0.00 \%$ & 1.574 & $0.00 \%$ & 0.009 & $0.00 \%$ & 0.002 & $0.00 \%$ & 0.010 & $0.00 \%$ & 0.003 \\
\hline-9 & $0.00 \%$ & 1.455 & $0.00 \%$ & 0.008 & $0.00 \%$ & 0.002 & $0.00 \%$ & 0.010 & $0.00 \%$ & 0.003 \\
\hline-8 & $0.00 \%$ & 1.405 & $0.00 \%$ & 0.007 & $0.00 \%$ & 0.002 & $0.00 \%$ & 0.009 & $0.00 \%$ & 0.003 \\
\hline-7 & $0.00 \%$ & 1.278 & $0.00 \%$ & 0.007 & $0.00 \%$ & 0.002 & $0.00 \%$ & 0.008 & $0.00 \%$ & 0.003 \\
\hline-6 & $0.00 \%$ & 1.046 & $0.00 \%$ & 0.005 & $0.00 \%$ & 0.001 & $0.00 \%$ & 0.006 & $0.00 \%$ & 0.002 \\
\hline-5 & $0.00 \%$ & 0.989 & $0.00 \%$ & 0.005 & $0.00 \%$ & 0.001 & $0.00 \%$ & 0.006 & $0.00 \%$ & 0.002 \\
\hline-4 & $0.00 \%$ & 1.025 & $0.00 \%$ & 0.005 & $0.00 \%$ & 0.001 & $0.00 \%$ & 0.006 & $0.00 \%$ & 0.002 \\
\hline-3 & $0.00 \%$ & 0.976 & $0.00 \%$ & 0.005 & $0.00 \%$ & 0.001 & $0.00 \%$ & 0.006 & $0.00 \%$ & 0.002 \\
\hline-2 & $0.00 \%$ & 0.970 & $0.00 \%$ & 0.005 & $0.00 \%$ & 0.001 & $0.00 \%$ & 0.006 & $0.00 \%$ & 0.002 \\
\hline
\end{tabular}

Table 3.12: Error rate and average time for, $\alpha_{\ell}=-18$ vs. $\alpha_{\mathrm{r}} \in$ $\{-2,-4,-5, \ldots,-19,-20\}$ with $n=8$

Figure 3.33 suggests that the smaller errors and more stable performances are obtained by T. Kruskal, T. Mann-Whitney and M. Gambini.

Table 3.12 shows that M. Gambini continues to display the largest execution times; T. Kruskal is approximately 970 times faster than M. Gambini when $\alpha_{r}=$ -2 and 713 times faster when $\alpha_{r}=-20$. The execution times of $\mathbf{M}$. Gambini reduce as $\alpha_{r}$ increases, which can be seen in Figure 3.34. To the right of Figure 3.34, we compare the time in seconds required by the non-parametric methods, noting that T. Kruskal and T. Mann-Whitney require the smallest execution times. 


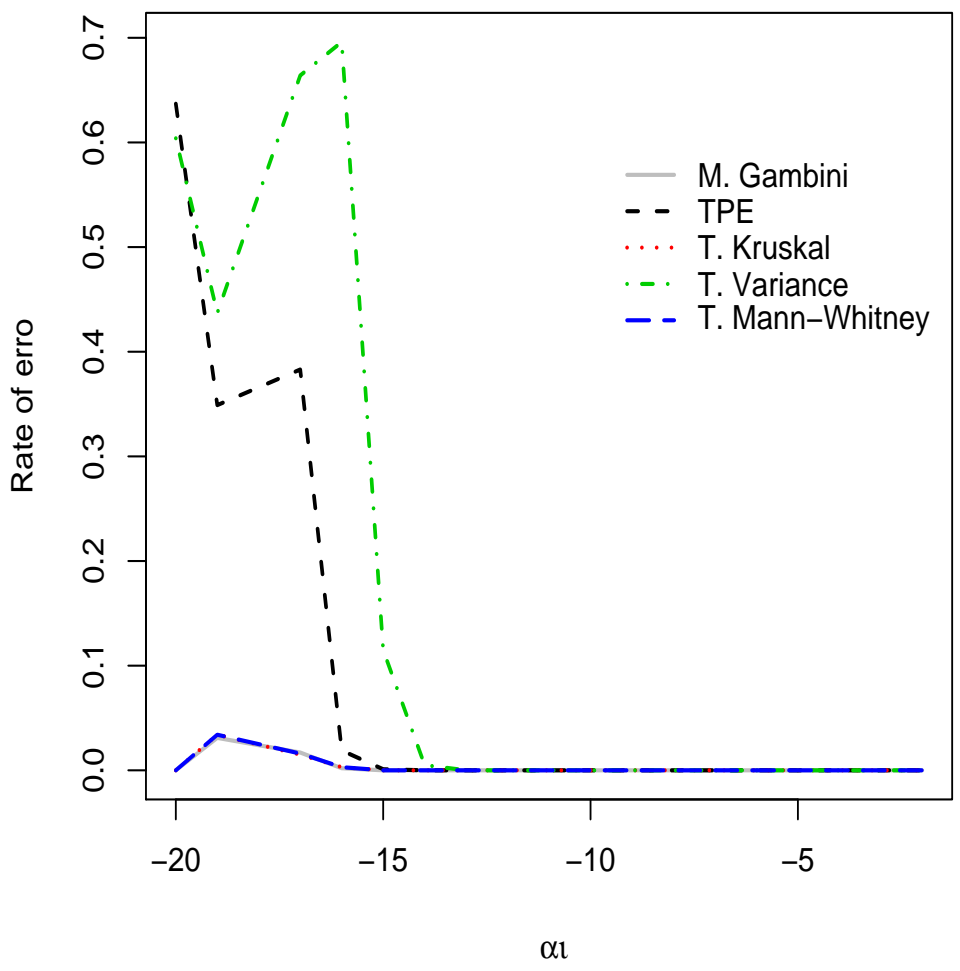

Figure 3.33: Error rate in detection of edge for Gambini, Kruskal, Mann-Whitney, Variance and TPE, $\alpha_{\ell}=-18$ vs. $\alpha_{r} \in\{-2,-4,-5, \ldots,-19,-20\}$ with $n=8$
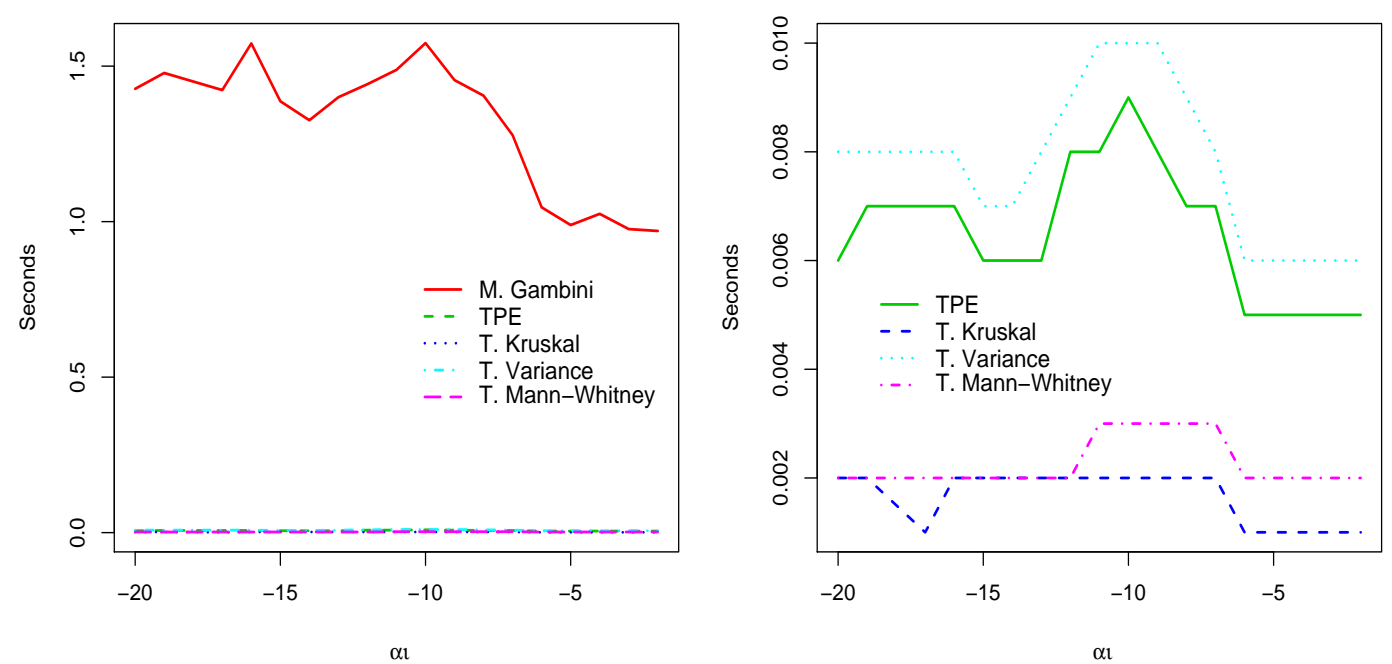

Figure 3.34: Average execution time in seconds for Gambini, Kruskal, MannWhitney, Variance and TPE, $\alpha_{\ell}=-18$ vs. $\alpha_{r} \in\{-2,-4,-5, \ldots,-19,-20\}$ with $\mathrm{n}=8$ 
This Chapter presented the Monte Carlo experience designed to assess the performance of five edge detection methods with respect to the error in finding an edge and to the execution time. Next Chapter will describe the conclusions. 


\section{Chapter 4}

\section{Conclusions}

\section{Resumo}

O objetivo deste trabalho foi estudar técnicas alternativas de detecção de bordas em imagens speckled, tendo como ponto de partida Gambini et al. $(2006,2008)$. O modelo utilizado para descrever os dados com ruído speckled é a distribuição $\mathcal{G}_{\mathrm{I}}^{0}$, a qual Mejail et al. $(2001,2003)$ mostra que pode ser usada como um modelo universal neste caso.

Os métodos sob avaliação buscam identificar a borda entre regiões com diferentes graus de rugosidade determinada por $\alpha$, o parâmetro de rugosidade da distribuição $\mathcal{G}_{\mathrm{I}}^{\mathcal{O}}(\alpha, \gamma, n)$.

Considerando os resultados obtidos através das simulações de Monte Carlo, podese concluir que o detector de T. Kruskal e o detector de T. Mann-Whitney são ligeiramente melhores do que M. Gambini. Comparados com os detectores TPE e T. Variance, T. Kruskal e T. Mann-Whitney fornecem os melhores resultados.

Todos os métodos sob estudo apresentam bom desempenho quando a borda separa áreas com rugosidade muito diferente. Quando a imagem gerada representa zonas homogêneas, as taxas de erro de todos os métodos são relativamente elevadas. No entanto, esse problema é atenuado com o aumento do número de looks $n$, que torna a detecção de bordas mais confiável. 
O detector T. Kruskal fornece os melhores resultados, tanto no que respeita ao erro como no que tange ao tempo de execução. Este último é, em muitos casos, 1000 vezes menor do que do M. Gambini.

Como conclusão final, em relação ao erro e ao tempo de execução, este trabalho fornece evidência de que a técnica de M. Gambini pode ser substituída com sucesso por T. Kruskal. O ganho reside em ter um algoritmo de até 1000 vezes mais rápido, sem comprometer a qualidade dos resultados. 


\section{Conclusions}

The aim of this thesis was to considerer alternative techniques for edge detection in speckled imagery, having as starting point the results in Gambini et al. (2006, 2008). The techniques here assessed do not try to eliminate speckle, but to extract information from its statistical properties. The model used to describe these data is the $\mathcal{G}_{\mathrm{I}}^{0}$ distribution, which, as shown by Mejail et al. $(2001,2003)$, can be used as an universal model.

The methods under assessment aim at identifying edges between regions with different degrees of roughness, which, in turn, is determined by $\alpha$, the roughness parameter of the $\mathcal{G}_{I}^{O}(\alpha, \gamma, n)$ distribution. Homogenous, e.g., pastures, heterogeneous regions, e.g., forests, and very heterogeneous regions, e.g., urban, targets are considered.

We describe a new edge detector based on the T. Kruskal test which proved to be an useful alternative to the approach of M. Gambini, which is based on the likelihood function of the data.

In order to make a comparison of the five methods, a Monte Carlo experiment was carried out, and two measures of quality were assessed: error in detecting an edge in a known position and execution time. Several situations were considered, namely, when the areas on each side of the edge have the same mean and the same number of looks differing only on the roughness.

From the experimental results it was observed that the T. Kruskal and T. MannWhitney detectors performed slightly better than M. Gambini. Compared with the TPE, T. Variance detectors, T. Kruskal and T. Mann-Whitney performed much better.

All methods under study perform well when the edge separates areas with very different roughnesses. When the generated image represents homogenous zones, the percentages of error of all methods are relatively high. Nevertheless, this problem is alleviated by the increase of the number of looks $n$, which causes the detection of edges to be more accurate. 
The T. Mann-Whitney and T. Kruskal detectors display the best results, both with respect to error and execution time. The latter is, in many cases, 1000 times smaller than M. Gambini.

The TPE method yields good results in the detection of edges when $\alpha_{\ell}$ differs from $\alpha_{r}$ by at least three units.

As a final conclusion, regarding the error and the execution time, we provide evidence that the M. Gambini technique can be successfully replaced by T. Kruskal. The latter can be up to 1000 times faster that the former. 


\section{Appendix A}

\section{Simulation results for $n=1$}

\begin{tabular}{|c|c|c|c|c|c|c|c|c|c|r|}
\hline \multicolumn{10}{|c|}{ TABLE 1. Error rate and average execution time for $\alpha_{\ell}=-3$} \\
\hline \hline & M. Gambini & \multicolumn{2}{|c|}{ TPE } & \multicolumn{2}{|c|}{ T. Kruskal } & \multicolumn{2}{|c|}{ T. Variance } & \multicolumn{2}{|c|}{ T. M-Whitney } \\
\hline$\alpha_{\mathrm{r}}$ & Error & Time & Error & Time & Error & Time & Error & Time & Error & Time \\
\hline-20 & $0.00 \%$ & 1.415 & $0.00 \%$ & 0.012 & $0.00 \%$ & 0.002 & $0.00 \%$ & 0.015 & $0.00 \%$ & 0.003 \\
\hline-19 & $0.00 \%$ & 1.401 & $0.00 \%$ & 0.012 & $0.00 \%$ & 0.002 & $0.00 \%$ & 0.015 & $0.00 \%$ & 0.003 \\
\hline-18 & $0.00 \%$ & 1.376 & $0.00 \%$ & 0.012 & $0.00 \%$ & 0.002 & $0.00 \%$ & 0.015 & $0.00 \%$ & 0.003 \\
\hline-17 & $0.00 \%$ & 1.362 & $0.00 \%$ & 0.012 & $0.00 \%$ & 0.002 & $0.00 \%$ & 0.015 & $0.00 \%$ & 0.003 \\
\hline-16 & $0.00 \%$ & 1.352 & $0.00 \%$ & 0.012 & $0.00 \%$ & 0.002 & $0.00 \%$ & 0.015 & $0.00 \%$ & 0.003 \\
\hline-15 & $0.00 \%$ & 1.338 & $0.00 \%$ & 0.012 & $0.00 \%$ & 0.002 & $0.00 \%$ & 0.015 & $0.00 \%$ & 0.003 \\
\hline-14 & $0.00 \%$ & 1.307 & $0.00 \%$ & 0.012 & $0.00 \%$ & 0.002 & $0.00 \%$ & 0.015 & $0.00 \%$ & 0.003 \\
\hline-13 & $0.00 \%$ & 1.287 & $0.00 \%$ & 0.012 & $0.00 \%$ & 0.002 & $0.00 \%$ & 0.015 & $0.00 \%$ & 0.003 \\
\hline-12 & $0.00 \%$ & 1.275 & $0.00 \%$ & 0.012 & $0.00 \%$ & 0.002 & $0.00 \%$ & 0.015 & $0.00 \%$ & 0.003 \\
\hline-11 & $0.00 \%$ & 1.257 & $0.00 \%$ & 0.012 & $0.00 \%$ & 0.002 & $0.00 \%$ & 0.015 & $0.00 \%$ & 0.003 \\
\hline-10 & $0.00 \%$ & 1.238 & $0.00 \%$ & 0.012 & $0.00 \%$ & 0.002 & $0.00 \%$ & 0.015 & $0.00 \%$ & 0.003 \\
\hline-9 & $0.00 \%$ & 1.221 & $0.00 \%$ & 0.012 & $0.00 \%$ & 0.002 & $0.00 \%$ & 0.015 & $0.00 \%$ & 0.003 \\
\hline-8 & $0.00 \%$ & 1.198 & $0.00 \%$ & 0.012 & $0.00 \%$ & 0.002 & $0.00 \%$ & 0.015 & $0.00 \%$ & 0.003 \\
\hline-7 & $0.00 \%$ & 1.189 & $0.10 \%$ & 0.012 & $0.00 \%$ & 0.002 & $0.00 \%$ & 0.015 & $0.00 \%$ & 0.003 \\
\hline-6 & $0.00 \%$ & 1.168 & $0.00 \%$ & 0.012 & $0.00 \%$ & 0.002 & $0.00 \%$ & 0.015 & $0.00 \%$ & 0.003 \\
\hline-5 & $0.00 \%$ & 1.158 & $0.40 \%$ & 0.012 & $0.00 \%$ & 0.002 & $0.60 \%$ & 0.015 & $0.00 \%$ & 0.003 \\
\hline-4 & $0.10 \%$ & 1.140 & $15.40 \%$ & 0.012 & $0.00 \%$ & 0.002 & $16.90 \%$ & 0.015 & $0.00 \%$ & 0.003 \\
\hline-2 & $0.00 \%$ & 1.101 & $2.80 \%$ & 0.012 & $0.00 \%$ & 0.002 & $9.30 \%$ & 0.015 & $0.00 \%$ & 0.003 \\
\hline
\end{tabular}




\begin{tabular}{|c|c|c|c|c|c|c|c|c|c|r|}
\hline \multicolumn{10}{|c|}{ TABLE 2. Error rates and average execution time for $\alpha_{\ell}=-4$} \\
\hline \hline & M. Gambini & \multicolumn{2}{|c|}{ TPE } & \multicolumn{2}{c|}{ T. Kruskal } & \multicolumn{2}{c|}{ T. Variance } & \multicolumn{2}{|c|}{ T. M-Whitney } \\
\hline$\alpha_{\mathrm{r}}$ & Error & Time & Error & Time & Error & Time & Error & Time & Error & Time \\
\hline-20 & $0.00 \%$ & 1.455 & $0.00 \%$ & 0.012 & $0.00 \%$ & 0.002 & $0.00 \%$ & 0.015 & $0.00 \%$ & 0.003 \\
\hline-19 & $0.00 \%$ & 1.423 & $0.00 \%$ & 0.012 & $0.00 \%$ & 0.002 & $0.00 \%$ & 0.015 & $0.00 \%$ & 0.003 \\
\hline-18 & $0.00 \%$ & 1.412 & $0.00 \%$ & 0.012 & $0.00 \%$ & 0.002 & $0.00 \%$ & 0.015 & $0.00 \%$ & 0.003 \\
\hline-17 & $0.00 \%$ & 1.379 & $0.00 \%$ & 0.012 & $0.00 \%$ & 0.002 & $0.00 \%$ & 0.015 & $0.00 \%$ & 0.003 \\
\hline-16 & $0.00 \%$ & 1.349 & $0.00 \%$ & 0.012 & $0.00 \%$ & 0.002 & $0.00 \%$ & 0.015 & $0.00 \%$ & 0.003 \\
\hline-15 & $0.00 \%$ & 1.357 & $0.00 \%$ & 0.012 & $0.00 \%$ & 0.002 & $0.00 \%$ & 0.015 & $0.00 \%$ & 0.003 \\
\hline-14 & $0.00 \%$ & 1.322 & $0.00 \%$ & 0.012 & $0.00 \%$ & 0.002 & $0.00 \%$ & 0.015 & $0.00 \%$ & 0.003 \\
\hline-13 & $0.00 \%$ & 1.313 & $0.00 \%$ & 0.012 & $0.00 \%$ & 0.002 & $0.00 \%$ & 0.015 & $0.00 \%$ & 0.003 \\
\hline-12 & $0.00 \%$ & 1.288 & $0.00 \%$ & 0.012 & $0.00 \%$ & 0.002 & $0.00 \%$ & 0.015 & $0.00 \%$ & 0.003 \\
\hline-11 & $0.00 \%$ & 1.277 & $0.00 \%$ & 0.012 & $0.00 \%$ & 0.002 & $0.00 \%$ & 0.015 & $0.00 \%$ & 0.003 \\
\hline-10 & $0.00 \%$ & 1.258 & $0.00 \%$ & 0.012 & $0.00 \%$ & 0.002 & $0.00 \%$ & 0.015 & $0.00 \%$ & 0.003 \\
\hline-9 & $0.00 \%$ & 1.246 & $0.00 \%$ & 0.012 & $0.00 \%$ & 0.002 & $0.00 \%$ & 0.015 & $0.00 \%$ & 0.003 \\
\hline-8 & $0.00 \%$ & 1.233 & $0.10 \%$ & 0.012 & $0.00 \%$ & 0.002 & $0.00 \%$ & 0.015 & $0.00 \%$ & 0.003 \\
\hline-7 & $0.00 \%$ & 1.222 & $0.80 \%$ & 0.012 & $0.00 \%$ & 0.002 & $0.00 \%$ & 0.015 & $0.00 \%$ & 0.003 \\
\hline-6 & $0.00 \%$ & 1.197 & $4.90 \%$ & 0.012 & $0.10 \%$ & 0.002 & $2.10 \%$ & 0.015 & $0.10 \%$ & 0.003 \\
\hline-5 & $0.70 \%$ & 1.176 & $36.20 \%$ & 0.012 & $1.90 \%$ & 0.002 & $29.10 \%$ & 0.015 & $1.90 \%$ & 0.003 \\
\hline-3 & $0.00 \%$ & 1.144 & $18.60 \%$ & 0.012 & $0.10 \%$ & 0.002 & $14.90 \%$ & 0.015 & $0.10 \%$ & 0.003 \\
\hline-2 & $0.00 \%$ & 1.112 & $0.00 \%$ & 0.012 & $0.00 \%$ & 0.002 & $1.40 \%$ & 0.015 & $0.00 \%$ & 0.003 \\
\hline
\end{tabular}

\begin{tabular}{|c|c|c|c|c|c|c|c|c|c|r|}
\hline \multicolumn{10}{|c|}{ TABLE 3. Error rates and average execution time for $\alpha_{\ell}=-6$} \\
\hline \hline & M. Gambini & \multicolumn{2}{|c|}{ TPE } & \multicolumn{2}{|c|}{ T. Kruskal } & \multicolumn{2}{|c|}{ T. Variance } & \multicolumn{2}{|c|}{ T. M-Whitney } \\
\hline$\alpha_{\mathrm{r}}$ & Error & Time & Error & Time & Error & Time & Error & Time & Error & Time \\
\hline-20 & $0.00 \%$ & 1.483 & $0.00 \%$ & 0.012 & $0.00 \%$ & 0.002 & $0.00 \%$ & 0.015 & $0.00 \%$ & 0.003 \\
\hline-19 & $0.00 \%$ & 1.467 & $0.00 \%$ & 0.012 & $0.00 \%$ & 0.002 & $0.00 \%$ & 0.015 & $0.00 \%$ & 0.003 \\
\hline-18 & $0.00 \%$ & 1.464 & $0.00 \%$ & 0.012 & $0.00 \%$ & 0.002 & $0.00 \%$ & 0.015 & $0.00 \%$ & 0.003 \\
\hline-17 & $0.00 \%$ & 1.448 & $0.00 \%$ & 0.012 & $0.00 \%$ & 0.002 & $0.00 \%$ & 0.015 & $0.00 \%$ & 0.003 \\
\hline-16 & $0.00 \%$ & 1.429 & $0.00 \%$ & 0.012 & $0.00 \%$ & 0.002 & $0.00 \%$ & 0.014 & $0.00 \%$ & 0.003 \\
\hline-15 & $0.00 \%$ & 1.404 & $0.00 \%$ & 0.012 & $0.00 \%$ & 0.002 & $0.00 \%$ & 0.015 & $0.00 \%$ & 0.003 \\
\hline-14 & $0.00 \%$ & 1.402 & $0.00 \%$ & 0.012 & $0.00 \%$ & 0.002 & $0.00 \%$ & 0.015 & $0.00 \%$ & 0.003 \\
\hline-13 & $0.00 \%$ & 1.369 & $0.00 \%$ & 0.012 & $0.00 \%$ & 0.002 & $0.00 \%$ & 0.015 & $0.00 \%$ & 0.003 \\
\hline-12 & $0.00 \%$ & 1.360 & $0.00 \%$ & 0.012 & $0.00 \%$ & 0.002 & $0.00 \%$ & 0.015 & $0.00 \%$ & 0.003 \\
\hline-11 & $0.00 \%$ & 1.342 & $0.70 \%$ & 0.012 & $0.00 \%$ & 0.002 & $0.00 \%$ & 0.015 & $0.00 \%$ & 0.003 \\
\hline-10 & $0.00 \%$ & 1.318 & $1.40 \%$ & 0.012 & $0.00 \%$ & 0.002 & $0.10 \%$ & 0.015 & $0.00 \%$ & 0.003 \\
\hline-9 & $0.00 \%$ & 1.316 & $4.60 \%$ & 0.012 & $0.00 \%$ & 0.002 & $1.50 \%$ & 0.015 & $0.00 \%$ & 0.003 \\
\hline-8 & $0.10 \%$ & 1.293 & $18.90 \%$ & 0.012 & $0.20 \%$ & 0.002 & $12.50 \%$ & 0.015 & $0.20 \%$ & 0.003 \\
\hline-7 & $5.50 \%$ & 1.309 & $64.00 \%$ & 0.012 & $6.40 \%$ & 0.002 & $51.10 \%$ & 0.015 & $6.40 \%$ & 0.003 \\
\hline-5 & $2.70 \%$ & 1.238 & $51.10 \%$ & 0.012 & $3.20 \%$ & 0.002 & $39.80 \%$ & 0.015 & $3.20 \%$ & 0.003 \\
\hline-4 & $0.00 \%$ & 1.194 & $6.60 \%$ & 0.012 & $0.00 \%$ & 0.002 & $1.30 \%$ & 0.015 & $0.00 \%$ & 0.003 \\
\hline-3 & $0.00 \%$ & 1.172 & $0.20 \%$ & 0.012 & $0.00 \%$ & 0.002 & $0.00 \%$ & 0.015 & $0.00 \%$ & 0.003 \\
\hline-2 & $0.00 \%$ & 1.155 & $0.00 \%$ & 0.012 & $0.00 \%$ & 0.002 & $0.10 \%$ & 0.015 & $0.00 \%$ & 0.003 \\
\hline
\end{tabular}




\begin{tabular}{|c|c|c|c|c|c|c|c|c|r|r|}
\hline \multicolumn{1}{|c|}{ TABLE 4. Error rates and average execution time for $\alpha_{\ell}=-8$} \\
\hline \hline & M. Gambini & \multicolumn{2}{|c|}{ TPE } & \multicolumn{2}{c|}{ T. Kruskal } & \multicolumn{2}{|c|}{ T. Variance } & \multicolumn{2}{|c|}{ T. M-Whitney } \\
\hline$\alpha_{\mathrm{r}}$ & Error & Time & Error & Time & Error & Time & Error & Time & Error & Time \\
\hline-20 & $0.00 \%$ & 1.513 & $0.00 \%$ & 0.012 & $0.00 \%$ & 0.002 & $0.00 \%$ & 0.015 & $0.00 \%$ & 0.003 \\
\hline-19 & $0.00 \%$ & 1.519 & $0.00 \%$ & 0.012 & $0.00 \%$ & 0.002 & $0.00 \%$ & 0.015 & $0.00 \%$ & 0.003 \\
\hline-18 & $0.00 \%$ & 1.502 & $0.00 \%$ & 0.012 & $0.00 \%$ & 0.002 & $0.00 \%$ & 0.015 & $0.00 \%$ & 0.003 \\
\hline-17 & $0.00 \%$ & 1.469 & $0.00 \%$ & 0.012 & $0.00 \%$ & 0.002 & $0.00 \%$ & 0.015 & $0.00 \%$ & 0.003 \\
\hline-16 & $0.00 \%$ & 1.449 & $0.00 \%$ & 0.012 & $0.00 \%$ & 0.002 & $0.00 \%$ & 0.015 & $0.00 \%$ & 0.003 \\
\hline-15 & $0.00 \%$ & 1.440 & $0.20 \%$ & 0.012 & $0.00 \%$ & 0.002 & $0.00 \%$ & 0.015 & $0.00 \%$ & 0.003 \\
\hline-14 & $0.00 \%$ & 1.414 & $0.50 \%$ & 0.012 & $0.00 \%$ & 0.002 & $0.00 \%$ & 0.014 & $0.00 \%$ & 0.003 \\
\hline-13 & $0.00 \%$ & 1.419 & $2.70 \%$ & 0.012 & $0.00 \%$ & 0.002 & $0.20 \%$ & 0.015 & $0.00 \%$ & 0.003 \\
\hline-12 & $0.00 \%$ & 1.396 & $6.50 \%$ & 0.012 & $0.00 \%$ & 0.002 & $1.20 \%$ & 0.015 & $0.00 \%$ & 0.003 \\
\hline-11 & $0.10 \%$ & 1.385 & $14.20 \%$ & 0.012 & $0.20 \%$ & 0.002 & $6.20 \%$ & 0.015 & $0.20 \%$ & 0.003 \\
\hline-10 & $0.50 \%$ & 1.406 & $33.80 \%$ & 0.012 & $1.60 \%$ & 0.002 & $26.50 \%$ & 0.015 & $1.60 \%$ & 0.003 \\
\hline-9 & $16.20 \%$ & 1.389 & $81.00 \%$ & 0.012 & $22.40 \%$ & 0.002 & $64.50 \%$ & 0.015 & $22.40 \%$ & 0.003 \\
\hline-7 & $11.20 \%$ & 1.353 & $73.30 \%$ & 0.012 & $12.20 \%$ & 0.002 & $61.30 \%$ & 0.015 & $12.80 \%$ & 0.003 \\
\hline-6 & $0.00 \%$ & 1.292 & $21.60 \%$ & 0.012 & $0.50 \%$ & 0.002 & $11.40 \%$ & 0.015 & $0.50 \%$ & 0.003 \\
\hline-5 & $0.00 \%$ & 1.242 & $3.80 \%$ & 0.012 & $0.00 \%$ & 0.002 & $0.60 \%$ & 0.015 & $0.00 \%$ & 0.003 \\
\hline-4 & $0.00 \%$ & 1.214 & $0.10 \%$ & 0.012 & $0.00 \%$ & 0.002 & $0.00 \%$ & 0.015 & $0.00 \%$ & 0.003 \\
\hline-3 & $0.00 \%$ & 1.196 & $0.00 \%$ & 0.012 & $0.00 \%$ & 0.002 & $0.00 \%$ & 0.014 & $0.00 \%$ & 0.003 \\
\hline-2 & $0.00 \%$ & 1.175 & $0.00 \%$ & 0.012 & $0.00 \%$ & 0.002 & $0.10 \%$ & 0.015 & $0.00 \%$ & 0.003 \\
\hline
\end{tabular}

\begin{tabular}{|c|r|r|r|r|r|r|r|r|r|r|}
\hline \multicolumn{1}{|c|}{ TABLE 5. Error rates and average execution time for $\alpha_{\ell}=-10$} \\
\hline \hline & M. Gambini & \multicolumn{2}{|c|}{ TPE } & \multicolumn{2}{|c|}{ T. Kruskal } & \multicolumn{2}{|c|}{ T. Variance } & \multicolumn{2}{|c|}{ T. M-Whitney } \\
\hline$\alpha_{\mathrm{r}}$ & Error & Time & Error & Time & Error & Time & Error & Time & Error & Time \\
\hline-20 & $0.00 \%$ & 1.600 & $0.10 \%$ & 0.012 & $0.00 \%$ & 0.002 & $0.00 \%$ & 0.015 & $0.00 \%$ & 0.003 \\
\hline-19 & $0.00 \%$ & 1.561 & $0.50 \%$ & 0.012 & $0.00 \%$ & 0.002 & $0.00 \%$ & 0.015 & $0.00 \%$ & 0.003 \\
\hline-18 & $0.00 \%$ & 1.542 & $0.40 \%$ & 0.012 & $0.00 \%$ & 0.002 & $0.00 \%$ & 0.015 & $0.00 \%$ & 0.003 \\
\hline-17 & $0.00 \%$ & 1.526 & $0.80 \%$ & 0.012 & $0.00 \%$ & 0.002 & $0.10 \%$ & 0.015 & $0.00 \%$ & 0.003 \\
\hline-16 & $0.00 \%$ & 1.520 & $2.70 \%$ & 0.012 & $0.00 \%$ & 0.002 & $0.20 \%$ & 0.015 & $0.00 \%$ & 0.003 \\
\hline-15 & $0.00 \%$ & 1.512 & $6.90 \%$ & 0.012 & $0.00 \%$ & 0.002 & $2.00 \%$ & 0.015 & $0.00 \%$ & 0.003 \\
\hline-14 & $0.00 \%$ & 1.501 & $14.10 \%$ & 0.012 & $0.00 \%$ & 0.002 & $5.20 \%$ & 0.015 & $0.00 \%$ & 0.003 \\
\hline-13 & $0.30 \%$ & 1.524 & $28.30 \%$ & 0.012 & $0.40 \%$ & 0.002 & $15.00 \%$ & 0.015 & $0.40 \%$ & 0.003 \\
\hline-12 & $5.50 \%$ & 1.641 & $53.80 \%$ & 0.013 & $5.50 \%$ & 0.002 & $41.90 \%$ & 0.016 & $5.50 \%$ & 0.003 \\
\hline-11 & $32.30 \%$ & 1.491 & $87.90 \%$ & 0.012 & $30.20 \%$ & 0.002 & $71.30 \%$ & 0.014 & $30.20 \%$ & 0.003 \\
\hline-9 & $22.70 \%$ & 1.431 & $85.50 \%$ & 0.011 & $25.20 \%$ & 0.002 & $69.60 \%$ & 0.014 & $25.20 \%$ & 0.003 \\
\hline-8 & $0.60 \%$ & 1.390 & $38.70 \%$ & 0.012 & $1.80 \%$ & 0.002 & $27.00 \%$ & 0.014 & $1.90 \%$ & 0.003 \\
\hline-7 & $0.00 \%$ & 1.332 & $13.10 \%$ & 0.012 & $0.00 \%$ & 0.002 & $3.40 \%$ & 0.014 & $0.00 \%$ & 0.003 \\
\hline-6 & $0.00 \%$ & 1.304 & $2.80 \%$ & 0.012 & $0.00 \%$ & 0.002 & $0.10 \%$ & 0.014 & $0.00 \%$ & 0.003 \\
\hline-5 & $0.00 \%$ & 1.264 & $0.20 \%$ & 0.012 & $0.00 \%$ & 0.002 & $0.00 \%$ & 0.014 & $0.00 \%$ & 0.003 \\
\hline-4 & $0.00 \%$ & 1.242 & $0.00 \%$ & 0.012 & $0.00 \%$ & 0.002 & $0.00 \%$ & 0.014 & $0.00 \%$ & 0.002 \\
\hline-3 & $0.00 \%$ & 1.217 & $0.00 \%$ & 0.012 & $0.00 \%$ & 0.002 & $0.00 \%$ & 0.015 & $0.00 \%$ & 0.003 \\
\hline-2 & $0.00 \%$ & 1.199 & $0.00 \%$ & 0.012 & $0.00 \%$ & 0.002 & $0.10 \%$ & 0.014 & $0.00 \%$ & 0.003 \\
\hline
\end{tabular}




\begin{tabular}{|c|r|r|r|r|r|r|r|r|r|r|}
\hline \multicolumn{1}{|c|}{ TABLE 6. Error rates and average execution time for $\alpha_{\ell}=-12$} \\
\hline \hline & M. Gambini & \multicolumn{2}{|c|}{ TPE } & \multicolumn{2}{c|}{ T. Kruskal } & \multicolumn{2}{|c|}{ T. Variance } & \multicolumn{2}{|c|}{ T. M-Whitney } \\
\hline$\alpha_{\mathrm{r}}$ & Error & Time & Error & Time & Error & Time & Error & Time & Error & Time \\
\hline-20 & $0.00 \%$ & 1.646 & $1.10 \%$ & 0.012 & $0.00 \%$ & 0.002 & $0.00 \%$ & 0.015 & $0.00 \%$ & 0.003 \\
\hline-19 & $0.00 \%$ & 1.640 & $3.00 \%$ & 0.012 & $0.00 \%$ & 0.002 & $0.20 \%$ & 0.015 & $0.00 \%$ & 0.003 \\
\hline-18 & $0.00 \%$ & 1.609 & $7.10 \%$ & 0.012 & $0.00 \%$ & 0.002 & $0.60 \%$ & 0.015 & $0.00 \%$ & 0.003 \\
\hline-17 & $0.00 \%$ & 1.612 & $13.50 \%$ & 0.012 & $0.20 \%$ & 0.002 & $4.40 \%$ & 0.015 & $0.20 \%$ & 0.003 \\
\hline-16 & $0.00 \%$ & 1.634 & $23.50 \%$ & 0.012 & $0.40 \%$ & 0.002 & $12.50 \%$ & 0.015 & $0.40 \%$ & 0.003 \\
\hline-15 & $0.80 \%$ & 1.608 & $39.00 \%$ & 0.012 & $1.60 \%$ & 0.002 & $27.70 \%$ & 0.015 & $1.60 \%$ & 0.003 \\
\hline-14 & $6.90 \%$ & 1.598 & $67.70 \%$ & 0.012 & $11.30 \%$ & 0.002 & $48.30 \%$ & 0.015 & $11.30 \%$ & 0.003 \\
\hline-13 & $40.30 \%$ & 1.622 & $92.50 \%$ & 0.012 & $45.90 \%$ & 0.002 & $75.90 \%$ & 0.015 & $45.40 \%$ & 0.003 \\
\hline-11 & $38.30 \%$ & 1.544 & $90.60 \%$ & 0.012 & $40.70 \%$ & 0.002 & $76.00 \%$ & 0.015 & $41.20 \%$ & 0.003 \\
\hline-10 & $3.20 \%$ & 1.512 & $53.90 \%$ & 0.012 & $5.80 \%$ & 0.002 & $45.10 \%$ & 0.015 & $5.80 \%$ & 0.003 \\
\hline-9 & $0.00 \%$ & 1.469 & $23.90 \%$ & 0.012 & $0.20 \%$ & 0.002 & $11.80 \%$ & 0.015 & $0.20 \%$ & 0.003 \\
\hline-8 & $0.00 \%$ & 1.399 & $9.00 \%$ & 0.012 & $0.00 \%$ & 0.002 & $1.30 \%$ & 0.014 & $0.00 \%$ & 0.003 \\
\hline-7 & $0.00 \%$ & 1.387 & $2.10 \%$ & 0.012 & $0.00 \%$ & 0.002 & $0.00 \%$ & 0.015 & $0.00 \%$ & 0.003 \\
\hline-6 & $0.00 \%$ & 1.343 & $0.20 \%$ & 0.012 & $0.00 \%$ & 0.002 & $0.00 \%$ & 0.015 & $0.00 \%$ & 0.003 \\
\hline-5 & $0.00 \%$ & 1.315 & $0.00 \%$ & 0.012 & $0.00 \%$ & 0.002 & $0.00 \%$ & 0.015 & $0.00 \%$ & 0.003 \\
\hline-4 & $0.00 \%$ & 1.281 & $0.00 \%$ & 0.012 & $0.00 \%$ & 0.002 & $0.00 \%$ & 0.015 & $0.00 \%$ & 0.003 \\
\hline-3 & $0.00 \%$ & 1.277 & $0.00 \%$ & 0.012 & $0.00 \%$ & 0.002 & $0.00 \%$ & 0.015 & $0.00 \%$ & 0.003 \\
\hline-2 & $0.00 \%$ & 1.252 & $0.00 \%$ & 0.012 & $0.00 \%$ & 0.002 & $0.00 \%$ & 0.015 & $0.00 \%$ & 0.003 \\
\hline
\end{tabular}

\begin{tabular}{|c|r|r|r|r|r|r|r|r|r|r|}
\hline \multicolumn{1}{|c|}{ TABLE 7. Error rates and average execution time for $\alpha_{\ell}=-14$} \\
\hline \hline & M. Gambini & \multicolumn{2}{|c|}{ TPE } & \multicolumn{2}{|c|}{ T. Kruskal } & \multicolumn{2}{|c|}{ T. Variance } & \multicolumn{2}{|c|}{ T. M-Whitney } \\
\hline$\alpha_{\mathrm{r}}$ & Error & Time & Error & Time & Error & Time & Error & Time & Error & Time \\
\hline-20 & $0.00 \%$ & 1.726 & $11.00 \%$ & 0.012 & $0.00 \%$ & 0.002 & $3.40 \%$ & 0.015 & $0.00 \%$ & 0.003 \\
\hline-19 & $0.00 \%$ & 1.747 & $17.30 \%$ & 0.012 & $0.40 \%$ & 0.002 & $7.20 \%$ & 0.015 & $0.40 \%$ & 0.003 \\
\hline-18 & $0.30 \%$ & 1.699 & $32.70 \%$ & 0.012 & $0.70 \%$ & 0.002 & $17.50 \%$ & 0.015 & $0.70 \%$ & 0.003 \\
\hline-17 & $2.50 \%$ & 1.721 & $52.50 \%$ & 0.012 & $4.80 \%$ & 0.002 & $35.60 \%$ & 0.015 & $4.80 \%$ & 0.003 \\
\hline-16 & $12.10 \%$ & 1.734 & $72.60 \%$ & 0.012 & $17.90 \%$ & 0.002 & $57.70 \%$ & 0.015 & $17.90 \%$ & 0.003 \\
\hline-15 & $50.20 \%$ & 1.774 & $94.90 \%$ & 0.012 & $52.90 \%$ & 0.002 & $78.60 \%$ & 0.015 & $54.10 \%$ & 0.003 \\
\hline-13 & $46.10 \%$ & 1.719 & $95.60 \%$ & 0.013 & $51.20 \%$ & 0.002 & $76.60 \%$ & 0.015 & $51.30 \%$ & 0.003 \\
\hline-12 & $5.80 \%$ & 1.613 & $67.40 \%$ & 0.012 & $6.40 \%$ & 0.002 & $52.40 \%$ & 0.015 & $6.40 \%$ & 0.003 \\
\hline-11 & $0.70 \%$ & 1.574 & $34.00 \%$ & 0.012 & $1.10 \%$ & 0.002 & $21.80 \%$ & 0.015 & $1.10 \%$ & 0.003 \\
\hline-10 & $0.00 \%$ & 1.512 & $15.30 \%$ & 0.012 & $0.10 \%$ & 0.002 & $3.50 \%$ & 0.015 & $0.10 \%$ & 0.003 \\
\hline-9 & $0.00 \%$ & 1.479 & $5.70 \%$ & 0.012 & $0.00 \%$ & 0.002 & $0.70 \%$ & 0.015 & $0.00 \%$ & 0.003 \\
\hline-8 & $0.00 \%$ & 1.443 & $1.00 \%$ & 0.012 & $0.00 \%$ & 0.002 & $0.00 \%$ & 0.015 & $0.00 \%$ & 0.003 \\
\hline-7 & $0.00 \%$ & 1.417 & $0.30 \%$ & 0.012 & $0.00 \%$ & 0.002 & $0.00 \%$ & 0.015 & $0.00 \%$ & 0.003 \\
\hline-6 & $0.00 \%$ & 1.387 & $0.10 \%$ & 0.012 & $0.00 \%$ & 0.002 & $0.00 \%$ & 0.015 & $0.00 \%$ & 0.003 \\
\hline-5 & $0.00 \%$ & 1.345 & $0.00 \%$ & 0.012 & $0.00 \%$ & 0.002 & $0.00 \%$ & 0.015 & $0.00 \%$ & 0.003 \\
\hline-4 & $0.00 \%$ & 1.340 & $0.00 \%$ & 0.012 & $0.00 \%$ & 0.002 & $0.00 \%$ & 0.015 & $0.00 \%$ & 0.003 \\
\hline-3 & $0.00 \%$ & 1.315 & $0.00 \%$ & 0.012 & $0.00 \%$ & 0.002 & $0.00 \%$ & 0.015 & $0.00 \%$ & 0.003 \\
\hline-2 & $0.00 \%$ & 1.302 & $0.00 \%$ & 0.012 & $0.00 \%$ & 0.002 & $0.00 \%$ & 0.015 & $0.00 \%$ & 0.003 \\
\hline
\end{tabular}




\begin{tabular}{|c|r|r|r|r|r|r|r|r|r|r|}
\hline \multicolumn{1}{|c|}{ TABLE 8. Error rates and average execution time for $\alpha_{\ell}=-16$} \\
\hline \hline & M. Gambini & \multicolumn{2}{|c|}{ TPE } & \multicolumn{2}{c|}{ T. Kruskal } & \multicolumn{2}{|c|}{ T. Variance } & \multicolumn{2}{|c|}{ T. M-Whitney } \\
\hline$\alpha_{\mathrm{r}}$ & Error & Time & Error & Time & Error & Time & Error & Time & Error & Time \\
\hline-20 & $0.80 \%$ & 1.811 & $37.50 \%$ & 0.012 & $1.30 \%$ & 0.002 & $27.90 \%$ & 0.015 & $1.30 \%$ & 0.003 \\
\hline-19 & $4.60 \%$ & 1.867 & $59.60 \%$ & 0.012 & $8.10 \%$ & 0.002 & $44.60 \%$ & 0.015 & $8.10 \%$ & 0.003 \\
\hline-18 & $18.00 \%$ & 1.844 & $81.80 \%$ & 0.012 & $20.80 \%$ & 0.003 & $66.40 \%$ & 0.015 & $20.80 \%$ & 0.003 \\
\hline-17 & $57.30 \%$ & 1.861 & $97.00 \%$ & 0.012 & $59.60 \%$ & 0.002 & $80.60 \%$ & 0.015 & $59.70 \%$ & 0.003 \\
\hline-15 & $55.30 \%$ & 1.819 & $96.50 \%$ & 0.012 & $57.40 \%$ & 0.002 & $78.40 \%$ & 0.015 & $57.60 \%$ & 0.003 \\
\hline-14 & $11.90 \%$ & 1.742 & $74.30 \%$ & 0.012 & $12.60 \%$ & 0.002 & $59.00 \%$ & 0.015 & $12.50 \%$ & 0.003 \\
\hline-13 & $1.40 \%$ & 1.656 & $43.30 \%$ & 0.012 & $2.20 \%$ & 0.002 & $33.60 \%$ & 0.015 & $2.20 \%$ & 0.003 \\
\hline-12 & $0.10 \%$ & 1.635 & $24.30 \%$ & 0.012 & $0.20 \%$ & 0.002 & $10.20 \%$ & 0.015 & $0.20 \%$ & 0.003 \\
\hline-11 & $0.00 \%$ & 1.589 & $12.10 \%$ & 0.012 & $0.00 \%$ & 0.002 & $1.70 \%$ & 0.015 & $0.00 \%$ & 0.003 \\
\hline-10 & $0.00 \%$ & 1.544 & $3.60 \%$ & 0.012 & $0.00 \%$ & 0.002 & $0.30 \%$ & 0.015 & $0.00 \%$ & 0.003 \\
\hline-9 & $0.00 \%$ & 1.513 & $1.60 \%$ & 0.012 & $0.00 \%$ & 0.002 & $0.00 \%$ & 0.015 & $0.00 \%$ & 0.003 \\
\hline-8 & $0.00 \%$ & 1.493 & $0.30 \%$ & 0.012 & $0.00 \%$ & 0.002 & $0.00 \%$ & 0.015 & $0.00 \%$ & 0.003 \\
\hline-7 & $0.00 \%$ & 1.457 & $0.10 \%$ & 0.012 & $0.00 \%$ & 0.002 & $0.00 \%$ & 0.015 & $0.00 \%$ & 0.003 \\
\hline-6 & $0.00 \%$ & 1.429 & $0.00 \%$ & 0.012 & $0.00 \%$ & 0.002 & $0.00 \%$ & 0.015 & $0.00 \%$ & 0.003 \\
\hline-5 & $0.00 \%$ & 1.406 & $0.00 \%$ & 0.012 & $0.00 \%$ & 0.002 & $0.00 \%$ & 0.015 & $0.00 \%$ & 0.003 \\
\hline-4 & $0.00 \%$ & 1.359 & $0.00 \%$ & 0.012 & $0.00 \%$ & 0.002 & $0.00 \%$ & 0.015 & $0.00 \%$ & 0.003 \\
\hline-3 & $0.00 \%$ & 1.352 & $0.00 \%$ & 0.012 & $0.00 \%$ & 0.002 & $0.00 \%$ & 0.015 & $0.00 \%$ & 0.003 \\
\hline-2 & $0.00 \%$ & 1.350 & $0.00 \%$ & 0.012 & $0.00 \%$ & 0.002 & $0.10 \%$ & 0.015 & $0.00 \%$ & 0.003 \\
\hline
\end{tabular}

\begin{tabular}{|c|r|r|r|r|r|r|r|r|r|r|}
\hline \multicolumn{1}{|c|}{ TABLE 9. Error rates and average execution time for $\alpha_{\ell}=-18$} \\
\hline \hline & M. Gambini & \multicolumn{2}{|c|}{ TPE } & \multicolumn{2}{|c|}{ T. Kruskal } & \multicolumn{2}{|c|}{ T. Variance } & \multicolumn{2}{|c|}{ T. M-Whitney } \\
\hline$\alpha_{\mathrm{r}}$ & Error & Time & Error & Time & Error & Time & Error & Time & Error & Time \\
\hline-20 & $23.80 \%$ & 1.995 & $84.40 \%$ & 0.012 & $24.20 \%$ & 0.002 & $67.50 \%$ & 0.015 & $24.20 \%$ & 0.003 \\
\hline-19 & $64.40 \%$ & 2.013 & $97.50 \%$ & 0.012 & $65.00 \%$ & 0.002 & $79.40 \%$ & 0.015 & $64.90 \%$ & 0.003 \\
\hline-17 & $62.70 \%$ & 1.893 & $98.00 \%$ & 0.012 & $63.60 \%$ & 0.002 & $79.60 \%$ & 0.015 & $63.80 \%$ & 0.003 \\
\hline-16 & $19.70 \%$ & 1.853 & $83.50 \%$ & 0.012 & $21.40 \%$ & 0.002 & $62.10 \%$ & 0.015 & $21.40 \%$ & 0.003 \\
\hline-15 & $2.60 \%$ & 1.777 & $56.30 \%$ & 0.012 & $4.00 \%$ & 0.002 & $39.40 \%$ & 0.015 & $4.10 \%$ & 0.003 \\
\hline-14 & $0.30 \%$ & 1.746 & $33.30 \%$ & 0.012 & $0.90 \%$ & 0.002 & $18.80 \%$ & 0.015 & $0.90 \%$ & 0.003 \\
\hline-13 & $0.00 \%$ & 1.669 & $17.50 \%$ & 0.012 & $0.00 \%$ & 0.002 & $4.10 \%$ & 0.015 & $0.00 \%$ & 0.003 \\
\hline-12 & $0.00 \%$ & 1.638 & $7.00 \%$ & 0.012 & $0.00 \%$ & 0.002 & $1.00 \%$ & 0.015 & $0.00 \%$ & 0.003 \\
\hline-11 & $0.00 \%$ & 1.600 & $2.70 \%$ & 0.012 & $0.00 \%$ & 0.002 & $0.20 \%$ & 0.015 & $0.00 \%$ & 0.003 \\
\hline-10 & $0.00 \%$ & 1.564 & $0.40 \%$ & 0.012 & $0.00 \%$ & 0.002 & $0.00 \%$ & 0.015 & $0.00 \%$ & 0.003 \\
\hline-9 & $0.00 \%$ & 1.538 & $0.50 \%$ & 0.012 & $0.00 \%$ & 0.002 & $0.00 \%$ & 0.015 & $0.00 \%$ & 0.003 \\
\hline-8 & $0.00 \%$ & 1.508 & $0.00 \%$ & 0.012 & $0.00 \%$ & 0.002 & $0.00 \%$ & 0.015 & $0.00 \%$ & 0.003 \\
\hline-7 & $0.00 \%$ & 1.495 & $0.00 \%$ & 0.012 & $0.00 \%$ & 0.002 & $0.00 \%$ & 0.015 & $0.00 \%$ & 0.003 \\
\hline-6 & $0.00 \%$ & 1.461 & $0.00 \%$ & 0.012 & $0.00 \%$ & 0.002 & $0.00 \%$ & 0.015 & $0.00 \%$ & 0.003 \\
\hline-5 & $0.00 \%$ & 1.436 & $0.00 \%$ & 0.012 & $0.00 \%$ & 0.002 & $0.00 \%$ & 0.015 & $0.00 \%$ & 0.003 \\
\hline-4 & $0.00 \%$ & 1.406 & $0.00 \%$ & 0.012 & $0.00 \%$ & 0.002 & $0.00 \%$ & 0.015 & $0.00 \%$ & 0.003 \\
\hline-3 & $0.00 \%$ & 1.404 & $0.00 \%$ & 0.012 & $0.00 \%$ & 0.002 & $0.00 \%$ & 0.015 & $0.00 \%$ & 0.003 \\
\hline-2 & $0.00 \%$ & 1.387 & $0.00 \%$ & 0.012 & $0.00 \%$ & 0.002 & $0.00 \%$ & 0.015 & $0.00 \%$ & 0.003 \\
\hline
\end{tabular}


TABLE 10. Error rates and average execution time for $\alpha_{\ell}=-20$

\begin{tabular}{|c|r|r|r|r|r|r|r|r|r|r|}
\hline \multicolumn{1}{|c|}{ TABLE 10. Error rates and average execution time for $\alpha_{\ell}=-20$} \\
\hline \hline & M. Gambini & \multicolumn{2}{|c|}{ TPE } & \multicolumn{2}{|c|}{ T. Kruskal } & \multicolumn{2}{|c|}{ T. Variance } & \multicolumn{2}{|c|}{ T. M-Whitney } \\
\hline$\alpha_{\mathrm{r}}$ & Error & Time & Error & Time & Error & Time & Error & Time & Error & Time \\
\hline-19 & $65.40 \%$ & 2.067 & $98.20 \%$ & 0.012 & $68.60 \%$ & 0.002 & $81.50 \%$ & 0.015 & $69.50 \%$ & 0.003 \\
\hline-18 & $25.70 \%$ & 1.964 & $86.70 \%$ & 0.012 & $28.80 \%$ & 0.002 & $68.30 \%$ & 0.015 & $29.10 \%$ & 0.003 \\
\hline-17 & $6.10 \%$ & 1.883 & $63.20 \%$ & 0.012 & $8.30 \%$ & 0.002 & $48.00 \%$ & 0.015 & $8.10 \%$ & 0.003 \\
\hline-16 & $1.50 \%$ & 1.837 & $42.80 \%$ & 0.012 & $2.70 \%$ & 0.002 & $27.80 \%$ & 0.015 & $2.70 \%$ & 0.003 \\
\hline-15 & $0.20 \%$ & 1.769 & $21.70 \%$ & 0.012 & $0.80 \%$ & 0.002 & $12.30 \%$ & 0.015 & $0.80 \%$ & 0.003 \\
\hline-14 & $0.00 \%$ & 1.773 & $12.50 \%$ & 0.013 & $0.00 \%$ & 0.002 & $2.90 \%$ & 0.015 & $0.00 \%$ & 0.003 \\
\hline-13 & $0.00 \%$ & 1.731 & $5.60 \%$ & 0.013 & $0.00 \%$ & 0.002 & $1.20 \%$ & 0.015 & $0.00 \%$ & 0.003 \\
\hline-12 & $0.00 \%$ & 1.725 & $3.80 \%$ & 0.013 & $0.00 \%$ & 0.002 & $0.00 \%$ & 0.015 & $0.00 \%$ & 0.003 \\
\hline-11 & $0.00 \%$ & 1.649 & $1.40 \%$ & 0.013 & $0.00 \%$ & 0.002 & $0.00 \%$ & 0.015 & $0.00 \%$ & 0.003 \\
\hline-10 & $0.00 \%$ & 1.595 & $0.10 \%$ & 0.012 & $0.00 \%$ & 0.002 & $0.00 \%$ & 0.015 & $0.00 \%$ & 0.003 \\
\hline-9 & $0.00 \%$ & 1.563 & $0.00 \%$ & 0.013 & $0.00 \%$ & 0.002 & $0.00 \%$ & 0.015 & $0.00 \%$ & 0.003 \\
\hline-8 & $0.00 \%$ & 1.528 & $0.00 \%$ & 0.012 & $0.00 \%$ & 0.002 & $0.00 \%$ & 0.015 & $0.00 \%$ & 0.003 \\
\hline-7 & $0.00 \%$ & 1.503 & $0.00 \%$ & 0.012 & $0.00 \%$ & 0.002 & $0.00 \%$ & 0.015 & $0.00 \%$ & 0.003 \\
\hline-6 & $0.00 \%$ & 1.492 & $0.00 \%$ & 0.012 & $0.00 \%$ & 0.002 & $0.00 \%$ & 0.015 & $0.00 \%$ & 0.003 \\
\hline-5 & $0.00 \%$ & 1.473 & $0.00 \%$ & 0.012 & $0.00 \%$ & 0.002 & $0.00 \%$ & 0.015 & $0.00 \%$ & 0.003 \\
\hline-4 & $0.00 \%$ & 1.452 & $0.00 \%$ & 0.012 & $0.00 \%$ & 0.002 & $0.00 \%$ & 0.015 & $0.00 \%$ & 0.003 \\
\hline-3 & $0.00 \%$ & 1.444 & $0.00 \%$ & 0.012 & $0.00 \%$ & 0.002 & $0.00 \%$ & 0.015 & $0.00 \%$ & 0.003 \\
\hline-2 & $0.00 \%$ & 1.406 & $0.00 \%$ & 0.012 & $0.00 \%$ & 0.002 & $0.00 \%$ & 0.015 & $0.00 \%$ & 0.003 \\
\hline
\end{tabular}




\section{Appendix B}

\section{Simulation results for $n=3$}

\begin{tabular}{|c|c|c|c|c|c|c|c|c|c|r|}
\hline \multicolumn{10}{|c|}{ TABLE 11. Error rates and average execution time for $\alpha_{\ell}=-3$} \\
\hline \hline & M. Gambini & \multicolumn{2}{|c|}{ TPE } & \multicolumn{2}{c|}{ T. Kruskal } & \multicolumn{2}{|c|}{ T. Variance } & \multicolumn{2}{|c|}{ T. M-Whitney } \\
\hline$\alpha_{r}$ & Error & Time & Error & Time & Error & Time & Error & Time & Error & Time \\
\hline-20 & $0.00 \%$ & 1.252 & $0.00 \%$ & 0.012 & $0.00 \%$ & 0.002 & $0.00 \%$ & 0.015 & $0.00 \%$ & 0.003 \\
\hline-19 & $0.00 \%$ & 1.216 & $0.00 \%$ & 0.012 & $0.00 \%$ & 0.002 & $0.00 \%$ & 0.015 & $0.00 \%$ & 0.003 \\
\hline-18 & $0.00 \%$ & 1.205 & $0.00 \%$ & 0.012 & $0.00 \%$ & 0.002 & $0.00 \%$ & 0.014 & $0.00 \%$ & 0.003 \\
\hline-17 & $0.00 \%$ & 1.355 & $0.00 \%$ & 0.012 & $0.00 \%$ & 0.002 & $0.00 \%$ & 0.015 & $0.00 \%$ & 0.003 \\
\hline-16 & $0.00 \%$ & 1.144 & $0.00 \%$ & 0.012 & $0.00 \%$ & 0.002 & $0.00 \%$ & 0.015 & $0.00 \%$ & 0.003 \\
\hline-15 & $0.00 \%$ & 1.136 & $0.00 \%$ & 0.012 & $0.00 \%$ & 0.002 & $0.00 \%$ & 0.015 & $0.00 \%$ & 0.003 \\
\hline-14 & $0.00 \%$ & 1.132 & $0.00 \%$ & 0.012 & $0.00 \%$ & 0.002 & $0.00 \%$ & 0.015 & $0.00 \%$ & 0.003 \\
\hline-13 & $0.00 \%$ & 1.141 & $0.00 \%$ & 0.012 & $0.00 \%$ & 0.002 & $0.00 \%$ & 0.015 & $0.00 \%$ & 0.003 \\
\hline-12 & $0.00 \%$ & 1.151 & $0.00 \%$ & 0.012 & $0.00 \%$ & 0.002 & $0.00 \%$ & 0.015 & $0.00 \%$ & 0.003 \\
\hline-11 & $0.00 \%$ & 1.137 & $0.00 \%$ & 0.012 & $0.00 \%$ & 0.002 & $0.00 \%$ & 0.015 & $0.00 \%$ & 0.003 \\
\hline-10 & $0.00 \%$ & 1.127 & $0.00 \%$ & 0.012 & $0.00 \%$ & 0.002 & $0.00 \%$ & 0.014 & $0.00 \%$ & 0.003 \\
\hline-9 & $0.00 \%$ & 1.127 & $0.00 \%$ & 0.012 & $0.00 \%$ & 0.002 & $0.00 \%$ & 0.015 & $0.00 \%$ & 0.003 \\
\hline-8 & $0.00 \%$ & 1.149 & $0.00 \%$ & 0.012 & $0.00 \%$ & 0.002 & $0.00 \%$ & 0.015 & $0.00 \%$ & 0.003 \\
\hline-7 & $0.00 \%$ & 1.142 & $0.00 \%$ & 0.012 & $0.00 \%$ & 0.002 & $0.00 \%$ & 0.015 & $0.00 \%$ & 0.003 \\
\hline-6 & $0.00 \%$ & 1.127 & $0.00 \%$ & 0.012 & $0.00 \%$ & 0.002 & $0.00 \%$ & 0.015 & $0.00 \%$ & 0.003 \\
\hline-5 & $0.00 \%$ & 1.137 & $0.00 \%$ & 0.012 & $0.00 \%$ & 0.002 & $0.30 \%$ & 0.015 & $0.00 \%$ & 0.003 \\
\hline-4 & $0.00 \%$ & 1.117 & $0.00 \%$ & 0.012 & $0.00 \%$ & 0.002 & $3.40 \%$ & 0.015 & $0.00 \%$ & 0.003 \\
\hline-2 & $0.00 \%$ & 1.090 & $0.00 \%$ & 0.012 & $0.00 \%$ & 0.002 & $5.90 \%$ & 0.015 & $0.00 \%$ & 0.003 \\
\hline
\end{tabular}




\begin{tabular}{|c|c|c|c|c|c|c|c|c|c|r|}
\hline \multicolumn{1}{|c|}{ TABLE 12. Error rates and average execution time for $\alpha_{\ell}=-4$} \\
\hline \hline & M. Gambini & \multicolumn{2}{|c|}{ TPE } & \multicolumn{2}{|c|}{ T. Kruskal } & \multicolumn{2}{|c|}{ T. Variance } & \multicolumn{2}{|c|}{ T. M-Whitney } \\
\hline$\alpha_{\mathrm{r}}$ & Error & Time & Error & Time & Error & Time & Error & Time & Error & Time \\
\hline-20 & $0.00 \%$ & 1.272 & $0.00 \%$ & 0.012 & $0.00 \%$ & 0.002 & $0.00 \%$ & 0.015 & $0.00 \%$ & 0.003 \\
\hline-19 & $0.00 \%$ & 1.171 & $0.00 \%$ & 0.012 & $0.00 \%$ & 0.002 & $0.00 \%$ & 0.015 & $0.00 \%$ & 0.003 \\
\hline-18 & $0.00 \%$ & 1.188 & $0.00 \%$ & 0.012 & $0.00 \%$ & 0.002 & $0.00 \%$ & 0.015 & $0.00 \%$ & 0.003 \\
\hline-17 & $0.00 \%$ & 1.178 & $0.00 \%$ & 0.012 & $0.00 \%$ & 0.002 & $0.00 \%$ & 0.014 & $0.00 \%$ & 0.003 \\
\hline-16 & $0.00 \%$ & 1.250 & $0.00 \%$ & 0.012 & $0.00 \%$ & 0.002 & $0.00 \%$ & 0.015 & $0.00 \%$ & 0.003 \\
\hline-15 & $0.00 \%$ & 1.256 & $0.00 \%$ & 0.012 & $0.00 \%$ & 0.002 & $0.00 \%$ & 0.014 & $0.00 \%$ & 0.003 \\
\hline-14 & $0.00 \%$ & 1.445 & $0.00 \%$ & 0.012 & $0.00 \%$ & 0.002 & $0.00 \%$ & 0.014 & $0.00 \%$ & 0.003 \\
\hline-13 & $0.00 \%$ & 1.164 & $0.00 \%$ & 0.012 & $0.00 \%$ & 0.002 & $0.00 \%$ & 0.014 & $0.00 \%$ & 0.003 \\
\hline-12 & $0.00 \%$ & 1.149 & $0.00 \%$ & 0.012 & $0.00 \%$ & 0.002 & $0.00 \%$ & 0.015 & $0.00 \%$ & 0.003 \\
\hline-11 & $0.00 \%$ & 1.132 & $0.00 \%$ & 0.012 & $0.00 \%$ & 0.002 & $0.00 \%$ & 0.014 & $0.00 \%$ & 0.003 \\
\hline-10 & $0.00 \%$ & 1.127 & $0.00 \%$ & 0.012 & $0.00 \%$ & 0.002 & $0.00 \%$ & 0.014 & $0.00 \%$ & 0.003 \\
\hline-9 & $0.00 \%$ & 1.136 & $0.00 \%$ & 0.012 & $0.00 \%$ & 0.002 & $0.00 \%$ & 0.015 & $0.00 \%$ & 0.003 \\
\hline-8 & $0.00 \%$ & 1.152 & $0.00 \%$ & 0.012 & $0.00 \%$ & 0.002 & $0.00 \%$ & 0.015 & $0.00 \%$ & 0.003 \\
\hline-7 & $0.00 \%$ & 1.164 & $0.00 \%$ & 0.012 & $0.00 \%$ & 0.002 & $0.00 \%$ & 0.015 & $0.00 \%$ & 0.003 \\
\hline-6 & $0.00 \%$ & 1.145 & $0.00 \%$ & 0.012 & $0.00 \%$ & 0.002 & $0.00 \%$ & 0.015 & $0.00 \%$ & 0.003 \\
\hline-5 & $0.00 \%$ & 1.133 & $0.50 \%$ & 0.012 & $0.00 \%$ & 0.002 & $13.40 \%$ & 0.015 & $0.00 \%$ & 0.003 \\
\hline-3 & $0.00 \%$ & 1.112 & $4.00 \%$ & 0.012 & $0.00 \%$ & 0.002 & $7.50 \%$ & 0.015 & $0.00 \%$ & 0.003 \\
\hline-2 & $0.00 \%$ & 1.082 & $0.00 \%$ & 0.012 & $0.00 \%$ & 0.002 & $1.00 \%$ & 0.015 & $0.00 \%$ & 0.003 \\
\hline
\end{tabular}

\begin{tabular}{|c|c|c|c|c|c|c|c|c|c|r|}
\hline \multicolumn{9}{|c|}{ TABLE 13. Error rates and average execution time for $\alpha_{\ell}=-6$} \\
\hline \hline & M. Gambini & \multicolumn{2}{|c|}{ TPE } & \multicolumn{2}{|c|}{ T. Kruskal } & \multicolumn{2}{|c|}{ T. Variance } & \multicolumn{2}{|c|}{ T. M-Whitney } \\
\hline$\alpha_{\mathrm{r}}$ & Error & Time & Error & Time & Error & Time & Error & Time & Error & Time \\
\hline-20 & $0.00 \%$ & 1.306 & $0.00 \%$ & 0.012 & $0.00 \%$ & 0.002 & $0.00 \%$ & 0.015 & $0.00 \%$ & 0.003 \\
\hline-19 & $0.00 \%$ & 1.211 & $0.00 \%$ & 0.012 & $0.00 \%$ & 0.002 & $0.00 \%$ & 0.015 & $0.00 \%$ & 0.003 \\
\hline-18 & $0.00 \%$ & 1.180 & $0.00 \%$ & 0.012 & $0.00 \%$ & 0.002 & $0.00 \%$ & 0.015 & $0.00 \%$ & 0.003 \\
\hline-17 & $0.00 \%$ & 1.375 & $0.00 \%$ & 0.012 & $0.00 \%$ & 0.002 & $0.00 \%$ & 0.015 & $0.00 \%$ & 0.003 \\
\hline-16 & $0.00 \%$ & 1.231 & $0.00 \%$ & 0.013 & $0.00 \%$ & 0.002 & $0.00 \%$ & 0.015 & $0.00 \%$ & 0.003 \\
\hline-15 & $0.00 \%$ & 1.175 & $0.00 \%$ & 0.012 & $0.00 \%$ & 0.002 & $0.00 \%$ & 0.015 & $0.00 \%$ & 0.003 \\
\hline-14 & $0.00 \%$ & 1.207 & $0.00 \%$ & 0.012 & $0.00 \%$ & 0.002 & $0.00 \%$ & 0.014 & $0.00 \%$ & 0.003 \\
\hline-13 & $0.00 \%$ & 1.263 & $0.00 \%$ & 0.012 & $0.00 \%$ & 0.002 & $0.00 \%$ & 0.015 & $0.00 \%$ & 0.003 \\
\hline-12 & $0.00 \%$ & 1.235 & $0.00 \%$ & 0.012 & $0.00 \%$ & 0.002 & $0.00 \%$ & 0.015 & $0.00 \%$ & 0.003 \\
\hline-11 & $0.00 \%$ & 1.185 & $0.00 \%$ & 0.012 & $0.00 \%$ & 0.002 & $0.00 \%$ & 0.015 & $0.00 \%$ & 0.003 \\
\hline-10 & $0.00 \%$ & 1.179 & $0.00 \%$ & 0.012 & $0.00 \%$ & 0.002 & $0.00 \%$ & 0.015 & $0.00 \%$ & 0.003 \\
\hline-9 & $0.00 \%$ & 1.228 & $0.00 \%$ & 0.012 & $0.00 \%$ & 0.002 & $0.00 \%$ & 0.015 & $0.00 \%$ & 0.003 \\
\hline-8 & $0.00 \%$ & 1.218 & $0.00 \%$ & 0.012 & $0.00 \%$ & 0.002 & $0.10 \%$ & 0.015 & $0.00 \%$ & 0.003 \\
\hline-7 & $0.10 \%$ & 1.276 & $9.30 \%$ & 0.012 & $0.00 \%$ & 0.002 & $44.80 \%$ & 0.015 & $0.00 \%$ & 0.003 \\
\hline-5 & $0.00 \%$ & 1.170 & $0.10 \%$ & 0.012 & $0.00 \%$ & 0.002 & $49.20 \%$ & 0.015 & $0.10 \%$ & 0.003 \\
\hline-4 & $0.00 \%$ & 1.166 & $0.10 \%$ & 0.012 & $0.00 \%$ & 0.002 & $0.00 \%$ & 0.015 & $0.00 \%$ & 0.003 \\
\hline-3 & $0.00 \%$ & 1.141 & $0.00 \%$ & 0.012 & $0.00 \%$ & 0.002 & $0.10 \%$ & 0.015 & $0.00 \%$ & 0.003 \\
\hline-2 & $0.00 \%$ & 1.124 & $0.00 \%$ & 0.012 & $0.00 \%$ & 0.002 & $0.10 \%$ & 0.015 & $0.00 \%$ & 0.003 \\
\hline
\end{tabular}




\begin{tabular}{|c|c|c|c|c|c|c|c|c|c|r|}
\hline \multicolumn{9}{|c|}{ TABLE 14. Error rates and average execution time for $\alpha_{\ell}=-8$} \\
\hline \hline & M. Gambini & \multicolumn{2}{|c|}{ TPE } & \multicolumn{2}{c|}{ T. Kruskal } & \multicolumn{2}{c|}{ T. Variance } & \multicolumn{2}{|c|}{ T. M-Whitney } \\
\hline$\alpha_{\mathrm{r}}$ & Error & Time & Error & Time & Error & Time & Error & Time & Error & Time \\
\hline-20 & $0.00 \%$ & 1.351 & $0.00 \%$ & 0.012 & $0.00 \%$ & 0.002 & $0.00 \%$ & 0.015 & $0.00 \%$ & 0.003 \\
\hline-19 & $0.00 \%$ & 1.186 & $0.00 \%$ & 0.012 & $0.00 \%$ & 0.002 & $0.00 \%$ & 0.015 & $0.00 \%$ & 0.003 \\
\hline-18 & $0.00 \%$ & 1.229 & $0.00 \%$ & 0.012 & $0.00 \%$ & 0.002 & $0.00 \%$ & 0.015 & $0.00 \%$ & 0.003 \\
\hline-17 & $0.00 \%$ & 1.277 & $0.00 \%$ & 0.012 & $0.00 \%$ & 0.002 & $0.00 \%$ & 0.015 & $0.00 \%$ & 0.003 \\
\hline-16 & $0.00 \%$ & 1.268 & $0.00 \%$ & 0.012 & $0.00 \%$ & 0.002 & $0.00 \%$ & 0.015 & $0.00 \%$ & 0.003 \\
\hline-15 & $0.00 \%$ & 1.506 & $0.00 \%$ & 0.012 & $0.00 \%$ & 0.002 & $0.00 \%$ & 0.015 & $0.00 \%$ & 0.003 \\
\hline-14 & $0.00 \%$ & 1.231 & $0.00 \%$ & 0.012 & $0.00 \%$ & 0.002 & $0.00 \%$ & 0.015 & $0.00 \%$ & 0.003 \\
\hline-13 & $0.00 \%$ & 1.196 & $0.00 \%$ & 0.012 & $0.00 \%$ & 0.002 & $0.00 \%$ & 0.015 & $0.00 \%$ & 0.003 \\
\hline-12 & $0.00 \%$ & 1.232 & $0.00 \%$ & 0.012 & $0.00 \%$ & 0.002 & $0.00 \%$ & 0.015 & $0.00 \%$ & 0.003 \\
\hline-11 & $0.00 \%$ & 1.262 & $0.00 \%$ & 0.012 & $0.00 \%$ & 0.002 & $0.40 \%$ & 0.015 & $0.00 \%$ & 0.003 \\
\hline-10 & $0.00 \%$ & 1.252 & $0.00 \%$ & 0.012 & $0.00 \%$ & 0.002 & $20.90 \%$ & 0.015 & $0.00 \%$ & 0.003 \\
\hline-9 & $0.00 \%$ & 1.279 & $57.90 \%$ & 0.012 & $0.00 \%$ & 0.002 & $32.20 \%$ & 0.015 & $0.00 \%$ & 0.003 \\
\hline-7 & $0.00 \%$ & 1.269 & $11.90 \%$ & 0.012 & $0.00 \%$ & 0.002 & $48.80 \%$ & 0.015 & $0.00 \%$ & 0.003 \\
\hline-6 & $0.00 \%$ & 1.237 & $0.00 \%$ & 0.012 & $0.00 \%$ & 0.002 & $3.00 \%$ & 0.015 & $0.00 \%$ & 0.003 \\
\hline-5 & $0.00 \%$ & 1.172 & $0.00 \%$ & 0.012 & $0.00 \%$ & 0.002 & $0.00 \%$ & 0.015 & $0.00 \%$ & 0.003 \\
\hline-4 & $0.00 \%$ & 1.141 & $0.00 \%$ & 0.012 & $0.00 \%$ & 0.002 & $0.00 \%$ & 0.015 & $0.00 \%$ & 0.003 \\
\hline-3 & $0.00 \%$ & 1.136 & $0.00 \%$ & 0.012 & $0.00 \%$ & 0.002 & $0.00 \%$ & 0.015 & $0.00 \%$ & 0.003 \\
\hline-2 & $0.00 \%$ & 1.157 & $0.00 \%$ & 0.012 & $0.00 \%$ & 0.002 & $0.20 \%$ & 0.015 & $0.00 \%$ & 0.003 \\
\hline
\end{tabular}

\begin{tabular}{|c|c|c|r|r|r|r|r|r|r|r|}
\hline \multicolumn{10}{|c|}{ TABLE 15. Error rates and average execution time for $\alpha_{\ell}=-10$} \\
\hline \hline & M. Gambini & \multicolumn{2}{|c|}{ TPE } & \multicolumn{2}{|c|}{ T. Kruskal } & \multicolumn{2}{|c|}{ T. Variance } & \multicolumn{2}{|c|}{ T. M-Whitney } \\
\hline$\alpha_{\mathrm{r}}$ & Error & Time & Error & Time & Error & Time & Error & Time & Error & Time \\
\hline-20 & $0.00 \%$ & 1.369 & $0.00 \%$ & 0.013 & $0.00 \%$ & 0.002 & $0.00 \%$ & 0.015 & $0.00 \%$ & 0.003 \\
\hline-19 & $0.00 \%$ & 1.337 & $0.00 \%$ & 0.012 & $0.00 \%$ & 0.002 & $0.00 \%$ & 0.015 & $0.00 \%$ & 0.003 \\
\hline-18 & $0.00 \%$ & 1.277 & $0.00 \%$ & 0.012 & $0.00 \%$ & 0.002 & $0.00 \%$ & 0.015 & $0.00 \%$ & 0.003 \\
\hline-17 & $0.00 \%$ & 1.348 & $0.00 \%$ & 0.012 & $0.00 \%$ & 0.002 & $0.00 \%$ & 0.015 & $0.00 \%$ & 0.003 \\
\hline-16 & $0.00 \%$ & 1.280 & $0.00 \%$ & 0.012 & $0.00 \%$ & 0.002 & $0.00 \%$ & 0.015 & $0.00 \%$ & 0.003 \\
\hline-15 & $0.00 \%$ & 1.298 & $0.00 \%$ & 0.012 & $0.00 \%$ & 0.002 & $0.00 \%$ & 0.015 & $0.00 \%$ & 0.003 \\
\hline-14 & $0.00 \%$ & 1.273 & $0.00 \%$ & 0.012 & $0.00 \%$ & 0.002 & $0.00 \%$ & 0.015 & $0.00 \%$ & 0.003 \\
\hline-13 & $0.00 \%$ & 1.349 & $19.90 \%$ & 0.012 & $0.00 \%$ & 0.002 & $5.00 \%$ & 0.015 & $0.00 \%$ & 0.003 \\
\hline-12 & $0.00 \%$ & 1.297 & $0.50 \%$ & 0.012 & $0.00 \%$ & 0.002 & $56.20 \%$ & 0.015 & $0.00 \%$ & 0.003 \\
\hline-11 & $0.10 \%$ & 1.278 & $87.80 \%$ & 0.012 & $0.00 \%$ & 0.002 & $33.10 \%$ & 0.015 & $0.00 \%$ & 0.003 \\
\hline-9 & $1.20 \%$ & 1.312 & $3.80 \%$ & 0.012 & $0.40 \%$ & 0.002 & $74.50 \%$ & 0.015 & $0.40 \%$ & 0.003 \\
\hline-8 & $0.00 \%$ & 1.296 & $47.30 \%$ & 0.012 & $0.00 \%$ & 0.002 & $6.10 \%$ & 0.015 & $0.00 \%$ & 0.003 \\
\hline-7 & $0.00 \%$ & 1.235 & $0.00 \%$ & 0.012 & $0.00 \%$ & 0.002 & $0.00 \%$ & 0.015 & $0.00 \%$ & 0.003 \\
\hline-6 & $0.00 \%$ & 1.169 & $0.00 \%$ & 0.012 & $0.00 \%$ & 0.002 & $0.00 \%$ & 0.015 & $0.00 \%$ & 0.003 \\
\hline-5 & $0.00 \%$ & 1.164 & $0.00 \%$ & 0.012 & $0.00 \%$ & 0.002 & $0.00 \%$ & 0.015 & $0.00 \%$ & 0.003 \\
\hline-4 & $0.00 \%$ & 1.183 & $0.00 \%$ & 0.012 & $0.00 \%$ & 0.002 & $0.00 \%$ & 0.015 & $0.00 \%$ & 0.003 \\
\hline-3 & $0.00 \%$ & 1.146 & $0.00 \%$ & 0.012 & $0.00 \%$ & 0.002 & $0.00 \%$ & 0.015 & $0.00 \%$ & 0.003 \\
\hline-2 & $0.00 \%$ & 1.123 & $0.00 \%$ & 0.012 & $0.00 \%$ & 0.002 & $0.20 \%$ & 0.015 & $0.00 \%$ & 0.003 \\
\hline
\end{tabular}




\begin{tabular}{|c|r|r|r|r|r|r|r|r|r|r|}
\hline \multicolumn{1}{|c|}{ TABLE 16. Error rates and average execution time for $\alpha_{\ell}=-12$} \\
\hline \hline & M. Gambini & \multicolumn{2}{|c|}{ TPE } & \multicolumn{2}{c|}{ T. Kruskal } & \multicolumn{2}{|c|}{ T. Variance } & \multicolumn{2}{|c|}{ T. M-Whitney } \\
\hline$\alpha_{\mathrm{r}}$ & Error & Time & Error & Time & Error & Time & Error & Time & Error & Time \\
\hline-20 & $0.00 \%$ & 1.555 & $0.00 \%$ & 0.006 & $0.00 \%$ & 0.001 & $0.00 \%$ & 0.007 & $0.00 \%$ & 0.002 \\
\hline-19 & $0.00 \%$ & 1.963 & $0.00 \%$ & 0.006 & $0.00 \%$ & 0.001 & $0.00 \%$ & 0.007 & $0.00 \%$ & 0.002 \\
\hline-18 & $0.00 \%$ & 1.509 & $0.00 \%$ & 0.006 & $0.00 \%$ & 0.002 & $0.00 \%$ & 0.008 & $0.00 \%$ & 0.002 \\
\hline-17 & $0.00 \%$ & 1.598 & $0.00 \%$ & 0.007 & $0.00 \%$ & 0.002 & $0.00 \%$ & 0.009 & $0.00 \%$ & 0.003 \\
\hline-16 & $0.00 \%$ & 1.639 & $0.00 \%$ & 0.008 & $0.00 \%$ & 0.002 & $0.00 \%$ & 0.009 & $0.00 \%$ & 0.003 \\
\hline-15 & $0.00 \%$ & 1.636 & $2.00 \%$ & 0.007 & $0.00 \%$ & 0.002 & $21.50 \%$ & 0.008 & $0.00 \%$ & 0.002 \\
\hline-14 & $0.40 \%$ & 1.452 & $1.50 \%$ & 0.007 & $0.10 \%$ & 0.002 & $22.50 \%$ & 0.009 & $0.10 \%$ & 0.002 \\
\hline-13 & $14.90 \%$ & 1.430 & $49.50 \%$ & 0.007 & $31.50 \%$ & 0.002 & $50.30 \%$ & 0.008 & $31.60 \%$ & 0.002 \\
\hline-11 & $26.40 \%$ & 1.491 & $41.70 \%$ & 0.007 & $24.50 \%$ & 0.002 & $88.80 \%$ & 0.008 & $25.20 \%$ & 0.002 \\
\hline-10 & $0.00 \%$ & 1.417 & $71.20 \%$ & 0.006 & $0.00 \%$ & 0.002 & $16.40 \%$ & 0.008 & $0.00 \%$ & 0.002 \\
\hline-9 & $0.00 \%$ & 1.448 & $0.00 \%$ & 0.006 & $0.00 \%$ & 0.001 & $0.00 \%$ & 0.008 & $0.00 \%$ & 0.002 \\
\hline-8 & $0.00 \%$ & 1.405 & $0.00 \%$ & 0.007 & $0.00 \%$ & 0.002 & $0.10 \%$ & 0.009 & $0.00 \%$ & 0.002 \\
\hline-7 & $0.00 \%$ & 1.315 & $0.00 \%$ & 0.007 & $0.00 \%$ & 0.002 & $0.00 \%$ & 0.008 & $0.00 \%$ & 0.002 \\
\hline-6 & $0.00 \%$ & 1.098 & $0.00 \%$ & 0.005 & $0.00 \%$ & 0.002 & $0.00 \%$ & 0.007 & $0.00 \%$ & 0.002 \\
\hline-5 & $0.00 \%$ & 1.038 & $0.00 \%$ & 0.005 & $0.00 \%$ & 0.001 & $0.00 \%$ & 0.006 & $0.00 \%$ & 0.002 \\
\hline-4 & $0.00 \%$ & 1.074 & $0.00 \%$ & 0.005 & $0.00 \%$ & 0.001 & $0.00 \%$ & 0.006 & $0.00 \%$ & 0.002 \\
\hline-3 & $0.00 \%$ & 0.982 & $0.00 \%$ & 0.005 & $0.00 \%$ & 0.002 & $0.00 \%$ & 0.006 & $0.00 \%$ & 0.002 \\
\hline-2 & $0.00 \%$ & 0.938 & $0.00 \%$ & 0.006 & $0.00 \%$ & 0.001 & $0.10 \%$ & 0.006 & $0.00 \%$ & 0.002 \\
\hline
\end{tabular}

\begin{tabular}{|c|c|c|c|c|c|c|c|c|c|r|}
\hline \multicolumn{1}{|c|}{ TABLE 17. Error rates and average execution time for $\alpha_{\ell}=-14$} \\
\hline \hline & M. Gambini & \multicolumn{2}{|c|}{ TPE } & \multicolumn{2}{c|}{ T. Kruskal } & \multicolumn{2}{c|}{ T. Variance } & \multicolumn{2}{|c|}{ T. M-Whitney } \\
\hline$\alpha_{\mathrm{r}}$ & Error & Time & Error & Time & Error & Time & Error & Time & Error & Time \\
\hline-20 & $0.00 \%$ & 1.738 & $0.00 \%$ & 0.006 & $0.00 \%$ & 0.002 & $0.50 \%$ & 0.007 & $0.00 \%$ & 0.002 \\
\hline-19 & $0.00 \%$ & 1.644 & $0.00 \%$ & 0.007 & $0.00 \%$ & 0.002 & $0.00 \%$ & 0.008 & $0.00 \%$ & 0.003 \\
\hline-18 & $0.00 \%$ & 1.784 & $1.20 \%$ & 0.007 & $0.00 \%$ & 0.002 & $2.30 \%$ & 0.008 & $0.00 \%$ & 0.002 \\
\hline-17 & $0.00 \%$ & 1.494 & $0.00 \%$ & 0.007 & $0.00 \%$ & 0.002 & $0.60 \%$ & 0.008 & $0.00 \%$ & 0.002 \\
\hline-16 & $0.50 \%$ & 1.604 & $37.20 \%$ & 0.006 & $1.30 \%$ & 0.002 & $11.20 \%$ & 0.008 & $1.30 \%$ & 0.002 \\
\hline-15 & $0.00 \%$ & 1.607 & $56.90 \%$ & 0.006 & $0.00 \%$ & 0.002 & $85.40 \%$ & 0.008 & $0.00 \%$ & 0.002 \\
\hline-13 & $0.70 \%$ & 1.607 & $35.80 \%$ & 0.007 & $0.00 \%$ & 0.002 & $88.60 \%$ & 0.008 & $0.00 \%$ & 0.002 \\
\hline-12 & $0.00 \%$ & 1.547 & $4.20 \%$ & 0.007 & $0.00 \%$ & 0.002 & $43.10 \%$ & 0.008 & $0.00 \%$ & 0.002 \\
\hline-11 & $0.00 \%$ & 1.506 & $0.40 \%$ & 0.007 & $0.00 \%$ & 0.002 & $1.30 \%$ & 0.008 & $0.00 \%$ & 0.002 \\
\hline-10 & $0.00 \%$ & 1.354 & $0.00 \%$ & 0.007 & $0.00 \%$ & 0.002 & $0.10 \%$ & 0.008 & $0.00 \%$ & 0.002 \\
\hline-9 & $0.00 \%$ & 1.324 & $0.00 \%$ & 0.007 & $0.00 \%$ & 0.002 & $0.00 \%$ & 0.008 & $0.00 \%$ & 0.002 \\
\hline-8 & $0.00 \%$ & 1.141 & $0.00 \%$ & 0.006 & $0.00 \%$ & 0.002 & $0.00 \%$ & 0.007 & $0.00 \%$ & 0.002 \\
\hline-7 & $0.00 \%$ & 1.190 & $0.00 \%$ & 0.006 & $0.00 \%$ & 0.002 & $0.00 \%$ & 0.008 & $0.00 \%$ & 0.002 \\
\hline-6 & $0.00 \%$ & 1.302 & $0.00 \%$ & 0.006 & $0.00 \%$ & 0.002 & $0.00 \%$ & 0.007 & $0.00 \%$ & 0.002 \\
\hline-5 & $0.00 \%$ & 1.124 & $0.00 \%$ & 0.006 & $0.00 \%$ & 0.001 & $0.00 \%$ & 0.007 & $0.00 \%$ & 0.002 \\
\hline-4 & $0.00 \%$ & 1.540 & $0.00 \%$ & 0.006 & $0.00 \%$ & 0.002 & $0.00 \%$ & 0.007 & $0.00 \%$ & 0.002 \\
\hline-3 & $0.00 \%$ & 1.119 & $0.00 \%$ & 0.006 & $0.00 \%$ & 0.002 & $0.00 \%$ & 0.007 & $0.00 \%$ & 0.002 \\
\hline-2 & $0.00 \%$ & 1.140 & $0.00 \%$ & 0.006 & $0.00 \%$ & 0.001 & $0.00 \%$ & 0.007 & $0.00 \%$ & 0.002 \\
\hline
\end{tabular}




\begin{tabular}{|c|r|r|r|r|r|r|r|r|r|r|}
\hline \multicolumn{1}{|c|}{ TABLE 18. Error rates and average execution time for $\alpha_{\ell}=-16$} \\
\hline \hline & M. Gambini & \multicolumn{2}{|c|}{ TPE } & \multicolumn{1}{c|}{ T. Kruskal } & \multicolumn{2}{|c|}{ T. Variance } & \multicolumn{2}{|c|}{ T. M-Whitney } \\
\hline$\alpha_{\mathrm{r}}$ & Error & Time & Error & Time & Error & Time & Error & Time & Error & Time \\
\hline-20 & $0.00 \%$ & 1.586 & $0.00 \%$ & 0.012 & $0.00 \%$ & 0.002 & $28.10 \%$ & 0.015 & $0.00 \%$ & 0.003 \\
\hline-19 & $0.00 \%$ & 1.264 & $0.60 \%$ & 0.012 & $0.00 \%$ & 0.002 & $7.80 \%$ & 0.015 & $0.00 \%$ & 0.003 \\
\hline-18 & $0.00 \%$ & 1.419 & $50.30 \%$ & 0.012 & $0.00 \%$ & 0.002 & $51.60 \%$ & 0.015 & $0.00 \%$ & 0.003 \\
\hline-17 & $0.00 \%$ & 1.366 & $26.80 \%$ & 0.012 & $0.00 \%$ & 0.002 & $17.30 \%$ & 0.015 & $0.00 \%$ & 0.003 \\
\hline-15 & $41.30 \%$ & 1.413 & $100.00 \%$ & 0.012 & $43.70 \%$ & 0.002 & $84.70 \%$ & 0.015 & $43.60 \%$ & 0.003 \\
\hline-14 & $0.00 \%$ & 1.456 & $6.20 \%$ & 0.012 & $1.50 \%$ & 0.002 & $30.40 \%$ & 0.015 & $1.60 \%$ & 0.003 \\
\hline-13 & $0.00 \%$ & 1.418 & $0.00 \%$ & 0.012 & $0.00 \%$ & 0.002 & $12.20 \%$ & 0.015 & $0.00 \%$ & 0.003 \\
\hline-12 & $0.00 \%$ & 1.369 & $0.00 \%$ & 0.013 & $0.00 \%$ & 0.002 & $0.60 \%$ & 0.015 & $0.00 \%$ & 0.003 \\
\hline-11 & $0.00 \%$ & 1.395 & $0.00 \%$ & 0.012 & $0.00 \%$ & 0.002 & $0.00 \%$ & 0.015 & $0.00 \%$ & 0.003 \\
\hline-10 & $0.00 \%$ & 1.266 & $0.00 \%$ & 0.012 & $0.00 \%$ & 0.002 & $0.00 \%$ & 0.015 & $0.00 \%$ & 0.003 \\
\hline-9 & $0.00 \%$ & 1.252 & $0.00 \%$ & 0.012 & $0.00 \%$ & 0.002 & $0.00 \%$ & 0.015 & $0.00 \%$ & 0.003 \\
\hline-8 & $0.00 \%$ & 1.238 & $0.00 \%$ & 0.012 & $0.00 \%$ & 0.002 & $0.00 \%$ & 0.015 & $0.00 \%$ & 0.003 \\
\hline-7 & $0.00 \%$ & 1.334 & $0.00 \%$ & 0.012 & $0.00 \%$ & 0.002 & $0.00 \%$ & 0.015 & $0.00 \%$ & 0.003 \\
\hline-6 & $0.00 \%$ & 1.255 & $0.00 \%$ & 0.012 & $0.00 \%$ & 0.002 & $0.00 \%$ & 0.015 & $0.00 \%$ & 0.003 \\
\hline-5 & $0.00 \%$ & 1.229 & $0.00 \%$ & 0.012 & $0.00 \%$ & 0.002 & $0.00 \%$ & 0.015 & $0.00 \%$ & 0.003 \\
\hline-4 & $0.00 \%$ & 1.248 & $0.00 \%$ & 0.012 & $0.00 \%$ & 0.002 & $0.00 \%$ & 0.015 & $0.00 \%$ & 0.003 \\
\hline-3 & $0.00 \%$ & 1.144 & $0.00 \%$ & 0.012 & $0.00 \%$ & 0.002 & $0.00 \%$ & 0.015 & $0.00 \%$ & 0.003 \\
\hline-2 & $0.00 \%$ & 1.230 & $0.00 \%$ & 0.012 & $0.00 \%$ & 0.002 & $0.00 \%$ & 0.015 & $0.00 \%$ & 0.003 \\
\hline
\end{tabular}

\begin{tabular}{|c|r|r|r|r|r|r|r|r|r|r|}
\hline \multicolumn{1}{|c|}{ TABLE 19. Error rates and average execution time for $\alpha_{\ell}=-18$} \\
\hline \hline & M. Gambini & \multicolumn{2}{|c|}{ TPE } & \multicolumn{2}{|c|}{ T. Kruskal } & \multicolumn{2}{|c|}{ T. Variance } & \multicolumn{2}{|c|}{ T. M-Whitney } \\
\hline$\alpha_{\mathrm{r}}$ & Error & Time & Error & Time & Error & Time & Error & Time & Error & Time \\
\hline-20 & $0.30 \%$ & 1.866 & $7.50 \%$ & 0.005 & $0.50 \%$ & 0.001 & $76.80 \%$ & 0.006 & $0.50 \%$ & 0.002 \\
\hline-19 & $15.70 \%$ & 1.417 & $33.30 \%$ & 0.005 & $13.10 \%$ & 0.001 & $83.20 \%$ & 0.006 & $13.10 \%$ & 0.002 \\
\hline-17 & $31.30 \%$ & 1.324 & $99.50 \%$ & 0.006 & $11.20 \%$ & 0.001 & $87.00 \%$ & 0.006 & $11.20 \%$ & 0.002 \\
\hline-16 & $0.00 \%$ & 1.278 & $2.90 \%$ & 0.005 & $0.00 \%$ & 0.002 & $20.00 \%$ & 0.006 & $0.00 \%$ & 0.002 \\
\hline-15 & $0.00 \%$ & 1.206 & $0.00 \%$ & 0.005 & $0.00 \%$ & 0.001 & $13.30 \%$ & 0.006 & $0.00 \%$ & 0.002 \\
\hline-14 & $0.00 \%$ & 1.351 & $6.10 \%$ & 0.005 & $0.00 \%$ & 0.002 & $17.20 \%$ & 0.007 & $0.00 \%$ & 0.002 \\
\hline-13 & $0.00 \%$ & 1.182 & $0.00 \%$ & 0.006 & $0.00 \%$ & 0.001 & $0.00 \%$ & 0.006 & $0.00 \%$ & 0.002 \\
\hline-12 & $0.00 \%$ & 1.097 & $0.00 \%$ & 0.006 & $0.00 \%$ & 0.001 & $0.00 \%$ & 0.006 & $0.00 \%$ & 0.002 \\
\hline-11 & $0.00 \%$ & 1.303 & $0.00 \%$ & 0.005 & $0.00 \%$ & 0.001 & $0.00 \%$ & 0.007 & $0.00 \%$ & 0.002 \\
\hline-10 & $0.00 \%$ & 1.264 & $0.00 \%$ & 0.005 & $0.00 \%$ & 0.001 & $0.00 \%$ & 0.007 & $0.00 \%$ & 0.002 \\
\hline-9 & $0.00 \%$ & 1.133 & $0.00 \%$ & 0.005 & $0.00 \%$ & 0.001 & $0.00 \%$ & 0.007 & $0.00 \%$ & 0.002 \\
\hline-8 & $0.00 \%$ & 1.046 & $0.00 \%$ & 0.005 & $0.00 \%$ & 0.001 & $0.00 \%$ & 0.006 & $0.00 \%$ & 0.002 \\
\hline-7 & $0.00 \%$ & 1.378 & $0.00 \%$ & 0.005 & $0.00 \%$ & 0.001 & $0.00 \%$ & 0.006 & $0.00 \%$ & 0.002 \\
\hline-6 & $0.00 \%$ & 1.097 & $0.00 \%$ & 0.005 & $0.00 \%$ & 0.001 & $0.00 \%$ & 0.006 & $0.00 \%$ & 0.002 \\
\hline-5 & $0.00 \%$ & 1.062 & $0.00 \%$ & 0.005 & $0.00 \%$ & 0.001 & $0.00 \%$ & 0.006 & $0.00 \%$ & 0.002 \\
\hline-4 & $0.00 \%$ & 1.056 & $0.00 \%$ & 0.005 & $0.00 \%$ & 0.001 & $0.00 \%$ & 0.006 & $0.00 \%$ & 0.002 \\
\hline-3 & $0.00 \%$ & 1.055 & $0.00 \%$ & 0.005 & $0.00 \%$ & 0.001 & $0.00 \%$ & 0.006 & $0.00 \%$ & 0.002 \\
\hline-2 & $0.00 \%$ & 1.021 & $0.00 \%$ & 0.005 & $0.00 \%$ & 0.001 & $0.00 \%$ & 0.006 & $0.00 \%$ & 0.002 \\
\hline
\end{tabular}


TABLE 20. Error rates and average execution time for $\alpha_{\ell}=-20$

\begin{tabular}{|c|r|r|r|r|r|r|r|r|r|r|}
\hline \multicolumn{10}{|c|}{ TABLE 20. Error rates and average execution time for $\alpha_{\ell}=-20$} \\
\hline \hline & M. Gambini & \multicolumn{2}{|c|}{ TPE } & \multicolumn{1}{c|}{ T. Kruskal } & \multicolumn{2}{|c|}{ T. Variance } & \multicolumn{2}{|c|}{ T. M-Whitney } \\
\hline$\alpha_{r}$ & Error & Time & Error & Time & Error & Time & Error & Time & Error & Time \\
\hline-19 & $87.40 \%$ & 2.411 & $100.00 \%$ & 0.007 & $89.30 \%$ & 0.002 & $77.70 \%$ & 0.008 & $89.90 \%$ & 0.002 \\
\hline-18 & $1.00 \%$ & 2.052 & $45.80 \%$ & 0.006 & $0.00 \%$ & 0.002 & $19.70 \%$ & 0.007 & $0.50 \%$ & 0.002 \\
\hline-17 & $3.60 \%$ & 1.636 & $10.50 \%$ & 0.006 & $3.30 \%$ & 0.001 & $48.60 \%$ & 0.007 & $3.30 \%$ & 0.002 \\
\hline-16 & $0.00 \%$ & 1.387 & $0.00 \%$ & 0.006 & $0.00 \%$ & 0.001 & $2.20 \%$ & 0.007 & $0.00 \%$ & 0.002 \\
\hline-15 & $0.00 \%$ & 1.474 & $0.00 \%$ & 0.006 & $0.00 \%$ & 0.001 & $1.60 \%$ & 0.007 & $0.00 \%$ & 0.002 \\
\hline-14 & $0.00 \%$ & 1.253 & $0.00 \%$ & 0.006 & $0.00 \%$ & 0.002 & $0.00 \%$ & 0.007 & $0.00 \%$ & 0.002 \\
\hline-13 & $0.00 \%$ & 1.693 & $0.00 \%$ & 0.006 & $0.00 \%$ & 0.001 & $0.00 \%$ & 0.007 & $0.00 \%$ & 0.002 \\
\hline-12 & $0.00 \%$ & 1.645 & $0.00 \%$ & 0.006 & $0.00 \%$ & 0.002 & $0.00 \%$ & 0.007 & $0.00 \%$ & 0.002 \\
\hline-11 & $0.00 \%$ & 1.248 & $0.00 \%$ & 0.006 & $0.00 \%$ & 0.001 & $0.00 \%$ & 0.006 & $0.00 \%$ & 0.002 \\
\hline-10 & $0.00 \%$ & 1.264 & $0.00 \%$ & 0.005 & $0.00 \%$ & 0.001 & $0.00 \%$ & 0.006 & $0.00 \%$ & 0.002 \\
\hline-9 & $0.00 \%$ & 1.092 & $0.00 \%$ & 0.005 & $0.00 \%$ & 0.001 & $0.00 \%$ & 0.006 & $0.00 \%$ & 0.002 \\
\hline-8 & $0.00 \%$ & 1.153 & $0.00 \%$ & 0.005 & $0.00 \%$ & 0.001 & $0.00 \%$ & 0.006 & $0.00 \%$ & 0.002 \\
\hline-7 & $0.00 \%$ & 1.281 & $0.00 \%$ & 0.005 & $0.00 \%$ & 0.001 & $0.00 \%$ & 0.007 & $0.00 \%$ & 0.002 \\
\hline-6 & $0.00 \%$ & 1.056 & $0.00 \%$ & 0.006 & $0.00 \%$ & 0.001 & $0.00 \%$ & 0.006 & $0.00 \%$ & 0.002 \\
\hline-5 & $0.00 \%$ & 1.081 & $0.00 \%$ & 0.005 & $0.00 \%$ & 0.001 & $0.00 \%$ & 0.006 & $0.00 \%$ & 0.002 \\
\hline-4 & $0.00 \%$ & 1.140 & $0.00 \%$ & 0.006 & $0.00 \%$ & 0.001 & $0.00 \%$ & 0.006 & $0.00 \%$ & 0.002 \\
\hline-3 & $0.00 \%$ & 1.177 & $0.00 \%$ & 0.006 & $0.00 \%$ & 0.002 & $0.00 \%$ & 0.007 & $0.00 \%$ & 0.002 \\
\hline-2 & $0.00 \%$ & 1.587 & $0.00 \%$ & 0.007 & $0.00 \%$ & 0.002 & $0.00 \%$ & 0.008 & $0.00 \%$ & 0.002 \\
\hline
\end{tabular}




\section{Appendix $\mathrm{C}$}

\section{Simulation results for $n=8$}

\begin{tabular}{|c|c|c|c|c|c|c|c|c|c|r|}
\hline \multicolumn{10}{|c|}{ TABLE 21. Error rates and average execution time for $\alpha_{\ell}=-3$} \\
\hline \hline & M. Gambini & \multicolumn{2}{|c|}{ TPE } & \multicolumn{2}{c|}{ T. Kruskal } & \multicolumn{2}{|c|}{ T. Variance } & \multicolumn{2}{|c|}{ T. M-Whitney } \\
\hline$\alpha_{r}$ & Error & Time & Error & Time & Error & Time & Error & Time & Error & Time \\
\hline-20 & $0.00 \%$ & 1.255 & $0.00 \%$ & 0.007 & $0.00 \%$ & 0.002 & $0.00 \%$ & 0.009 & $0.00 \%$ & 0.003 \\
\hline-19 & $0.00 \%$ & 1.110 & $0.00 \%$ & 0.006 & $0.00 \%$ & 0.002 & $0.00 \%$ & 0.007 & $0.00 \%$ & 0.002 \\
\hline-18 & $0.00 \%$ & 1.082 & $0.00 \%$ & 0.006 & $0.00 \%$ & 0.002 & $0.00 \%$ & 0.007 & $0.00 \%$ & 0.002 \\
\hline-17 & $0.00 \%$ & 1.121 & $0.00 \%$ & 0.006 & $0.00 \%$ & 0.001 & $0.00 \%$ & 0.007 & $0.00 \%$ & 0.002 \\
\hline-16 & $0.00 \%$ & 1.111 & $0.00 \%$ & 0.006 & $0.00 \%$ & 0.001 & $0.00 \%$ & 0.007 & $0.00 \%$ & 0.002 \\
\hline-15 & $0.00 \%$ & 1.116 & $0.00 \%$ & 0.006 & $0.00 \%$ & 0.002 & $0.00 \%$ & 0.007 & $0.00 \%$ & 0.002 \\
\hline-14 & $0.00 \%$ & 1.052 & $0.00 \%$ & 0.006 & $0.00 \%$ & 0.001 & $0.00 \%$ & 0.007 & $0.00 \%$ & 0.002 \\
\hline-13 & $0.00 \%$ & 1.032 & $0.00 \%$ & 0.005 & $0.00 \%$ & 0.002 & $0.00 \%$ & 0.007 & $0.00 \%$ & 0.002 \\
\hline-12 & $0.00 \%$ & 1.038 & $0.00 \%$ & 0.005 & $0.00 \%$ & 0.002 & $0.00 \%$ & 0.007 & $0.00 \%$ & 0.002 \\
\hline-11 & $0.00 \%$ & 0.991 & $0.00 \%$ & 0.006 & $0.00 \%$ & 0.001 & $0.10 \%$ & 0.007 & $0.00 \%$ & 0.002 \\
\hline-10 & $0.00 \%$ & 1.000 & $0.00 \%$ & 0.006 & $0.00 \%$ & 0.001 & $0.00 \%$ & 0.006 & $0.00 \%$ & 0.002 \\
\hline-9 & $0.00 \%$ & 1.011 & $0.00 \%$ & 0.006 & $0.00 \%$ & 0.001 & $0.00 \%$ & 0.006 & $0.00 \%$ & 0.002 \\
\hline-8 & $0.00 \%$ & 1.065 & $0.00 \%$ & 0.006 & $0.00 \%$ & 0.001 & $0.00 \%$ & 0.007 & $0.00 \%$ & 0.002 \\
\hline-7 & $0.00 \%$ & 1.008 & $0.00 \%$ & 0.006 & $0.00 \%$ & 0.001 & $0.00 \%$ & 0.006 & $0.00 \%$ & 0.002 \\
\hline-6 & $0.00 \%$ & 1.030 & $0.00 \%$ & 0.006 & $0.00 \%$ & 0.002 & $0.00 \%$ & 0.007 & $0.00 \%$ & 0.002 \\
\hline-5 & $0.00 \%$ & 1.010 & $0.00 \%$ & 0.006 & $0.00 \%$ & 0.002 & $0.10 \%$ & 0.007 & $0.00 \%$ & 0.002 \\
\hline-4 & $0.00 \%$ & 0.949 & $0.10 \%$ & 0.005 & $0.00 \%$ & 0.001 & $3.60 \%$ & 0.006 & $0.00 \%$ & 0.002 \\
\hline-2 & $0.00 \%$ & 0.953 & $0.00 \%$ & 0.005 & $0.00 \%$ & 0.001 & $6.20 \%$ & 0.006 & $0.00 \%$ & 0.002 \\
\hline
\end{tabular}




\begin{tabular}{|c|c|c|c|c|c|c|c|c|c|r|}
\hline \multicolumn{9}{|c|}{ TABLE 22. Error rates and average execution time for $\alpha_{\ell}=-4$} \\
\hline \hline & M. Gambini & \multicolumn{2}{|c|}{ TPE } & \multicolumn{2}{c|}{ T. Kruskal } & \multicolumn{2}{|c|}{ T. Variance } & \multicolumn{2}{|c|}{ T. M-Whitney } \\
\hline$\alpha_{\mathrm{r}}$ & Error & Time & Error & Time & Error & Time & Error & Time & Error & Time \\
\hline-20 & $0.00 \%$ & 0.983 & $0.00 \%$ & 0.005 & $0.00 \%$ & 0.001 & $0.00 \%$ & 0.006 & $0.00 \%$ & 0.002 \\
\hline-19 & $0.00 \%$ & 1.125 & $0.00 \%$ & 0.006 & $0.00 \%$ & 0.001 & $0.00 \%$ & 0.007 & $0.00 \%$ & 0.002 \\
\hline-18 & $0.00 \%$ & 0.988 & $0.00 \%$ & 0.005 & $0.00 \%$ & 0.001 & $0.00 \%$ & 0.006 & $0.00 \%$ & 0.002 \\
\hline-17 & $0.00 \%$ & 1.035 & $0.00 \%$ & 0.005 & $0.00 \%$ & 0.001 & $0.00 \%$ & 0.006 & $0.00 \%$ & 0.002 \\
\hline-16 & $0.00 \%$ & 0.978 & $0.00 \%$ & 0.005 & $0.00 \%$ & 0.001 & $0.00 \%$ & 0.006 & $0.00 \%$ & 0.002 \\
\hline-15 & $0.00 \%$ & 1.002 & $0.00 \%$ & 0.005 & $0.00 \%$ & 0.001 & $0.00 \%$ & 0.006 & $0.00 \%$ & 0.002 \\
\hline-14 & $0.00 \%$ & 0.974 & $0.00 \%$ & 0.005 & $0.00 \%$ & 0.001 & $0.00 \%$ & 0.006 & $0.00 \%$ & 0.002 \\
\hline-13 & $0.00 \%$ & 0.984 & $0.00 \%$ & 0.005 & $0.00 \%$ & 0.001 & $0.00 \%$ & 0.006 & $0.00 \%$ & 0.002 \\
\hline-12 & $0.00 \%$ & 0.975 & $0.00 \%$ & 0.005 & $0.00 \%$ & 0.001 & $0.00 \%$ & 0.006 & $0.00 \%$ & 0.002 \\
\hline-11 & $0.00 \%$ & 0.989 & $0.00 \%$ & 0.005 & $0.00 \%$ & 0.001 & $0.00 \%$ & 0.006 & $0.00 \%$ & 0.002 \\
\hline-10 & $0.00 \%$ & 0.958 & $0.00 \%$ & 0.005 & $0.00 \%$ & 0.001 & $0.00 \%$ & 0.006 & $0.00 \%$ & 0.002 \\
\hline-9 & $0.00 \%$ & 0.975 & $0.00 \%$ & 0.005 & $0.00 \%$ & 0.001 & $0.00 \%$ & 0.006 & $0.00 \%$ & 0.002 \\
\hline-8 & $0.00 \%$ & 0.965 & $0.00 \%$ & 0.005 & $0.00 \%$ & 0.001 & $0.00 \%$ & 0.006 & $0.00 \%$ & 0.002 \\
\hline-7 & $0.00 \%$ & 0.974 & $0.00 \%$ & 0.005 & $0.00 \%$ & 0.001 & $0.00 \%$ & 0.006 & $0.00 \%$ & 0.002 \\
\hline-6 & $0.00 \%$ & 0.970 & $0.00 \%$ & 0.005 & $0.00 \%$ & 0.001 & $0.10 \%$ & 0.006 & $0.00 \%$ & 0.002 \\
\hline-5 & $0.00 \%$ & 0.959 & $3.10 \%$ & 0.005 & $0.00 \%$ & 0.001 & $6.50 \%$ & 0.006 & $0.00 \%$ & 0.002 \\
\hline-3 & $0.00 \%$ & 0.937 & $1.20 \%$ & 0.005 & $0.00 \%$ & 0.001 & $4.20 \%$ & 0.006 & $0.00 \%$ & 0.002 \\
\hline-2 & $0.00 \%$ & 0.914 & $0.00 \%$ & 0.005 & $0.00 \%$ & 0.001 & $0.50 \%$ & 0.006 & $0.00 \%$ & 0.002 \\
\hline
\end{tabular}

\begin{tabular}{|c|c|c|c|c|c|c|c|c|c|r|}
\hline \multicolumn{10}{|c|}{ TABLE 23. Error rates and average execution time for $\alpha_{\ell}=-6$} \\
\hline \hline & M. Gambini & \multicolumn{2}{|c|}{ TPE } & \multicolumn{2}{|c|}{ T. Kruskal } & \multicolumn{2}{|c|}{ T. Variance } & \multicolumn{2}{|c|}{ T. M-Whitney } \\
\hline$\alpha_{\mathrm{r}}$ & Error & Time & Error & Time & Error & Time & Error & Time & Error & Time \\
\hline-20 & $0.00 \%$ & 1.105 & $0.00 \%$ & 0.006 & $0.00 \%$ & 0.001 & $0.00 \%$ & 0.007 & $0.00 \%$ & 0.002 \\
\hline-19 & $0.00 \%$ & 1.303 & $0.00 \%$ & 0.007 & $0.00 \%$ & 0.002 & $0.00 \%$ & 0.008 & $0.00 \%$ & 0.002 \\
\hline-18 & $0.00 \%$ & 1.364 & $0.00 \%$ & 0.007 & $0.00 \%$ & 0.002 & $0.00 \%$ & 0.009 & $0.00 \%$ & 0.002 \\
\hline-17 & $0.00 \%$ & 1.282 & $0.00 \%$ & 0.006 & $0.00 \%$ & 0.002 & $0.00 \%$ & 0.008 & $0.00 \%$ & 0.002 \\
\hline-16 & $0.00 \%$ & 1.160 & $0.00 \%$ & 0.006 & $0.00 \%$ & 0.002 & $0.00 \%$ & 0.007 & $0.00 \%$ & 0.002 \\
\hline-15 & $0.00 \%$ & 1.257 & $0.00 \%$ & 0.006 & $0.00 \%$ & 0.002 & $0.00 \%$ & 0.008 & $0.00 \%$ & 0.002 \\
\hline-14 & $0.00 \%$ & 1.224 & $0.00 \%$ & 0.006 & $0.00 \%$ & 0.002 & $0.00 \%$ & 0.008 & $0.00 \%$ & 0.002 \\
\hline-13 & $0.00 \%$ & 1.186 & $0.00 \%$ & 0.006 & $0.00 \%$ & 0.001 & $0.00 \%$ & 0.007 & $0.00 \%$ & 0.002 \\
\hline-12 & $0.00 \%$ & 1.246 & $0.00 \%$ & 0.006 & $0.00 \%$ & 0.002 & $0.00 \%$ & 0.008 & $0.00 \%$ & 0.002 \\
\hline-11 & $0.00 \%$ & 1.180 & $0.00 \%$ & 0.006 & $0.00 \%$ & 0.002 & $0.00 \%$ & 0.007 & $0.00 \%$ & 0.002 \\
\hline-10 & $0.00 \%$ & 1.132 & $0.00 \%$ & 0.006 & $0.00 \%$ & 0.001 & $0.00 \%$ & 0.007 & $0.00 \%$ & 0.002 \\
\hline-9 & $0.00 \%$ & 1.220 & $0.00 \%$ & 0.006 & $0.00 \%$ & 0.002 & $0.00 \%$ & 0.008 & $0.00 \%$ & 0.002 \\
\hline-8 & $0.00 \%$ & 1.176 & $0.00 \%$ & 0.006 & $0.00 \%$ & 0.002 & $0.40 \%$ & 0.008 & $0.00 \%$ & 0.002 \\
\hline-7 & $0.00 \%$ & 1.244 & $12.30 \%$ & 0.006 & $0.00 \%$ & 0.001 & $46.50 \%$ & 0.007 & $0.00 \%$ & 0.002 \\
\hline-5 & $0.00 \%$ & 1.131 & $4.90 \%$ & 0.006 & $0.00 \%$ & 0.002 & $14.40 \%$ & 0.007 & $0.00 \%$ & 0.002 \\
\hline-4 & $0.00 \%$ & 1.153 & $0.00 \%$ & 0.006 & $0.00 \%$ & 0.002 & $0.00 \%$ & 0.008 & $0.00 \%$ & 0.002 \\
\hline-3 & $0.00 \%$ & 1.179 & $0.00 \%$ & 0.006 & $0.00 \%$ & 0.002 & $0.10 \%$ & 0.008 & $0.00 \%$ & 0.002 \\
\hline-2 & $0.00 \%$ & 1.113 & $0.00 \%$ & 0.006 & $0.00 \%$ & 0.001 & $0.30 \%$ & 0.008 & $0.00 \%$ & 0.002 \\
\hline
\end{tabular}




\begin{tabular}{|c|c|c|c|c|c|c|c|c|c|r|}
\hline \multicolumn{9}{|c|}{ TABLE 24. Error rates and average execution time for $\alpha_{\ell}=-8$} \\
\hline \hline & M. Gambini & \multicolumn{2}{|c|}{ TPE } & \multicolumn{2}{c|}{ T. Kruskal } & \multicolumn{2}{c|}{ T. Variance } & \multicolumn{2}{|c|}{ T. M-Whitney } \\
\hline$\alpha_{\mathrm{r}}$ & Error & Time & Error & Time & Error & Time & Error & Time & Error & Time \\
\hline-20 & $0.00 \%$ & 1.145 & $0.00 \%$ & 0.006 & $0.00 \%$ & 0.001 & $0.00 \%$ & 0.007 & $0.00 \%$ & 0.002 \\
\hline-19 & $0.00 \%$ & 1.106 & $0.00 \%$ & 0.006 & $0.00 \%$ & 0.001 & $0.00 \%$ & 0.007 & $0.00 \%$ & 0.002 \\
\hline-18 & $0.00 \%$ & 1.485 & $0.00 \%$ & 0.008 & $0.00 \%$ & 0.002 & $0.00 \%$ & 0.010 & $0.00 \%$ & 0.003 \\
\hline-17 & $0.00 \%$ & 1.415 & $0.00 \%$ & 0.008 & $0.00 \%$ & 0.002 & $0.00 \%$ & 0.009 & $0.00 \%$ & 0.002 \\
\hline-16 & $0.00 \%$ & 1.215 & $0.00 \%$ & 0.006 & $0.00 \%$ & 0.002 & $0.00 \%$ & 0.007 & $0.00 \%$ & 0.002 \\
\hline-15 & $0.00 \%$ & 1.193 & $0.00 \%$ & 0.006 & $0.00 \%$ & 0.001 & $0.00 \%$ & 0.007 & $0.00 \%$ & 0.002 \\
\hline-14 & $0.00 \%$ & 1.279 & $0.00 \%$ & 0.006 & $0.00 \%$ & 0.002 & $0.00 \%$ & 0.008 & $0.00 \%$ & 0.002 \\
\hline-13 & $0.00 \%$ & 1.212 & $0.00 \%$ & 0.006 & $0.00 \%$ & 0.002 & $0.00 \%$ & 0.007 & $0.00 \%$ & 0.002 \\
\hline-12 & $0.00 \%$ & 1.211 & $0.00 \%$ & 0.006 & $0.00 \%$ & 0.002 & $0.10 \%$ & 0.008 & $0.00 \%$ & 0.002 \\
\hline-11 & $0.00 \%$ & 1.207 & $0.00 \%$ & 0.006 & $0.00 \%$ & 0.002 & $0.70 \%$ & 0.007 & $0.00 \%$ & 0.002 \\
\hline-10 & $0.00 \%$ & 1.121 & $0.00 \%$ & 0.006 & $0.00 \%$ & 0.001 & $4.40 \%$ & 0.007 & $0.00 \%$ & 0.002 \\
\hline-9 & $0.00 \%$ & 1.091 & $10.30 \%$ & 0.005 & $0.00 \%$ & 0.001 & $41.50 \%$ & 0.006 & $0.00 \%$ & 0.002 \\
\hline-7 & $0.20 \%$ & 1.160 & $66.50 \%$ & 0.006 & $0.00 \%$ & 0.001 & $58.00 \%$ & 0.007 & $0.10 \%$ & 0.002 \\
\hline-6 & $0.00 \%$ & 1.084 & $0.00 \%$ & 0.006 & $0.00 \%$ & 0.001 & $1.20 \%$ & 0.007 & $0.00 \%$ & 0.002 \\
\hline-5 & $0.00 \%$ & 1.026 & $0.00 \%$ & 0.005 & $0.00 \%$ & 0.002 & $0.00 \%$ & 0.007 & $0.00 \%$ & 0.002 \\
\hline-4 & $0.00 \%$ & 1.130 & $0.00 \%$ & 0.007 & $0.00 \%$ & 0.002 & $0.00 \%$ & 0.007 & $0.00 \%$ & 0.002 \\
\hline-3 & $0.00 \%$ & 0.998 & $0.00 \%$ & 0.006 & $0.00 \%$ & 0.001 & $0.00 \%$ & 0.007 & $0.00 \%$ & 0.002 \\
\hline-2 & $0.00 \%$ & 1.098 & $0.00 \%$ & 0.006 & $0.00 \%$ & 0.002 & $0.10 \%$ & 0.008 & $0.00 \%$ & 0.002 \\
\hline
\end{tabular}

\begin{tabular}{|c|c|c|c|c|c|c|c|c|c|r|}
\hline \multicolumn{10}{|c|}{ TABLE 25. Error rates and average execution time for $\alpha_{\ell}=-10$} \\
\hline \hline & M. Gambini & \multicolumn{2}{|c|}{ TPE } & \multicolumn{2}{|c|}{ T. Kruskal } & \multicolumn{2}{|c|}{ T. Variance } & \multicolumn{2}{|c|}{ T. M-Whitney } \\
\hline$\alpha_{\mathrm{r}}$ & Error & Time & Error & Time & Error & Time & Error & Time & Error & Time \\
\hline-20 & $0.00 \%$ & 1.159 & $0.00 \%$ & 0.006 & $0.00 \%$ & 0.002 & $0.00 \%$ & 0.007 & $0.00 \%$ & 0.002 \\
\hline-19 & $0.00 \%$ & 1.251 & $0.00 \%$ & 0.007 & $0.00 \%$ & 0.002 & $0.00 \%$ & 0.007 & $0.00 \%$ & 0.002 \\
\hline-18 & $0.00 \%$ & 1.279 & $0.00 \%$ & 0.006 & $0.00 \%$ & 0.002 & $0.00 \%$ & 0.007 & $0.00 \%$ & 0.002 \\
\hline-17 & $0.00 \%$ & 1.124 & $0.00 \%$ & 0.006 & $0.00 \%$ & 0.001 & $0.00 \%$ & 0.006 & $0.00 \%$ & 0.002 \\
\hline-16 & $0.00 \%$ & 1.074 & $0.00 \%$ & 0.005 & $0.00 \%$ & 0.001 & $0.00 \%$ & 0.006 & $0.00 \%$ & 0.002 \\
\hline-15 & $0.00 \%$ & 1.067 & $0.00 \%$ & 0.005 & $0.00 \%$ & 0.001 & $0.00 \%$ & 0.006 & $0.00 \%$ & 0.002 \\
\hline-14 & $0.00 \%$ & 1.079 & $0.00 \%$ & 0.005 & $0.00 \%$ & 0.001 & $0.00 \%$ & 0.006 & $0.00 \%$ & 0.002 \\
\hline-13 & $0.00 \%$ & 1.113 & $0.00 \%$ & 0.005 & $0.00 \%$ & 0.001 & $0.80 \%$ & 0.006 & $0.00 \%$ & 0.002 \\
\hline-12 & $0.00 \%$ & 1.093 & $0.00 \%$ & 0.005 & $0.00 \%$ & 0.001 & $11.50 \%$ & 0.006 & $0.00 \%$ & 0.002 \\
\hline-11 & $0.00 \%$ & 1.079 & $31.80 \%$ & 0.005 & $0.00 \%$ & 0.001 & $63.90 \%$ & 0.006 & $0.00 \%$ & 0.002 \\
\hline-9 & $0.00 \%$ & 1.103 & $8.20 \%$ & 0.005 & $0.00 \%$ & 0.001 & $46.50 \%$ & 0.006 & $0.00 \%$ & 0.002 \\
\hline-8 & $0.00 \%$ & 1.067 & $0.10 \%$ & 0.005 & $0.00 \%$ & 0.001 & $2.30 \%$ & 0.006 & $0.00 \%$ & 0.002 \\
\hline-7 & $0.00 \%$ & 1.035 & $0.00 \%$ & 0.005 & $0.00 \%$ & 0.002 & $0.00 \%$ & 0.006 & $0.00 \%$ & 0.002 \\
\hline-6 & $0.00 \%$ & 1.008 & $0.00 \%$ & 0.005 & $0.00 \%$ & 0.001 & $0.00 \%$ & 0.006 & $0.00 \%$ & 0.002 \\
\hline-5 & $0.00 \%$ & 0.987 & $0.00 \%$ & 0.005 & $0.00 \%$ & 0.001 & $0.00 \%$ & 0.006 & $0.00 \%$ & 0.002 \\
\hline-4 & $0.00 \%$ & 0.967 & $0.00 \%$ & 0.005 & $0.00 \%$ & 0.001 & $0.00 \%$ & 0.006 & $0.00 \%$ & 0.002 \\
\hline-3 & $0.00 \%$ & 0.955 & $0.00 \%$ & 0.005 & $0.00 \%$ & 0.002 & $0.00 \%$ & 0.006 & $0.00 \%$ & 0.002 \\
\hline-2 & $0.00 \%$ & 0.938 & $0.00 \%$ & 0.005 & $0.00 \%$ & 0.001 & $0.10 \%$ & 0.006 & $0.00 \%$ & 0.002 \\
\hline
\end{tabular}




\begin{tabular}{|c|c|c|c|c|c|c|c|c|c|r|}
\hline \multicolumn{10}{|c|}{ TABLE 26. Error rates and average execution time for $\alpha_{\ell}=-12$} \\
\hline \hline & M. Gambini & \multicolumn{2}{|c|}{ TPE } & \multicolumn{2}{c|}{ T. Kruskal } & \multicolumn{2}{c|}{ T. Variance } & \multicolumn{2}{|c|}{ T. M-Whitney } \\
\hline$\alpha_{\mathrm{r}}$ & Error & Time & Error & Time & Error & Time & Error & Time & Error & Time \\
\hline-20 & $0.00 \%$ & 1.129 & $0.00 \%$ & 0.006 & $0.00 \%$ & 0.001 & $0.00 \%$ & 0.006 & $0.00 \%$ & 0.002 \\
\hline-19 & $0.00 \%$ & 1.159 & $0.00 \%$ & 0.006 & $0.00 \%$ & 0.002 & $0.00 \%$ & 0.007 & $0.00 \%$ & 0.002 \\
\hline-18 & $0.00 \%$ & 1.243 & $0.00 \%$ & 0.006 & $0.00 \%$ & 0.002 & $0.10 \%$ & 0.007 & $0.00 \%$ & 0.002 \\
\hline-17 & $0.00 \%$ & 1.344 & $0.00 \%$ & 0.006 & $0.00 \%$ & 0.002 & $0.00 \%$ & 0.008 & $0.00 \%$ & 0.002 \\
\hline-16 & $0.00 \%$ & 1.376 & $0.00 \%$ & 0.006 & $0.00 \%$ & 0.002 & $0.20 \%$ & 0.008 & $0.00 \%$ & 0.002 \\
\hline-15 & $0.00 \%$ & 1.301 & $0.00 \%$ & 0.006 & $0.00 \%$ & 0.002 & $0.50 \%$ & 0.008 & $0.00 \%$ & 0.002 \\
\hline-14 & $0.00 \%$ & 1.318 & $0.00 \%$ & 0.006 & $0.00 \%$ & 0.001 & $35.50 \%$ & 0.008 & $0.00 \%$ & 0.002 \\
\hline-13 & $0.30 \%$ & 1.303 & $37.30 \%$ & 0.006 & $0.40 \%$ & 0.001 & $47.10 \%$ & 0.007 & $0.40 \%$ & 0.002 \\
\hline-11 & $1.20 \%$ & 1.326 & $11.70 \%$ & 0.007 & $1.30 \%$ & 0.002 & $67.90 \%$ & 0.008 & $1.30 \%$ & 0.002 \\
\hline-10 & $0.00 \%$ & 1.254 & $17.70 \%$ & 0.006 & $0.00 \%$ & 0.002 & $5.90 \%$ & 0.007 & $0.00 \%$ & 0.002 \\
\hline-9 & $0.00 \%$ & 1.214 & $0.00 \%$ & 0.006 & $0.00 \%$ & 0.002 & $0.60 \%$ & 0.007 & $0.00 \%$ & 0.002 \\
\hline-8 & $0.00 \%$ & 1.161 & $0.00 \%$ & 0.006 & $0.00 \%$ & 0.001 & $0.00 \%$ & 0.007 & $0.00 \%$ & 0.002 \\
\hline-7 & $0.00 \%$ & 1.242 & $0.00 \%$ & 0.006 & $0.00 \%$ & 0.002 & $0.00 \%$ & 0.008 & $0.00 \%$ & 0.002 \\
\hline-6 & $0.00 \%$ & 1.262 & $0.00 \%$ & 0.007 & $0.00 \%$ & 0.001 & $0.00 \%$ & 0.008 & $0.00 \%$ & 0.002 \\
\hline-5 & $0.00 \%$ & 1.310 & $0.00 \%$ & 0.008 & $0.00 \%$ & 0.002 & $0.00 \%$ & 0.010 & $0.00 \%$ & 0.003 \\
\hline-4 & $0.00 \%$ & 1.388 & $0.00 \%$ & 0.008 & $0.00 \%$ & 0.002 & $0.00 \%$ & 0.011 & $0.00 \%$ & 0.003 \\
\hline-3 & $0.00 \%$ & 1.324 & $0.00 \%$ & 0.008 & $0.00 \%$ & 0.002 & $0.00 \%$ & 0.010 & $0.00 \%$ & 0.003 \\
\hline-2 & $0.00 \%$ & 1.253 & $0.00 \%$ & 0.007 & $0.00 \%$ & 0.002 & $0.00 \%$ & 0.009 & $0.00 \%$ & 0.002 \\
\hline
\end{tabular}

\begin{tabular}{|c|r|r|r|r|r|r|r|r|r|r|}
\hline \multicolumn{1}{|c|}{ TABLE 27. Error rates and average execution time for $\alpha_{\ell}=-14$} \\
\hline \hline & M. Gambini & \multicolumn{2}{|c|}{ TPE } & \multicolumn{2}{c|}{ T. Kruskal } & \multicolumn{2}{c|}{ T. Variance } & \multicolumn{2}{|c|}{ T. M-Whitney } \\
\hline$\alpha_{\mathrm{r}}$ & Error & Time & Error & Time & Error & Time & Error & Time & Error & Time \\
\hline-20 & $0.00 \%$ & 1.250 & $0.00 \%$ & 0.006 & $0.00 \%$ & 0.001 & $0.00 \%$ & 0.007 & $0.00 \%$ & 0.002 \\
\hline-19 & $0.00 \%$ & 1.631 & $0.00 \%$ & 0.008 & $0.00 \%$ & 0.002 & $0.40 \%$ & 0.010 & $0.00 \%$ & 0.003 \\
\hline-18 & $0.00 \%$ & 1.390 & $0.00 \%$ & 0.007 & $0.00 \%$ & 0.002 & $0.90 \%$ & 0.008 & $0.00 \%$ & 0.002 \\
\hline-17 & $0.00 \%$ & 1.385 & $0.50 \%$ & 0.007 & $0.00 \%$ & 0.002 & $5.40 \%$ & 0.008 & $0.00 \%$ & 0.002 \\
\hline-16 & $0.00 \%$ & 1.392 & $7.90 \%$ & 0.007 & $0.10 \%$ & 0.002 & $63.50 \%$ & 0.008 & $0.10 \%$ & 0.002 \\
\hline-15 & $0.10 \%$ & 1.274 & $91.70 \%$ & 0.006 & $0.10 \%$ & 0.001 & $60.20 \%$ & 0.007 & $0.10 \%$ & 0.002 \\
\hline-13 & $39.70 \%$ & 1.149 & $60.90 \%$ & 0.005 & $31.70 \%$ & 0.001 & $78.00 \%$ & 0.006 & $31.80 \%$ & 0.002 \\
\hline-12 & $0.00 \%$ & 1.110 & $0.10 \%$ & 0.005 & $0.00 \%$ & 0.001 & $20.50 \%$ & 0.006 & $0.00 \%$ & 0.002 \\
\hline-11 & $0.00 \%$ & 1.104 & $0.00 \%$ & 0.005 & $0.00 \%$ & 0.001 & $7.70 \%$ & 0.006 & $0.00 \%$ & 0.002 \\
\hline-10 & $0.00 \%$ & 1.078 & $0.00 \%$ & 0.005 & $0.00 \%$ & 0.001 & $0.10 \%$ & 0.006 & $0.00 \%$ & 0.002 \\
\hline-9 & $0.00 \%$ & 1.086 & $0.00 \%$ & 0.005 & $0.00 \%$ & 0.001 & $0.00 \%$ & 0.006 & $0.00 \%$ & 0.002 \\
\hline-8 & $0.00 \%$ & 1.028 & $0.00 \%$ & 0.005 & $0.00 \%$ & 0.001 & $0.00 \%$ & 0.006 & $0.00 \%$ & 0.002 \\
\hline-7 & $0.00 \%$ & 1.080 & $0.00 \%$ & 0.005 & $0.00 \%$ & 0.001 & $0.00 \%$ & 0.006 & $0.00 \%$ & 0.002 \\
\hline-6 & $0.00 \%$ & 1.026 & $0.00 \%$ & 0.005 & $0.00 \%$ & 0.001 & $0.00 \%$ & 0.006 & $0.00 \%$ & 0.002 \\
\hline-5 & $0.00 \%$ & 0.984 & $0.00 \%$ & 0.005 & $0.00 \%$ & 0.001 & $0.00 \%$ & 0.006 & $0.00 \%$ & 0.002 \\
\hline-4 & $0.00 \%$ & 0.983 & $0.00 \%$ & 0.005 & $0.00 \%$ & 0.002 & $0.00 \%$ & 0.006 & $0.00 \%$ & 0.002 \\
\hline-3 & $0.00 \%$ & 0.950 & $0.00 \%$ & 0.005 & $0.00 \%$ & 0.001 & $0.00 \%$ & 0.006 & $0.00 \%$ & 0.002 \\
\hline-2 & $0.00 \%$ & 0.948 & $0.00 \%$ & 0.005 & $0.00 \%$ & 0.001 & $0.10 \%$ & 0.006 & $0.00 \%$ & 0.002 \\
\hline
\end{tabular}




\begin{tabular}{|c|r|r|r|r|r|r|r|r|r|r|}
\hline \multicolumn{1}{|c|}{ TABLE 28. Error rates and average execution time for $\alpha_{\ell}=-16$} \\
\hline \hline & M. Gambini & \multicolumn{2}{|c|}{ TPE } & \multicolumn{2}{|c|}{ T. Kruskal } & \multicolumn{2}{|c|}{ T. Variance } & \multicolumn{2}{|c|}{ T. M-Whitney } \\
\hline$\alpha_{r}$ & Error & Time & Error & Time & Error & Time & Error & Time & Error & Time \\
\hline-20 & $0.00 \%$ & 1.199 & $0.40 \%$ & 0.006 & $0.00 \%$ & 0.001 & $4.90 \%$ & 0.006 & $0.00 \%$ & 0.002 \\
\hline-19 & $0.00 \%$ & 1.273 & $0.80 \%$ & 0.006 & $0.00 \%$ & 0.001 & $47.60 \%$ & 0.007 & $0.00 \%$ & 0.002 \\
\hline-18 & $0.00 \%$ & 1.473 & $4.80 \%$ & 0.007 & $0.00 \%$ & 0.002 & $13.00 \%$ & 0.008 & $0.00 \%$ & 0.002 \\
\hline-17 & $10.20 \%$ & 1.406 & $61.90 \%$ & 0.006 & $9.90 \%$ & 0.001 & $87.00 \%$ & 0.007 & $9.90 \%$ & 0.002 \\
\hline-15 & $5.40 \%$ & 1.627 & $37.10 \%$ & 0.007 & $6.20 \%$ & 0.002 & $78.00 \%$ & 0.009 & $6.20 \%$ & 0.003 \\
\hline-14 & $0.00 \%$ & 1.586 & $8.10 \%$ & 0.007 & $0.00 \%$ & 0.002 & $8.90 \%$ & 0.010 & $0.00 \%$ & 0.003 \\
\hline-13 & $0.00 \%$ & 1.457 & $0.10 \%$ & 0.007 & $0.00 \%$ & 0.002 & $4.70 \%$ & 0.009 & $0.00 \%$ & 0.002 \\
\hline-12 & $0.00 \%$ & 1.454 & $0.00 \%$ & 0.007 & $0.00 \%$ & 0.002 & $3.50 \%$ & 0.008 & $0.00 \%$ & 0.002 \\
\hline-11 & $0.00 \%$ & 1.383 & $0.00 \%$ & 0.007 & $0.00 \%$ & 0.002 & $0.00 \%$ & 0.008 & $0.00 \%$ & 0.002 \\
\hline-10 & $0.00 \%$ & 1.319 & $0.00 \%$ & 0.007 & $0.00 \%$ & 0.002 & $0.00 \%$ & 0.008 & $0.00 \%$ & 0.002 \\
\hline-9 & $0.00 \%$ & 1.208 & $0.00 \%$ & 0.006 & $0.00 \%$ & 0.002 & $0.00 \%$ & 0.007 & $0.00 \%$ & 0.002 \\
\hline-8 & $0.00 \%$ & 1.204 & $0.00 \%$ & 0.006 & $0.00 \%$ & 0.001 & $0.00 \%$ & 0.007 & $0.00 \%$ & 0.002 \\
\hline-7 & $0.00 \%$ & 1.223 & $0.00 \%$ & 0.006 & $0.00 \%$ & 0.002 & $0.00 \%$ & 0.008 & $0.00 \%$ & 0.002 \\
\hline-6 & $0.00 \%$ & 1.192 & $0.00 \%$ & 0.006 & $0.00 \%$ & 0.002 & $0.00 \%$ & 0.007 & $0.00 \%$ & 0.002 \\
\hline-5 & $0.00 \%$ & 1.038 & $0.00 \%$ & 0.005 & $0.00 \%$ & 0.001 & $0.00 \%$ & 0.006 & $0.00 \%$ & 0.002 \\
\hline-4 & $0.00 \%$ & 1.069 & $0.00 \%$ & 0.005 & $0.00 \%$ & 0.002 & $0.00 \%$ & 0.007 & $0.00 \%$ & 0.002 \\
\hline-3 & $0.00 \%$ & 0.990 & $0.00 \%$ & 0.005 & $0.00 \%$ & 0.001 & $0.00 \%$ & 0.006 & $0.00 \%$ & 0.002 \\
\hline-2 & $0.00 \%$ & 0.973 & $0.00 \%$ & 0.005 & $0.00 \%$ & 0.001 & $0.10 \%$ & 0.006 & $0.00 \%$ & 0.002 \\
\hline
\end{tabular}

\begin{tabular}{|c|c|c|c|c|c|c|c|c|c|r|}
\hline \multicolumn{9}{|c|}{ TABLE 29. Error rates and average execution time for $\alpha_{\ell}=-18$} \\
\hline \hline & M. Gambini & \multicolumn{2}{|c|}{ TPE } & \multicolumn{2}{c|}{ T. Kruskal } & \multicolumn{2}{c|}{ T. Variance } & \multicolumn{2}{c|}{ T. M-Whitney } \\
\hline$\alpha_{\mathrm{r}}$ & Error & Time & Error & Time & Error & Time & Error & Time & Error & Time \\
\hline-20 & $0.00 \%$ & 1.427 & $63.70 \%$ & 0.006 & $0.00 \%$ & 0.002 & $60.40 \%$ & 0.008 & $0.00 \%$ & 0.002 \\
\hline-19 & $3.10 \%$ & 1.478 & $34.90 \%$ & 0.007 & $3.40 \%$ & 0.002 & $43.70 \%$ & 0.008 & $3.40 \%$ & 0.002 \\
\hline-17 & $1.70 \%$ & 1.423 & $38.30 \%$ & 0.007 & $1.50 \%$ & 0.001 & $66.40 \%$ & 0.008 & $1.80 \%$ & 0.002 \\
\hline-16 & $0.20 \%$ & 1.573 & $1.90 \%$ & 0.007 & $0.30 \%$ & 0.002 & $69.60 \%$ & 0.008 & $0.30 \%$ & 0.002 \\
\hline-15 & $0.00 \%$ & 1.387 & $0.10 \%$ & 0.006 & $0.00 \%$ & 0.002 & $11.50 \%$ & 0.007 & $0.00 \%$ & 0.002 \\
\hline-14 & $0.00 \%$ & 1.326 & $0.00 \%$ & 0.006 & $0.00 \%$ & 0.002 & $0.50 \%$ & 0.007 & $0.00 \%$ & 0.002 \\
\hline-13 & $0.00 \%$ & 1.400 & $0.00 \%$ & 0.006 & $0.00 \%$ & 0.002 & $0.00 \%$ & 0.008 & $0.00 \%$ & 0.002 \\
\hline-12 & $0.00 \%$ & 1.442 & $0.00 \%$ & 0.008 & $0.00 \%$ & 0.002 & $0.00 \%$ & 0.009 & $0.00 \%$ & 0.002 \\
\hline-11 & $0.00 \%$ & 1.488 & $0.00 \%$ & 0.008 & $0.00 \%$ & 0.002 & $0.00 \%$ & 0.010 & $0.00 \%$ & 0.003 \\
\hline-10 & $0.00 \%$ & 1.574 & $0.00 \%$ & 0.009 & $0.00 \%$ & 0.002 & $0.00 \%$ & 0.010 & $0.00 \%$ & 0.003 \\
\hline-9 & $0.00 \%$ & 1.455 & $0.00 \%$ & 0.008 & $0.00 \%$ & 0.002 & $0.00 \%$ & 0.010 & $0.00 \%$ & 0.003 \\
\hline-8 & $0.00 \%$ & 1.405 & $0.00 \%$ & 0.007 & $0.00 \%$ & 0.002 & $0.00 \%$ & 0.009 & $0.00 \%$ & 0.003 \\
\hline-7 & $0.00 \%$ & 1.278 & $0.00 \%$ & 0.007 & $0.00 \%$ & 0.002 & $0.00 \%$ & 0.008 & $0.00 \%$ & 0.003 \\
\hline-6 & $0.00 \%$ & 1.046 & $0.00 \%$ & 0.005 & $0.00 \%$ & 0.001 & $0.00 \%$ & 0.006 & $0.00 \%$ & 0.002 \\
\hline-5 & $0.00 \%$ & 0.989 & $0.00 \%$ & 0.005 & $0.00 \%$ & 0.001 & $0.00 \%$ & 0.006 & $0.00 \%$ & 0.002 \\
\hline-4 & $0.00 \%$ & 1.025 & $0.00 \%$ & 0.005 & $0.00 \%$ & 0.001 & $0.00 \%$ & 0.006 & $0.00 \%$ & 0.002 \\
\hline-3 & $0.00 \%$ & 0.976 & $0.00 \%$ & 0.005 & $0.00 \%$ & 0.001 & $0.00 \%$ & 0.006 & $0.00 \%$ & 0.002 \\
\hline-2 & $0.00 \%$ & 0.970 & $0.00 \%$ & 0.005 & $0.00 \%$ & 0.001 & $0.00 \%$ & 0.006 & $0.00 \%$ & 0.002 \\
\hline
\end{tabular}


TABLE 30. Error rates and average execution time for $\alpha_{\ell}=-20$

\begin{tabular}{|c|c|c|c|c|c|c|c|c|c|r|}
\hline \multicolumn{10}{|c|}{ TABLE 30. Error rates and average execution time for $\alpha_{\ell}=-20$} \\
\hline \hline & M. Gambini & \multicolumn{2}{|c|}{ TPE } & \multicolumn{2}{|c|}{ T. Kruskal } & \multicolumn{2}{|c|}{ T. Variance } & \multicolumn{2}{|c|}{ T. M-Whitney } \\
\hline$\alpha_{\mathrm{r}}$ & Error & Time & Error & Time & Error & Time & Error & Time & Error & Time \\
\hline-19 & $5.80 \%$ & 1.368 & $58.70 \%$ & 0.006 & $5.50 \%$ & 0.001 & $93.80 \%$ & 0.007 & $5.50 \%$ & 0.002 \\
\hline-18 & $0.00 \%$ & 1.384 & $2.00 \%$ & 0.006 & $0.10 \%$ & 0.002 & $40.80 \%$ & 0.007 & $0.20 \%$ & 0.002 \\
\hline-17 & $0.00 \%$ & 1.546 & $15.90 \%$ & 0.006 & $0.00 \%$ & 0.001 & $10.50 \%$ & 0.008 & $0.00 \%$ & 0.002 \\
\hline-16 & $0.00 \%$ & 1.241 & $0.00 \%$ & 0.006 & $0.00 \%$ & 0.001 & $3.30 \%$ & 0.007 & $0.00 \%$ & 0.002 \\
\hline-15 & $0.00 \%$ & 1.227 & $0.00 \%$ & 0.005 & $0.00 \%$ & 0.001 & $0.10 \%$ & 0.007 & $0.00 \%$ & 0.002 \\
\hline-14 & $0.00 \%$ & 1.231 & $0.00 \%$ & 0.005 & $0.00 \%$ & 0.001 & $0.00 \%$ & 0.007 & $0.00 \%$ & 0.002 \\
\hline-13 & $0.00 \%$ & 1.209 & $0.00 \%$ & 0.006 & $0.00 \%$ & 0.002 & $0.00 \%$ & 0.007 & $0.00 \%$ & 0.002 \\
\hline-12 & $0.00 \%$ & 1.141 & $0.00 \%$ & 0.006 & $0.00 \%$ & 0.001 & $0.00 \%$ & 0.006 & $0.00 \%$ & 0.002 \\
\hline-11 & $0.00 \%$ & 1.135 & $0.00 \%$ & 0.005 & $0.00 \%$ & 0.001 & $0.00 \%$ & 0.007 & $0.00 \%$ & 0.002 \\
\hline-10 & $0.00 \%$ & 1.188 & $0.00 \%$ & 0.006 & $0.00 \%$ & 0.001 & $0.00 \%$ & 0.007 & $0.00 \%$ & 0.002 \\
\hline-9 & $0.00 \%$ & 1.111 & $0.00 \%$ & 0.006 & $0.00 \%$ & 0.001 & $0.00 \%$ & 0.007 & $0.00 \%$ & 0.002 \\
\hline-8 & $0.00 \%$ & 1.111 & $0.00 \%$ & 0.006 & $0.00 \%$ & 0.001 & $0.00 \%$ & 0.007 & $0.00 \%$ & 0.002 \\
\hline-7 & $0.00 \%$ & 1.128 & $0.00 \%$ & 0.006 & $0.00 \%$ & 0.001 & $0.00 \%$ & 0.007 & $0.00 \%$ & 0.002 \\
\hline-6 & $0.00 \%$ & 1.144 & $0.00 \%$ & 0.006 & $0.00 \%$ & 0.001 & $0.00 \%$ & 0.007 & $0.00 \%$ & 0.002 \\
\hline-5 & $0.00 \%$ & 1.085 & $0.00 \%$ & 0.005 & $0.00 \%$ & 0.001 & $0.00 \%$ & 0.007 & $0.00 \%$ & 0.002 \\
\hline-4 & $0.00 \%$ & 1.029 & $0.00 \%$ & 0.006 & $0.00 \%$ & 0.001 & $0.00 \%$ & 0.007 & $0.00 \%$ & 0.002 \\
\hline-3 & $0.00 \%$ & 1.111 & $0.00 \%$ & 0.006 & $0.00 \%$ & 0.002 & $0.00 \%$ & 0.008 & $0.00 \%$ & 0.002 \\
\hline-2 & $0.00 \%$ & 1.044 & $0.00 \%$ & 0.005 & $0.00 \%$ & 0.001 & $0.00 \%$ & 0.007 & $0.00 \%$ & 0.002 \\
\hline
\end{tabular}




\section{Appendix D}

\section{Ox Codes}

This appendix presents the program written in the matrix programming language Ox that was used in the simulation corresponding to the detection of edges. This program provides the following results:

- Estimation of parameters of the $\mathcal{G}_{\mathcal{J}}^{0}$ distribution for the method of moments.

- Detection of edges and times in seconds for the used methods.

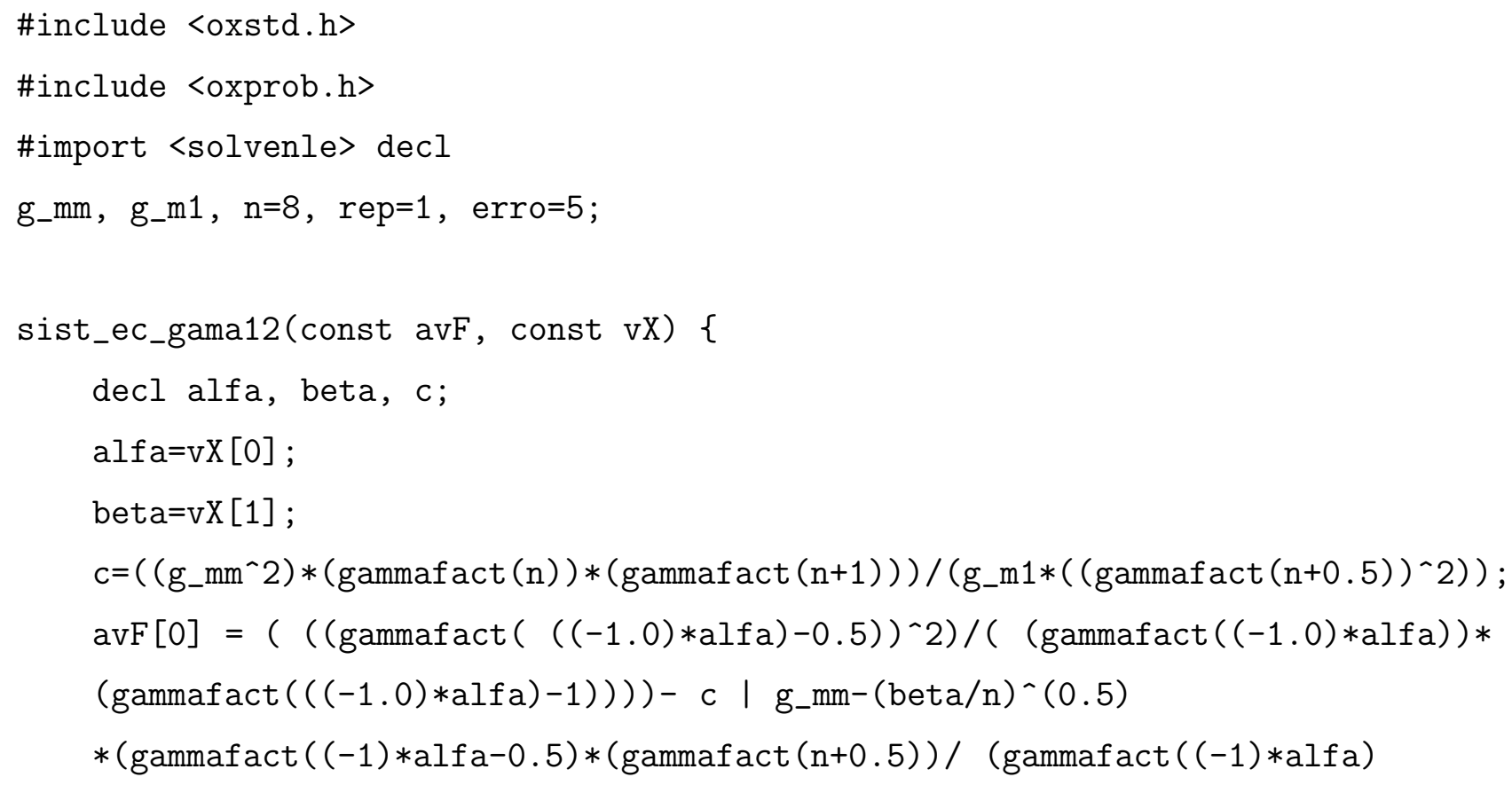




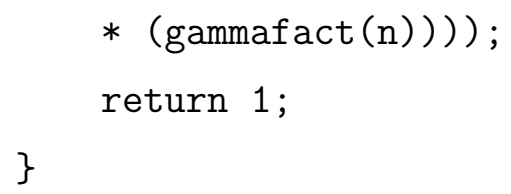




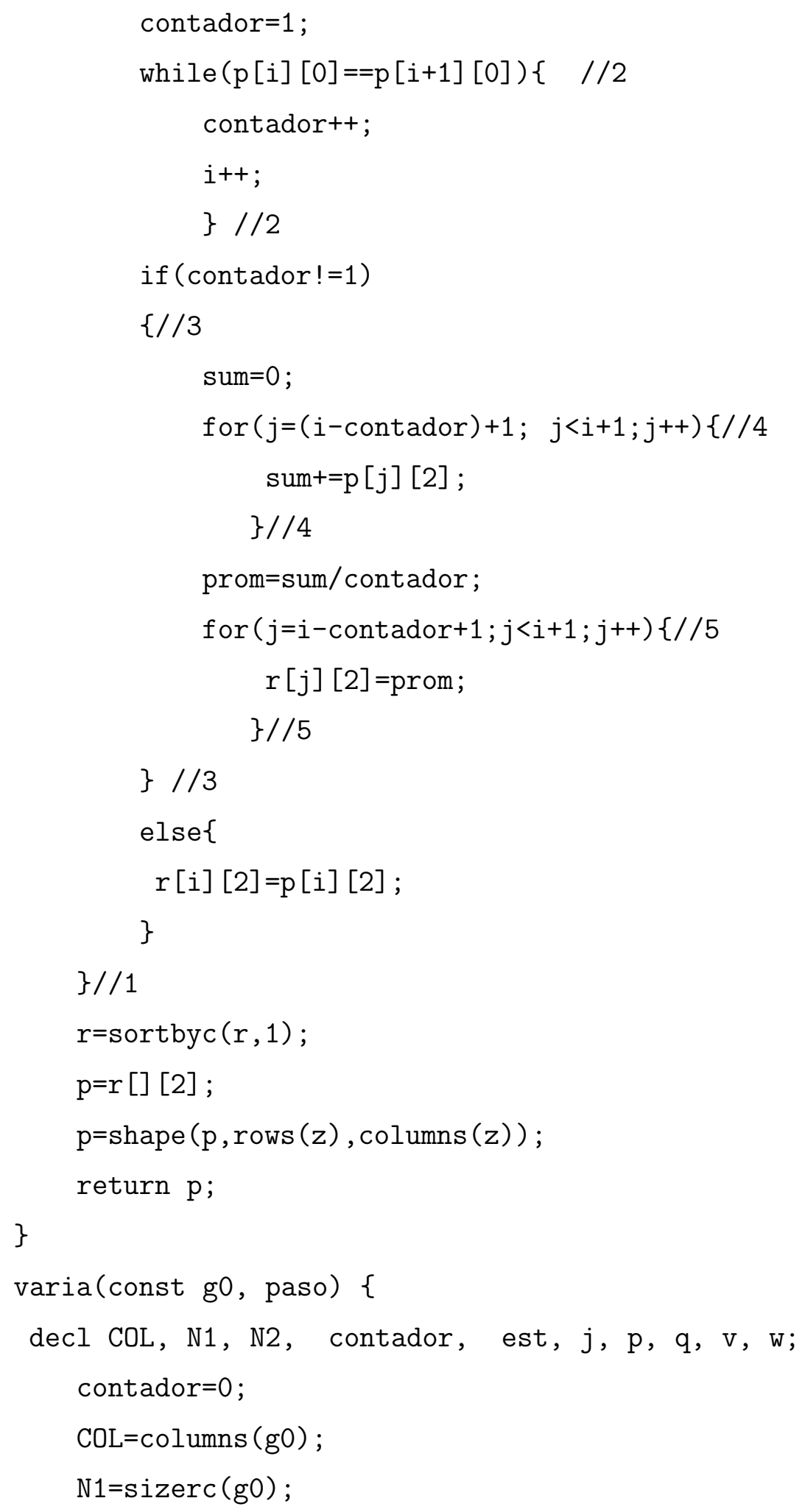




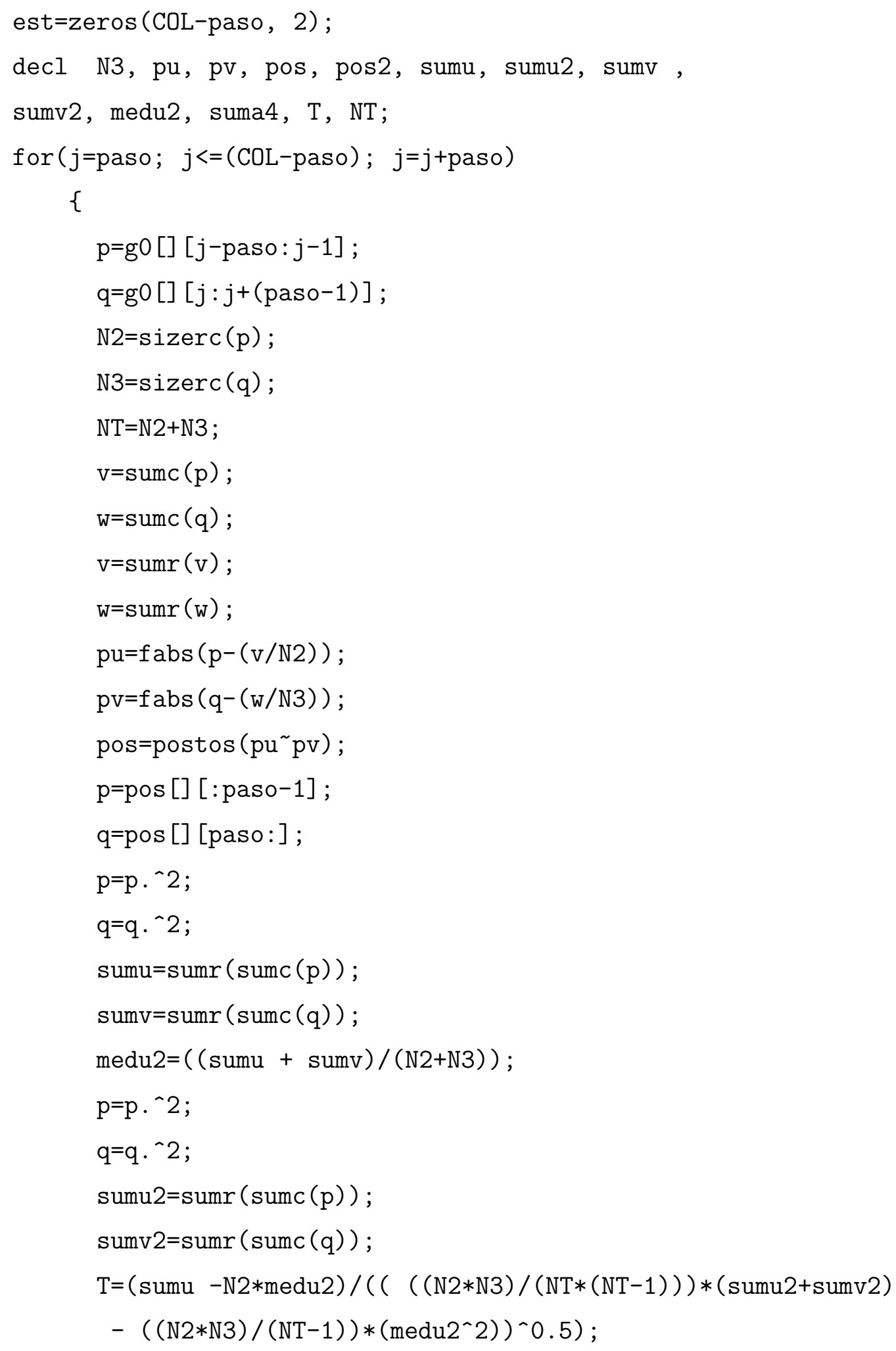




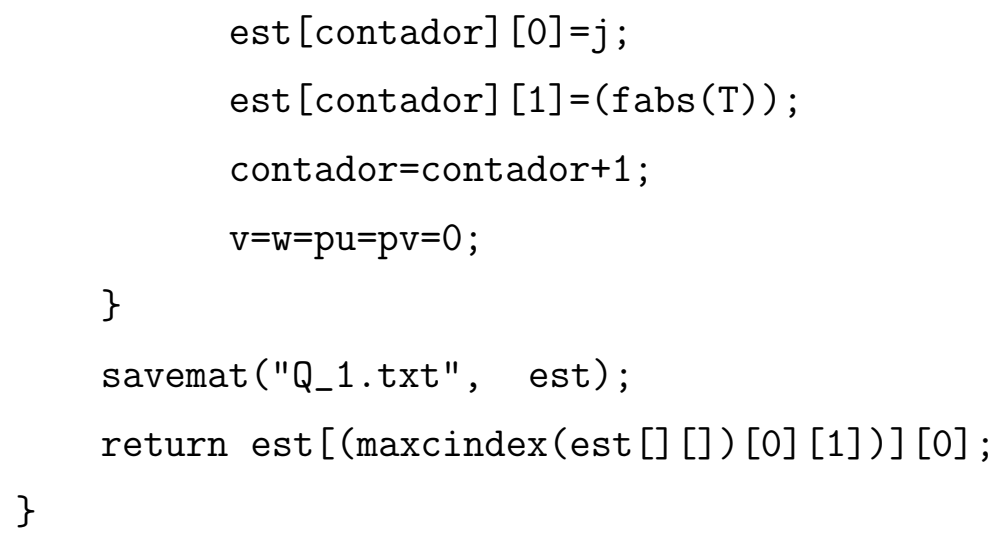




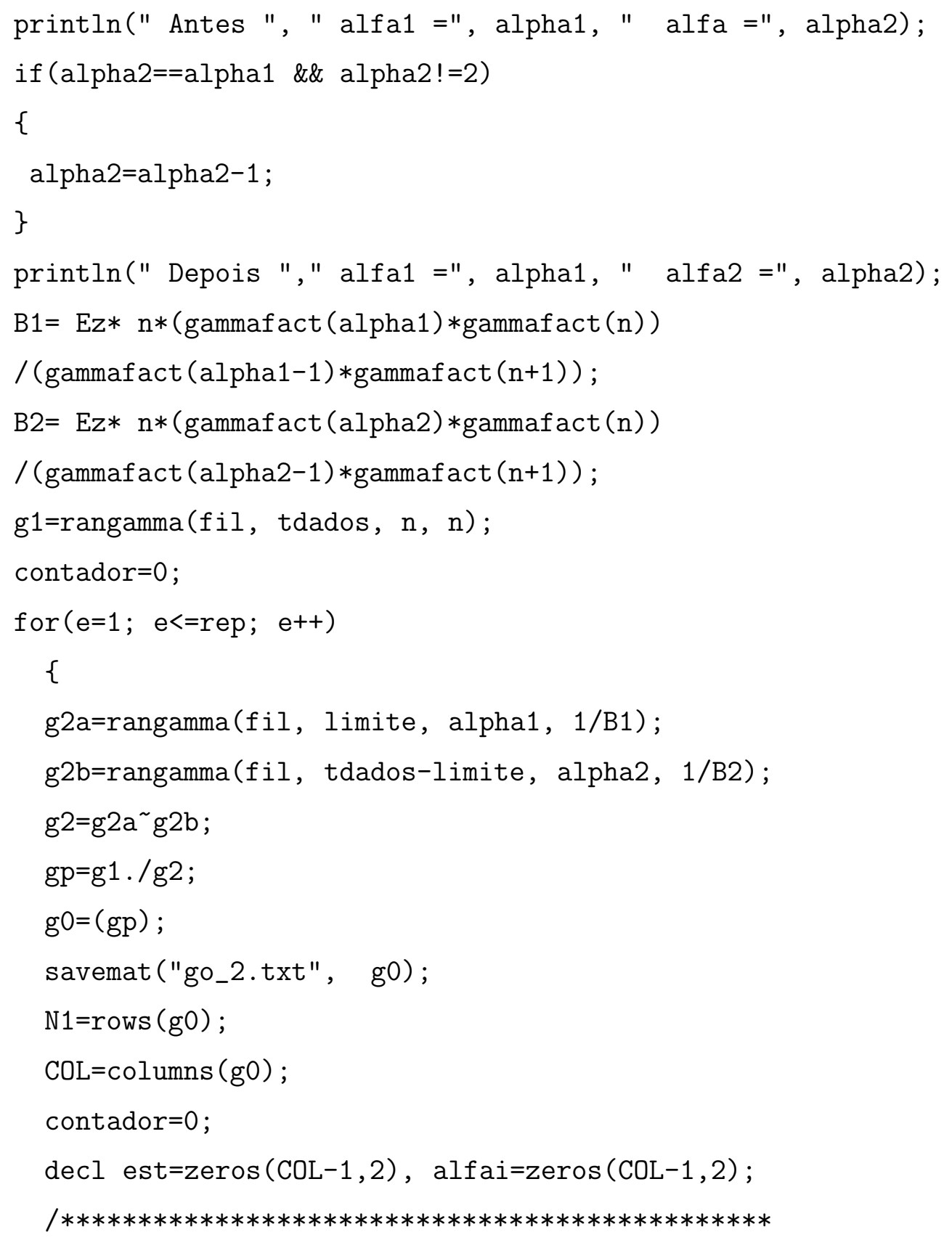




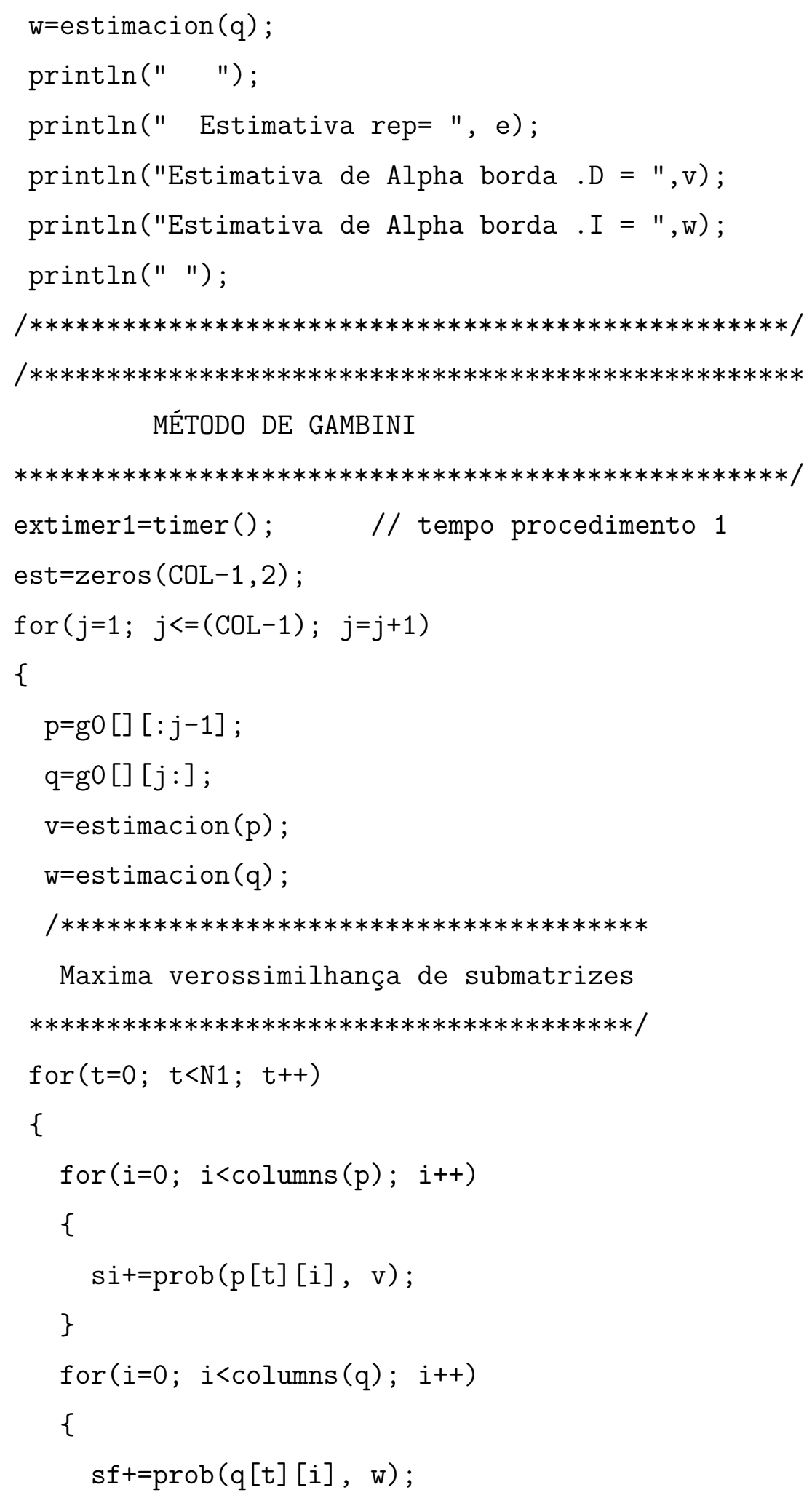




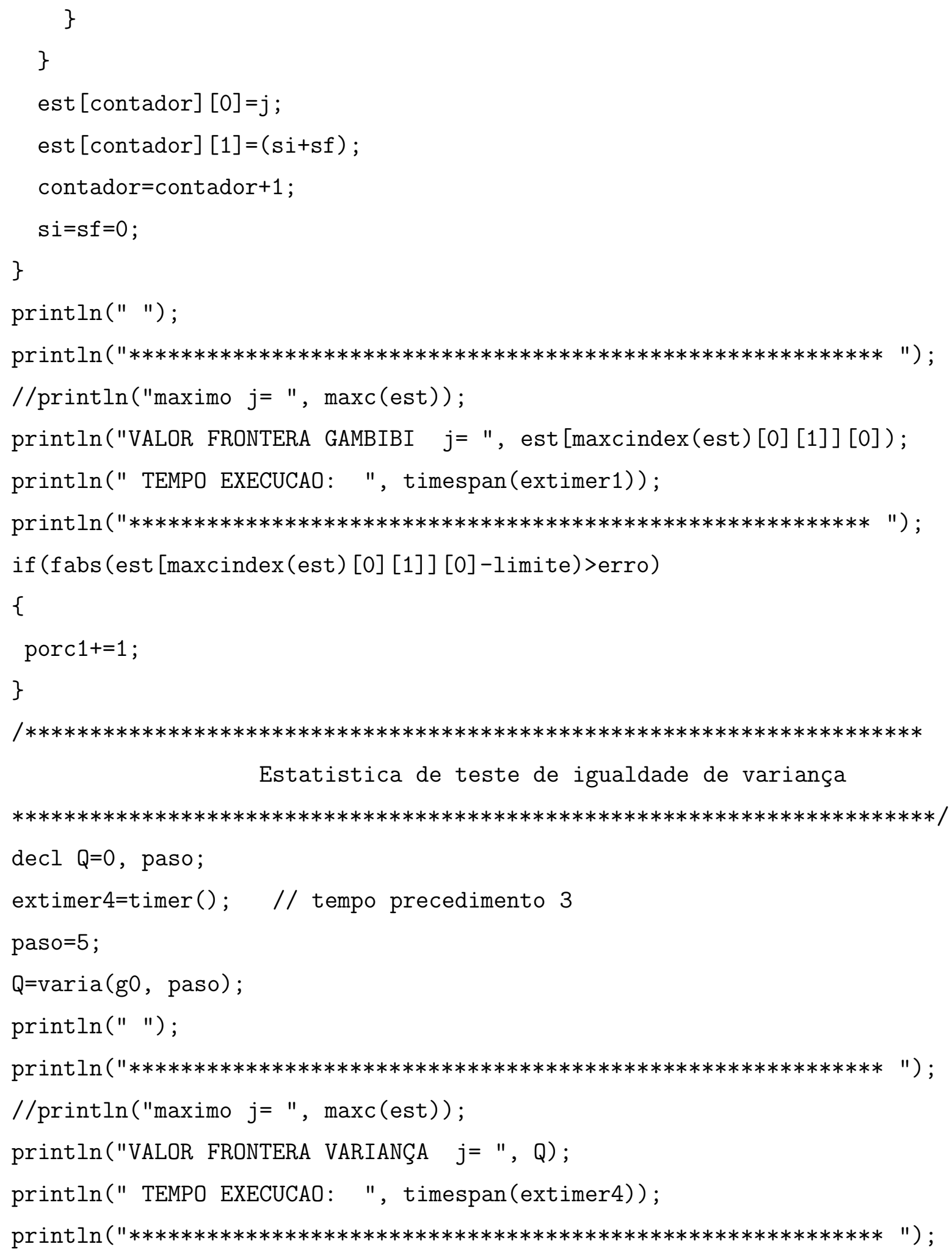




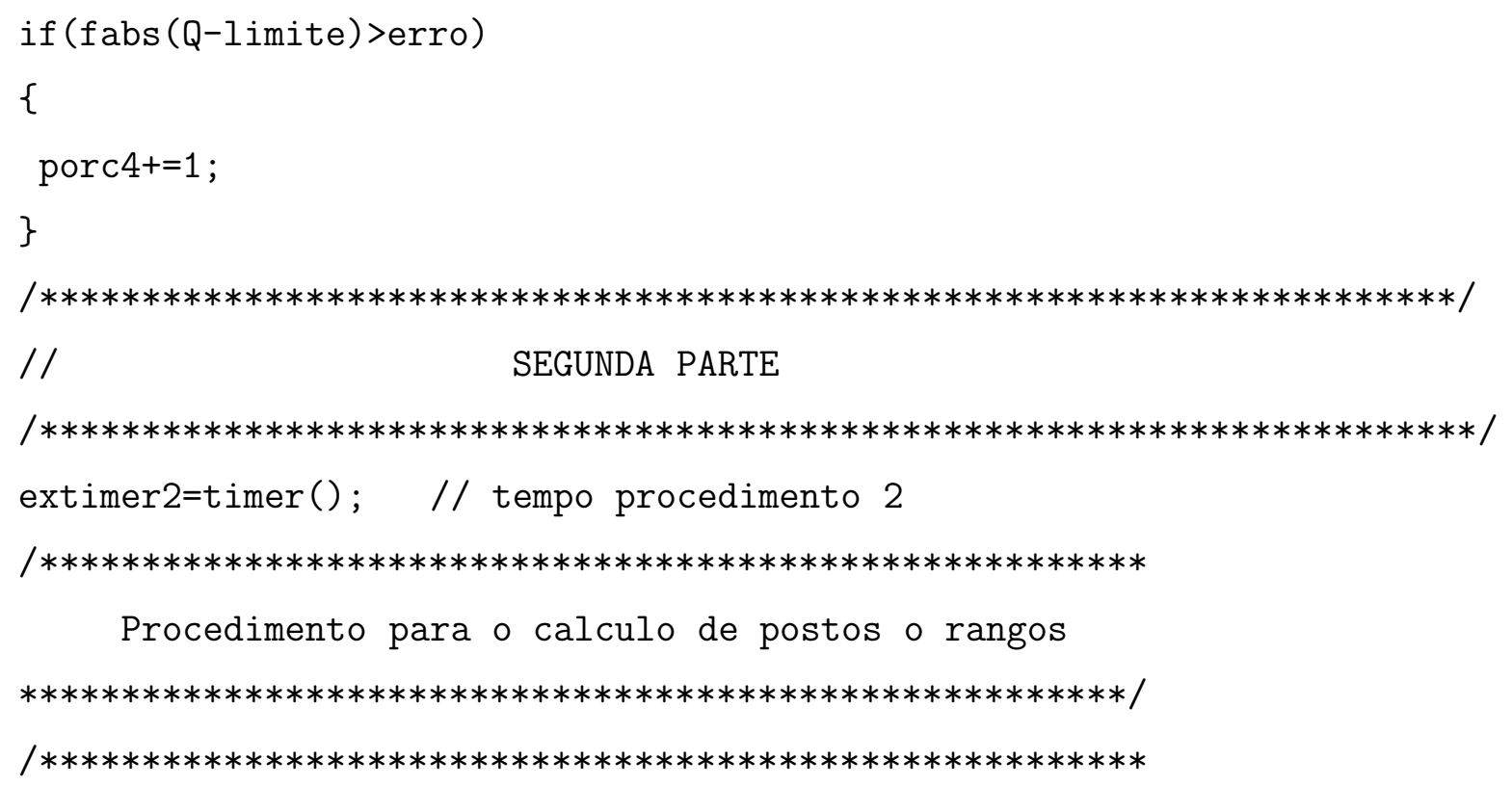

GO MATRIZ DE RANGOS OU POSTOS

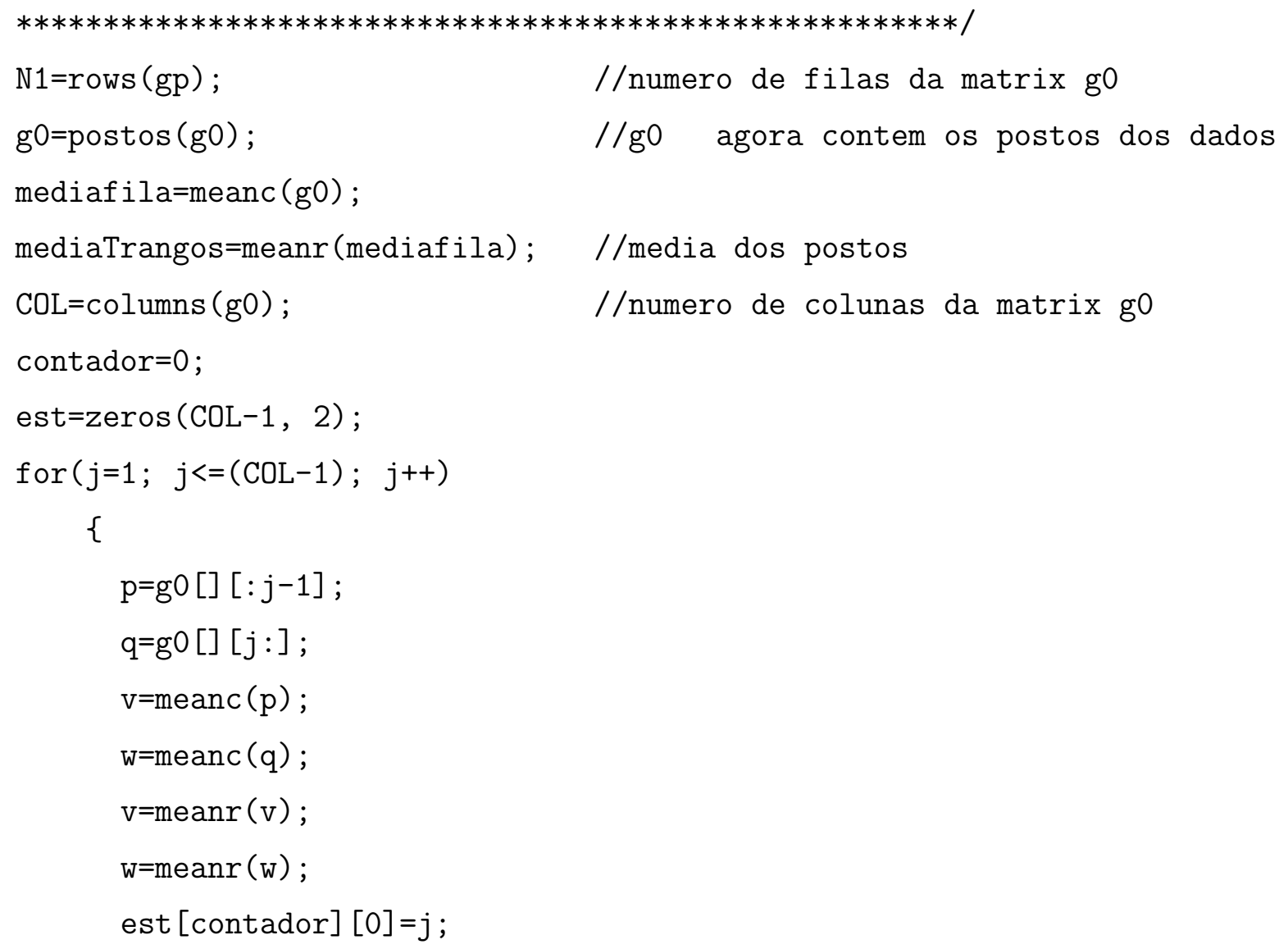




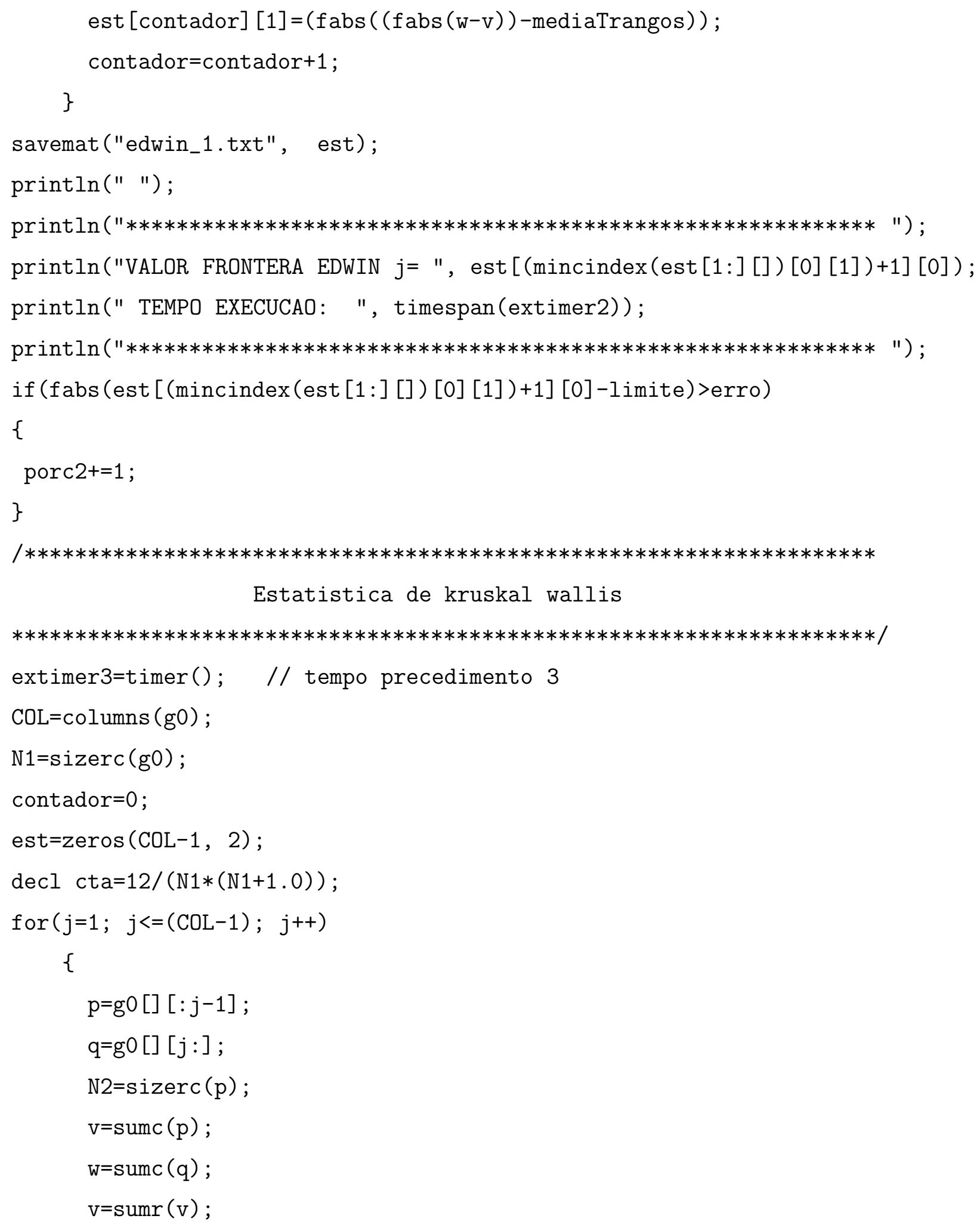




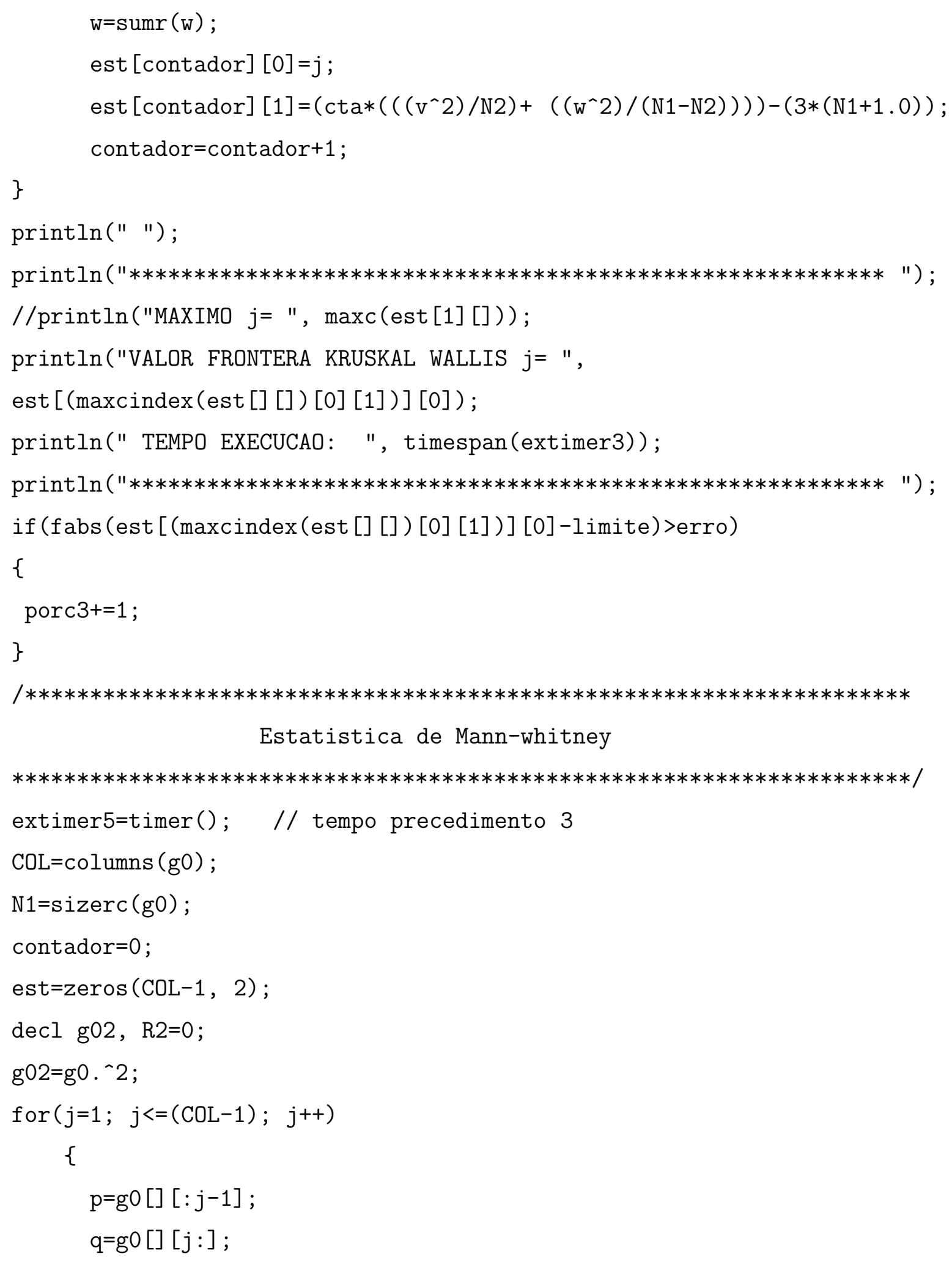




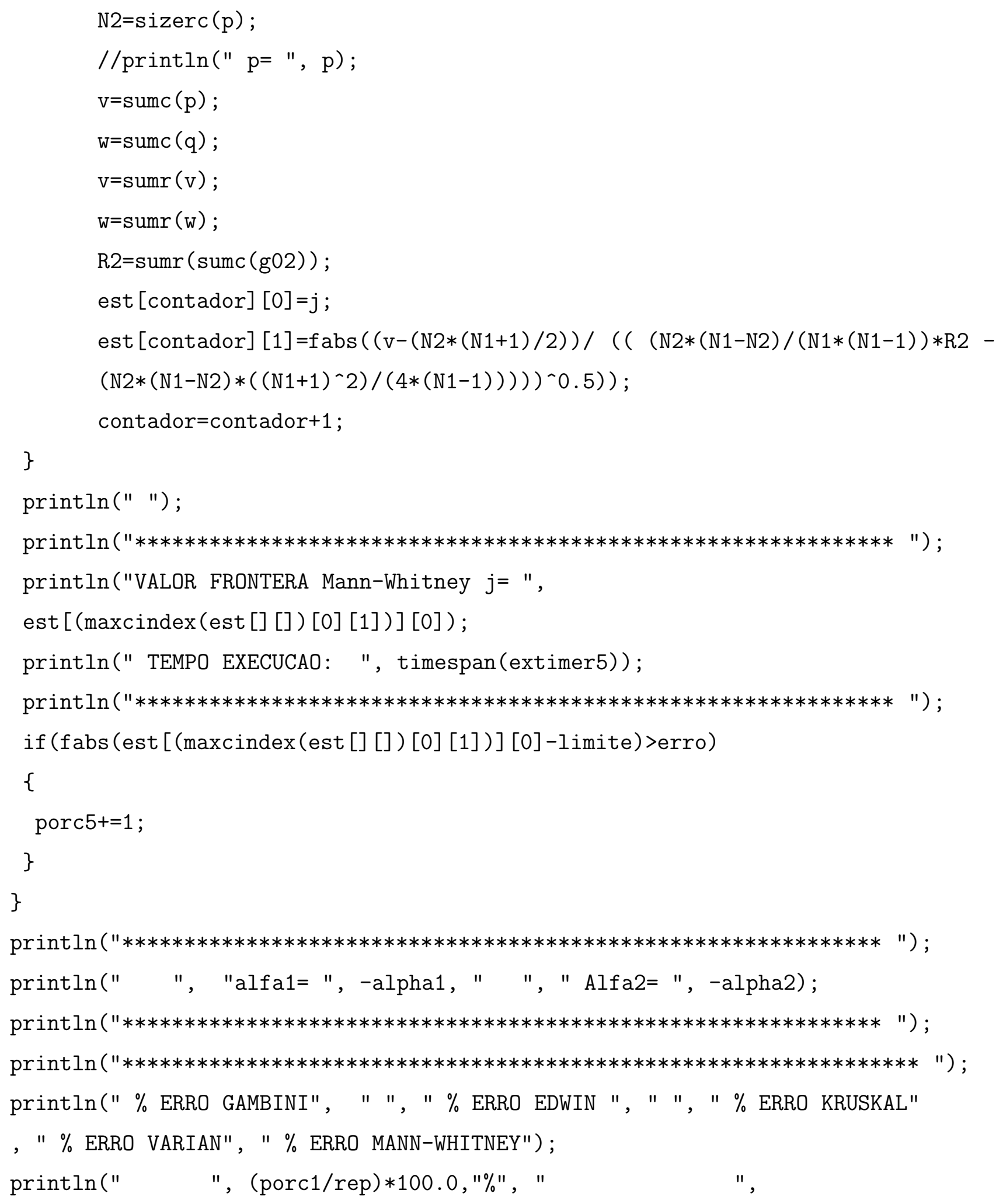




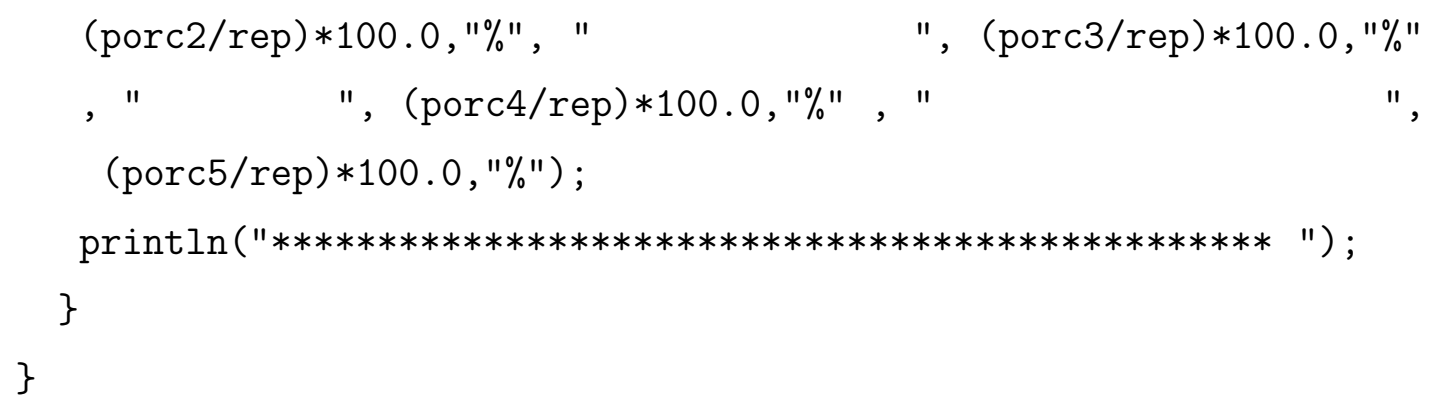




\section{Bibliography}

Allende, H., Frery, A. C., Galbiati, J. \& Pizarro, L. (2006), 'M-estimators with asymmetric influence functions: the $\mathcal{G}_{A}^{0}$ distribution case', Journal of Statistical Computation and Simulation 76(11), 941-956.

Beauchemin, M., Thomson, K. P. B. \& Edwards, G. (1998), 'On nonparametric edge detection in multilook SAR images', IEEE Transactions on Geoscience and Remote Sensing 36(5), 1826-1829.

Bovik, A. C., Huang, T. S. \& Munson, D. C. (1986), 'Nonparametric-tests for edgedetection in noise', Pattern Recognition 19(3), 209-219.

Brigger, P., Hoeg, J. \& Unser, M. (2000), 'B-spline snakes: A flexible tool for parametric contour detection', IEEE Transactions on Image Processing 9(9), 14841496.

Bustos, O. H., Lucini, M. M. \& Frery, A. C. (2002), 'M-estimators of roughness and scale for $\mathcal{G}_{A}^{\circ}$ modelled SAR imagery', Eurasip Journal on Applied Signal Processing 2002(1), 105-114.

Casella, G. \& Lehman, E. L. (1998), Theory of Point Estimation, Springer Verlag, New York.

Conover, W. J. (1980), Practical Nonparametric Statistics, John Wiley, New York.

Cribari-Neto, F., Frery, A. C. \& Silva, M. F. (2002), 'Improved estimation of clutter properties in speckled imagery', Computational Statistics \&6 Data Analysis $40(4), 801-824$.

Doornik, J. A. (2002), Object-Oriented Matrix Programming Using Ox, 3 edn, Timberlake Consultants Press \& Oxford, London.

URL: http://www.doornik.com 
Fesharaki, M. N. \& Hellestrand, G. R. (1994), A new edge detection algorithm based on a statistical approach, in 'International Symposium on Speech, Image Processing and Neural Networks (ISSIPNN)', Vol. 1, pp. 21-24.

Freitas, C. C., Frery, A. C. \& Correia, A. H. (2005), 'The polarimetric G distribution for SAR data analysis', Environmetrics 16(1), 13-31.

Frery, A. C., Correia, A. H. \& Freitas, C. C. (2007), 'Classifying multifrequency fully polarimetric imagery with multiple sources of statistical evidence and contextual information', IEEE Transactions on Geoscience and Remote Sensing 45(10), 3098-3109.

Frery, A. C., Müller, H. J., Freitas, C. C. \& Siqueira, S. J. (1997), 'A model for extremely heterogeneous clutter', IEEE Transactions on Geoscience and Remote Sensing. 35(3), 648-659.

Gambini, J., Mejail, M. E., Jacobo-Berlles, J. \& Frery, A. C. (2006), 'Feature extraction in speckled imagery using dynamic B-spline deformable contours under the $\mathcal{G}^{0}$ model', International Journal of Remote Sensing 27(22), 5037-5059.

Gambini, J., Mejail, M., Jacobo-Berlles, J. \& Frery, A. C. (2008), 'Accuracy of edge detection methods with local information in speckled imagery', Statistics and Computing 18(1), 15-26.

Goodman, J. (1985), Statistical Optics, Wiley, New York.

Gradshteyn, I. \& Ryzhik, I. (1998), Tables of Integrals, Series and Products., Academic Press.

Hampel, F. R., Ronchetti, E. M., Rousseeuw, P. J. \& Stahel, W. A. (1986), Robust Statistics: The Approach Based on Influence Functions, Wiley, New York.

Hoon Lim, D. \& Ju Jang, S. (2002), 'Comparison of two-sample tests for edge detection in noisy images', Journal of the Royal Statistical Society: Series D (The Statistician) 51(1), 21-30.

Jakeman, E. \& Pusey, P. N. (1976), 'Model for non-Rayleigh sea echo', IEEE Transactions on Antennas and Propagation 24(6), 806-814.

Jao, K. (1984), 'Amplitud distribution of composite terrain radar clutter and the K distribution.', IEEE Transactions on Antennas and Propagation 32, 1049 1061. 
Kruskal, W. H. \& Wallis, W. A. (1952), 'Use of ranks in one-criterion variance analysis', Journal of the American Statistical Association 47(260), 583-621.

Lim, D. H. (2006), 'Robust edge detection in noisy images', Computational Statistics \& Data Analysis 50(3), 803-812.

Manski, C. F. (1988), Analog Estimation Methods in Econometrics, number 39 in 'Monographs on Statistics and Applied Probability', Chapman \& Hall.

URL: http://elsa.berkeley.edu/books/analog.html

Mejail, M. E., Frery, A. C., Jacobo-Berlles, J. \& Bustos, O. (2001), 'Approximation of distributions for SAR images: Proposal, evaluation and practical consequences', Latin American Applied Research 31(2), 83-92.

Mejail, M. E., Jacobo-Berlles, J. C., Frery, A. C. \& Bustos, O. H. (2003), 'Classification of SAR images using a general and tractable multiplicative model', International Journal of Remote Sensing 24(18), 3565-3582.

Oliver, C. \& Quegan, S. (1998), Understanding Synthetic Aperture Radar Images, Artech House, Boston.

Picco, M., Moschetti, E., Palacio, M. G. \& Frery, A. C. (2007), Evaluación de filtros map para nuevos modelos de imágenes SAR, in 'Anais XIII Simpósio Brasileiro de Sensoriamento Remoto', pp. 6043-6050.

Pizarro, L. H. (2003), Estimación robusta de parámetros en distribuciones con datos SAR, Master's thesis, Universidad Técnica Federico Santa María. Valparaíso, Chile.

Tur, M., Chin, K. C. \& Goodman, J. W. (1982), 'When is speckle noise multiplicative', Applied Optics 21(7), 1157-1159.

Vasconcellos, K. L. P., Frery, A. C. \& Silva, L. B. (2005), 'Improving estimation in speckled imagery', Computational Statistics 20(3), 503-519.

Venables, W. N. \& Ripley, B. D. (2002), Modern Applied Statistics with S, Statistics and Computing, 4 edn, Springer, New York.

Yanasse, C. C., Frery, A. C. \& Santanna, S. (1995), Stochastic distributions and the multiplicative model: relations, properties, estimators and applications to SAR image analysis, Relatório Técnico 5630-NTC/318, INPE, São José dos Campos, SP, Brazil. 